\title{
Role for the endothelial glycocalyx in regulation of insulin sensitivity in muscle
}

Citation for published version (APA):

Eskens, B. J. M. (2014). Role for the endothelial glycocalyx in regulation of insulin sensitivity in muscle. [Doctoral Thesis, Maastricht University]. Uitgeverij BOXPress. https://doi.org/10.26481/dis.20140523be

Document status and date:

Published: 01/01/2014

DOI:

10.26481/dis.20140523be

Document Version:

Publisher's PDF, also known as Version of record

\section{Please check the document version of this publication:}

- A submitted manuscript is the version of the article upon submission and before peer-review. There can be important differences between the submitted version and the official published version of record.

People interested in the research are advised to contact the author for the final version of the publication, or visit the DOI to the publisher's website.

- The final author version and the galley proof are versions of the publication after peer review.

- The final published version features the final layout of the paper including the volume, issue and page numbers.

Link to publication

\footnotetext{
General rights rights.

- You may freely distribute the URL identifying the publication in the public portal. please follow below link for the End User Agreement:

www.umlib.nl/taverne-license

Take down policy

If you believe that this document breaches copyright please contact us at:

repository@maastrichtuniversity.nl

providing details and we will investigate your claim.
}

Copyright and moral rights for the publications made accessible in the public portal are retained by the authors and/or other copyright owners and it is a condition of accessing publications that users recognise and abide by the legal requirements associated with these

- Users may download and print one copy of any publication from the public portal for the purpose of private study or research.

- You may not further distribute the material or use it for any profit-making activity or commercial gain

If the publication is distributed under the terms of Article $25 \mathrm{fa}$ of the Dutch Copyright Act, indicated by the "Taverne" license above, 


\section{Role for the endothelial glycocalyx in regulation of insulin sensitivity in muscle}


Design cover: Mathieu Hagelaars

Printed \& Lay Out by: Proefschriftmaken.nl || Uitgeverij BOXPress

Published by: Uitgeverij BOXPress, 's-Hertogenbosch

The printing of this thesis was financially supported by Amgen B.V.

ISBN: 978-90-8891-868-1

The research presented in this thesis was performed at the department of Physiology, Cardiovascular Research Institute Maastricht (CARIM), and financially supported by the Dutch Diabetes Research Foundation (grant number 2006.00.027), the Netherlands Heart Foundation (grant number 2005T037) and the Center for Translational Molecular Medicine (Work package 01C-104-04-PREDICCT) 


\title{
Role for the endothelial glycocalyx in regulation of insulin sensitivity in muscle
}

\author{
Proefschrift
}

Ter verkrijging van de graad van doctor aan de Universiteit Maastricht, op gezag van de Rector Magnificus, Prof. Dr. L.L.G. Soete,

volgens het besluit van College van Decanen,

in het openbaar te verdedigen

op vrijdag 23 mei 2014 om 12.00 uur

door

\section{Bart Johannes Maria Eskens,}

Geboren 3 februari 1983 te Tilburg 


\section{Promotor}

Prof. Dr. T. Unger

Co-promotor

Dr. H. Vink

Dr. J.W.G.E. Van Teeffelen

\section{Beoordelingscommissie}

Prof. Dr. M.G.A. Oude Egbrink (voorzitter)

Prof. Dr. C.G. Schalkwijk

Prof. Dr. L.J.C. van Loon

Prof. Dr. H.A.J. Struijker-Boudier

Dr. E.H. Serné

Financial support by the Dutch Heart Foundation for the publication of this thesis is gratefully acknowledged. 


\section{Contents}

1. General introduction and outline of the thesis

2. Insulin-induced increase in intracapillary blood volume in cremaster muscle is impaired in $\mathrm{db} / \mathrm{db}$ mice

3. Rapid insulin-mediated increase in microvascular glycocalyx accessibility in skeletal muscle may contribute to insulin-mediated glucose disposal in rats

4. Acute enzymatic glycocalyx degradation results in reduced insulin sensitivity but normal glucose tolerance in conscious rats

5. Early impairment of skeletal muscle endothelial glycocalyx barrier properties in diet-induced obesity in mice

6. Effects of two weeks of metformin treatment on whole-body glycocalyx barrier properties in $\mathrm{db} / \mathrm{db}$ mice

7. Improvement of insulin resistance in diet-induced obese mice by sulodexide, an endothelial glycocalyx mimetic.

8. General discussion

9. Appendix

Summary

Nederlandse samenvatting

List of publications

Dankwoord

Curriculum vitae 


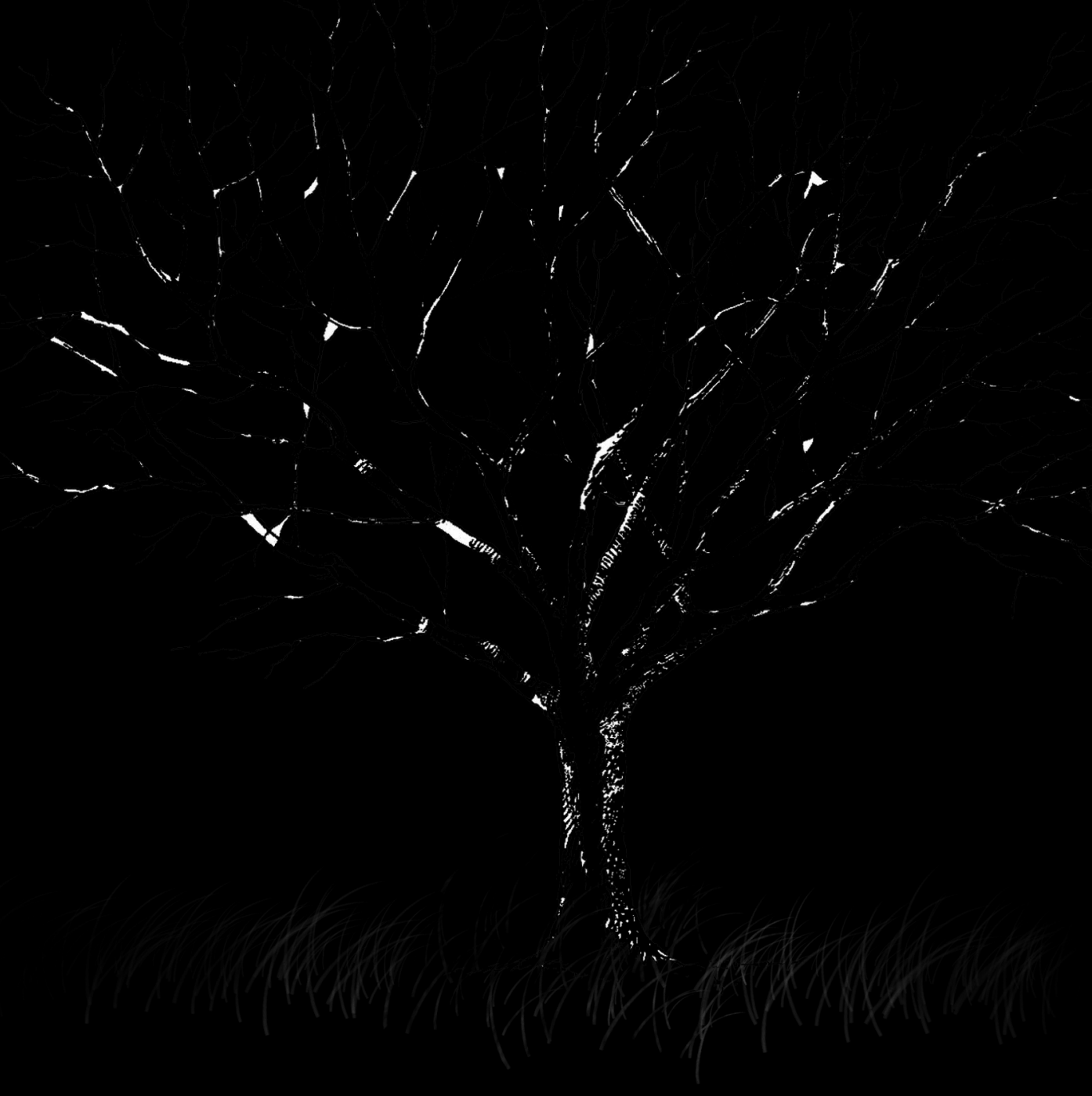


Chapter 1

General introduction and outline of the thesis 


\section{Introduction}

The percentage of people diagnosed with diabetes is increasing rapidly, from 153 million in 1980 to 347 million in 2008, and by 2030 the number of individuals with diabetes worldwide is expected to rise to 472 million people [1]. Approximately $90 \%$ of these people are diagnosed with type II diabetes, and are characterized by high blood glucose due to insulin resistance and relative insulin deficiency. In the late or end-stage of type II diabetes major pathological complications may arise, including cardiovascular complications, kidney failure, and eye and nerve diseases. Insulin resistance may underlie the development of all these conditions. Although the treatment at the late stage of diabetes has become increasingly sophisticated, a normalization of blood glucose at this stage for any a period of time is seldom achieved, and serious complications at the late stage still likely occur [2]. Furthermore, microvascular disease is often already present at this stage. Therefore, it is important to diagnose and treat the people at risk at an early stage during the development of insulin resistance and thereby prevent the onset of type II diabetes. Since insulin resistance has been associated with an impaired insulin delivery from the pancreas via the circulation to its target tissues, it is important to understand the processes controlling insulin delivery. There is substantial experimental evidence that the delivery of insulin from the microcirculation to the interstitium is a rate-limiting step for insulin-induced glucose uptake $[3,4,5,6,7]$. The endothelial glycocalyx, which is located between the circulating blood and the endothelium throughout the circulation, is the compartment which insulin encounters on its way from the blood to the interstitium. The glycocalyx has been demonstrated to be largely inaccessible for the flowing blood and circulating macromolecules during resting conditions, but was in previous studies shown to be modulated by adenosine, bradykinin and sodium nitroprusside, enabling an increase in its accessibility for circulating blood $[8,9]$. In the current thesis we hypothesize that insulin can modulate the glycocalyx barrier properties as well and that this promotes the delivery of insulin from the blood towards its target tissues. In this introductory chapter, the glucose regulation and role of insulin herein is first described; subsequently, the effects of insulin on the microcirculation which promote its delivery, and the potential contribution of the glycocalyx are discussed, leading to our hypothesis that the glycocalyx is involved in regulation of insulin sensitivity, and that glycocalyx degradation may be linked to insulin resistance. From this, we will arrive at the specific aims and outline of the current thesis.

\section{Glucose homeostasis}

Glucose is a simple sugar and is the primary source for energy. In the blood circulates approximately 4 grams of glucose, and although this is a small fraction of the mass of 
the total organism, glucose is important to sustain metabolism in a variety of tissues. In the fasted state the brain consumes approximate $60 \%$ of the blood glucose, and the liver releases glucose formed by glycogenolysis and gluconeogenesis into the blood equal to the uptake of blood glucose. However, the real glucoregulation comes into play when blood glucose rises, e.g. after ingestion of a meal high in carbohydrates which causes an incretin response and increased $ß$-cell insulin secretion. In healthy conditions, insulin suppresses the entry of glucose from the liver to the blood and stimulates glucose removal from the circulation into muscle, liver and fat; in this way glucose levels in the blood are maintained at a relatively constant level. Individuals with insulin resistance are characterized by hyperglycemia, and this persistent elevation in blood glucose leads to glucose toxicity, which contributes to $\beta$-cell dysfunction and the pathology grouped together as complications of diabetes [10]. Microvascular complications form a major part of these, affecting flow resistance and tissue perfusion which further compromise insulin action, and ultimately leading to the development of organ damage, hypertension and other cardiovascular disease. This latter may include atherosclerosis, since there is evidence that in insulin-resistant conditions microvascular dysfunction and the development of macrovascular disease are related $[11,12]$.

\section{Insulin actions in the microvasculature and their contribution to insulin delivery}

When insulin is released by the $\beta$-cells of the pancreas it needs to be delivered by the circulatory system towards its target tissues (skeletal muscle, adipose tissue, liver), finally leading to glucose uptake by these tissues and disposal of glucose from the blood [10]. The circulatory system is important for the delivery of oxygen, hormones (e.g. insulin), and nutrients (e.g. glucose) to tissues and organs in the body and for the removal of $\mathrm{CO}_{2}$ and metabolic waste products from them. The system can be divided into the macrovasculature and the microvasculature. The macrovasculature is composed of arteries and veins, which are large diameter vessels responsible for transporting blood rapidly from the heart towards the organs, and away from the organs back to the heart. The microvasculature consists of arterioles, capillaries and venules, which form a network that regulates local blood perfusion and blood to tissue exchange [13]. When oxygen, hormones and nutrients are delivered by the blood to the capillaries, they have to pass the endothelium to reach the tissues [14].

Insulin is supplied from the macrocirculation to the microcirculation by the circulating blood. Insulin at physiological concentrations is able to vasodilate arterioles by the release of nitric oxide (NO), and to vasoconstrict these by the release of endothelin (ET-1). To initiate these divergent effects insulin has to bind to the insulin receptors 
on endothelial cells. In general, the integrated response of these vasodilator and vasoconstrictor effects of insulin causes an increased blood flow [15,16]. In case of endothelial dysfunction, however, the balance between the insulin-stimulated production of NO and ET-1 may be altered, in favor of ET-1, leading to a reduction in total blood flow to the target tissues $[17,18]$. In addition to these effects on total blood flow, it has been indicated that insulin can recruit blood volume in the microcirculation and that this is an important step for the delivery of insulin itself, and glucose as well, to the myocytes $[6,19,20]$. It was demonstrated that insulin recruits capillary blood volume within 5-10 minutes in skeletal muscle in anesthetized rats [21], and that this effect precedes increases in total blood flow and in glucose metabolism. This increase in capillary blood volume by insulin is considered to increase the exchange capacity of insulin, thereby facilitating its delivery to the muscle. However, to reach its target tissues insulin has to cross the endothelium, which structure appears to be tight in the muscle microcirculation [22]. It has been shown that intravenous insulin infusion rapidly increases plasma insulin, yet glucose disposal occurs at a much slower rate. This delay in insulin's action may be related to the protracted time for insulin to traverse the capillary endothelium [4]. In addition, it has been suggested that insulin concentrations in the interstitial rather than the plasma compartment dictate insulin's action. In previous studies, using various techniques to monitor the microcirculation, in insulin-resistant animal models [23,24] as well as humans [5], the transendothelial exchange of insulin has been shown to be delayed and this defect was accompanied by a diminished insulin-mediated glucose disposal. The data altogether indicate that the endothelium plays an important role in the delivery of insulin to its target tissues and, that as a consequence, dysfunction of the endothelium may relate to the development of insulin resistance due to impairments in insulin and nutrient access to muscle and other tissues [15,25]. While traditionally insulin resistance is typically defined as decreased sensitivity or responsiveness to metabolic actions of insulin there is more and more evidence indicating that diminished vascular actions of insulin also play an important role in the development of insulin resistance. Nevertheless, the hemodynamic and cellular mechanisms underlying the insulin-mediated increases in capillary blood volume and subsequent transcapillary insulin transport, and how these are affected in conditions of insulin resistance, are largely unknown at the moment. We hypothesize in the current thesis that the endothelial glycocalyx plays a significant role in these processes, and that as a result of glycocalyx damage insulin resistance may develop, which may be alleviated by therapeutic restoration of the glycocalyx. 


\section{The endothelial glycocalyx: the missing link between endothelial function and insulin delivery?}

In the vasculature the endothelium is covered with a relatively thick gel-like layer, called the glycocalyx. This negatively charged layer consists of a network of end othelial membrane-bound and -unbound proteoglycans, glycoproteins and glycosaminoglycans, in which numerous molecules from the circulating blood and a considerable amount of water are incorporated [26,27,28] (Fig 1.1).
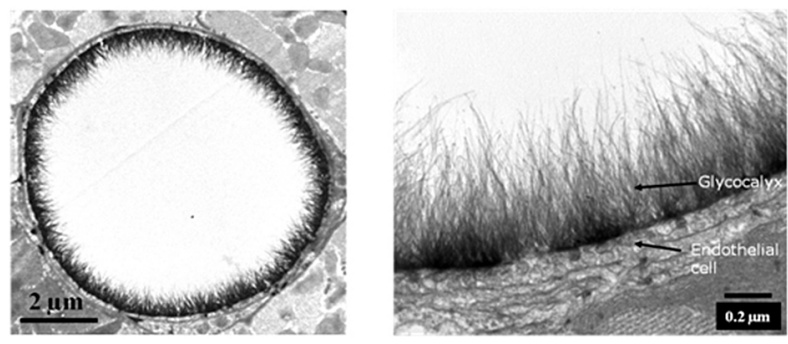

Fig 1.1 Electron microscopic overview of alcian blue 8GX-stained goat coronary capillary [29]

The last decades our research group has focused on understanding the role of the endothelial glycocalyx in the vasculature. Substantial experimental evidence has been provided indicating that the glycocalyx protects the endothelium to direct exposure to blood flow, thereby contributing to the vascular permeability barrier and the antiadhesive properties of the vascular wall. Furthermore, the glycocalyx is involved in endothelial release of nitric oxide by mechanotransducing fluid shear stresses. Previous studies showed that red blood cells (RBCs) and macromolecules are normally excluded from the endothelium by the glycocalyx, and that degradation of the glycocalyx with e.g. hyaluronidase, light-dye treatment, oxidized LDL, hyperglycemia, and inflammatory stimulation impaired these glycocalyx barrier properties [8,30,31,32]. Evidence has also been provided that in healthy conditions agonists, like adenosine, bradykinin and sodium nitroprusside are able to impair the barrier properties of the glycocalyx and that this is associated with an increase in functionally perfused capillary blood volume, as reflected by an increase in capillary tube hematocrit $[8,9,33]$. These findings indicate that the glycocalyx may be a locus of blood volume regulation at the level of the individual capillary.

While there has been clear evidence of a relation between insulin's ability to dispose glucose and insulin's ability to increase capillary blood volume in skeletal muscle, the underlying mechanism has not been resolved. Traditionally, the increase has been explained by an increase in the number of perfused capillaries (i.e., capillary recruitment) $[6,34]$. We hypothesize in the current thesis that insulin has the ability to 
modulate the glycocalyx barrier properties in the microcirculation and thereby increase blood volume within already perfused capillaries. This proposed concept is depicted in the cartoon in Fig. 1.2.

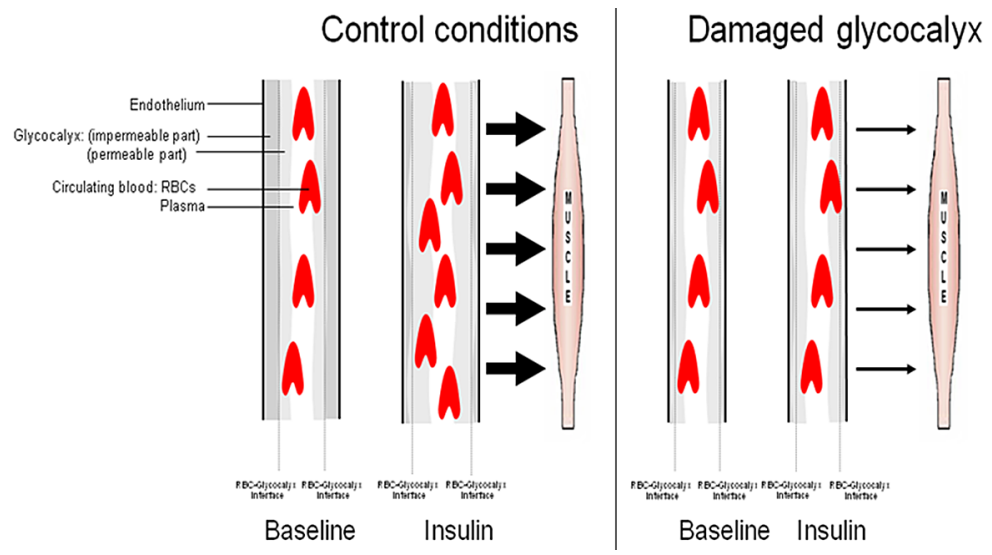

Fig 1.2 Proposed hypothesized action of insulin.

By modulation of the glycocalyx barrier properties, insulin can increase the accessibility of the glycocalyx for the flowing blood, resulting in an increased capillary blood volume within an individual capillary and facilitation of insulin exchange to the muscle (left, thick arrows denote insulin delivery to muscle). In contrast, glycocalyx degradation is associated with an impaired ability of insulin to modulate the glycocalyx barrier properties and to increase capillary blood volume. As a consequence, insulin exchange to the muscle is reduced (right, thin arrows).

Degradation of the glycocalyx is, according to our hypothesis, expected to be accompanied by an impaired ability of insulin to increase capillary blood volume and as a consequence a reduced insulin-mediated glucose disposal (Fig 1.2). Consequently, therapies aiming at restoration of the glycocalyx when damaged could be useful in improving insulin sensitivity and preventing the development of diabetes.

\section{Outline of the thesis}

This thesis can be divided in three parts. The first part (chapters 2 and 3) focuses on microvascular and capillary effects of insulin in relation to the glycocalyx, the second part (chapters 3, 4, 5) aims at determination of the effect of acute glycocalyx degradation on regulation of insulin sensitivity and glucose homeostasis, while in the last part (chapters $6, \mathbf{7}, \mathbf{8}$ ) the role of glycocalyx degradation, and the potential of therapies to restore this, in models of obesity and diabetes are tested (Fig 1.3). 


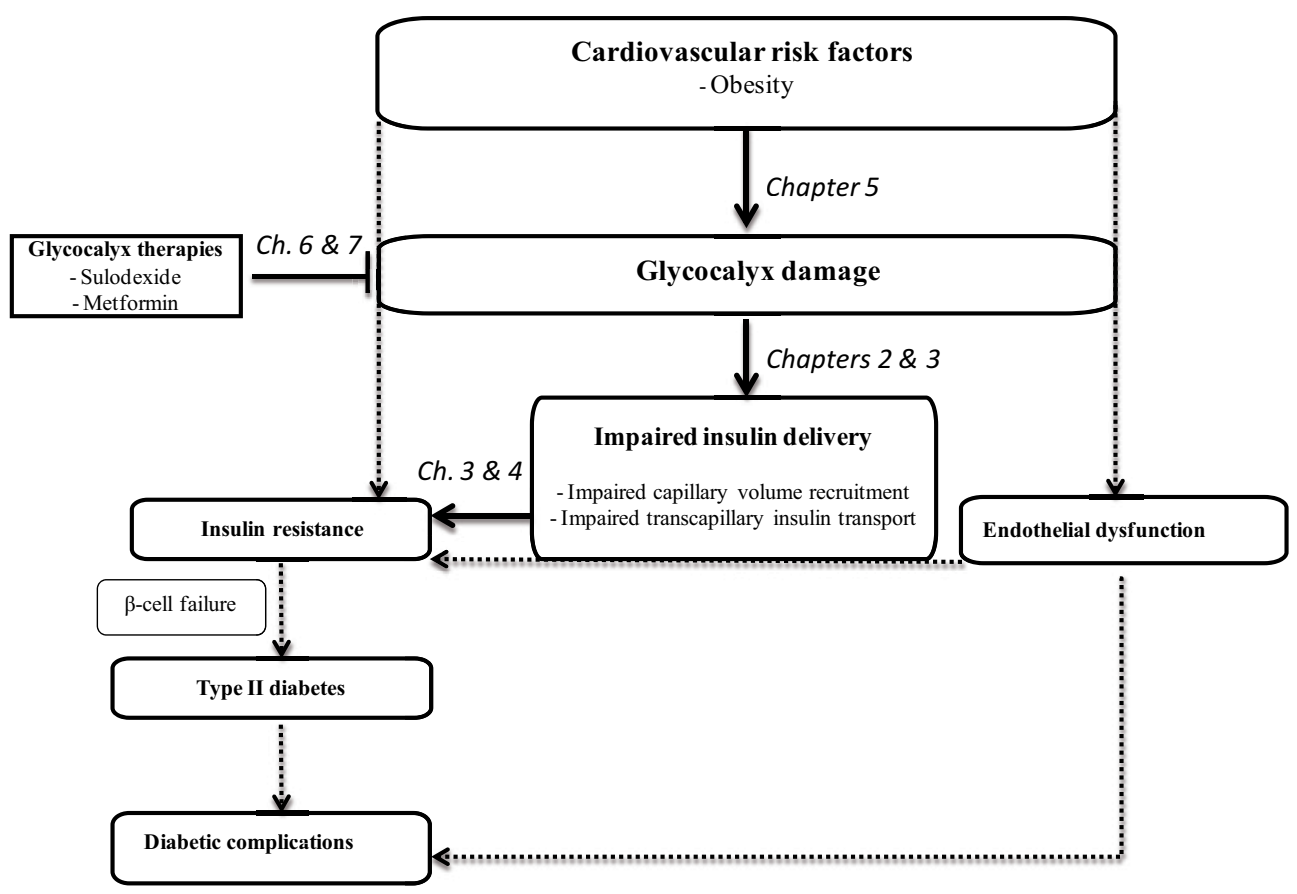

Fig 1.3 Schematic outline of the current thesis.

It is hypothesized that damage to the glycocalyx resulting from exposure to cardiovascular risk factors may be "the common soil" for both insulin resistance and endothelial dysfunction. Thick arrows denote the different research questions which are addressed in the various chapters of the thesis. The dotted arrows illustrate the well-known relationships between cardiovascular risk factors, endothelial dysfunction, insulin resistance, and type II diabetes and its complications.

In short, the following studies were performed:

As a proof of principle of the concept illustrated in Fig. 1.2, it was first studied, whether insulin was able to increase blood volume in individual capillaries in healthy muscle, and if this effect would be impaired in case of a damaged glycocalyx. Thereto, intravital microscopy was performed on the cremaster muscle of control mice as well as of diabetic mice (chapter 2). To monitor sublingual glycocalyx properties non-invasively in humans, we developed a new technique to measure glycocalyx barrier properties in vivo. Herefore, a Sidestream Dark-field (SDF) camera was used to visualize the microcirculation [35] and an in house developed software program developed to assess glycocalyx barrier properties. This technique was also used to measure glycocalyx barrier properties in the microcirculation of skeletal muscle of rats and mice in the studies described in the thesis. In chapter 3 SDF imaging was applied to measure to effect of insulin on glycocalyx barrier properties in rat skeletal muscle microcirculation, and the effect of acute enzymatic glycocalyx degradation on insulin sensitivity was measured with an intravenous insulin tolerance tests during anesthesia. Next, the effect 
of acute glycocalyx degradation on insulin sensitivity and insulin release was measured in conscious rats using both intravenous insulin and glucose tolerance tests, and these results are described in chapter 4 . Obesity has been shown to be an important risk factor for the development of insulin resistance and type II diabetes. In chapter $\mathbf{5}$, we used the high-fat diet (HFD)-fed mouse model to determine the effect of obesity on development of glycocalyx degradation in the muscle microcirculation in relation to the development of glucose intolerance. In chapter $\mathbf{6}$ and $\mathbf{7}$ therapies were administrated in the drinking water of HFD-fed mice, as well as in a genetic mouse model for diabetes ( $\mathrm{db} / \mathrm{db}$ mouse), to test if the glycocalyx may be a useful target for therapeutic treatment of insulin resistance and type II diabetes. Finally, the findings of the thesis are discussed in an integrative manner in chapter 8. 


\section{References}

1. (2011) The diabetes pandemic. Lancet 378: 99.

2. Sherwin RS, Anderson RM, Buse JB, Chin MH, Eddy D, et al. (2004) Prevention or delay of type 2 diabetes. Diabetes Care 27 Suppl 1: S47-54.

3. Barrett EJ, Eggleston EM, Inyard AC, Wang H, Li G, et al. (2009) The vascular actions of insulin control its delivery to muscle and regulate the rate-limiting step in skeletal muscle insulin action. Diabetologia 52: 752-764.

4. Chiu JD, Richey JM, Harrison LN, Zuniga E, Kolka CM, et al. (2008) Direct administration of insulin into skeletal muscle reveals that the transport of insulin across the capillary endothelium limits the time course of insulin to activate glucose disposal. Diabetes 57: 828835.

5. Clerk LH, Rattigan S, Clark MG (2002) Lipid infusion impairs physiologic insulin-mediated capillary recruitment and muscle glucose uptake in vivo. Diabetes 51: 1138-1145.

6. Vincent MA, Clerk LH, Rattigan S, Clark MG, Barrett EJ (2005) Active role for the vasculature in the delivery of insulin to skeletal muscle. Clin Exp Pharmacol Physiol 32: 302-307.

7. Yang YJ, Hope ID, Ader M, Bergman RN (1989) Insulin transport across capillaries is rate limiting for insulin action in dogs. J Clin Invest 84: 1620-1628.

8. VanTeeffelen JW, Brands J, Vink H (2010) Agonist-induced impairment of glycocalyx exclusion properties: contribution to coronary effects of adenosine. Cardiovasc Res 87: 311-319.

9. VanTeeffelen JW, Constantinescu AA, Brands J, Spaan JA, Vink H (2008) Bradykinin- and sodium nitroprusside-induced increases in capillary tube hematocrit in mouse cremaster muscle are associated with impaired glycocalyx barrier properties. J Physiol 586: 32073218.

10. Wasserman DH (2009) Four grams of glucose. Am J Physiol Endocrinol Metab 296: E11-21.

11. De Boer MP, Meijer RI, Wijnstok NJ, Jonk AM, Houben AJ, et al. (2012) Microvascular dysfunction: a potential mechanism in the pathogenesis of obesity-associated insulin resistance and hypertension. Microcirculation 19: 5-18.

12. Serne EH, de Jongh RT, Eringa EC, RG IJ, Stehouwer CD (2007) Microvascular dysfunction: a potential pathophysiological role in the metabolic syndrome. Hypertension 50: 204-211.

13. Levy BI, Ambrosio G, Pries AR, Struijker-Boudier HA (2001) Microcirculation in hypertension: a new target for treatment? Circulation 104: 735-740.

14. Segal SS (2005) Regulation of blood flow in the microcirculation. Microcirculation 12: 3345.

15. Kolka CM, Bergman RN (2013) The endothelium in diabetes: its role in insulin access and diabetic complications. Rev Endocr Metab Disord 14: 13-19.

16. Rattigan S, Zhang L, Mahajan H, Kolka CM, Richards SM, et al. (2006) Factors influencing the hemodynamic and metabolic effects of insulin in muscle. Curr Diabetes Rev 2: 61-70. 
17. Cardillo C, Nambi SS, Kilcoyne CM, Choucair WK, Katz A, et al. (1999) Insulin stimulates both endothelin and nitric oxide activity in the human forearm. Circulation 100: 820-825.

18. Kim JA, Montagnani M, Koh KK, Quon MJ (2006) Reciprocal relationships between insulin resistance and endothelial dysfunction: molecular and pathophysiological mechanisms. Circulation 113: 1888-1904.

19. Clark MG (2008) Impaired microvascular perfusion: a consequence of vascular dysfunction and a potential cause of insulin resistance in muscle. Am J Physiol Endocrinol Metab 295: E732-750.

20. Muniyappa R, Montagnani M, Koh KK, Quon MJ (2007) Cardiovascular actions of insulin. Endocr Rev 28: 463-491.

21. Vincent MA, Clerk LH, Lindner JR, Klibanov AL, Clark MG, et al. (2004) Microvascular recruitment is an early insulin effect that regulates skeletal muscle glucose uptake in vivo. Diabetes 53: 1418-1423.

22. Barrett EJ, Wang H, Upchurch CT, Liu Z (2011) Insulin regulates its own delivery to skeletal muscle by feed-forward actions on the vasculature. Am J Physiol Endocrinol Metab 301: E252-263.

23. Halseth AE, Bracy DP, Wasserman DH (2000) Limitations to basal and insulin-stimulated skeletal muscle glucose uptake in the high-fat-fed rat. Am J Physiol Endocrinol Metab 279: E1064-1071.

24. Wallis MG, Wheatley CM, Rattigan S, Barrett EJ, Clark AD, et al. (2002) Insulin-mediated hemodynamic changes are impaired in muscle of Zucker obese rats. Diabetes 51: 34923498.

25. Liu Z (2013) The vascular endothelium in diabetes and its potential as a therapeutic target. Rev Endocr Metab Disord 14: 1-3.

26. Pries AR, Secomb TW, Gaehtgens P (2000) The endothelial surface layer. Pflugers Arch 440: 653-666.

27. Tarbell JM, Pahakis MY (2006) Mechanotransduction and the glycocalyx. J Intern Med 259: 339-350.

28. Van Teeffelen JW, Brands J, Stroes ES, Vink H (2007) Endothelial glycocalyx: sweet shield of blood vessels. Trends Cardiovasc Med 17: 101-105.

29. van den Berg BM, Vink H, Spaan JA (2003) The endothelial glycocalyx protects against myocardial edema. Circ Res 92: 592-594.

30. Constantinescu AA, Vink H, Spaan JA (2001) Elevated capillary tube hematocrit reflects degradation of endothelial cell glycocalyx by oxidized LDL. Am J Physiol Heart Circ Physiol 280: H1051-1057.

31. Nieuwdorp M, van Haeften TW, Gouverneur MC, Mooij HL, van Lieshout MH, et al. (2006) Loss of endothelial glycocalyx during acute hyperglycemia coincides with endothelial dysfunction and coagulation activation in vivo. Diabetes 55: 480-486.

32. Vink H, Duling BR (1996) Identification of distinct luminal domains for macromolecules, erythrocytes, and leukocytes within mammalian capillaries. Circ Res 79: 581-589. 
33. Klitzman B, Duling BR (1979) Microvascular hematocrit and red cell flow in resting and contracting striated muscle. Am J Physiol 237: H481-490.

34. Wheatley CM, Rattigan S, Richards SM, Barrett EJ, Clark MG (2004) Skeletal muscle contraction stimulates capillary recruitment and glucose uptake in insulin-resistant obese Zucker rats. Am J Physiol Endocrinol Metab 287: E804-809.

35. Goedhart PT, Khalilzada M, Bezemer R, Merza J, Ince C (2007) Sidestream Dark Field (SDF) imaging: a novel stroboscopic LED ring-based imaging modality for clinical assessment of the microcirculation. Opt Express 15: 15101-15114. 


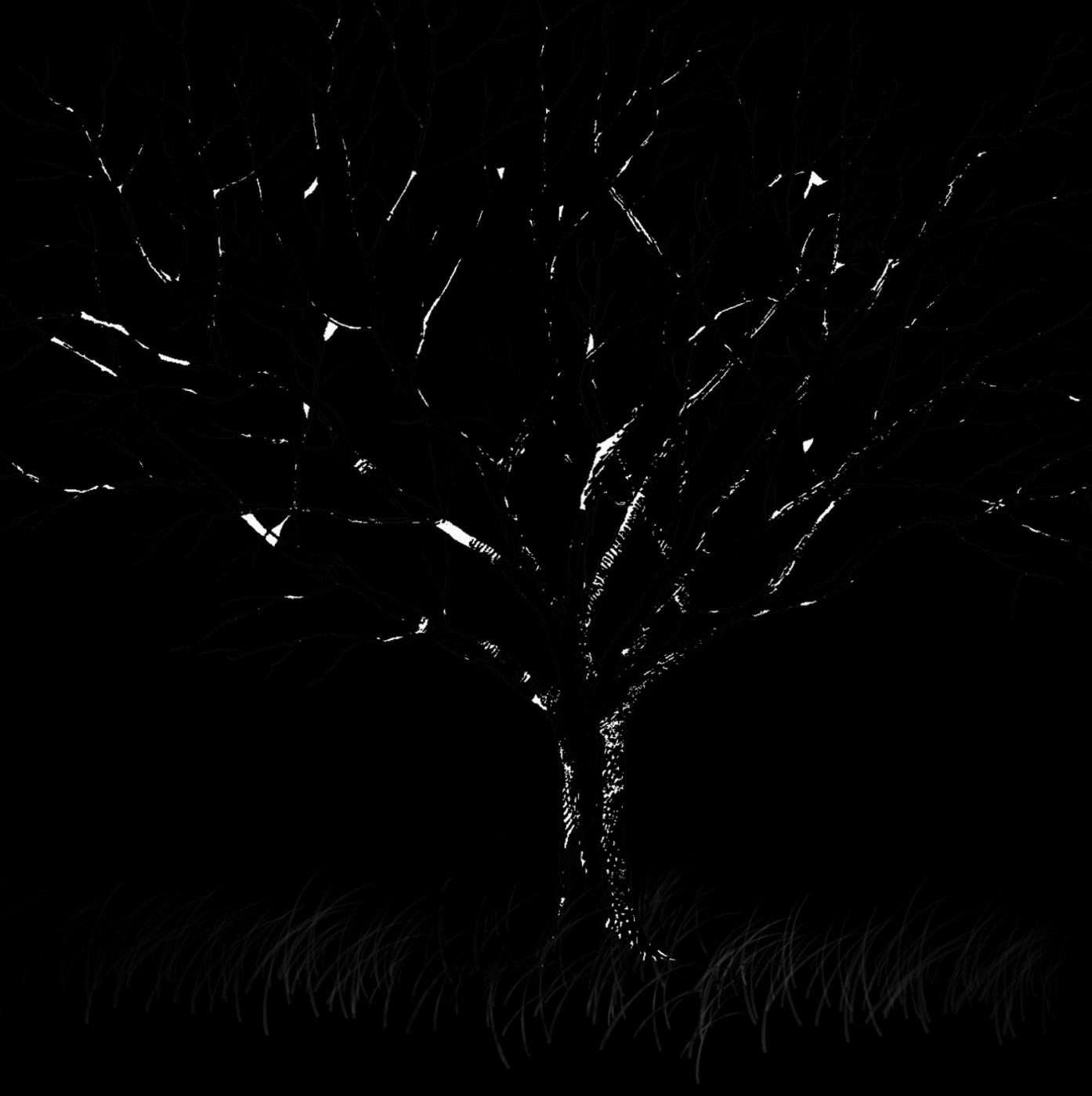


Chapter 2

\title{
Insulin-induced increase in intracapillary blood volume in cremaster muscle is impaired in $\mathrm{db} / \mathrm{db}$ mice
}

\author{
Bart J.M. Eskens \\ Hanneke E. Cobelens \\ Hans Vink \\ Jurgen W.G.E. VanTeeffelen
}




\section{Abstract}

Insulin sensitivity has been coupled to the ability of insulin to increase capillary blood volume in skeletal muscle, but the underlying hemodynamic events have not been elucidated. In the current study, we hypothesize that insulin increases blood volume within individual capillaries in muscle of healthy mice but not of diabetic mice.

Intravital microscopy of cremaster muscle was performed in anaesthetized control ( $\mathrm{C} 57 \mathrm{Bl} / 6, \mathrm{n}=5)$ and diabetic $(\mathrm{db} / \mathrm{db}, \mathrm{n}=5)$ mice, and capillary hemodynamics were monitored at baseline and during topical insulin administration $(20 \& 200 \mu \mathrm{U} / \mathrm{ml})$. In control mice, insulin increased $(\mathrm{P}<0.05)$ capillary tube hematocrit (Hcap) from a baseline of $0.093 \pm 0.008$ (SEM, $\mathrm{n}=25$ capillaries) to $0.143 \pm 0.011(20 \mu \mathrm{U} / \mathrm{ml}$ ) and 0.139 $\pm 0.008(200 \mu \mathrm{U} / \mathrm{ml})$. In diabetic mice, Hcap was elevated at baseline $(0.154 \pm 0.01$, $\mathrm{n}=36$ capillaries), and not changed during subsequent insulin administration. Insulin administration was associated with a loss of RBC perfused capillaries in diabetic but not in control mice.

While insulin-mediated recruitment of capillary blood volume takes place at the level of the individual muscle capillary in normal mice, this effect is abolished in $\mathrm{db} / \mathrm{db}$ mice. These data indicate the capillary as locus of impaired vascular insulin action in diabetes. 


\section{Introduction}

Skeletal muscle constitutes a major site of insulin-mediated glucose uptake in the body [1]. There is substantial experimental evidence which indicates that in vivo the delivery of insulin from the circulation to the muscle tissue is a rate-limiting step for insulininduced glucose uptake $[2,3,4,5,6,7,8,9]$. The notion that accurate regulation of insulin delivery is a prerequisite for glucose homeostasis is underscored by studies suggesting that insulin delivery may be delayed in conditions of insulin resistance $[8,10,11,12,13]$. Whereas the precise hemodynamic and cellular events underlying the relation between insulin delivery and insulin-mediated glucose uptake in muscle are not fully understood at the moment, a recurring finding has been that capillary blood volume in skeletal muscle may rapidly increase in response to insulin infusion $[9,14,15,16]$. Using the technique of contrast-enhanced ultrasound (CEU), where gas-filled microbubbles were used as marker of circulating red blood cells it was demonstrated in experimental animals and humans that insulin administration during an euglycemic clamp is associated with a relatively rapid (within 5-20 min) increase in echo intensity in skeletal muscle in response to insulin administration $[15,16]$. This increase typically precedes increases in total blood flow and insulin signalling or glucose uptake in the muscle [15], and was shown to be reduced in conditions of acute insulin resistance (e.g. during FFA infusion [17], and L-NAME and TNF- $\alpha$ treatment $[18,19]$ ), as well as in obesity and overt diabetes $[13,20,21]$. From these observations the concept has been put forward that the ability of insulin to dispose glucose in skeletal muscle is related to its ability to increase capillary blood volume in this tissue. While CEU has not the resolution to assess capillary blood volume increases in individual muscle capillaries, the increase in echo intensity during insulin has primarily explained by an increased number of perfused capillaries (i.e., capillary recruitment) due to dilation of terminal arterioles [5]; the associated increase in surface area for exchange of insulin has been inferred to facilitate transcapillary delivery of insulin towards the muscle interstitium $[6,8]$. Although observations of an increased metabolism of 1-methylxanthine (1-MX) in response to insulin suggest an increased exposure of this substrate to xanthine oxidase in the capillary compartment $[11,14,22]$, direct evidence for insulin actually increasing the number of perfused capillaries has been lacking at the moment, and the concept of capillary recruitment has actually been challenged by the observation that normally about $\sim 90 \%$ of the capillaries are already perfused at rest in skeletal muscle $[23,24]$. Further, although some experimental evidence has been provided showing the ability of insulin to dilate pre-capillary arterioles in muscle $[25,26]$, its relation to an actual change in blood volume in the capillaries has not been established. 
Additional to an increase in the number of perfused capillaries, the insulin-mediated increase in capillary blood volume may also involve an increase in blood-accessible volume within already perfused capillaries, which can occur as a result of glycocalyx modulation $[27,28]$. Recent pilot intravital microscopic data showed that 10 minutes of systemic hyperinsulinemia in the rat were associated with an increase in tube hematocrit in the observed cremaster muscle capillaries [28]. The contribution of the endothelial glycocalyx to the blood volume increase was indicated by the finding that prior intravenous hyaluronidase treatment virtually abolished the insulin-induced increase in capillary tube hematocrit [28]. These data indicate that insulin, like other agonists, may robustly increase blood volume in individual capillaries by modulating the barrier properties of the endothelial glycocalyx [29]. Consequently, since diabetes has been associated with damage to the glycocalyx [30,31], it is anticipated that the reported impairment in insulin-mediated increase in muscle capillary blood volume during conditions of insulin resistance $[13,20,21]$ may be a result of an inability of insulin to increase blood volume in individual capillaries by glycocalyx modulation.

In the current study, cremaster muscle capillary hemodynamic responses to topical insulin administration were examined in non-diabetic control mice versus $\mathrm{db} / \mathrm{db}$ mice, which were previously characterized by impaired glycocalyx barrier properties [30]. It was hypothesized that in control mice insulin stimulation would be associated with an increase in blood volume in individual capillaries, but that the capillary response to insulin would be impaired in the diabetic mice. 


\section{Methods}

\section{General surgery and anesthesia}

All procedures and protocols were approved by, and carried out according to, the guidelines of the Animal Care and Use committee of Maastricht University. Experiments were performed on male $\mathrm{C} 57 \mathrm{Bl} / 6$ mice $(n=5$; body weight $26.0 \pm 1.5 \mathrm{~g})$ and $\mathrm{db} /$ $\mathrm{db}$ mice ( $n=5$; body weight $41.4 \pm 2.7 \mathrm{~g}$ ) which were obtained from Harlan (Horst, the Netherlands). Mice received standard mouse chow and water ad libitum. At the beginning of an experiment, mice were anesthetized with an i.p. injection of ketamine hydrochloride $(125 \mathrm{mg} / \mathrm{kg})$ and medetomidine $(0.2 \mathrm{mg} / \mathrm{kg})$, and tracheotomised to ensure airway patency $[32,33,34]$. Depth of anesthesia was maintained according to respiration rate and lack of toe pinch reflex by supplemental administration (every $\sim 1$ h) of anaesthetics (ketamine: $15 \mathrm{mg} / \mathrm{kg}$, i.p.; medetomidine: $35 \mu \mathrm{g} / \mathrm{kg}$, i.p.); to counter decreases in blood pressure and heart rate induced by medetomidine, atropine was administered (initial dose: $0.5 \mathrm{mg} / \mathrm{kg}$, s.c.; maintenance: $0.125 \mathrm{mg} / \mathrm{kg} / \mathrm{h}$, i.p.). Blood pressures and heart rates using this anaesthetic protocol in previous experiments were typically 60-70 $\mathrm{mmHg}$ and 300-400 bpm [32,33,34]. Oesophageal temperature was maintained at $\sim 37^{\circ} \mathrm{C}$ by radiant heat. At the end of the experimental procedures, the animal was euthanized using an overdose of ketamine.

\section{Mouse cremaster preparation and video microscopy}

Before preparation of the cremaster muscle, baseline blood glucose levels were measured (Ascensia Contour, Bayer) in $<5 \mu$ of blood obtained by tail bleeding. The mouse was placed in a supine position on a custom built animal platform and the right cremaster muscle was prepared [32,34]. Briefly, an incision was made through the skin and the muscle dissected from the surrounding connective tissue. The exposed muscle was positioned on a clear Silicon pedestal and longitudinally incised from the apex to the inguinal canal with minimal disruption of the vascular supply. After severing the deferential artery and vein, the testis and epididymis were dissected away and repositioned in the abdominal cavity. The cremaster muscle was spread radially on the pedestal and pinned at the edges. The muscle was continuously $(\sim 5 \mathrm{ml} / \mathrm{min})$ superfused at $34{ }^{\circ} \mathrm{C}$ with a bicarbonate-buffered physiological salt solution (PSS) of the following composition (in mM): $131.9 \mathrm{NaCl}, 4.7 \mathrm{KCl}, 2.0 \mathrm{CaCl}_{2}, 1.2 \mathrm{MgSO}_{4}, 20 \mathrm{NaHCO}_{3}$ and equilibrated with $5 \% \mathrm{CO}_{2} / 95 \% \mathrm{~N}_{2}$ to obtain a $\mathrm{pH}$ of $\sim 7.4$.

Following surgery, the completed preparation was transferred to the stage of an intravital microscope (Leitz, Wetzlar, Germany), coupled to a cooled CCD video camera (C9100; Hamamatsu, Hamamatsu City, Japan). Microvessels were observed using bright-field (100 W Hg lamp) microscopy with a $435 \mathrm{~nm}$ band pass interference filter 
(blue light) in the light path and a condenser with a numerical aperture of 0.6 , and for examination of capillary hemodynamics a x50 salt water immersion objective lens with a numerical aperture of 1.0 was used.

\section{Experimental protocol}

The preparation was equilibrated for 30 min, during which period a site for data collection was identified. Typically, 5-8 capillaries were chosen for examination during an experiment. Capillaries were selected based on image clarity and on the observation that they had continuous RBC perfusion. From each capillary three $30 \mathrm{~s}$ digital video recordings were made during a period of 5 minutes using Wasabi Imaging Software (Hamamatsu Photonics, Germany). After baseline recordings were obtained ( $30 \mathrm{~min}$ ), the PSS solution superfusing the muscle was exchanged with PSS containing insulin at a concentration of $20 \mu \mathrm{U} / \mathrm{ml}$; recordings of the same capillaries were made, starting after $10 \mathrm{~min}$, and lasting another $30 \mathrm{~min}$. Finally, a 10-fold higher dose of insulin (200 $\mu \mathrm{U} / \mathrm{ml}$ ) in the superfusate was applied, and recordings again repeated after $10 \mathrm{~min}$ for another half an hour. The duration of the entire experiment was $\sim 3$ hours (1 hour of surgery, 30 min equilibration, and 90 min of measurements). The applied insulin doses were based on previous studies and can be considered to represent an intermediate $(20 \mu \mathrm{U} / \mathrm{ml})$ and high $(200 \mu \mathrm{U} / \mathrm{ml})$ physiological insulin level in rodents [25,35]. Solutions were made by diluting $50 \mu \mathrm{l}$ of $100 \mathrm{U} / \mathrm{ml}$ purified pork insulin (Novo Nordisk Pharmaceuticals) in $50 \mathrm{ml}$ of saline to obtain a working stock of $100 \mathrm{mU} / \mathrm{ml}$, and further diluting this stock solution in PSS.

\section{Data analysis}

The digital video images were analysed using image analysis software [36]. Capillary tube hematocrit (Hcap) was calculated from measurements of capillary anatomical diameter (Dcap, in $\mu \mathrm{m}$ ), flux of RBCs (RBC flux, in cells/s), and velocity of RBCs (Vrbc, in $\mu \mathrm{m} / \mathrm{s}$ ) in a capillary using the formula: Hcap $=\left[\mathrm{RBC}\right.$ flux $\left./\left(\operatorname{Vrbc} \cdot \pi / 4 \cdot \mathrm{Dcap}^{2}\right)\right] \mathrm{x} \mathrm{MCV}$ $[34,37]$, where MCV is the mean corpuscular volume of RBCs in mice (44 $\mu \mathrm{m}^{3}$ ) [38]. Capillary anatomical diameters were estimated from the distance between the opposite insides of the capillary wall. RBC flux was determined during slow-motion playback from the time required for at least $50 \mathrm{RBC}$ to pass through a reference point inside the capillary. Vrbc was determined by measuring the length of a capillary segment and dividing it by the time required for RBCs to traverse this segment. Data are presented as means \pm SEM with $n$ referring to the number of vessels studied. In both animal groups, effects of incremental doses of insulin were tested against baseline using a Repeated Measures Analysis of Variance; Tukey's multiple comparison test was used for post-hoc 
comparison. Baseline differences between $\mathrm{C} 57 \mathrm{Bl} / 6$ and $\mathrm{db} / \mathrm{db}$ mice were tested using unpaired t-tests. Results were considered statistically significant with $P \leq 0.05$. 


\section{Results}

Baseline blood glucose levels were $4.8 \pm 1.3 \mathrm{mmol} /$ Lin the control mice and $26.1 \pm 4.8$ $\mathrm{mmol} /$ Lin the $\mathrm{db} / \mathrm{db}$ mice $(\mathrm{P}<0.05)$. Intravital microscopic observations of cremaster muscle capillaries were performed, and video recordings were obtained during resting conditions and during superfusion of two increasing doses of insulin. Figure 2.1 shows pooled data of capillary hemodynamics in the control mice (left panels) and $\mathrm{db} / \mathrm{db}$ mice (right). All examined capillaries $(n=25)$ in the control group sustained RBC perfusion during the protocol, and paired observations could be performed for these vessels. In line with previous studies, capillary tube hematocrit (panel A) was less than 0.10 during baseline in the $\mathrm{C} 57 \mathrm{Bl} / 6$ mice (i.e., $0.093 \pm 0.008$ ). During superfusion of insulin, tube hematocrit was increased $(\mathrm{P}<0.05)$, to $166 \pm 8 \%$ of baseline during the $20 \mu \mathrm{U} / \mathrm{ml}$ concentration, and to $176 \pm 20 \%$ of baseline during the $200 \mu \mathrm{U} / \mathrm{ml}$ concentration in the superfusate.

In the $\mathrm{db} / \mathrm{db}$ mice $(\mathrm{n}=5)$, a total of 36 capillaries were examined at baseline. In these capillaries, tube hematocrit was $0.154 \pm 0.10$, which was higher $(\mathrm{P}<0.05)$ compared to the $\mathrm{C} 57 \mathrm{Bl} / 6$ mice at baseline. In contrast to the $\mathrm{C} 57 \mathrm{Bl} / 6$ group, there was a loss of capillaries with RBC perfusion during the protocol; of the 36 capillaries examined during baseline conditions 4 showed stagnant RBCs during superfusion with the 20 $\mu \mathrm{U} / \mathrm{ml}$ insulin dose and an additional 12 capillaries lost RBC perfusion in the presence of the $200 \mu \mathrm{U} / \mathrm{ml}$ insulin dose in the superfusate. Hcap in the capillaries of the $\mathrm{db} / \mathrm{db}$ mice with sustained RBC perfusion during the first dose of insulin $(n=32)$ was $0.153 \pm$ 0.011 at baseline and not affected during administration of insulin $(0.163 \pm 0.01)$. Also, in the capillaries with sustained RBC perfusion during the entire experiment $(n=20$; presented in right panels of Figure 2.1), Hcap at baseline was higher than in the control mice, and did not change during superfusion with insulin at both concentrations (panel A, right).

The increase in Hcap in the presence of insulin in the control mice coincided with an increase of RBC flux (panel B, left), to $157 \pm 12 \%$ of baseline during the $20 \mu \mathrm{U} / \mathrm{ml}$ dose, and to $135 \pm 13 \%$ of baseline during the $200 \mu \mathrm{U} / \mathrm{ml}$ insulin dose, respectively. RBC velocity (panel C, left) was was unchanged during the lower dose of insulin (i.e., to 102 $\pm 5 \%$ of baseline), yet significantly lower in the presence of the $200 \mu \mathrm{U} / \mathrm{ml}(91 \pm 6 \%$ of baseline). In the capillaries with remaining RBC perfusion of the $\mathrm{db} / \mathrm{db}$ mice, RBC flux (panel B, right) and velocity (panel C, right) were both significantly decreased (to $67 \pm$ $9 \%$ and $49 \pm 4 \%$ of baseline, respectively) during the higher insulin dose.

Anatomical diameters of the examined capillaries are presented in panels D. In the control mice (left panel), capillaries had a baseline anatomical diameter of $5.4 \pm 0.2 \mu \mathrm{m}$, which was not affected during exposure to the $20 \mu \mathrm{U} / \mathrm{ml}$ insulin concentration, yet was 
significantly smaller compared to baseline at the higher insulin concentration (i.e., 94 $\pm 2 \%$ ). Baseline anatomical diameters of the flow-maintaining capillaries in the $\mathrm{db} / \mathrm{db}$ mice (right panel D) were smaller $(\mathrm{P}<0.05)$ compared to those in the $\mathrm{C} 57 \mathrm{Bl} / 6$ control group. Similar as in the control mice, capillary anatomical diameter in the $\mathrm{db} / \mathrm{db}$ mice was not affected by the lower dose of insulin, yet, in contrast to the $\mathrm{C} 57 \mathrm{Bl} / 6$ mice, it appeared larger $(\mathrm{P}<0.05)$ at the higher insulin dose $(108 \pm 3 \%$ of baseline $)$.

control

A

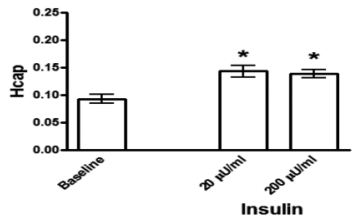

B

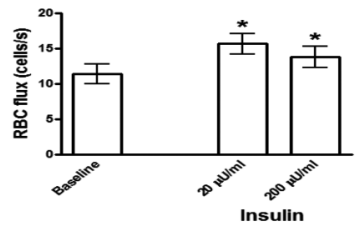

C

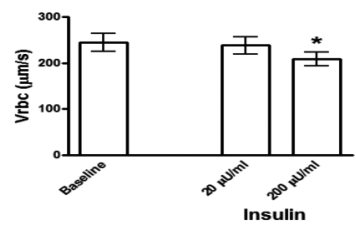

D

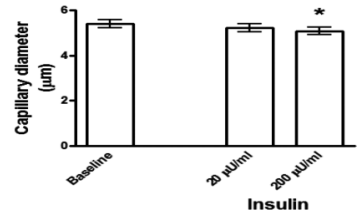

$d b / d b$
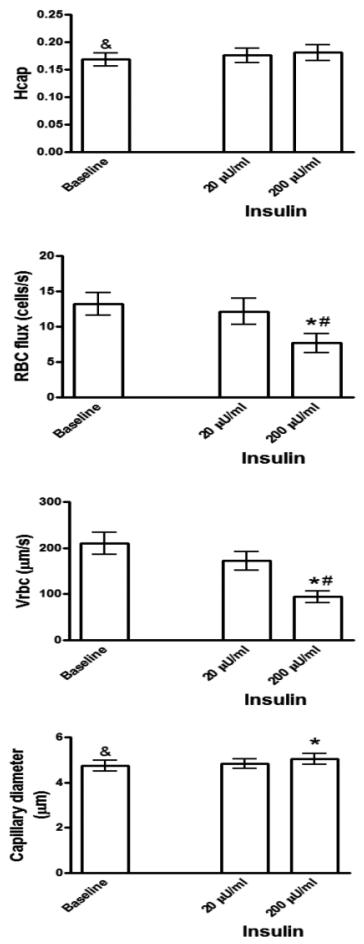

Figure 2.1 Capillary hemodynamics during baseline and insulin administration.

Left panels: control (C57Bl/6) mice (pooled data of $n=25$ vessels in $n=5$ animals). Right panels: diabetic (db/ $\mathrm{db}$ ) mice (pooled data of $n=20$ vessels in $n=5$ animals). Panels A: Capillary tube hematocrit; B: RBC flux; C: RBC velocity; D: Capillary anatomical diameter. *, $\mathrm{P}<0.05$ compared to Baseline (Tukey's); \#, P $<0.05$ compared to $20 \mu \mathrm{U} / \mathrm{ml}$ insulin dose (Tukey's); \& $\mathrm{P}<0.05$ compared to Baseline control (unpaired t-test). 


\section{Discussion}

Ample experimental evidence has been provided in the past indicating that insulinmediated glucose uptake in muscle is coupled to insulin-induced increases in capillary blood volume $[9,14,15,16]$. While this effect has typically been interpreted as insulin having the ability to increase the number of perfused capillaries in muscle, our previous experimental data suggest that intracapillary blood volume may also increase as a result of increased blood accessibility into the endothelial glycocalyx. In the current study it was shown that administration of insulin onto the cremaster muscle in C57Bl/ 6 mice was associated with an increase in blood volume in individual capillaries which had baseline perfusion. In contrast, topical insulin administration onto the cremaster muscle of diabetic $(\mathrm{db} / \mathrm{db})$ mice, which were previously associated with a generalized glycocalyx loss, was associated with a reduction in the number of blood-perfused capillaries and a lack of effect on blood content in the remaining capillaries. While confirming previous studies indicating that metabolic insulin resistance is characterized by an inability for insulin to increase capillary blood volume in skeletal muscle, the current observations indicate that this defect occurs at the at the level of the individual capillary.

\section{Insulin increases blood volume in individual capillaries of healthy mice}

Whereas several previous studies have pointed out the potential of insulin to increase capillary blood volume in muscle $[9,14,15,16]$, the origin for this microvascular insulin effect has remained unknown due to the lack of in vivo observations of individual capillary responses to insulin. The current study follows up on previous intravital microscopic studies in the cremaster muscle showing that tube hematocrit in single capillaries is low under baseline conditions, i.e., about $20 \%$ of systemic hematocrit, but may rapidly increase upon stimulation by vasoactive agents $[34,39,40]$. As in previous studies $[34,41,42,43]$, capillary tube hematocrit, which is the fractional volume of a capillary occupied by RBCs, was derived from capillary anatomical diameter and the velocity and flux of RBCs in the examined capillary. Insulin was topically applied to the muscle, thereby minimizing systemic effects of the hormone. We used two concentrations with a 10 fold dose difference (20 and $200 \mu \mathrm{U} / \mathrm{ml}$ ) which were in a sequential order applied; this approach resembled the study of McKay and Hester in the rat [25], with the difference that they used an initial insulin dose of $10 \mu \mathrm{U} / \mathrm{ml}$. These authors evaluated vasodilator responses in second- to fourth-order arterioles, and observed diameter increases in these vessels only during superfusion with the $200 \mu \mathrm{U} / \mathrm{ml}$ dose. In contrast, we observed in the current study that tube hematocrit robustly increased in the observed capillaries during administration of the $20 \mu \mathrm{U} / \mathrm{ml}$ dose already, and did not further increase at the $200 \mu \mathrm{U} / \mathrm{ml}$ dose (Fig. 2.1A), confirming previous studies 
using CEU and 1-MX metabolism indicating that the increase in capillary blood volume in skeletal muscle is more insulin sensitive than the increase in blood flow $[5,8,14]$. Also, the magnitude of the increase in capillary tube hematocrit (60-80\%) fell in the range of reported increases in CEU signal intensity and 1-MX metabolism during insulin administration $[14,15,17,21,44]$.

Capillary hemodynamics were evaluated during steady state superfusion of the muscle with insulin, starting 10 minutes after topical administration of insulin was initiated. The current study, therefore, follows up on our previous study in the rat, in which additional intravital microscopy of the cremaster muscle was performed in a small number of animals during the first $10 \mathrm{~min}$ of a hyperinsulinemic-euglycemic clamp only [28]. The reason for this short time interval was that we were interested in the rapid effect of insulin only, since it was found that the glycocalyx barrier properties in the microcirculation of the hindlimb were already impaired within 5-10 minutes after start of the clamp [28]. In that study, tube hematocrit was found to rapidly increase $\sim 50 \%$ in the observed capillaries, and to be paralleled by an increase in capillary RBC flux without a change in RBC velocity and anatomical diameter. A similar response pattern was found in the current study when the muscle was exposed to the lower insulin concentration (Fig. 2.1). The unaltered capillary RBC velocity seems to preclude a contribution of the Fåhraeus effect to the tube hematocrit increase [45], and is in line with numerous previous intravital microscopic studies which showed that capillary tube hematocrit increases as a result of an increase in glycocalyx accessibility may occur independent of changes in RBC velocity $[34,37,42,46]$. The $200 \mu \mathrm{U} / \mathrm{ml}$ concentration of insulin was, however, besides the increase in capillary RBC flux also associated with small (i.e., 9\% and $6 \%$, respectively) decreases in capillary RBC velocity and anatomical diameter (Figure 2.1C \& D, left panels).

\section{Impairment of capillary response to insulin in $\mathrm{db} / \mathrm{db}$ mice}

The $\mathrm{db} / \mathrm{db}$ mouse, which is characterized by a genetic absence of the leptin receptor, has been well established as experimental rodent model of obesity and type II diabetes. The $\mathrm{db} / \mathrm{db}$ mouse is hyperglycaemic and hyperinsulinemic, and was in a previous study from our group indicated to have reduced glycocalyx barrier properties [30]. Microvascular studies have shown that the $\mathrm{db} / \mathrm{db}$ model displays structural rarefaction in the cremaster, seen as a generalized loss of capillaries and small arterioles $[47,48]$, and remodelling of the terminal arteriolar network [49]. These alterations have been associated with robust functional microvascular impairments in the cremaster, including a loss of arteriolar vasomotor tone and impaired capacity for vasodilation $[47,48]$, and an unequal flow distribution in the terminal arteriolar network [49]. Cremaster capillaries 
of the $\mathrm{db} / \mathrm{db}$ mice in the current study were found to have somewhat smaller anatomical diameters compared to the control mice (Fig. 2.1D). Perfusion impairments in these muscles were not clearly evident at baseline, however. Capillary tube hematocrit was elevated in the observed capillaries at baseline, indicating an increased intracapillary volume available for blood likely as a result of the impaired glycocalyx barrier properties that were reported in these mice [30]. The increased Hcap was, however, not associated with an increased RBC flux or decreased RBC velocity, as observed during glycocalyx degradation by an atherogenic challenge in our previous studies $[34,42]$. These baseline capillary hemodynamics in the $\mathrm{db} / \mathrm{db}$ mice, therefore, contrast with other intravital microscopic studies in rat models of type 1 and type 2 diabetes showing severe reductions in RBC flux and velocity in capillaries of resting spinotrapezius muscle $[41,43]$. While it is possible that our observations were biased towards capillaries with relatively unaffected RBC perfusion due to the applied selection criteria (image clarity, continuous RBC perfusion), capillary perfusion impairments in the $\mathrm{db} / \mathrm{db}$ mice clearly manifested during insulin stimulation, particularly at the high insulin dose. Thus, in contrast to the control $\mathrm{C} 57 \mathrm{Bl} / 6$ mice, capillaries lost RBC perfusion during insulin, resulting in a considerable proportion (16 out of 36) of capillaries with stagnant RBCs during stimulation with the $200 \mu \mathrm{U} / \mathrm{ml}$ insulin dose, while in the capillaries that sustained RBC perfusion both capillary RBC flux and velocity were reduced at the 200 $\mu \mathrm{U} / \mathrm{ml}$ dose as well. In line with our hypothesis, in the capillaries of the $\mathrm{db} / \mathrm{db}$ mice that sustained RBC flow in the presence of insulin, tube hematocrit was unchanged at both concentrations, indicating an inability for insulin to augment blood volume in these capillaries. These data comply with reported data obtained in Zucker rats in which integrated capillary blood volume responses derived from 1-MX metabolism or CEU were found to be impaired during a hyperinsulinemic clamp $[11,13]$. The current data indicate that the impairment may occur at the level of the individual capillary, and correspond to the finding in our previous study in which the insulin-induced increase in capillary tube hematocrit was impaired in rats in which glycocalyx degradation was induced by systemic hyaluronidase infusion [28]. In these hyaluronidase treated rats capillary RBC flux and velocity were also found to be decreased in response to insulin, resembling the current observations in $\mathrm{db} / \mathrm{db}$ mice during exposure of the cremaster to the high dose of insulin (Fig. 2.1B \& C, right panels).

In conclusion, the results of the current study show that insulin is able to increase blood volume in individual capillaries of the cremaster muscle of control mice, but not of db/ $\mathrm{db}$ mice, in which stagnation of RBC flow in capillaries was found in response to insulin as well. It might be anticipated that the detrimental capillary response to insulin in $\mathrm{db} / \mathrm{db}$ mice is associated with an impaired delivery of insulin towards muscle, thereby 
contributing to the compromised insulin-mediated glucose uptake in this mouse model of diabetes.

\section{Physiological relevance}

Muscle insulin sensitivity has been coupled to the ability of insulin to increase capillary blood volume. While traditionally explained by an increase in the number of perfused capillaries (i.e., capillary recruitment), the current study shows that insulin increases blood volume at the level of the individual capillary in healthy mice but not in diabetic mice. These results indicate the capillary itself as locus for control of blood volume and exchange capacity. 


\section{References}

1. DeFronzo RA, Gunnarsson R, Bjorkman O, Olsson M, Wahren J (1985) Effects of insulin on peripheral and splanchnic glucose metabolism in noninsulin-dependent (type II) diabetes mellitus. The Journal of clinical investigation 76: 149-155.

2. Yang YJ, Hope ID, Ader M, Bergman RN (1989) Insulin transport across capillaries is rate limiting for insulin action in dogs. The Journal of clinical investigation 84: 1620-1628.

3. Miles PD, Levisetti M, Reichart D, Khoursheed M, Moossa AR, et al. (1995) Kinetics of insulin action in vivo. Identification of rate-limiting steps. Diabetes 44: 947-953.

4. Sjostrand M, Holmang A, Lonnroth P (1999) Measurement of interstitial insulin in human muscle. The American journal of physiology 276: E151-154.

5. Clerk LH, Vincent MA, Lindner JR, Clark MG, Rattigan S, et al. (2004) The vasodilatory actions of insulin on resistance and terminal arterioles and their impact on muscle glucose uptake. Diabetes/metabolism research and reviews 20: 3-12.

6. Vincent MA, Clerk LH, Rattigan S, Clark MG, Barrett EJ (2005) Active role for the vasculature in the delivery of insulin to skeletal muscle. Clinical and experimental pharmacology \& physiology 32: 302-307.

7. Chiu JD, Richey JM, Harrison LN, Zuniga E, Kolka CM, et al. (2008) Direct administration of insulin into skeletal muscle reveals that the transport of insulin across the capillary endothelium limits the time course of insulin to activate glucose disposal. Diabetes 57: 828835.

8. Barrett EJ, Eggleston EM, Inyard AC, Wang H, Li G, et al. (2009) The vascular actions of insulin control its delivery to muscle and regulate the rate-limiting step in skeletal muscle insulin action. Diabetologia 52: 752-764.

9. Barrett EJ, Wang H, Upchurch CT, Liu Z (2011) Insulin regulates its own delivery to skeletal muscle by feed-forward actions on the vasculature. American journal of physiology Endocrinology and metabolism 301: E252-263.

10. Sjostrand M, Gudbjornsdottir S, Holmang A, Strindberg L, Ekberg K, et al. (2002) Measurements of interstitial muscle glycerol in normal and insulin-resistant subjects. The Journal of clinical endocrinology and metabolism 87: 2206-2211.

11. Wallis MG, Wheatley CM, Rattigan S, Barrett EJ, Clark AD, et al. (2002) Insulin-mediated hemodynamic changes are impaired in muscle of Zucker obese rats. Diabetes 51: 34923498.

12. Ellmerer M, Hamilton-Wessler M, Kim SP, Huecking K, Kirkman E, et al. (2006) Reduced access to insulin-sensitive tissues in dogs with obesity secondary to increased fat intake. Diabetes 55: 1769-1775.

13. Clerk LH, Vincent MA, Barrett EJ, Lankford MF, Lindner JR (2007) Skeletal muscle capillary responses to insulin are abnormal in late-stage diabetes and are restored by angiotensinconverting enzyme inhibition. American journal of physiology Endocrinology and metabolism 293: E1804-1809. 
14. Zhang L, Vincent MA, Richards SM, Clerk LH, Rattigan S, et al. (2004) Insulin sensitivity of muscle capillary recruitment in vivo. Diabetes 53: 447-453.

15. Vincent MA, Clerk LH, Lindner JR, Klibanov AL, Clark MG, et al. (2004) Microvascular recruitment is an early insulin effect that regulates skeletal muscle glucose uptake in vivo. Diabetes 53: 1418-1423.

16. Eggleston EM, Jahn LA, Barrett EJ (2007) Hyperinsulinemia rapidly increases human muscle microvascular perfusion but fails to increase muscle insulin clearance: evidence that a saturable process mediates muscle insulin uptake. Diabetes 56: 2958-2963.

17. Clerk LH, Rattigan S, Clark MG (2002) Lipid infusion impairs physiologic insulin-mediated capillary recruitment and muscle glucose uptake in vivo. Diabetes 51: 1138-1145.

18. Youd JM, Rattigan S, Clark MG (2000) Acute impairment of insulin-mediated capillary recruitment and glucose uptake in rat skeletal muscle in vivo by TNF-alpha. Diabetes 49: 1904-1909.

19. Vincent MA, Barrett EJ, Lindner JR, Clark MG, Rattigan S (2003) Inhibiting NOS blocks microvascular recruitment and blunts muscle glucose uptake in response to insulin. American journal of physiology Endocrinology and metabolism 285: E123-129.

20. Clark MG, Barrett EJ, Wallis MG, Vincent MA, Rattigan S (2002) The microvasculature in insulin resistance and type 2 diabetes. Seminars in vascular medicine 2: 21-31.

21. Clerk LH, Vincent MA, Jahn LA, Liu Z, Lindner JR, et al. (2006) Obesity blunts insulinmediated microvascular recruitment in human forearm muscle. Diabetes 55: 1436-1442.

22. Rattigan S, Clark MG, Barrett EJ (1997) Hemodynamic actions of insulin in rat skeletal muscle: evidence for capillary recruitment. Diabetes 46: 1381-1388.

23. Poole DC, Brown MD, Hudlicka O (2008) Counterpoint: There is not capillary recruitment in active skeletal muscle during exercise. Journal of applied physiology 104: 891-893; discussion 893-894.

24. Poole DC, Copp SW, Hirai DM, Musch TI (2011) Dynamics of muscle microcirculatory and blood-myocyte O(2) flux during contractions. Acta physiologica 202: 293-310.

25. McKay MK, Hester RL (1996) Role of nitric oxide, adenosine, and ATP-sensitive potassium channels in insulin-induced vasodilation. Hypertension 28: 202-208.

26. Renaudin C, Michoud E, Rapin JR, Lagarde M, Wiernsperger N (1998) Hyperglycaemia modifies the reaction of microvessels to insulin in rat skeletal muscle. Diabetologia 41: 2633.

27. Van Teeffelen J, Vink H (2008) Capillary blood volume increase in already perfused capillaries: Role for glycocalyx modulation. Journal of Applied Physiology 104: 895-895.

28. Eskens BJ, Mooij HL, Cleutjens JP, Roos JM, Cobelens JE, et al. (2013) Rapid insulin-mediated increase in microvascular glycocalyx accessibility in skeletal muscle may contribute to insulin-mediated glucose disposal in rats. PloS one 8: e55399.

29. VanTeeffelen JWGE, Brands J, Vink H (2010) Agonist-induced impairment of glycocalyx exclusion properties: contribution to coronary effects of adenosine. Cardiovasc Res 87: 311-319. 
30. Zuurbier CJ, Demirci C, Koeman A, Vink H, Ince C (2005) Short-term hyperglycemia increases endothelial glycocalyx permeability and acutely decreases lineal density of capillaries with flowing red blood cells. J Appl Physiol 99: 1471-1476.

31. Nieuwdorp M, Mooij HL, Kroon J, Atasever B, Spaan JA, et al. (2006) Endothelial glycocalyx damage coincides with microalbuminuria in type 1 diabetes. Diabetes 55: 1127-1132.

32. VanTeeffelen J, Constantinescu AA, Vink H, Spaan JAE (2005) Hypercholesterolemia impairs reactive hyperemic vasodilation of $2 \mathrm{~A}$ but not $3 \mathrm{~A}$ arterioles in mouse cremaster muscle. American Journal of Physiology-Heart and Circulatory Physiology 289: H447-H454.

33. VanTeeffelen JW, Brands J, Jansen C, Spaan JA, Vink H (2007) Heparin impairs glycocalyx barrier properties and attenuates shear dependent vasodilation in mice. Hypertension 50 : 261-267.

34. Van Teeffelen JWGE, Constantinescu AA, Brands J, Spaan JAE, Vink H (2008) Bradykinin- and sodium nitroprusside-induced increases in capillary tube hematocrit in mouse cremaster muscle are associated with impaired glycocalyx barrier properties. Journal of PhysiologyLondon 586: 3207-3218.

35. Eringa EC, Stehouwer CD, Merlijn T, Westerhof N, Sipkema P (2002) Physiological concentrations of insulin induce endothelin-mediated vasoconstriction during inhibition of NOS or PI3-kinase in skeletal muscle arterioles. Cardiovascular research 56: 464-471.

36. Rasband WS (1997-2012) Image J, U. S. National Institutes of Health, Bethesda, Maryland, USA, http://rsb.info.nih.gov/ij/.

37. Vink H, Duling BR (1996) Identification of distinct luminal domains for macromolecules, erythrocytes, and leukocytes within mammalian capillaries. Circ Res 79: 581-589.

38. Murdock RC, Reynolds C, Sarelius IH, Waugh RE (2000) Adaptation and survival of surfacedeprived red blood cells in mice. American journal of physiology Cell physiology 279: C970980.

39. Duling BR, Desjardins C (1987) Capillary hematocrit - What does it mean? News Physiol Sci 2: 66-69.

40. Klitzman B, Duling BR (1979) Microvascular hematocrit and red cell flow in resting and contracting striated muscle. Am J Physiol 237: H481-490.

41. Kindig CA, Sexton WL, Fedde MR, Poole DC (1998) Skeletal muscle microcirculatory structure and hemodynamics in diabetes. Respiration physiology 111: 163-175.

42. Constantinescu AA, Vink H, Spaan JA (2001) Elevated capillary tube hematocrit reflects degradation of endothelial cell glycocalyx by oxidized LDL. American journal of physiology Heart and circulatory physiology 280: H1051-1057.

43. Padilla DJ, McDonough P, Behnke BJ, Kano Y, Hageman KS, et al. (2006) Effects of Type II diabetes on capillary hemodynamics in skeletal muscle. American journal of physiology Heart and circulatory physiology 291: H2439-2444.

44. Kubota T, Kubota N, Kumagai H, Yamaguchi S, Kozono H, et al. (2011) Impaired insulin signaling in endothelial cells reduces insulin-induced glucose uptake by skeletal muscle. Cell metabolism 13: 294-307. 
45. Goldsmith HL, Cokelet GR, Gaehtgens P (1989) Robin Fahraeus: evolution of his concepts in cardiovascular physiology. The American journal of physiology 257: H1005-1015.

46. Desjardins C, Duling BR (1990) Heparinase treatment suggests a role for the endothelial cell glycocalyx in regulation of capillary hematocrit. Am J Physiol Heart Circ Physiol 258: H647-654.

47. Bohlen HG, Niggl BA (1979) Arteriolar anatomical and functional abnormalities in juvenile mice with genetic or streptozotocin-induced diabetes mellitus. Circulation research 45 : 390-396.

48. Bohlen HG, Niggl BA (1979) Adult microvascular disturbances as a result of juvenile onset diabetes in $\mathrm{Db} / \mathrm{Db}$ mice. Blood vessels 16: 269-276.

49. Georgi MK, Vigilance J, Dewar AM, Frame MD (2011) Terminal arteriolar network structure/function and plasma cytokine levels in $\mathrm{db} / \mathrm{db}$ and ob/ob mouse skeletal muscle. Microcirculation 18: 238-251. 


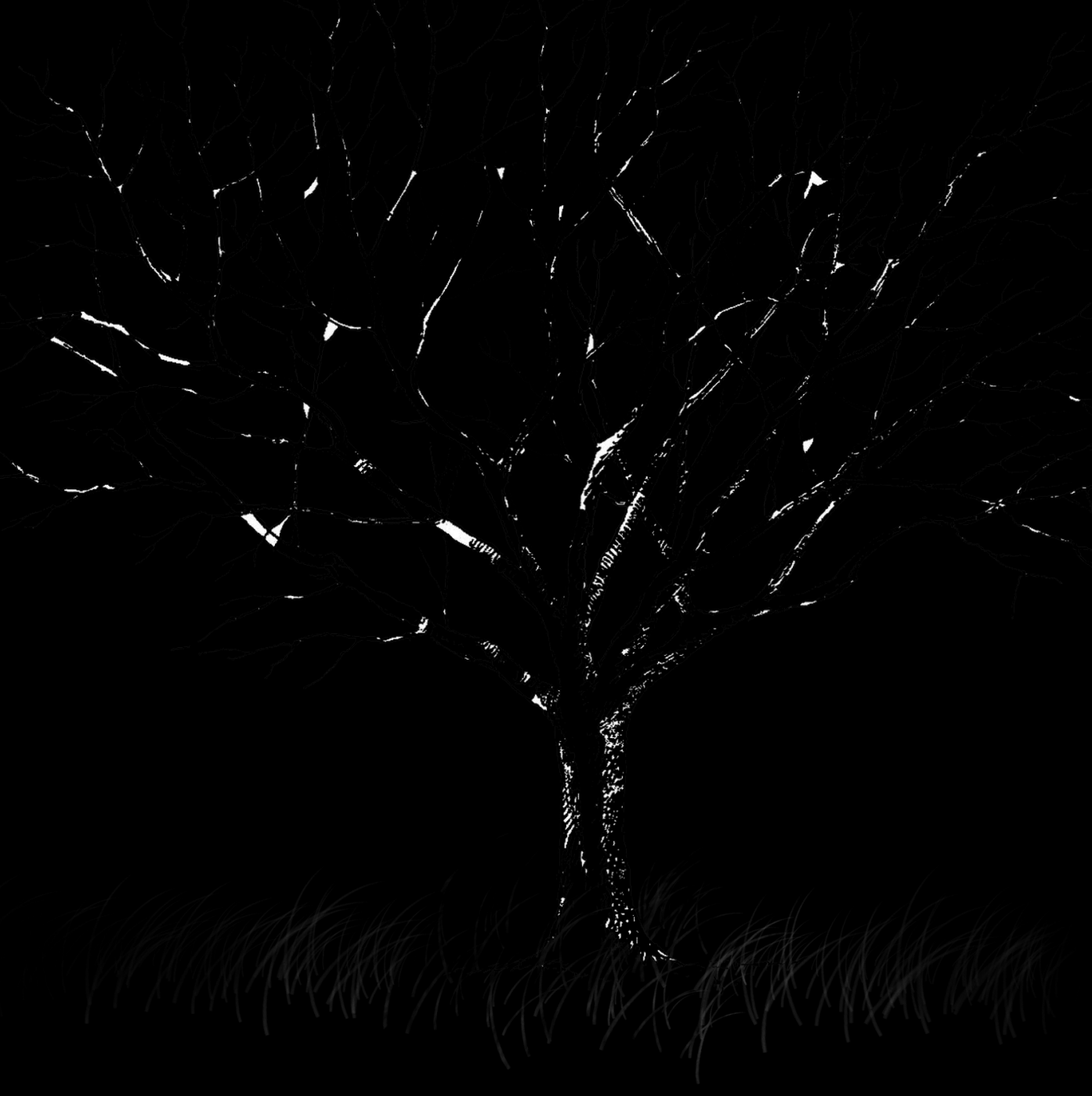


Chapter 3

\title{
Rapid insulin-mediated increase in microvascular glycocalyx accessibility in skeletal muscle may contribute to insulin- mediated glucose disposal in rats
}

\author{
Bart J.M. Eskens \\ Hans L. Mooij \\ Jack P.M. Cleutjens \\ Sjef M.A. Roos \\ Hanneke E. Cobelens \\ Hans Vink \\ Jurgen W.G.E. VanTeeffelen
} PloS ONE 2013; 8:e55399 


\begin{abstract}
It has been demonstrated that insulin-mediated recruitment of microvascular blood volume is associated with insulin sensitivity. We hypothesize that insulin rapidly stimulates penetration of red blood cells (RBC) and plasma into the glycocalyx and thereby promotes insulin-mediated glucose uptake by increasing intracapillary blood volume.
\end{abstract}

Experiments were performed in rats; the role of the glycocalyx was assessed by enzymatic degradation using a bolus of hyaluronidase. First, the effect of insulin on glycocalyx accessibility was assessed by measuring the depth of penetration of RBCs into the glycocalyx in microvessels of the gastrocnemius muscle with Sidestream Darkfield imaging. Secondly, peripheral insulin sensitivity was determined using intravenous insulin tolerance tests (IVITT). In addition, in a smaller set of experiments, intravital microscopy of capillary hemodynamics in cremaster muscle and histological analysis of the distribution of fluorescently labeled $40 \mathrm{kDa}$ dextrans (D40) in hindlimb muscle was used to evaluate insulin-mediated increases in capillary blood volume.

Insulin increased glycocalyx penetration of RBCs by $0.34 \pm 0.44 \mu \mathrm{m}(\mathrm{P}<0.05)$ within 10 minutes, and this effect of insulin was greatly impaired in hyaluronidase treated rats. Further, hyaluronidase treated rats showed a $35 \pm 25 \%$ reduction in wholebody insulin-mediated glucose disposal compared to control rats. Insulin-mediated increases in capillary blood volume were reflected by a rapid increase in capillary tube hematocrit from $21.1 \pm 10.1 \%$ to $29.0 \pm 9.8 \%(\mathrm{P}<0.05)$, and an increase in D40 intensity in individual capillaries of $134 \pm 138 \%$ compared to baseline at the end of the IVITT. These effects of insulin were virtually abolished in hyaluronidase treated animals. In conclusion, insulin rapidly increases glycocalyx accessibility for circulating blood in muscle, and this is associated with an increased blood volume in individual capillaries. Hyaluronidase treatment of the glycocalyx abolishes the effects of insulin on capillary blood volume and impairs insulin-mediated glucose disposal. 


\section{Introduction}

After insulin has been secreted by the pancreas into the bloodstream, it is distributed by the microcirculation towards the capillaries where it has to cross the endothelium to bind to insulin receptors on target tissues, such as skeletal muscle. There is increasing evidence that both insulin delivery by the blood and the subsequent exchange from capillaries to the tissue may be rate limiting steps for the metabolic actions of insulin $[1,2,3]$. In skeletal muscle microcirculation, insulin has been indicated to rapidly (within 10-15 minutes) recruit capillary blood volume [4,5], an effect which occurs before an increase of total blood flow, and which appears to be important for insulin's metabolic actions [5]. While there is substantial experimental evidence for this link between the ability of insulin to increase capillary blood volume and its ability to efficiently dispose glucose from the circulation $[5,6]$, the mechanism by which insulin mediates the increase in capillary blood volume in muscle is not well understood at the moment [7]. While traditionally the increase in capillary blood volume has been explained by an increase in number of perfused capillaries, our previous studies suggest that agonists are also able to increase functionally perfused capillary blood volume within individual microvessels by modulating the barrier properties of the endothelial glycocalyx $[8,9,10]$. The endothelial glycocalyx is the $0.5-1.0 \mu \mathrm{m}$ thick gel-like layer on the luminal side of the vascular endothelial cells. It consists of a mesh of polysaccharide structures and absorbed plasma proteins and water $[11,12]$, and has the last decade been indicated to have an important role in protection of the vessel wall, as well as in regulation of microvascular perfusion and nutrient exchange $[9,13]$. Intravital microscopy studies in rodent cremaster muscle indicate that under control conditions the glycocalyx is to a large extent inaccessible for red blood cells (RBCs) and plasma macromolecules $[14,15]$, but that its accessibility can be rapidly increased in the presence of the agonists adenosine, bradykinin and sodium nitroprusside, resulting in a robust increase in capillary tube hematocrit $[8,10,16]$. Conversely, glycocalyx degradation during chronic hyperlipidemic conditions or acute enzymatic treatment has been associated with an impaired ability for these agonists to increase capillary blood volume $[10,17]$.

The aim of the current study was to determine whether insulin also has the ability to rapidly increase blood volume in individual capillaries in muscle by modulation of the glycocalyx, and if this mechanism is important for insulin-mediated glucose disposal. In rats, we measured insulin effects on microvascular glycocalyx barrier properties and capillary blood volume in muscle, and assessed insulin sensitivity by an intravenous insulin tolerance test. The role of the glycocalyx was evaluated by acute enzymatic degradation with hyaluronidase $[18,19]$. Our results indicate that insulin, by rapidly increasing glycocalyx accessibility for circulating blood, is able to augment blood volume 
Chapter 3

within individual capillaries in skeletal muscle, and this effect is indicated to contribute to insulin-mediated glucose disposal. 


\section{Methods}

\section{Animals and general instrumentation}

The experimental protocols were approved by the Animal Ethics Care and Use committee of Maastricht University (AEC protocol numbers: 2007-167 and 2009-015). Experiments were performed in male Wistar rats $(350-400$ gram; $n=42)$ that received standard chow and water ad libitum. After arrival from the external supplier (Harlan, Horst, The Netherlands) the animals were housed at the animal facility of Maastricht University and allowed to acclimatize for at least one week before the experiments. At the day of the experiment, after an overnight fast (10-12 h), rats received the narcotic analgesic buprenorphine (Temgesic $0.03 \mathrm{mg} / \mathrm{mL}$; Schering-Plough) at $0.1 \mathrm{mg} / \mathrm{kg}$ subcutaneously, while 30-45 minutes later the animals were put under isoflurane anesthesia (2\%). Their femoral vein was cannulated with a polyurethane catheter $(1.02 \mathrm{~mm}$ outer diameter (OD); 0.61 mm inner diameter (ID), Charles River Wiga GmbH, Sulzfeld, Germany), and either a bolus of $1 \mathrm{ml}$ saline or $1 \mathrm{ml}$ hyaluronidase (500 U/ml) was infused. One hour later baseline glucose ( $\mathrm{Gluc}_{0}$ ) and baseline insulin ( $\mathrm{Ins}_{0}$ ) were measured in each animal, and as a measure for baseline insulin sensitivity the HOMA-IR was calculated (( $\operatorname{Ins}_{0} \mathrm{X}$ Gluc $_{0}$ )/405). Insulin infusion started 60-90 min after bolus injection in the different protocols described below. The choice for a 1-1.5 hour incubation period was based on previous reports of a time-dependent effect of bolus administration of hyaluronidase on impairment of glycocalyx exclusion properties $[18,19]$. At the end of the experiments rats were sacrificed by exsanguination while under anesthesia.

\section{Experimental protocols}

Table 3.1 depicts the different protocols used in the current study. Two main protocols were used. In the first protocol, it was studied whether glycocalyx barrier properties were rapidly impaired upon insulin infusion, and in the second it was studied whether enzymatic glycocalyx degradation was associated with an impaired insulin sensitivity. To evaluate whether the effects observed in these two studies were associated with changes in perfused capillary blood volume, for each protocol additional experiments were performed in a smaller group of animals (named protocol 1a and 2a, respectively). 


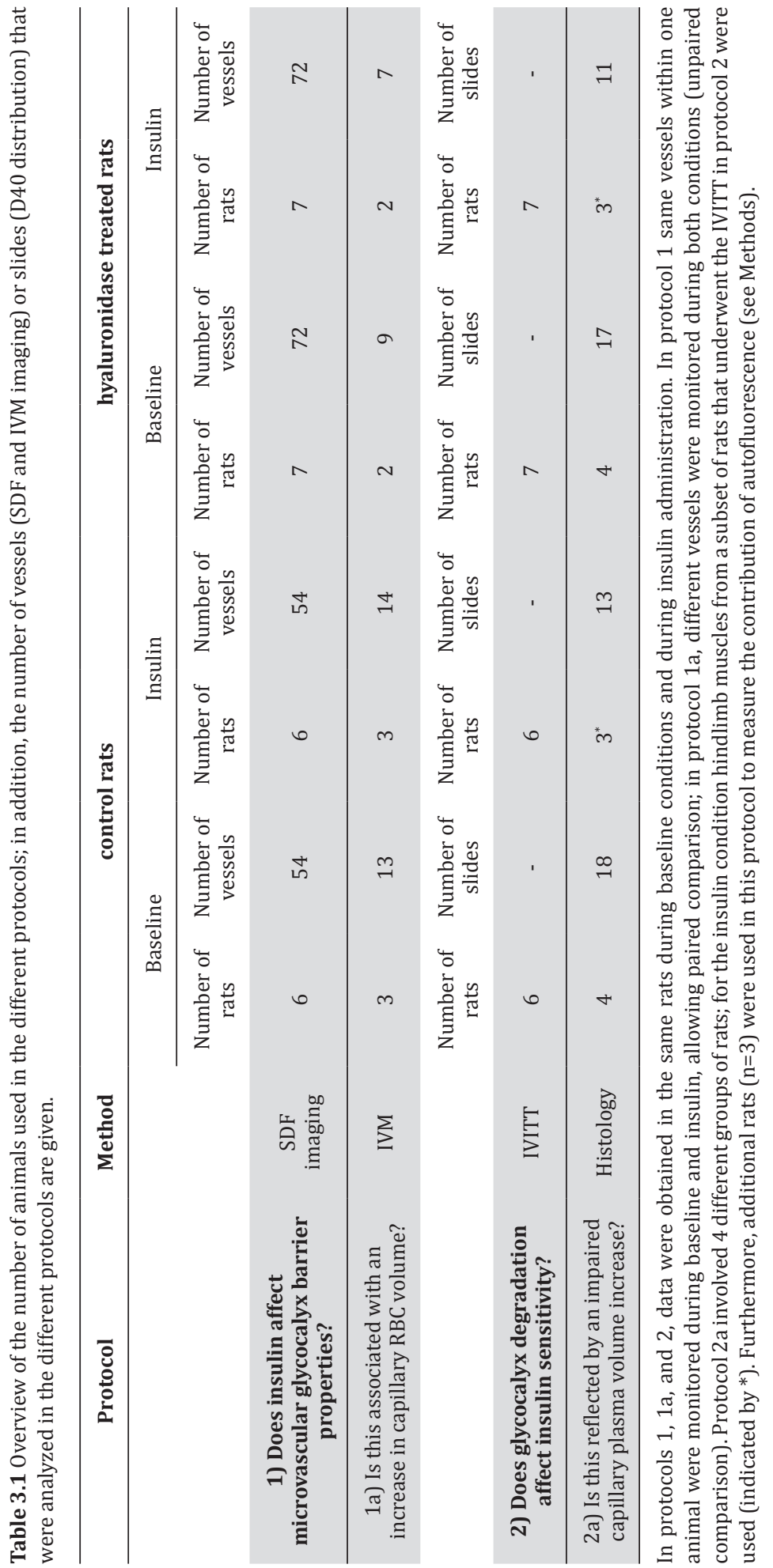




\section{1) Rapid effect of insulin on glycocalyx barrier properties in hindlimb muscle}

To determine the potency of insulin to rapidly modulate microvascular glycocalyx barrier properties, rats received a constant infusion of insulin $(6 \mathrm{mU} / \mathrm{min} / \mathrm{kg})$, somatostatin $(0.8 \mu \mathrm{g} / \mathrm{kg} / \mathrm{min})$ and glucose $(12 \mathrm{mg} / \mathrm{kg} / \mathrm{min})$ for 30 minutes. Somatostatin was used to block endogenous insulin and glucagon secretion. The co-infusion of glucose enabled blood glucose levels to be maintained above $75 \mathrm{mg} / \mathrm{dl}$, as checked by regular blood glucose measurements (Ascensia Contour). To measure the effect of insulin on glycocalyx barrier properties, changes in RBC column width in individual microvessels were determined. Herefore, the superficial part of the gastrocnemius muscle in rats was exposed, and a bicarbonate-buffered physiological salt solution (PSS) of the following composition (mM): $131.9 \mathrm{NaCl}, 4.7 \mathrm{KCl}, 2.0 \mathrm{CaCl} 2,1.2 \mathrm{MgSO} 4,20 \mathrm{NaHCO} 3$ and equilibrated with $5 \% \mathrm{CO}_{2}-95 \% \mathrm{~N}_{2}$ to obtain a $\mathrm{pH}$ of \pm 7.4 was used to suffuse the muscle. The microcirculation was imaged with a SDF camera, which is equipped with a $5 \mathrm{X}$ magnifying objective lens system-containing probe, imaging the RBCs in the tissue-embedded microcirculation using green pulsed LED ring illumination [20]. After equilibration, the microcirculation was visualized 10 times at baseline (for 30 minutes) and during the constant infusion of insulin for 30 minutes. In each animal, paired measurements of the muscle microcirculation were made by holding the SDF at the same position using a micromanipulator.

\section{1a) Rapid effect of insulin on capillary tube hematocrit in cremaster muscle}

To test if the rapid changes (i.e., within 10 minutes) in glycocalyx barrier properties by insulin were accompanied by concomitant rapid increases in capillary blood volume, capillary tube hematocrit measurements were performed in cremaster muscle using intravital microscopy. Herefore, rats were placed in a supine position on a custom built animal platform and the right cremaster muscle was prepared as previously described for the mouse [21,22]. Briefly, an incision was made through the skin and the muscle dissected from the surrounding connective tissue. The exposed muscle was positioned on a clear Silicon pedestal and longitudinally incised from the apex to the inguinal canal with minimal disruption of the vascular supply. After severing the deferential artery and vein, the testis and epididymis were dissected away and repositioned in the abdominal cavity. The cremaster muscle was spread radially on the pedestal and pinned at the edges. The muscle was continuously $\left(\sim 5 \mathrm{ml} \mathrm{min}{ }^{-1}\right)$ superfused at $34{ }^{\circ} \mathrm{C}$ with PSS. Following surgery, the completed preparation was transferred to the stage of an intravital microscope (Leica Microsystems, Wetzlar, Germany), coupled to a CCD video camera (C9100; Hamamatsu, Hamamatsu City, Japan). Microvessels were observed using bright-field (100 W Hg lamp) microscopy (condensor: numerical aperture (NA): 
0.6; salt water immersion objective lens (SW100, NA 1.2)). Bright-field images were made with a $435 \mathrm{~nm}$ band pass interference filter (blue light) in the light path. The preparation was equilibrated for 20-30 min, during which time the arteriolar network was scanned for the presence of vasomotor tone. Cremaster capillaries from different microscopic fields were randomly chosen for examination and recorded with Wasabi software (Hamamatsu) before (for 30 minutes) and during 10 minutes after start of the insulin infusion.

\section{2) Effect of enzymatic glycocalyx treatment on insulin-mediated glucose disposal}

An intravenous insulin tolerance test (IVITT) was performed to measure insulinmediated glucose disposal. To avoid hypoglycemia resulting from the insulin infusion, first a bolus of $1 \mathrm{~g} / \mathrm{kg}$ glucose $(0.5 \mathrm{~g} / \mathrm{mL})$ was given via the venous line and this was followed by a bolus of $1 \mathrm{U} / \mathrm{kg}$ insulin $(1 \mathrm{U} / \mathrm{mL})$ after 30 minutes. Blood glucose was measured, via tail bleeding, with a glucose meter (Ascensia contour) at $\mathrm{t}=-10$ and 0 (pre) and $\mathrm{t}=2,4,6,8,10,15,20$ and 30 minutes after glucose infusion; then the bolus of insulin at $t=31$ was given and blood glucose was further monitored at $t=33,35$, $37,39,41,46,51$, and 61 minutes. Plasma insulin levels were measured with an ELISA (ALPCO Diagnostics, Salem, NH) at $\mathrm{t}=0$ (pre) and $\mathrm{t}=2,6,10,15,30,33,37,41,46$ and 61 minutes after glucose infusion; systemic hematocrit was also measured at these time points.

\section{2a) Effect of enzymatic glycocalyx treatment on insulin-mediated increases in plasma volume in hindlimb capillaries}

At the end of the IVITT ( $\mathrm{t}=61 \mathrm{~min}$ ), $0.5 \mathrm{ml}$ of Texas-Red labeled $40 \mathrm{kDa}$ dextrans (5 $\mathrm{mg} / \mathrm{ml}$ ) (D40; Invitrogen) was infused, and 3 minutes later hindlimb muscles were rapidly removed and immediately fixed in a 4\% formaldehyde solution for subsequent histological analysis. Additional control experiments were performed to determine the D40 distribution in the absence of insulin, and to correct for the contribution of autofluorescence (no D40 infusion).

\section{Data analysis}

\section{1) Glycocalyx barrier properties}

Insulin-mediated changes in glycocalyx barrier properties were derived from dynamic RBC column width measurements, which were determined in all visualized microvessels that were a) in focus, b) had a sufficient length and were not close to bifurcations, and c) 
were continuously filled with RBCs and did not contain plasma gaps. Movies consisted of 40 consecutive frames and contained 5-15 useful microvessels per observed muscle area (950 $\mu \mathrm{m}$ by $700 \mu \mathrm{m}$ ) (Fig 1A). In each frame, lines were placed every $10 \mu \mathrm{m}$ perpendicular to the vessel direction along the length of each visible microvessel. Each line represented a measurement site; at each site a total of 21 parallel (every $\pm 0.5 \mu \mathrm{m}$ ) intensity profiles was plotted (using ImageJ, National Institutes of Health, Bethesda, MD) and RBC column width (full width half maximum (FWHM)) was determined at each line for all 40 consecutive frames in a movie, revealing a total of $840 \mathrm{RBC}$ column width measurements at a single measurement site ( 21 profiles X 40 frames). The cumulative distribution of the RBC column widths for these 840 measurements was constructed and used to determine median $\mathrm{RBC}$ column diameter $\left(\mathrm{D}_{\mathrm{P} 50}\right)$ at each measurement site; in addition, RBC column widths percentiles between P25 and P75 were fitted with a linear fit to determine the distance between opposite positions of the RBC-glycocalyx interface at each measurement site, which is defined as the RBC-perfused diameter $\left(D_{\text {perf }}\right.$ ) (Fig. 3.1B) [23]. For each microvessel in an experiment, $D_{P 50}$ and $D_{\text {perf }}$ were averaged for all measurement sites along the vessel, and this was done at each time point.

\section{1a) Capillary tube hematocrit}

Capillary hemodynamics in 4-5 capillaries per muscle were monitored at baseline and during insulin infusion for 10 minutes. Capillary tube hematocrit (Hcap) was determined from the digitally recorded movies from capillary anatomical diameter $\left(D_{a}\right)$, the flux of RBCs (F) and the velocity of RBCs (V) in each recorded capillary using the formula: Hcap $=\mathrm{F} /\left(\mathrm{V}^{*} \pi / 4 * \mathrm{Da}^{2}\right) * \mathrm{MCV}[10,21]$, where MCV is the mean corpuscular volume in rats $\left( \pm 70 \mathrm{um}^{3}\right)[24,25]$. Using frame by frame playback RBC flux in a capillary was determined, at least 5 times per measurement, by counting the number of RBCs to pass through a reference point in 1 second. The velocity of RBCs in each capillary was determined by measuring the length of a capillary segment and dividing it by the time required for RBCs to traverse this segment [21]. Further, capillary blood flow (Qcap) was calculated using the formula:

$\mathrm{Qcap}=\mathrm{V} * \pi^{*}(\mathrm{D} / 2)^{2}$.

\section{2) Insulin-mediated glucose disposal}

As a reflection of the insulin sensitivity during the IVITT, the decline in blood glucose between 2 and 30 minutes after insulin infusion was determined, and the glucose disposal rate (Kitt) calculated from the slope of the linear regression line of the logarithm of blood glucose against time multiplied by -100 [26]. 


\section{2a) D40 distribution}

Muscles were paraffin-embedded and sectioned in the transverse direction. Of each muscle 5 slides were analyzed; only slides were included in which microvessels were sectioned perpendicular, as checked by the hexagonal pattern of the cross-sectioned muscle fibers and roundness of the D40 / WGA-FITC stain (see below). Images (713 $\mu \mathrm{m} \times 532 \mu \mathrm{m}$ ) were captured with a Leica DFC320 digital camera (Leica, Rijswijk, Netherlands) at 20x magnification (Leica DM3000 microscope) (Fig. 3.3). Within a slide both diameter and total intensity of each D40 filled capillary were derived using MATLAB software (MATLAB 7.8.0). Thereto, the number of fluorescent pixels per capillary was used as a measurement of the total surface area (A) of a filled capillary, and diameter (D) calculated using the formula: $\mathrm{D}=2 * \sqrt{\frac{A}{\mathrm{p}}}$.. Total intensity per filled capillary was calculated by dividing the intensity of each fluorescent pixel in the vessel by the mean background intensity from the surrounding muscle tissue, and subsequent summation of all normalized pixel intensities. In the slides that were analyzed, for all four conditions, approximately $85 \%$ of all microvessels had a D40 diameter $<10 \mu \mathrm{m}$, indicating that primarily capillaries were analyzed.

In addition, in each slide the total number of D40 perfused capillaries per muscle area was calculated using specialized morphometry software (Leica QWin V3, Cambridge, United Kingdom). For reference, structural capillary density was measured in a number of the slides as well. Hereto, slides were deparaffinized and stained using $50 \mu \mathrm{g} / \mathrm{ml}$ FITClabeled lectin from triticum vulgaris (WGA-FITC; Sigma). Images were captured at the same $x-y$ position of the slide as for the D40 image and the total number of WGA-FITC stained capillaries per muscle area was calculated also using specialized morphometry software.

\section{Statistical analysis}

Statistical analysis for protocols 1 and 2 was performed on the number of animals; for protocols $1 \mathrm{a}$ and $2 \mathrm{a}$ analysis was performed on the number of vessels and number of slides, respectively. These numbers were based on power analyses (power $=0,8 ; \alpha$ =0.05). Thus, the study of Vincent et al. [5], showed, using contrast-enhanced ultrasound, that insulin rapidly increased microvascular blood volume by $\sim 50 \%$, and we supposed that insulin would have comparable effects on capillary tube hematocrit (SD: $40 \%$ ) and D40 intensity (SD: $41 \%$ ), revealing that a total number of 11 vessels and 12 slides were needed, respectively, to observe significant increases by insulin. The number of animals that were used in each protocol as well as the number of vessels (SDF and IVM imaging) or slides (D40 distribution) that were analyzed are summarized in Table 1 . All data are presented as means \pm SD; coefficient of variation is expressed as (SD/mean $x 100 \%)$. The 
normality of the data was checked with the D'Agostino \& Pearson omnibus normality test for groups with a $n>6$ and the Shapiro Kolmogorov-Smirnov test for groups with a $\mathrm{n}<6$. If data were not normally distributed, the range (minimum to maximum) has been added. The effect of insulin on glycocalyx barrier properties measured with SDF was tested for the first 10 minutes as well as for the entire 30 minute infusion period, a 1-way ANOVA test with Tukey's posthoc test was used if all data passed the normality test, while a Friedman test with Dunn's post-hoc multiple comparison test was used in case when groups did not pass the normality test. Statistical differences in the other experiments were tested with Student's t-tests or Mann-Whitney U test. A value of $\mathrm{P}<0.05$ was considered statistically significant. 


\section{Results}

To determine the potency of insulin to rapidly modulate microvascular glycocalyx properties and thereby increase blood volume in capillaries (Protocol 1), control and hyaluronidase treated rats received a constant infusion of insulin $(6 \mathrm{mU} / \mathrm{min} / \mathrm{kg})$, somatostatin $(0.8 \mu \mathrm{g} / \mathrm{kg} / \mathrm{min})$ and glucose $(12 \mathrm{mg} / \mathrm{kg} / \mathrm{min})$ for 30 minutes. Baseline glucose and insulin levels were $115.0 \pm 30.4$ (75.7 -198.2) mg/dl and $7.6 \pm 1.5$ (5.7 -9.7) $\mu \mathrm{U} / \mathrm{ml}$ respectively in control rats and were not different in the hyaluronidase treated rats $(130.0 \pm 29.6(82.9-187.4) \mathrm{mg} / \mathrm{dl}$ and $8.7 \pm 6.0(4.2-21.5) \mu \mathrm{U} / \mathrm{ml})$.In line with the comparable glucose and insulin levels, the HOMA-IR was not different between the control group and the hyaluronidase treated group, $2.0 \pm 0.4$ versus $2.4 \pm 1.8$, respectively.

\section{1) Glycocalyx barrier properties}

For assessment of glycocalyx barrier properties, the microcirculation of the gastrocnemius muscle was visualized with a SDF camera. Dynamic variations in red blood cell (RBC) column width were measured in each visible useful microvessel and the position of the RBC-glycocalyx interface was used to monitor the level of penetration of RBCs into the glycocalyx (Fig. 3.1). In the control rats, the coefficient of variation between the 10 measurements in a vessel during the baseline period for $\mathrm{D}_{\mathrm{P} 50}$ and $\mathrm{D}_{\text {perf }}$ were $4.5 \pm 2.4 \%$ and $6.4 \pm 5.0 \%$ respectively; pooled values were respectively $9.5 \pm 1.3$ $\mu \mathrm{m}\left(\mathrm{D}_{\mathrm{P} 50}\right)$ and $13.4 \pm 1.2 \mu \mathrm{m}\left(\mathrm{D}_{\text {perf }}\right)$. Mean coefficients of variation of $\mathrm{D}_{\mathrm{P} 50}$ and $\mathrm{D}_{\text {perf }}$ within an animal were $11.3 \pm 3.0 \%$ and $15.0 \pm 5.5 \%$, between animals they were $3.5 \%$ and $9.0 \%$ and between vessels they were $12.4 \%$ and $18.6 \%$, respectively. Subsequent insulin infusion resulted in an increase in outward movement of the RBC-glycocalyx interface of $0.34 \pm 0.44 \mu \mathrm{m}$ at both sides within 10 minutes ( $\mathrm{p}<0.05$; Fig $3.1 \mathrm{C}$, right panel), while there was no significant effect of insulin on RBC-glycocalyx interface when tested for the entire 30 minutes infusion period. $\mathrm{D}_{\mathrm{P} 50}$ did not change within the first 10 minutes after start of the insulin infusion, nor during the 30 minutes of insulin infusion (Fig 3.1C, left panel). Compared to the control rats, $\mathrm{D}_{\mathrm{P} 50}$ in the microvessels of the hyaluronidase treated rats was lower during baseline $(8.6 \pm 0.9 \mu \mathrm{m} ; \mathrm{p}<0.05)$ and did not change in response to insulin infusion as well (Fig 3.1D, left panel). The $\mathrm{D}_{\text {perf }}$ at baseline did not differ $(12.6 \pm 1.4 \mu \mathrm{m})$ in the hyaluronidase treated rats compared to the control rats; in contrast to control, $\mathrm{D}_{\text {perf }}$ did not increase in the initial 10 minutes after start of insulin infusion in the hyaluronidase treated rats (Fig 3.1D, right panel). The response of $\mathrm{D}_{\text {perf }}$ during the insulin infusion was heterogeneous with respect to the time of the peak and the magnitude of the response between vessels within an animal. When statistical analysis was performed on the total number of vessels, $\mathrm{D}_{\text {perf }}$ was found to be increased 
in control animals at $\mathrm{t}=5,10,15,20$ and 30 minutes after insulin infusion compared to baseline, without a change in $\mathrm{D}_{\mathrm{P} 50}$. In contrast, both $\mathrm{D}_{\text {perf }}$ and $\mathrm{D}_{\mathrm{p} 50}$ were unaffected at any time point after insulin infusion in the hyaluronidase treated animals.

A)

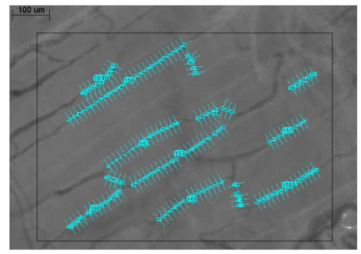

C)

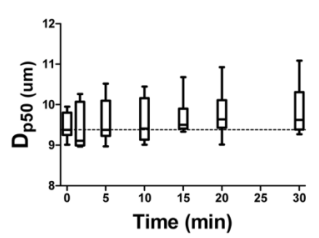

B)

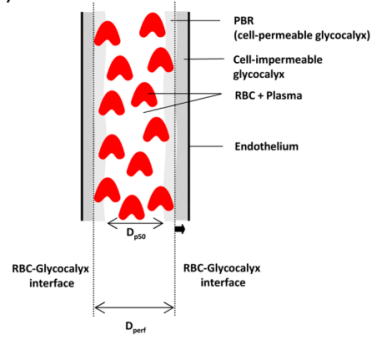

Control rats

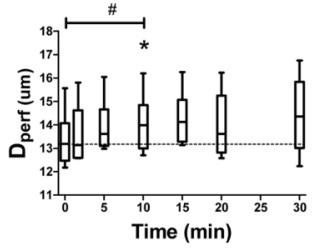

D) Hyaluronidase treated rats
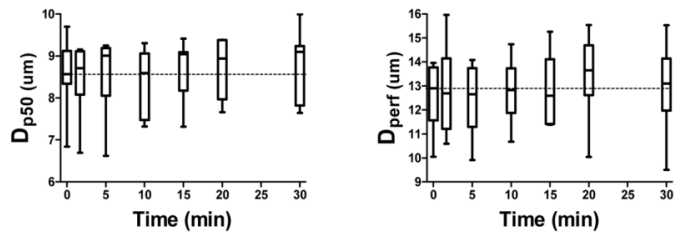

Figure 3.1 A. Example of a single SDF image of rat gastrocnemius microcirculation. From each movie (total length: 40 frames) recorded by the SDF camera the distribution of the width of the red blood cell (RBC) column in each microvessel that fitted the criteria of the analysis (a) in focus, b) had a sufficient length and were not close to bifurcations, and c) were continuously filled with RBCs and did not contain plasma gaps) was determined along the vessel by placement of lines \pm every $10 \mu \mathrm{m}$ perpendicular to the vessel direction (as shown by numbered lines in image), and calculating the full width at half maximum of the intensity profile 10 times in front and 10 times behind each line frame by frame in all 40 consecutive frames (see methods). Per vessel, the $\mathrm{D}_{\mathrm{P} 50}$ and $\mathrm{D}_{\text {perf }}$, by linear extrapolation of the distribution of RBC column width, were determined, revealing the perfused boundary region (PBR), which includes the cell-permeable part of the glycocalyx (see Discussion, page 16). Between the PBR and the endothelium the cell-impermeable glycocalyx resides. An increase in the accessibility of this part of the glycocalyx for the flowing RBCs is associated with an outward movement of the RBC-glycocalyx interface as shown by the thick arrow in panel B. Effects of insulin on the $\mathrm{D}_{\mathrm{p} 50}$ and $D_{\text {perf }}$ in control rats $(n=6)$ are shown in panel $C$ and effect of insulin on the $D_{p 50}$ and $D_{\text {Perf }}$ in hyaluronidase treated rats $(n=7)$ are shown in panel D. \#, $\mathrm{P}<0.05$ (1-way ANOVA), ${ }^{*}, \mathrm{P}<0.05$ versus baseline ( $\mathrm{t}=0$ ) (Tukey's post hoc test)

\section{1a) Capillary tube hematocrit}

Rapid changes in capillary hemodynamics in response to hyperinsulinemia were evaluated in cremaster muscle with intravital microscopy. Capillary tube hematocrit 
was derived from measurements of capillary RBC flux, velocity, and anatomic diameter, in multiple vessels in an experiment (see Methods). These parameters showed a considerable range during baseline conditions already, resulting in a mean coefficient of variation of $\mathrm{H}_{\text {cap }}$ within an animal of $51.8 \pm 16.2 \%$, between animals of $20.2 \%$, and between vessels of $47.8 \%$ in control rats. Nevertheless, capillary tube hematocrit was observed to significantly increase within the first 10 minutes after start of the insulin infusion already (Table 3.2). RBC flux tended to increase $(\mathrm{p}=0.08)$, without changes in RBC velocity and anatomic diameter. Hyaluronidase treatment itself was associated with an elevated capillary tube hematocrit under baseline conditions, which was not further increased by insulin infusion within the first 10 minutes (Table 3.2). However, $\mathrm{RBC}$ flux tended to decrease after insulin infusion in the hyaluronidase treated rats $(\mathrm{P}=0.06)$.

Table 3.2 Capillary hemodynamics measured in the cremaster muscle

\begin{tabular}{|c|c|c|c|c|}
\hline & Control & & Hyaluronidase & \\
\hline & $\begin{array}{c}\text { Baseline } \\
(n=13)\end{array}$ & $\begin{array}{l}\text { Insulin } 10 \text { min } \\
\qquad(n=14)\end{array}$ & $\begin{array}{c}\text { Baseline } \\
(n=9)\end{array}$ & $\begin{array}{l}\text { Insulin } 10 \mathrm{~min} \\
\quad(n=7)\end{array}$ \\
\hline Hсар (\%) & $21.1 \pm 10.1$ & $29.0 \pm 9.8^{*}$ & $42.6 \pm 20.2^{\#}$ & $40.6 \pm 25.9$ \\
\hline $\begin{array}{l}\text { RBC velocity } \\
(\mu \mathrm{m} / \mathrm{s})\end{array}$ & $216 \pm 93$ & $207 \pm 83$ & $220 \pm 133$ & $148 \pm 89$ \\
\hline RBC flux (cells/s) & $18.2 \pm 11.8$ & $27.6 \pm 15.1$ & $23.5 \pm 13.0$ & $12.9 \pm 5.6$ \\
\hline $\begin{array}{l}\text { Anatomic } \\
\text { diameter }(\mu \mathrm{m})\end{array}$ & $6.2 \pm 1.5(4.6-10.0)$ & $6.5 \pm 1.4(4.9-9.0)$ & $5.4 \pm 0.55(4.9-6.5)$ & $5.0 \pm 0.7(4.0-5.7)$ \\
\hline $\begin{array}{l}\text { Capillary blood } \\
\text { flow (pL/s) }\end{array}$ & $6.3 \pm 3.4(1.6-16.1)$ & $6.7 \pm 2.8(3.2-11.9)$ & $5.0 \pm 3.3(0.8-10.3)$ & $2.9 \pm 1.9(0.7-6.2)$ \\
\hline
\end{tabular}

Capillary hemodynamics were obtained during baseline conditions and in the first 10 minutes period during infusion of insulin in control (saline-treated) rats $(n=3)$ and hyaluronidase-treated rats $(n=2)$. Data are means $\pm \mathrm{SD}$, number of vessels given in upper row. ${ }^{*}, \mathrm{P}<0.05$ effects of insulin compared to baseline (unpaired Student's t-test), " $\mathrm{P}<0.05$, hyaluronidase baseline compared to baseline control rats (unpaired Student's t-test).

\section{2) Insulin-mediated glucose disposal}

To determine the effect of glycocalyx degradation on whole-body insulin-mediated glucose disposal, IVITTs were performed in anesthetized rats, and the glucose disposal rate monitored for $30 \mathrm{~min}$. The Kitt was decreased in the hyaluronidase treated rats compared to control rats $(\mathrm{p}<0.05)$ (Fig. 3.2). Systemic hematocrit before the infusion of glucose was $43.8 \pm 3.4 \%$ in the control rats and $46.3 \pm 7.4 \%$ in the hyaluronidase treated rats and did not change after the insulin infusion in both groups of animals. 
A)

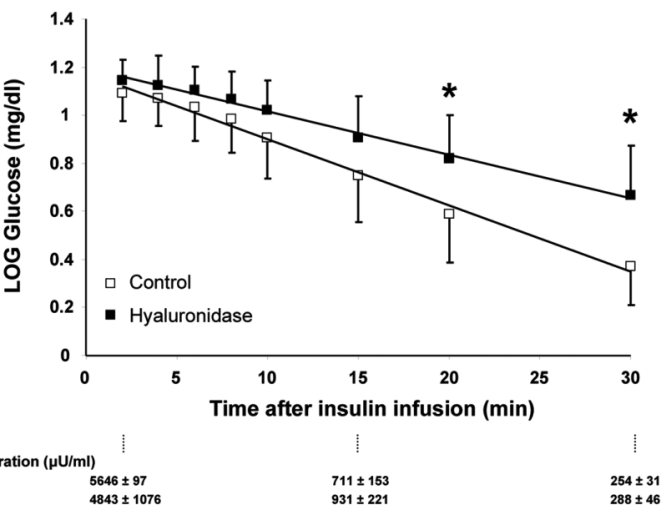

B)

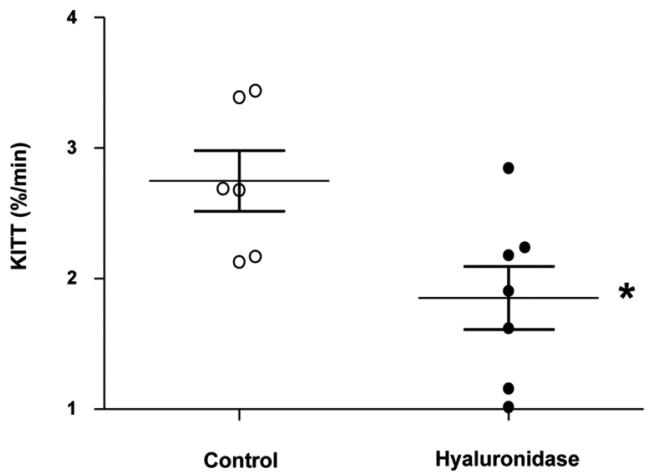

Figure 3.2 A. Mean \pm SEM of the logarithm of blood glucose in time after an i.v. bolus of insulin $(1 \mathrm{U} / \mathrm{kg}) \mathrm{in}$ control rats $(n=6)$ and hyaluronidase treated rats $(n=7)$. Insulin levels (in $\mu U / m l)$ measured at different times during the test are shown in the panel below the graph. ${ }^{*} \mathrm{P}<0.05$ versus control (unpaired Student's t-test). B. The glucose disposal rate (Kitt), calculated from the slope of the linear regression line of the logarithm of blood glucose against time multiplied by -100 , for each individual experiment as well as the mean \pm SEM of all experiments *, $\mathrm{P}<0.05$ versus control (unpaired student's t-test).

\section{2a) D40 distribution}

Figure 3.3A shows representative histological images of D40 filling in capillaries of hindlimb muscle in the four different treatment groups. These images were used to determine both intensity (Fig 3.3B) and diameter (Fig 3.3C) for each filled capillary, as well as the total number of D40 perfused capillaries per muscle area (Fig 3.3D). Mean intensity and number of fluorescent capillaries were $18.8 \pm 7.1$ a.u. and $102 \pm 62$ capillaries $/ \mathrm{mm}^{2}$ respectively, in muscle without D40 infusion; these autofluorescence values were subtracted from the experimental values presented in Figure 3.3. Both mean intensity, as well as diameter of the D40 filled vessels were greater $(\mathrm{p}<0.05)$ in the rats that underwent the IVITT compared to the rats that did not receive insulin. The 
number of D40 filled capillaries was lower in the rats that received insulin $(\mathrm{p}<0.05$, Fig 3.3D).

A)

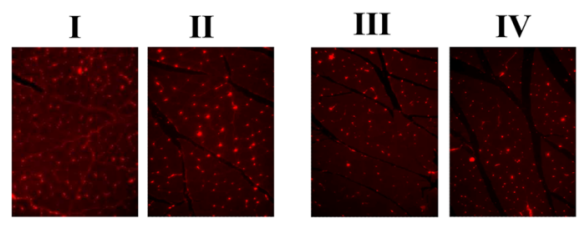

B)

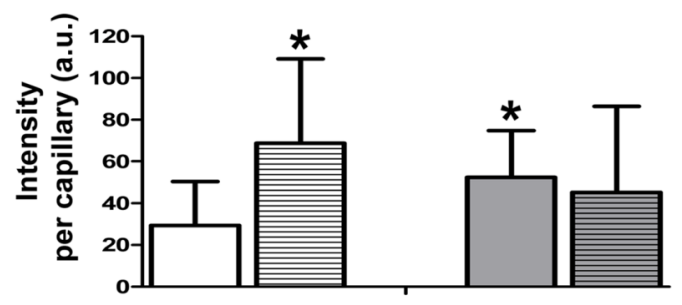

C)

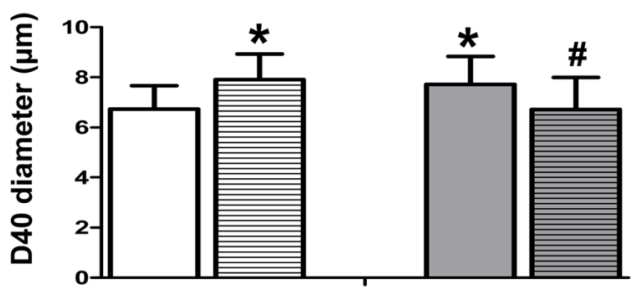

D)

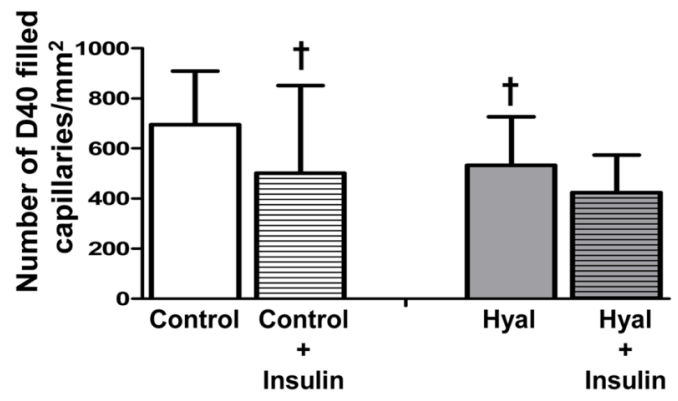

Figure 3.3 A. Typical examples of histological cross sections of rat hindlimb muscles at baseline in control rats (1 hour after saline; I, $\mathrm{n}=18$ slides), 30 minutes after insulin administration in control rats (II, $\mathrm{n}=13$ slides), 1 hour after a bolus of hyaluronidase (III, $\mathrm{n}=17$ slides) and 30 minutes after insulin in hyaluronidase treated rats (IV, $n=11$ slides). In each slide the total intensity (B) and diameter (C) of each tracer filled capillary were determined, as well as the number of filled capillaries (D) (see Methods). In muscles of rats in which no tracer was infused $(\mathrm{n}=12)$, the number of counted capillaries was 102 and total intensity in these capillaries was 18.8; data in panels B and D are corrected for these values. *, $\mathrm{P}<0.05$ versus control baseline (unpaired Student's t-test); ${ }^{\dagger} \mathrm{P}<0.05$ versus control baseline (Mann-Whitney $\mathrm{U}$ test); ${ }^{\#}, \mathrm{P}<0.05$ versus hyaluronidase baseline (unpaired Student's t-test).

In the hyaluronidase treated rats, mean intensity and D40 diameter were greater compared to control baseline $(\mathrm{P}<0.05)$, and the number of $\mathrm{D} 40$ filled capillaries was significantly lower. In contrast to the effect of insulin in control animals, mean D40 
intensity did not increase and the diameter of D40 filled capillaries was actually reduced $(\mathrm{p}<0.05)$ at the end of the IVITT in the hyaluronidase treated rats. In these rats, insulin infusion appeared not to affect the number of D40 filled capillaries. Structural capillary densities (WGA-FITC staining) were not different in the four groups (control: baseline $821 \pm 206$ capillaries $/ \mathrm{mm}^{2}$, insulin $816 \pm 120$ capillaries $/ \mathrm{mm}^{2}$; hyaluronidase: baseline $989 \pm 198$ capillaries $/ \mathrm{mm}^{2}$, insulin $766 \pm 189$ capillaries $/ \mathrm{mm}^{2}$ ) 


\section{Discussion}

The observations in the current study demonstrate that insulin rapidly increases the accessibility of circulating blood into the glycocalyx, which enables an increase in blood volume within already perfused capillaries. In contrast, after enzymatic glycocalyx degradation the ability of insulin to modulate glycocalyx properties and to increase capillary blood volume in individual capillaries is impaired, and this impairment is associated with a $\sim 35 \%$ reduction in insulin-mediated glucose disposal from the circulation. While confirming previous studies indicating that the ability of insulin to dispose glucose is coupled to its ability to increase capillary blood volume in muscle $[5,6]$, the current results indicate that the latter includes volume increases at the level of the individual capillary by insulin increasing the accessibility of the glycocalyx for flowing blood.

\section{Methodological considerations}

SDF imaging: The microcirculation on the external part of the gastrocnemius muscle was monitored with SDF imaging. The advantage of the SDF camera is that it can readily be applied for visualization of the sublingual microcirculation in humans $[20,27,28,29]$, and of skeletal muscle microcirculation in rodents as done in the current study. Changes in glycocalyx barrier properties were assessed using specialized software tools developed in our laboratory. Since the anatomic borders of the vessels are not depicted when using epi-illumination, we analyzed the dynamic range of the RBC column width as a reflection of the glycocalyx barrier properties (Fig 3.1B). The analysis requires sufficient continuous RBC filling of the microvessels. The average $D_{p 50}$ was $\sim 9 \mu \mathrm{m}$, illustrating that the analysis was not directed to true capillaries only and most likely included pre- and post-capillary microvessels. SDF measurements were reproducible during the baseline period in control rats as indicated by the small coefficients of variation for $\mathrm{D}_{\mathrm{p} 50}$ and $\mathrm{D}_{\text {perf. }}$ The SDF camera has a low magnification, giving pixel sizes of $1.26 \mu \mathrm{m}$. Linear interpolation of the intensity profiles into virtual subpixels of $\sim 0.15$ $\mu \mathrm{m}$, however, allowed for more accurate measurements of FWHM positions while in addition to this, there were 21 measurements along the length of a vascular segment for each measurement site. The analysis revealed that during control conditions, $\mathrm{D}_{\mathrm{P} 50}$ was bordered by a cell poor region of approximately $2 \mu \mathrm{m}$ at both sides. This region resembles the so-called perfused boundary region (PBR; Fig. 3.1), which results from the phase separation between the RBCs and plasma in microvessels and includes the most luminal part of glycocalyx that allows cell penetration [30,31,32]. Accordingly, an increase in $\mathrm{D}_{\text {perf }}$ at a given $\mathrm{D}_{\mathrm{P} 50}$ width is indicated to reflect an increased glycocalyx accessibility due to impaired glycocalyx barrier properties (as indicated by the arrow in Fig. 3.1B) [23]. 
In line with this approach, Vink et al. recently showed, using high magnification brightfield microscopy in microvessels of the cremaster muscle of transgenic mice in which the endothelial cells were labeled with a green fluorescent protein, that hyaluronidase treatment was associated with an outward radial displacement of RBCs without a change in anatomic vessel diameter [33].

Intravital microscopy: Agonist- or enzyme-induced impairments of glycocalyx barrier properties have been shown to coincide with increases in functionally perfused capillary volume, as reflected by an increased capillary tube hematocrit $[10,14,21]$. To confirm that the increases in glycocalyx accessibility in the microvessels during insulin infusion would be accompanied by increases in capillary blood volume, we performed additional intravital microscopy experiments in a small number of animals, in which capillary hemodynamics were measured in multiple vessels in one animal $[10,21]$. Capillary tube hematocrit was derived from RBC flux and velocity, anatomic diameter and MCV; while these measurements have potential errors associated with them this estimate has been used in many previous studies and the possible error associated with the calculation is regarded to be small [34]. In line with previous studies [10,35,36], capillary tube hematocrit showed a considerable range, as illustrated by a coefficient of variation between vessels of 48\%; nevertheless, in line with our previous study [10], we observed a rapid and substantial increase in this parameter upon insulin infusion. Compared to the increases in capillary tube hematocrit of 250\% found after bradykinin and SNP administration [10], the increases in hematocrit found with insulin were, however, relatively small, indicating that there still seems potential for capillary blood volume to increase further. Of note, MCV was based on previous studies [24,25]; while effects of insulin or hyaluronidase on MCV have not been reported, possible affects of a change in MCV on capillary tube hematocrit in the present study cannot be ruled out.

IVITT: In accordance with previous studies $[37,38]$ we used an IVITT for measuring insulin sensitivity. We used an IVITT instead of a clamp as a more physiological stimulus with respect to the timing of the vascular insulin effect. When using a hyperinsulinemic euglycemic clamp, the glucose infusion rate is typically measured during steady state conditions which occur approximately 120 minutes after start of insulin infusion and it might be anticipated that at this time point insulin-mediated glucose uptake is dominated by processes occurring at the level of the myocytes and not at the level of the microvasculature. Note that in order to avoid hypoglycemia and to have a useful range for blood glucose to be decreased by insulin, we first gave a bolus of glucose in our IVITT experiments. As a result of the glucose bolus, counterregulatory mechanisms kicked in later than 30 minutes in our experiments, as shown by the dynamics of the 
glucose response (Fig. 2A), thereby warranting use of the entire blood sampling period for calculation of the Kitt.

Histology: To check if insulin-mediated increases in capillary blood volume occurred during the IVITT, fluorescent D40 was infused as a small-sized plasma tracer [15] at the end of the test (30 $\mathrm{min}$ ), and its distribution in the hindlimb muscle microcirculation was analyzed on histological sections. While during control conditions approximately $80 \%$ of the present capillaries (i.e. labeled by WGA) were filled with D40, the number of D40 filled capillaries decreased after hyaluronidase and insulin infusion. The lower number of D40 filled capillaries may reflect a redistribution of blood flow into the capillary network, as was previously described for hyaluronidase by Cabrales et al. [18], as well as an increase in the number of capillaries containing an erythrocyte (and hence no D40) in the histological cross-section. Further, the increases in D40 diameter occurred without changes in systemic hematocrit suggesting that the increase in D40 intensity did not reflect an increased D40 concentration in the plasma due to fluid leakage. Although all D40 filled microvessels were used for the analysis, capillaries were prominent in these cross-sections, as reflected by the calculated D40 diameters (Fig 3.3C).

Hyaluronidase treatment: The rationale for using hyaluronidase treatment to study the role of the glycocalyx in insulin-mediated responses comes from previous studies which demonstrated loss of glycocalyx structures [39] and impairment of its barrier properties after administration of the enzyme $[18,19,40]$. These studies indicated that a period of $\sim 45-60$ minutes was needed for an optimal effect of hyaluronidase; hereafter, the effect waned, but was still present after 2 hours [19]. Based on these findings we used an incubation period of 1-1.5 hour for the enzyme in the current experiments. In line with these previous studies, hyaluronidase treats rats showed decreased glycocalyx barrier properties which coincided with increases in capillary blood volume. Thus, hyaluronidase treatment was associated with a significant increased $\mathrm{D}_{\text {perf }}$ compared to the $\mathrm{D}_{\mathrm{P} 50}$ and increased capillary tube hematocrits in the cremaster microcirculation at baseline; furthermore, in the histology experiments, the intensity of D40 within a capillary, as well as D40 diameter were higher in the hyaluronidase treated animals compared to controls at baseline This observation appears to contrast the finding of a smaller $\mathrm{D}_{\mathrm{P} 50}$ in the SDF experiments. However, when taking into consideration that the vessels examined with SDF were not primarily capillaries but included also small arterioles and venules, it is possible that increased blood volume in the capillaries is associated with a reduced blood volume in the upstream and downstream microvessels. In line herewith, a previous study of VanTeeffelen et al [40] showed that hyaluronidase 
treatment was associated with decreases in anatomic diameter in second- and thirdorder arterioles in the mouse cremaster, which was suggested to reflect a decreased NO-bioavailability.

\section{Insulin-mediated blood volume increase within already perfused capillaries by rapid modulation of glycocalyx barrier properties}

In previous studies, using contrast-enhanced ultrasound (CEU) and 1-methylxanthine metabolism (1-MX), it has been shown that insulin infusion results in a rapid increase in microvascular blood volume and functionally available endothelial surface area in skeletal muscle $[5,41,42,43]$. Based on these studies, the concept was put forward that these microvascular effects of insulin may promote its own delivery and that of glucose towards the myocytes $[5,42,44]$. These previous studies did, however, not distinguish whether the increase in capillary volume or surface area were the result of an increased number of perfused capillaries, an increased volume in already perfused capillaries, or both. Based on the idea that skeletal muscle capillaries at rest are only partly perfused [45], the data so far have been merely interpreted as insulin increasing the number of perfused capillaries by inducing vasodilatation of precapillary arterioles $[46,47,48]$. The data of the current study show that insulin, by attenuating glycocalyx barrier properties, may increase capillary blood volume within already perfused capillaries. As reflected by the outward movement of the RBC-glycocalyx interface, insulin stimulated farther penetration of the outer RBC edge into the glycocalyx by 0.34 $\pm 0.44 \mu \mathrm{m}$ within 10 minutes, indicating that the barrier properties of the glycocalyx were rapidly decreased by insulin. Reports by others showed that the dose of insulin used in the current study increases total skeletal muscle blood flow only after 20 to 30 minutes $[47,49]$, confirming that the agonist-induced impairment of glycocalyx barrier properties might precede its action on the resistance vasculature [21]. Capillary tube hematocrit in cremaster muscle increased with 40\% within 10 min after start of a continuous insulin infusion, and we observed a more than 2 -fold increase in the amount of D40 per capillary in hindlimb muscle capillaries $30 \mathrm{~min}$ after a bolus injection of an even higher dose of insulin. The D40 increase in control rats was partially due to an increase in D40 diameter, which is in line with the increased $\mathrm{D}_{\text {perf }}$ during insulin infusion found with SDF imaging. These results confirm previous studies which showed that insulin rapidly increases capillary blood volume in muscle tissue; our data show that the increase can occur within already perfused capillaries by an increase in glycocalyx accessibility. The effect of insulin on glycocalyx barrier properties and capillary blood volume was greatly impaired after enzymatic degradation of the glycocalyx with hyaluronidase (Fig 3.1C, Table 2, Fig 3.3B), which is in line with previous studies, which 
showed a lack of effect of agonists on glycocalyx dextran accessibility and capillary tube hematocrit after glycocalyx degradation [10,17]. Subsequent insulin infusion in the hyaluronidase treated rats was even associated with smaller D40 diameters in the histological slides, which contrasts to the unaltered capillary diameters in the intravital microscopy experiments. The differences could be due to a difference in timing between the observations and/or the different insulin concentrations used. The decrease in D40 diameter might reflect a reduction in capillary anatomic diameter for example due to perivascular edema [39], or a reduction in capillary pressure coinciding with the impaired capillary perfusion observed in the IVM experiments, which could be a consequence of vasoconstriction of arterioles as also illustrated by the reduced median $\mathrm{RBC}$ column after hyaluronidase treatment

\section{Glycocalyx degradation is associated with impaired vascular and metabolic insulin actions}

Hyaluronidase treatment was associated with similar changes in baseline glycocalyx properties and capillary blood volume as compared to the effect of insulin during control conditions, but apparently did not affect insulin sensitivity at baseline as illustrated by unchanged fasting glucose levels, fasting insulin levels and HOMA-IR compared to fasting control conditions. Importantly, insulin infusion in the hyaluronidase treated rat was accompanied by a 35\% delayed glucose disposal from the circulation. It has been indicated, using 1-MX and CEU, that insulin increases capillary surface area for exchange by recruiting the number of perfused capillaries, and it is suggested that these increases in capillary blood volume are important for insulin's ability to efficiently dispose glucose from the circulation $[5,6,45]$. However, the hyaluronidase results of the current study suggest that a single increase in capillary blood volume within individual capillaries in itself is not sufficient to increase glucose disposal. In the hyaluronidase treated animals, the decrease in insulin-mediated glucose disposal may be explained by an impaired microvascular delivery of insulin and glucose due to a compromised capillary perfusion, as evidenced by the reduced number of D40 filled capillaries, the decrease in RBC flux, and smaller D40 filled diameters found after insulin infusion in these animals.

The findings of the current study suggest that an intact glycocalyx is necessary for optimal regulation of transcapillary transport of insulin. It has been shown that the transcapillary exchange of insulin, despite its small size ( $6 \mathrm{kDa})$, does not simply occur via diffusion but that it likely involves a receptor-mediated process, involving caveolae [50]. Further, Vink \& Duling [15] showed that the penetration of plasma proteins/ peptides into the glycocalyx most likely involves molecular interactions with low affinity 
glycocalyx binding sites and does not simply follow a pattern based on molecular size or charge alone. It is therefore hypothesized that glycocalyx components like heparan sulfate proteoglycans may interact with insulin and affect its transcapillary transport. Numerous studies have reported that these polysaccharide structures are able to store various plasma proteins, to organize and regulate cell surface receptors, to interact with caveolae, and to be able to modulate the vasodilator effects of endothelial receptordependent, NO-mediated, agonists [51,52]. In addition, a remarkable correlation between the localization of the insulin receptor and the presence of glycocalyx coating has been demonstrated in isolated adipocytes [53], and it might well be that this association also holds for the endothelium. The impaired insulin response after enzymatic glycocalyx modification might thus include compromised transport of insulin through the glycocalyx mesh towards its receptors on the endothelium.

In conclusion, the present study provides evidence that the endothelial glycocalyx plays a role in regulation of an efficient insulin and associated glucose delivery into skeletal muscle. The precise molecular and cellular mechanisms involved in the insulinmediated modulation of glycocalyx barrier properties are unknown at the moment, and future studies are needed to determine the effects of insulin on the composition of the glycocalyx and to study the role of the glycocalyx in the transport of insulin towards and across the endothelium.

\section{Clinical relevance}

In recent years, it has been recognized that the endothelial glycocalyx exerts protective effects towards the vessel wall, in particular towards preservation of endothelial function. This layer was shown to be highly vulnerable to acute and chronic atherogenic, hyperglycemic and inflammatory conditions [13,54,55], and as a result, loss of the glycocalyx has been indicated a marker of, and potentially a contributing factor to, the development of endothelial dysfunction associated with conditions of increased cardiovascular risk. Since the current data show that glycocalyx degradation may not only be a consequence of hyperglycemia [56,57], but that it may also directly compromise insulin-mediated uptake of glucose from the circulation by impairing the insulin-mediated capillary blood volume increase in muscle, loss of glycocalyx may be a common factor in the established relationship between insulin resistance and endothelial dysfunction in patients and experimental animals [58,59]. As a result the glycocalyx may constitute an important target for early diagnosis as well as therapy in people at risk for the development of endothelial dysfunction and insulin resistance, such as in the metabolic syndrome. In this respect, a previous study showed that 8 week treatment with sulodexide, a mixture of the glycocalyx components heparan 
and chondroitin sulfates, improved both sublingual glycocalyx dimensions as well as the vascular retention of albumin in type II diabetes patients [27]. While the effect of sulodexide on insulin sensitivity was not determined in this latter study, our current data would suggest a potential improvement by this glycocalyx therapy as well. 


\section{References}

1. Chiu JD, Richey JM, Harrison LN, Zuniga E, Kolka CM, et al. (2008) Direct administration of insulin into skeletal muscle reveals that the transport of insulin across the capillary endothelium limits the time course of insulin to activate glucose disposal. Diabetes 57: 828835.

2. Herkner H, Klein N, Joukhadar C, Lackner E, Langenberger H, et al. (2003) Transcapillary insulin transfer in human skeletal muscle. Eur J Clin Invest 33: 141-146.

3. Yang YJ, Hope ID, Ader M, Bergman RN (1989) Insulin transport across capillaries is rate limiting for insulin action in dogs. J Clin Invest 84: 1620-1628.

4. Eggleston EM, Jahn LA, Barrett EJ (2007) Hyperinsulinemia rapidly increases human muscle microvascular perfusion but fails to increase muscle insulin clearance: evidence that a saturable process mediates muscle insulin uptake. Diabetes 56: 2958-2963.

5. Vincent MA, Clerk LH, Lindner JR, Klibanov AL, Clark MG, et al. (2004) Microvascular recruitment is an early insulin effect that regulates skeletal muscle glucose uptake in vivo. Diabetes 53: 1418-1423.

6. Clerk LH, Rattigan S, Clark MG (2002) Lipid infusion impairs physiologic insulin-mediated capillary recruitment and muscle glucose uptake in vivo. Diabetes 51: 1138-1145.

7. Clark MG, Rattigan S, Barrett EJ, Vincent MA (2008) Point: There is capillary recruitment in active skeletal muscle during exercise. J Appl Physiol 104: 889-891.

8. Brands J, Spaan JA, Van den Berg BM, Vink H, VanTeeffelen JW (2010) Acute attenuation of glycocalyx barrier properties increases coronary blood volume independently of coronary flow reserve. Am J Physiol Heart Circ Physiol 298: H515-523.

9. VanTeeffelen JW, Brands J, Vink H (2010) Agonist-induced impairment of glycocalyx exclusion properties: contribution to coronary effects of adenosine. Cardiovasc Res 87: 311-319.

10. VanTeeffelen JW, Constantinescu AA, Brands J, Spaan JA, Vink H (2008) Bradykinin- and sodium nitroprusside-induced increases in capillary tube hematocrit in mouse cremaster muscle are associated with impaired glycocalyx barrier properties. J Physiol 586: 32073218.

11. Reitsma S, Slaaf DW, Vink H, van Zandvoort MA, oude Egbrink MG (2007) The endothelial glycocalyx: composition, functions, and visualization. Pflugers Arch 454: 345-359.

12. Tarbell JM, Pahakis MY (2006) Mechanotransduction and the glycocalyx. J Intern Med 259: 339-350.

13. Van Teeffelen JW, Brands J, Stroes ES, Vink H (2007) Endothelial glycocalyx: sweet shield of blood vessels. Trends Cardiovasc Med 17: 101-105.

14. Vink H, Duling BR (1996) Identification of distinct luminal domains for macromolecules, erythrocytes, and leukocytes within mammalian capillaries. Circ Res 79: 581-589.

15. Vink H, Duling BR (2000) Capillary endothelial surface layer selectively reduces plasma solute distribution volume. Am J Physiol Heart Circ Physiol 278: H285-289. 
16. Klitzman B, Duling BR (1979) Microvascular hematocrit and red cell flow in resting and contracting striated muscle. Am J Physiol 237: H481-490.

17. Desjardins C, Duling BR (1990) Heparinase treatment suggests a role for the endothelial cell glycocalyx in regulation of capillary hematocrit. Am J Physiol 258: H647-654.

18. Cabrales P, Vazquez BY, Tsai AG, Intaglietta M (2007) Microvascular and capillary perfusion following glycocalyx degradation. J Appl Physiol 102: 2251-2259.

19. Henry CB, Duling BR (1999) Permeation of the luminal capillary glycocalyx is determined by hyaluronan. Am J Physiol 277: H508-514.

20. Goedhart PT, Khalilzada M, Bezemer R, Merza J, Ince C (2007) Sidestream Dark Field (SDF) imaging: a novel stroboscopic LED ring-based imaging modality for clinical assessment of the microcirculation. Opt Express 15: 15101-15114.

21. Constantinescu AA, Vink H, Spaan JA (2001) Elevated capillary tube hematocrit reflects degradation of endothelial cell glycocalyx by oxidized LDL. Am J Physiol Heart Circ Physiol 280: H1051-1057.

22. VanTeeffelen JW, Constantinescu AA, Vink H, Spaan JA (2005) Hypercholesterolemia impairs reactive hyperemic vasodilation of $2 \mathrm{~A}$ but not $3 \mathrm{~A}$ arterioles in mouse cremaster muscle. Am J Physiol Heart Circ Physiol 289: H447-454.

23. Vlahu CA, Lemkes BA, Struijk DG, Koopman MG, Krediet RT, et al. (2012) Damage of the endothelial glycocalyx in dialysis patients. J Am Soc Nephrol 23: 1900-1908.

24. Dominighini A, Ferrero M, Crosetti D, Alvarez Mde L, Ronco MT, et al. (2010) Effect of Ligaria cuneifolia catechin- and quercetin-enriched fractions on hemorheology and plasma cholesterol. Clin Hemorheol Microcirc 44: 217-225.

25. Tober-Meyer BK, Bieniek HJ, Kupke IR (1981) Studies on the hygiene of drinking water for laboratory animals. 2. Clinical and biochemical studies in rats and rabbits during long-term provision of acidified drinking water. Lab Anim 15: 111-117.

26. Borghouts LB, Backx K, Mensink MF, Keizer HA (1999) Effect of training intensity on insulin sensitivity as evaluated by insulin tolerance test. Eur J Appl Physiol Occup Physiol 80: 461466.

27. Broekhuizen LN, Lemkes BA, Mooij HL, Meuwese MC, Verberne H, et al. (2010) Effect of sulodexide on endothelial glycocalyx and vascular permeability in patients with type 2 diabetes mellitus. Diabetologia 53: 2646-2655.

28. Ince C (2005) The microcirculation is the motor of sepsis. Crit Care 9 Suppl 4: S13-19.

29. Sheikh MY, Javed U, Singh J, Choudhury J, Deen O, et al. (2009) Bedside sublingual video imaging of microcirculation in assessing bacterial infection in cirrhosis. Dig Dis Sci 54: 2706-2711.

30. Kim S, Kong RL, Popel AS, Intaglietta M, Johnson PC (2007) Temporal and spatial variations of cell-free layer width in arterioles. Am J Physiol Heart Circ Physiol 293: H1526-1535.

31. Kim S, Ong PK, Yalcin O, Intaglietta M, Johnson PC (2009) The cell-free layer in microvascular blood flow. Biorheology 46: 181-189. 
32. Ong PK, Namgung B, Johnson PC, Kim S (2010) Effect of erythrocyte aggregation and flow rate on cell-free layer formation in arterioles. Am J Physiol Heart Circ Physiol 298: H18701878.

33. Vink H, Eskens B, Mooij HL, Cobelens H, VanTeeffelen JW (2012) Loss of glycocalyx dimension is reflected by increase of erythrocyte perfused boundary region. Biorheology 201249 (4): 172.

34. Sarelius IH, Duling BR (1982) Direct measurement of microvessel hematocrit, red cell flux, velocity, and transit time. Am J Physiol 243: H1018-1026.

35. Desjardins C, Duling BR (1987) Microvessel hematocrit: measurement and implications for capillary oxygen transport. Am J Physiol 252: H494-503.

36. Duling BR, Desjardins C (1987) Capillary Hematokrit - What Does It Mean? Physiology 2: 66-69.

37. Akinmokun A, Selby PL, Ramaiya K, Alberti KG (1992) The short insulin tolerance test for determination of insulin sensitivity: a comparison with the euglycaemic clamp. Diabet Med 9: 432-437.

38. Schrauwen-Hinderling VB, Schrauwen P, Hesselink MK, van Engelshoven JM, Nicolay K, et al. (2003) The increase in intramyocellular lipid content is a very early response to training. J Clin Endocrinol Metab 88: 1610-1616.

39. van den Berg BM, Vink H, Spaan JA (2003) The endothelial glycocalyx protects against myocardial edema. Circ Res 92: 592-594.

40. VanTeeffelen JW, Brands J, Jansen C, Spaan JA, Vink H (2007) Heparin impairs glycocalyx barrier properties and attenuates shear dependent vasodilation in mice. Hypertension 50 : 261-267.

41. Gudbjornsdottir S, Sjostrand M, Strindberg L, Wahren J, Lonnroth P (2003) Direct measurements of the permeability surface area for insulin and glucose in human skeletal muscle. J Clin Endocrinol Metab 88: 4559-4564.

42. Meijer RI, De Boer MP, Groen MR, Eringa EC, Rattigan S, et al. (2012) Insulin-induced microvascular recruitment in skin and muscle are related and both are associated with whole-body glucose uptake. Microcirculation 19: 494-500.

43. Zhang L, Vincent MA, Richards SM, Clerk LH, Rattigan S, et al. (2004) Insulin sensitivity of muscle capillary recruitment in vivo. Diabetes 53: 447-453.

44. Barrett EJ, Wang H, Upchurch CT, Liu Z (2011) Insulin regulates its own delivery to skeletal muscle by feed-forward actions on the vasculature. Am J Physiol Endocrinol Metab 301: E252-263.

45. Clark MG (2008) Impaired microvascular perfusion: a consequence of vascular dysfunction and a potential cause of insulin resistance in muscle. Am J Physiol Endocrinol Metab 295: E732-750.

46. Clerk LH, Vincent MA, Lindner JR, Clark MG, Rattigan S, et al. (2004) The vasodilatory actions of insulin on resistance and terminal arterioles and their impact on muscle glucose uptake. Diabetes Metab Res Rev 20: 3-12. 
47. Vincent MA, Clerk LH, Rattigan S, Clark MG, Barrett EJ (2005) Active role for the vasculature in the delivery of insulin to skeletal muscle. Clin Exp Pharmacol Physiol 32: 302-307.

48. Wheatley CM, Rattigan S, Richards SM, Barrett EJ, Clark MG (2004) Skeletal muscle contraction stimulates capillary recruitment and glucose uptake in insulin-resistant obese Zucker rats. Am J Physiol Endocrinol Metab 287: E804-809.

49. Baron AD, Brechtel-Hook G, Johnson A, Cronin J, Leaming R, et al. (1996) Effect of perfusion rate on the time course of insulin-mediated skeletal muscle glucose uptake. Am J Physiol 271: E1067-1072.

50. Barrett EJ, Eggleston EM, Inyard AC, Wang H, Li G, et al. (2009) The vascular actions of insulin control its delivery to muscle and regulate the rate-limiting step in skeletal muscle insulin action. Diabetologia 52: 752-764.

51. Bernfield M, Gotte M, Park PW, Reizes O, Fitzgerald ML, et al. (1999) Functions of cell surface heparan sulfate proteoglycans. Annu Rev Biochem 68: 729-777.

52. Li J, Partovian C, Hampton TG, Metais C, Tkachenko E, et al. (2002) Modulation of microvascular signaling by heparan sulfate matrix: studies in syndecan-4 transgenic mice. Microvasc Res 64: 38-46.

53. Jarett L, Smith RM (1975) Ultrastructural localization of insulin receptors on adipocytes. Proc Natl Acad Sci U S A 72: 3526-3530.

54. Constantinescu AA, Vink H, Spaan JA (2003) Endothelial cell glycocalyx modulates immobilization of leukocytes at the endothelial surface. Arterioscler Thromb Vasc Biol 23: 1541-1547.

55. Nieuwdorp M, Meuwese MC, Vink H, Hoekstra JB, Kastelein JJ, et al. (2005) The endothelial glycocalyx: a potential barrier between health and vascular disease. Curr Opin Lipidol 16: 507-511.

56. Nieuwdorp M, Mooij HL, Kroon J, Atasever B, Spaan JA, et al. (2006) Endothelial glycocalyx damage coincides with microalbuminuria in type 1 diabetes. Diabetes 55: 1127-1132.

57. Zuurbier CJ, Demirci C, Koeman A, Vink H, Ince C (2005) Short-term hyperglycemia increases endothelial glycocalyx permeability and acutely decreases lineal density of capillaries with flowing red blood cells. J Appl Physiol 99: 1471-1476.

58. Muniyappa R, Montagnani M, Koh KK, Quon MJ (2007) Cardiovascular actions of insulin. Endocr Rev 28: 463-491.

59. Muniyappa R, Quon MJ (2007) Insulin action and insulin resistance in vascular endothelium. Curr Opin Clin Nutr Metab Care 10: 523-530. 


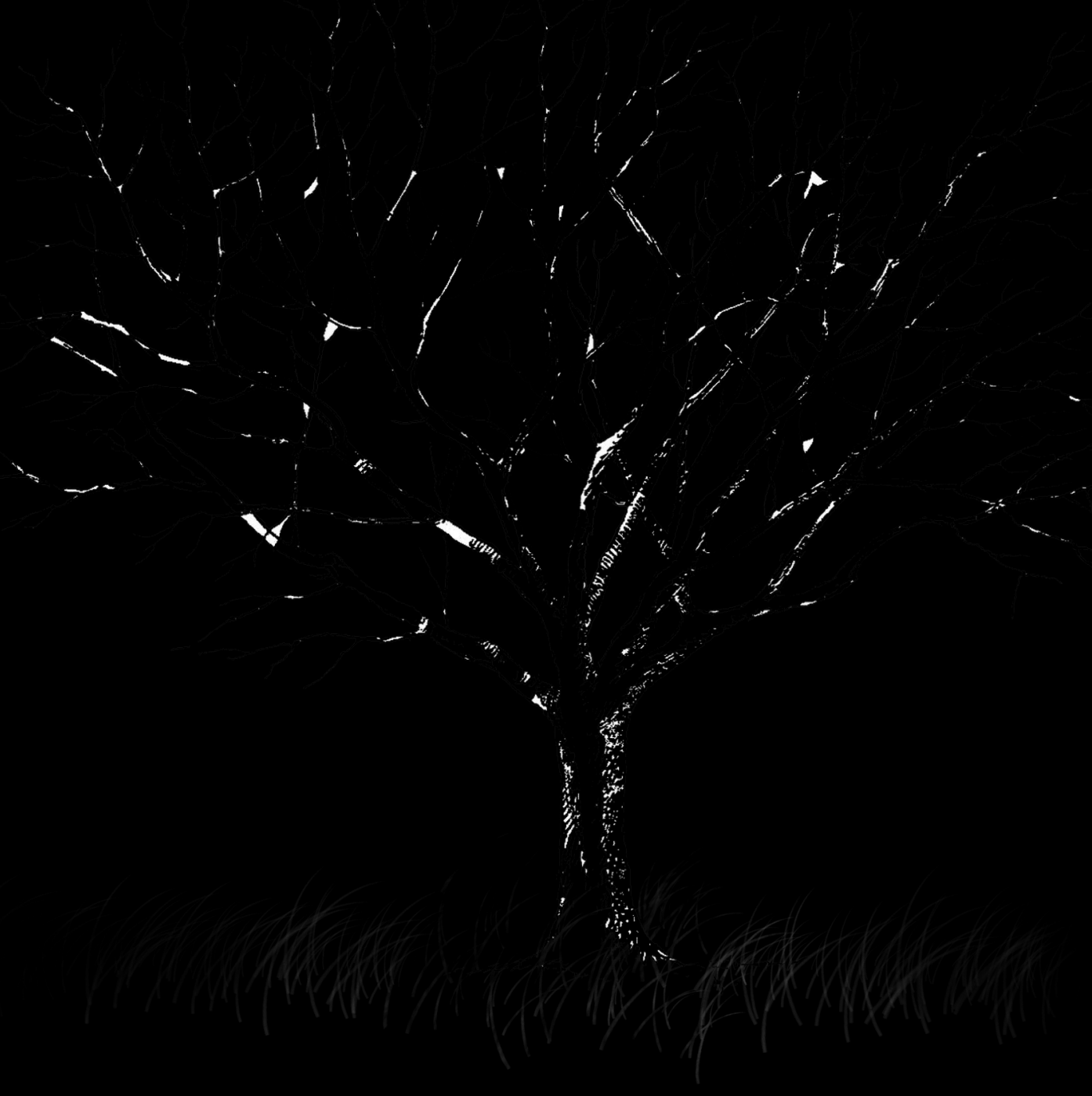


Chapter 4

\title{
Acute enzymatic glycocalyx degradation results in reduced insulin sensitivity but normal glucose tolerance in conscious rats
}

\author{
Bart J.M. Eskens \\ Hanneke E. Cobelens \\ Hans Vink \\ Jurgen W.G.E. VanTeeffelen
}

In adapted form published in Cardiovascular Endocrinology. 2013: Dec 18 (Published online before print) 


\begin{abstract}
Perturbation of the endothelial glycocalyx has been suggested to be an early event in the development of endothelial dysfunction during increased cardiovascular risk exposure. Previously, we showed in anesthetized rats that acute enzymatic degradation of the endothelial glycocalyx was associated with an impaired insulin-mediated glucose disposal, suggesting a role of the glycocalyx in regulation of glucose homeostasis. In the current study, we tested the acute effect of enzymatic glycocalyx treatment on glucose tolerance and insulin sensitivity in conscious rats.

In rats, which had their femoral artery and vein cannulated one week before the experiment, intravenous glucose (IVGTT) and insulin tolerance tests (IVITT) were performed before and after acute degradation of the endothelial glycocalyx using an intravenous bolus of hyaluronidase. During the IVGTT, glucose tolerance did not differ between the hyaluronidase treated and control animals, but was associated with 1.5 fold higher plasma insulin levels in the former group. Furthermore, glycocalyx treatment significantly decreased the insulin-mediated glucose disposal during an IVITT, as illustrated by the reduced insulin-mediated glucose disposal rate from $3.3 \pm 0.1 \% / \mathrm{min}$ in control rats to $2.6 \pm 0.2 \% / \mathrm{min}$ in the hyaluronidase treated rats.

These results support a role for the endothelial glycocalyx in the regulation of peripheral insulin sensitivity. The reduction in insulin sensitivity during acute glycocalyx damage does, however, not have an immediate effect on glucose tolerance due to a compensatory increase in plasma insulin levels.
\end{abstract}




\section{Introduction}

Type II Diabetes, characterized by elevated glucose levels in the context of insulin resistance and relative insulin deficiency, is an increasingly prevalent health problem in our society. When fully manifested type II diabetes can be considered a chronic disease which at the moment can only be managed but not be cured. Hence, type II diabetes is often recognized at an advanced stage by physicians when significant vascular complications have already occurred [1]. Recent experimental evidence has been provided suggesting that vascular defects, in particular at the level of the endothelium, may not only be a consequence of type II diabetes, but also contribute to the development of it by impairing insulin action [2,3]. Detection of a vulnerable endothelium may, therefore, have added value for early diagnosis and treatment of people at risk for type II diabetes. The endothelial glycocalyx, which shields the vascular wall from direct exposure to the flowing blood, has the last decade been indicated to play an important role in protection of the endothelium against atherogenic insults. [4,5], while we recently provided evidence suggesting that this compartment may be involved in the regulation of insulin sensitivity as well. In anesthetized rats, we showed that insulin, by diminishing the barrier properties of the glycocalyx and increasing its accessibility for the flowing blood rapidly increased microvascular blood volume in muscle [6], an action which had been indicated by studies of Rattigan, Barrett and co-workers [7,8,9] to contribute to insulin-mediated glucose disposal. Indeed, we observed that acute enzymatic degradation of the glycocalyx in the rats by intravenous administration of hyaluronidase was associated with an acute decrease in whole-body insulin-mediated glucose disposal during an intravenous insulin tolerance test [6]. The physiological relevance of these latter observations for glucose regulation may, however, be questioned since the insulin tolerance test was performed during isoflurane anesthesia, requiring a supraphysiological dose of insulin to be administered. In the current study we, therefore, tested in conscious rats if acute glycocalyx degradation would reduce insulin sensitivity as well, and whether this would affect glucose tolerance. Herefore, intravenous glucose tolerance tests (IVGTT) and insulin tolerance tests (IVITT) were performed in chronically instrumented rats, and compared between control conditions and after intravenous hyaluronidase administration, an enzyme treatment which has been demonstrated in several experimental studies to result in a loss of glycocalyx $[10,11,12,13]$. 


\section{Methods}

\section{Animals and instrumentation}

Experiments were performed in male Wistar rats (350-450 gram; $n=29$ ) that received standard chow and water ad libitum. All procedures were in accordance with the requirements of the Animal Ethics Care and Use committee of Maastricht University. After arrival from the external supplier (Harlan, Horst, The Netherlands) the animals were housed at the animal facility of Maastricht University and allowed to acclimatize for at least one week before surgery. At the day of surgery rats received the narcotic analgesic buprenorphine (Temgesic $0.03 \mathrm{mg} / \mathrm{mL}$; Schering-Plough) at $0.1 \mathrm{mg} / \mathrm{kg}$ subcutaneously, while 30-45 minutes later the animals were put under isoflurane anesthesia (2\%), and their femoral artery and vein cannulated with a polyurethane catheter (1.02 mm outer diameter (OD); $0.61 \mathrm{~mm}$ inner diameter (ID), Charles River Wiga GmbH, Sulzfeld, Germany). The cannulas were tunneled subcutaneously and attached to the skin by sutures and closed with an iron plug. After surgery the cannulas were filled with heparinized glycerol and closed. Cannulas were flushed every 3 days with heparinized saline. At least one week later an insulin or glucose tolerance test was performed after an overnight fast (10-12h). Hereto, both the cannulas in the femoral artery and vein were connected with a blunt 30-gauge needle to a polyethylene tube of approximately $20 \mathrm{~cm}$ length (1.45 mm OD; $0.75 \mathrm{~mm}$ ID), allowing the rat to move freely in the cage. The cannula in the femoral artery was connected to a data acquisition system (IdeeQ 1.70; Instrument Development Engineering and Evaluation, Maastricht University, The Netherlands) to measure blood pressure and heart rate. The rats were handled regularly (at least 3 times a week) during the acclimatization period, so that the rats got used to this connection within 15-30 minutes, as evidenced by stability of blood pressure and heart rate, and the absence of protest movement. Hereafter the intravenous glucose tolerance test (IVGTT) or intravenous insulin tolerance test (IVITT) was performed.

\section{Intravenous glucose tolerance test}

To determine the effect of acute glycocalyx degradation on glucose tolerance, IVGTTs were performed in the first group of rats. All animals underwent two IVGTTs: the first test (run 1) was considered a reference test, while the second test (run 2) was the experimental test with the rats receiving either a bolus of hyaluronidase or as a control a bolus of saline before the run. During the IVGTT, $1 \mathrm{~g} / \mathrm{kg}$ glucose was infused into the femoral vein, and blood samples were collected to measure blood glucose and plasma insulin levels. The arterial line was used for the withdrawal of these blood samples. Blood glucose was measured with a glucose meter (Ascensia contour) at $t=-5$ and -3 , 
(pre) and $t=2,4,6,8,10,12,15,20,30,60$ and 90 minutes after glucose infusion. Plasma insulin concentrations were measured with an ELISA (ALPCO Diagnostics, Salem, NH) in samples taken at $t=-5$ and -3 (pre), and $t=6,10,15,30,60$ and 90 minutes after glucose infusion (flowchart 1 ). After the measurements the animals were disconnected from the sampling and infusion lines, the canulas flushed and the rats returned to the housing facility. One week later the second IVGTT was performed in the rats, one group of rats received a bolus of $1 \mathrm{~mL}$ of saline via the femoral vein $(\mathrm{n}=8)$ and the other a bolus of $1 \mathrm{~mL}$ of hyaluronidase (500 U/ml; bovine testes, type IV-S, Sigma-Aldrich) (n=7) 1 hour before the start of the second IVGTT. Because the initial experiments indicated that insulin levels were increased after hyaluronidase treatment, c-peptide levels were determined as a reference for insulin secretion in the later experiments as well. The c-peptide levels were measured (ELISA, ALPCO Diagnostics, Salem, NH) in the plasma samples taken for insulin determination in 3 animals of the control group and in 4 animals of the experimental group during the $1^{\text {st }}$ and $2^{\text {nd }}$ IVGTT.

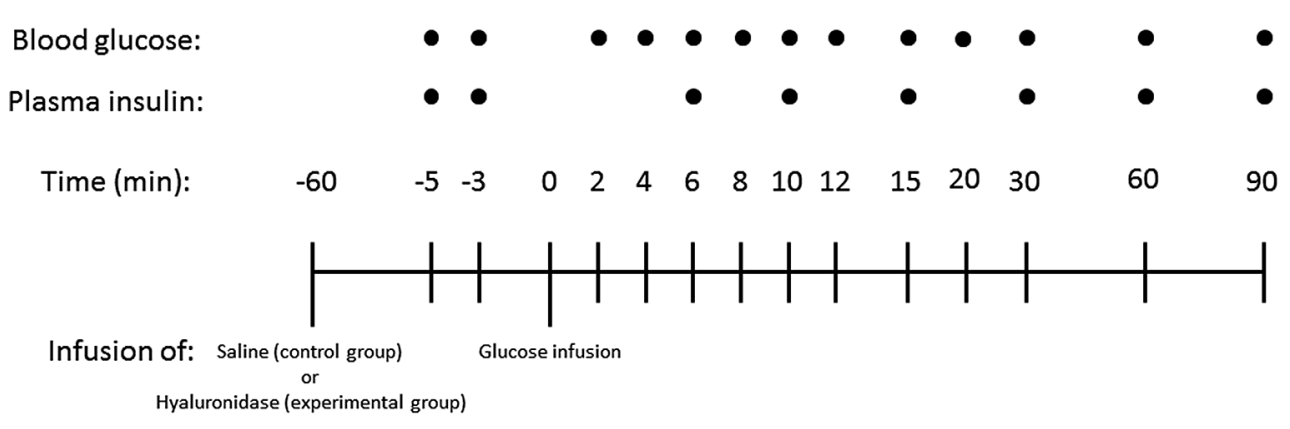

Flowchart 1 Time points of blood sampling during the IVGTT.

Glucose was infused at time $=0 \mathrm{~min}$. All rats underwent two IVGTTs, the first served as reference and the second as experimental test. Saline (control group) or hyaluronidase (experimental group) infusion was only performed before the start of run 2 (time $=-60 \mathrm{~min}$ )

\section{Intravenous insulin tolerance test}

To verify that acute glycocalyx degradation was, similar to our previous study in the anesthetized rat, associated with an acute reduction in insulin sensitivity, whole-body insulin sensitivity was tested in a second group of conscious rats by an IVITT. Again, two runs were performed in the rats, a reference test and an experimental test. First, endogenous insulin and glucagon production by the pancreas was blocked by a constant infusion of somatostatin $(300 \mu \mathrm{g} / \mathrm{kg} / \mathrm{h} ; 100 \mu \mathrm{g} / \mathrm{mL})$ which started 30 minutes before the run. Then, to prevent hypoglycemia, a bolus of $1 \mathrm{~g} / \mathrm{kg}$ glucose $(0.5 \mathrm{~g} / \mathrm{mL})$ was given via the venous line and subsequently a bolus of $0.1 \mathrm{U} / \mathrm{kg}$ insulin $(0.1 \mathrm{U} / \mathrm{mL})$ was given after 10 minutes. Blood glucose $( \pm 0.6 \mu$ L blood $)$ was measured with a glucose meter, by 
sampling blood from the cannula in the femoral artery, at $\mathrm{t}=-30,-20,-10$ and -0 (pre) and $t=2,4,6,8,10$ minutes after glucose infusion; then the bolus of insulin at $t=11$ was given and blood glucose was further measured at $\mathrm{t}=13,15,17,19,21,26,31,41$ and 61 minutes. Plasma insulin levels ( $\pm 60 \mu \mathrm{L}$ blood) were measured with an ELISA at $\mathrm{t}=-30$ and 0 (pre) and $\mathrm{t}=2,6,10,13,17,21,26,41$ and 61 minutes (flowchart 2). After the measurements the animals were disconnected from the sampling and infusion lines, the canulas flushed and the rats returned to the housing facility. As in the IVGTT experiments, one week later a second IVITT was performed in the rats which were split into a control group $(n=7)$ and an experimental group $(n=7)$. In the control group a bolus of saline was infused via the femoral vein one hour before the start of the IVITT, and in the experimental group a bolus of $1 \mathrm{ml}$ hyaluronidase was given.

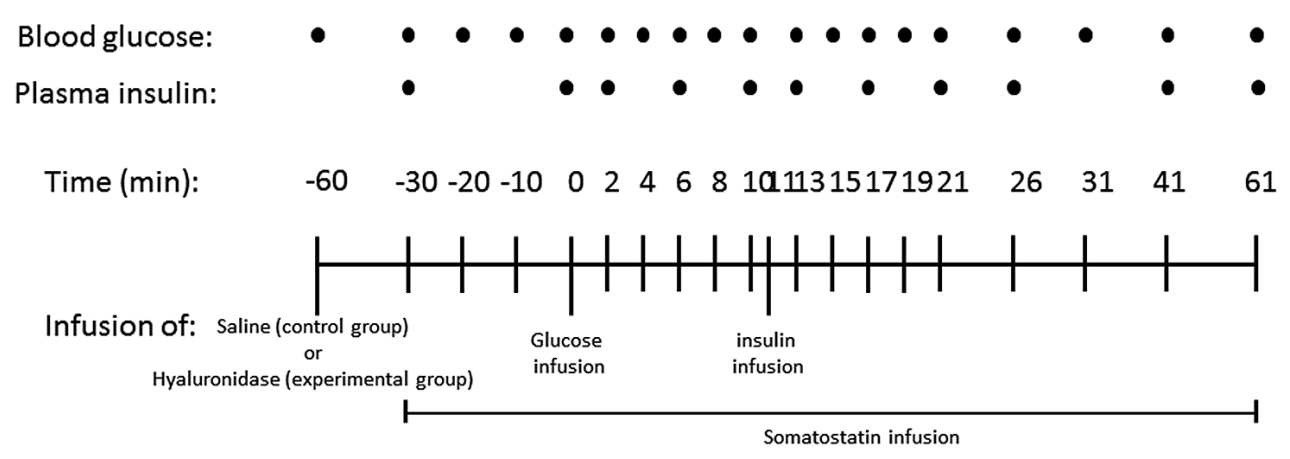

Flowchart 2 Time points of blood sampling during the IVITT.

To avoid hypoglycemia, a bolus of glucose was given at time $=0 \mathrm{~min}$, while the infusion of insulin was given 11 minutes later. All rats underwent two IVITTs, the first served as reference and the second as experimental test. Saline (control group) or hyaluronidase (experimental group) infusion was only performed before the start of run 2.

\section{Data analysis}

\section{IVGTT}

As a reflection of the circulating levels of glucose, insulin and c-peptide during the IVGTT we calculated the incremental area under the curve (AUC) of their concentrations, corrected for baseline, versus time after glucose infusion using the linear trapezoidal rule [14].

\section{IVITT}

As a measure of the insulin sensitivity the decline in blood glucose between 2 and 15 minutes after insulin infusion was determined, and the glucose disposal rate (Kitt) calculated from the slope of the linear regression line of the logarithm of blood glucose against time multiplied by -100 [15]. 


\section{Statistical analysis}

The data are presented as the mean \pm SEM. Differences between the first and second IVGTT and IVITT were tested with paired t-tests. A value of $\mathrm{P}<0.05$ was considered statistically significant. 


\section{Results}

Baseline characteristics are listed in table 4.1. There were no significant differences in baseline glucose and insulin levels, body weight, heart rate and blood pressure between the first and second run in control rats as well as in hyaluronidase treated rats. Somatostatin infusion resulted in significant decreases in glucose and insulin levels in all groups.

Table 4.1 Baseline characteristics

\begin{tabular}{ccccc}
\hline & \multicolumn{2}{c}{ Control } & Experimental \\
\hline & Run 1 & $\begin{array}{c}\text { Run 2 } \\
\text { (saline) }\end{array}$ & Run 1 & $\begin{array}{c}\text { Run 2 } \\
\text { (hyaluronidase) }\end{array}$ \\
\hline Body weights (gram) & $353.5 \pm 8.8$ & $348.6 \pm 6.8$ & $358.4 \pm 8.0$ & $365.9 \pm 8.3$ \\
\hline Blood pressure (mmHg) & $110.8 \pm 3.6$ & $111.0 \pm 3.7$ & $107.7 \pm 3.2$ & $106.7 \pm 2.8$ \\
\hline Heart rate (bpm) & $442.8 \pm 22.0$ & $389.9 \pm 14.2$ & $393.9 \pm 15.3$ & $380.8 \pm 14.3$ \\
\hline Baseline glucose (mg/dL) & $94.0 \pm 3.2$ & $92.7 \pm 2.8$ & $100.4 \pm 3.9$ & $93.7 \pm 2.5$ \\
\hline Baseline insulin (uU/mL) & $18.6 \pm 6.0$ & $20.0 \pm 8.8$ & $20.0 \pm 8.3$ & $12.9 \pm 4.5$ \\
\hline $\begin{array}{c}\text { Glucose levels after somatostin } \\
\text { infusion (mg/dL) }\end{array}$ & $77.0 \pm 3.1^{*}$ & $69.8 .0 \pm 1.9^{*}$ & $87.0 \pm 4.3^{*}$ & $81.9 \pm 3.9^{*}$ \\
\hline $\begin{array}{c}\text { Insulin levels after somatostin } \\
\text { infusion (uU/mL) }\end{array}$ & $2.0 \pm 0.5^{*}$ & $2.0 \pm 0.5^{*}$ & $3.6 \pm 1.0^{*}$ & $2.9 \pm 0.5^{*}$ \\
\hline
\end{tabular}

Data are means \pm SEM ( $n=15$ control (saline) rats; $n=14$ treated (hyaluronidase) rats). The baseline glucose and insulin levels are the values derived after an overnight fast before the IVGTT ( $\mathrm{t}=-5$ ) and IVITT ( $\mathrm{t}=-30$ ) started. Glucose levels and insulin levels were also measured 30 minutes after somatostatin infusion in the rats that underwent an IVGTT ( $\mathrm{n}=8$ control rats; $\mathrm{n}=7$ hyaluronidase treated rats). Somatostatin infusion resulted in significant decreases in glucose and insulin levels in all groups. ${ }^{*} \mathrm{P}<0.05$ (paired t-test), compared to baseline glucose and insulin levels before somatostatin. Blood pressure and heart rate represent values during baseline before the glucose or insulin tolerance test (i.e., from $t=-10$ to $t=0 \mathrm{~min}$ ).

\section{IVGTT}

To determine the effect of glycocalyx degradation on glucose tolerance and glucose stimulated insulin secretion, IVGTTs were performed in conscious rats. Mean glucose and insulin curves after the intravenous glucose infusion are shown in Figure 4.1A and Figure 4.2A. The AUC of glucose did not change between the first and second run in control rats $(112 \pm 8 \%$ of run 1$)$, as well as in the hyaluronidase treated rats ( $99 \pm 9 \%$ of run 1) (Fig. 4.1B). In control rats the AUC of insulin (100 $\pm 11 \%$ of run 1, Fig. 4.2B) was not different between the first and second run. In contrast, the AUC of insulin (152 $\pm 16 \%$ of run 1 , Fig. 4.1B) was significantly increased after enzymatic treatment of the glycocalyx with hyaluronidase $(\mathrm{P}<0.05)$. For reference we also measured $\mathrm{C}$-peptide 
levels during both runs in 3 animals of the control group and in 4 animals of the reference group. The AUC of c-peptide levels (220 $\pm 52 \%$ of run 1; Fig. 4.3) tended to increase after hyaluronidase treatment, however not in the control group ( $94 \pm 34 \%$ of run 1 ; Fig. 4.3) (P=0.08).
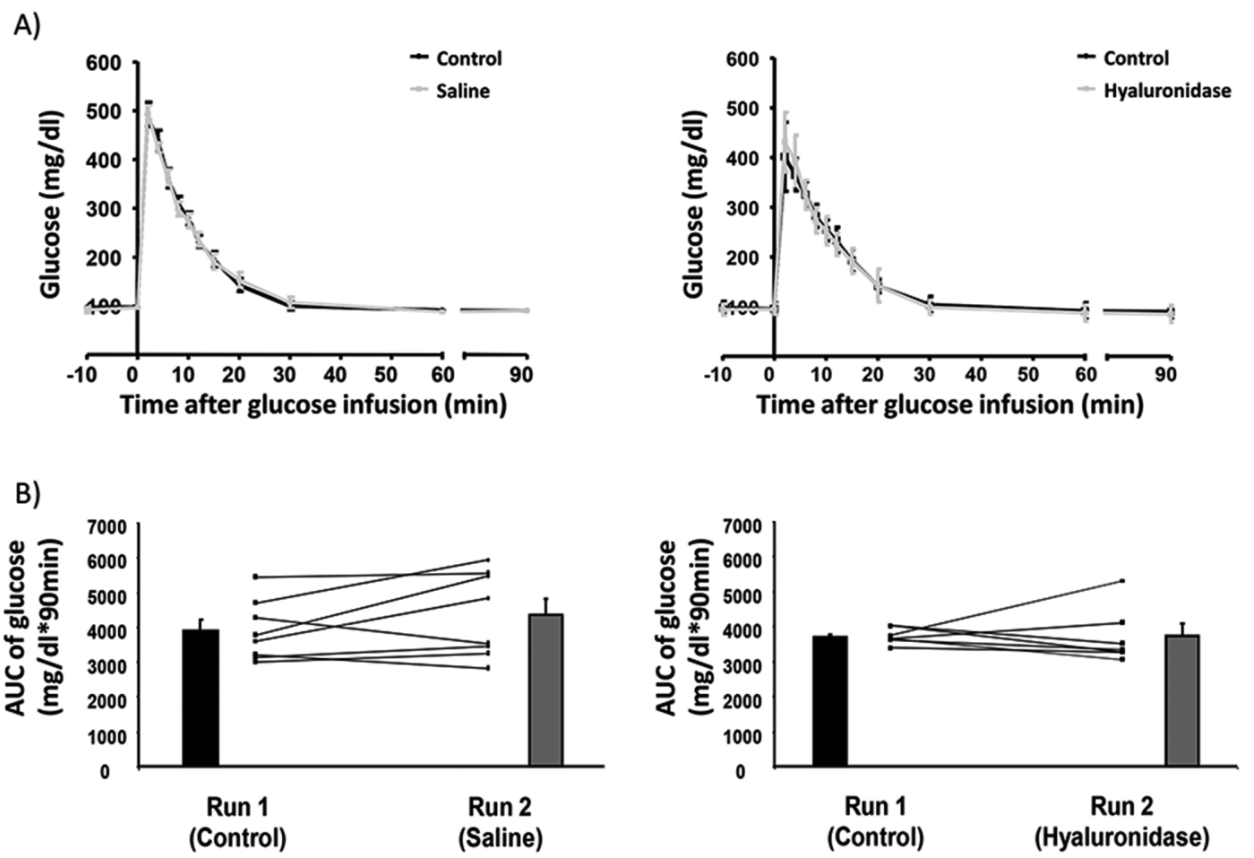

Figure 4.1 A. Circulating glucose levels (means \pm SEM) in conscious rats during the $1^{\text {st }}$ (reference) and $2^{\text {nd }}$ glucose tolerance test (IVGTT) in control $(n=8$, left panel) and hyaluronidase treated rats $(n=7$; right panel). B. As a reflection of the glucose levels during the test the incremental area under the curve (AUC) was calculated for the period of 0-90 minutes after glucose infusion by the linear trapezoidal rule. AUCs of paired individual experiments and mean \pm S.E.M during the $1^{\text {ste }}$ and $2^{\text {nd }}$ IVGTT are shown for control (left panel) and hyaluronidase treated rats (right panel). 
A)

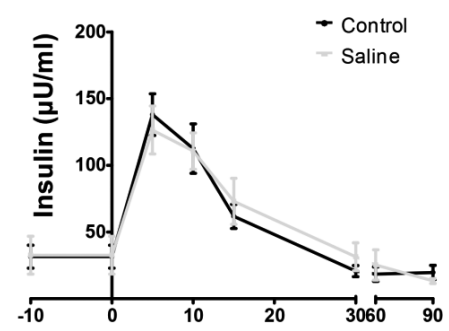

Time after glucose infusion (min)

B)

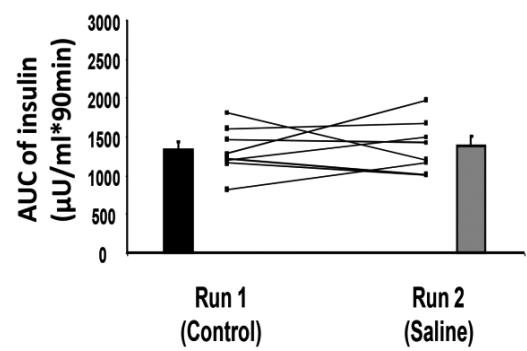

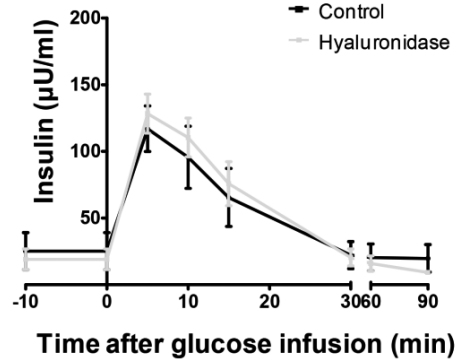

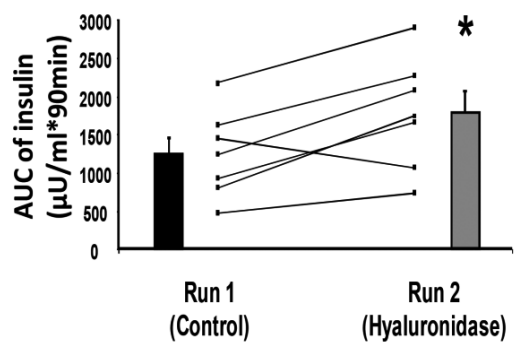

Figure 4.2 A. Circulating insulin levels (mean \pm SEM) in conscious rats during the $1^{\text {st }}$ (reference) and $2^{\text {nd }}$ glucose tolerance test (IVGTT) in control ( $\mathrm{n}=8$, left panel) and hyaluronidase treated rats $(\mathrm{n}=7$; right panel). B. As a reflection of the insulin levels during the test the incremental area under the curve (AUC) was calculated for the period 0-90 minutes after glucose infusion by the linear trapezoidal rule. AUCs of paired individual experiments and mean \pm S.E.M during the $1^{\text {ste }}$ and $2^{\text {nd }}$ IVGTT are shown for control rats (left panel) and hyaluronidase treated rats (right panel). ${ }^{*} \mathrm{P}<0.05$ (paired t-test).
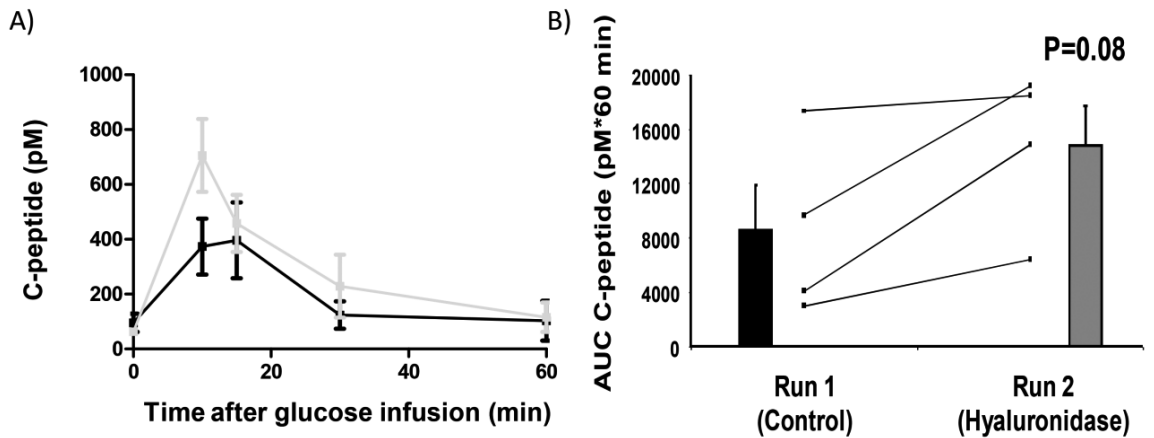

Figure 4.3 A. C-peptide levels (relative to run 1) measured in control rats and hyaluronidase treated rats during an IVGTT. B. As a reflection of the c-peptide levels during the test the incremental area under the curve (AUC) was calculated for the period of 0-60 minutes after glucose infusion by the linear trapezoidal rule. AUCs are shown for control rats $(n=3)$ and hyaluronidase treated rats $(n=4)$. Because of the variation in the c-peptide levels in run 1 (range AUC: $3001 \mathrm{pM}^{*} 60$ minutes - $28719 \mathrm{pM}^{*} 60$ minutes) and the small $\mathrm{n}$, we corrected the values measured in run 2 for the paired values measured in run 1. The AUC of insulin in these 3 control rats was $1569 \pm 213$ during the $1^{\text {st }}$ IVGTT and $1423 \pm 203(\mathrm{P}=\mathrm{NS})$ during the $2^{\text {nd }}$ IVGTT. The AUC of insulin in 4 hyaluronidase treated rats was $1179 \pm 369$ during the $1^{\text {st }}$ IVGTT and $1876 \pm 448(\mathrm{P}<0.05)$ during the $2^{\text {nd }}$ IVGTT. 


\section{IVITT}

To determine the effect of glycocalyx degradation on whole-body insulin-mediated glucose disposal, IVITTs were performed in conscious rats, and the glucose disposal rate monitored. The Kitt, which is the slope of the linear regression line of the logarithm of blood glucose, is shown for each individual experiment together with the mean Kitt of all experiments in Figure 4.4. There was no change in Kitt after a bolus of saline (102 $\pm 6 \%$ of run 1 ), however after treatment with hyaluronidase the Kitt decreased significantly (to $81 \pm 6 \%$ of run $1, \mathrm{P}<0.05$ ).
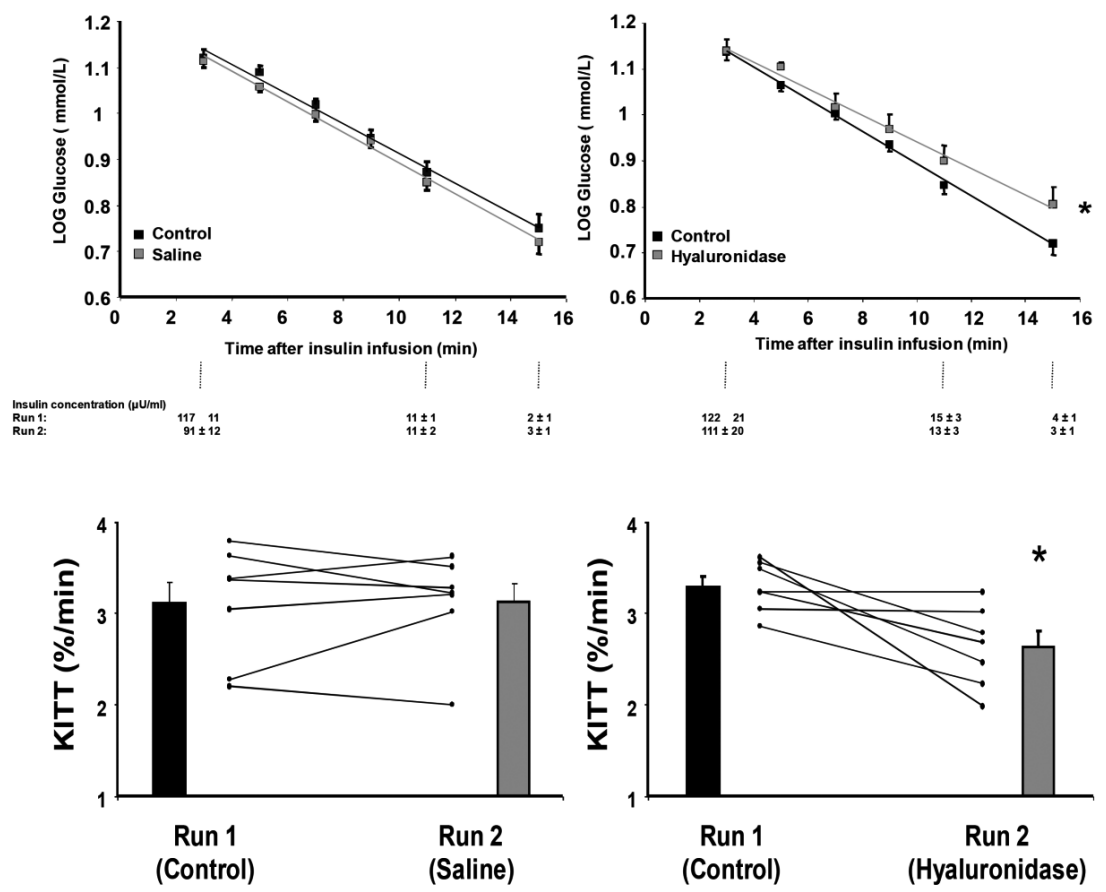

Figure 4.4 A. Mean \pm SEM of the logarithm of blood glucose in time after an i.v. bolus of insulin $(0.1 \mathrm{U} / \mathrm{kg})$ during the 1st and 2nd insulin tolerance test in the conscious control rats ( $\mathrm{n}=7$; left panel) and conscious hyaluronidase treated rats ( $n=7$; right panel). Insulin levels (in $\mu \mathrm{U} / \mathrm{ml}$ ) measured during the test are shown in the panel below the graph. B. Glucose disposal rate (Kitt) for each paired individual experiment as well as the mean \pm SEM of all experiments during both IVITTs for control rats (left panel) and hyaluronidase treated rats (right panel). ${ }^{*} \mathrm{P}<0.05$ (paired t-test). 


\section{Discussion}

When plasma glucose rises by an exogenous glucose load, insulin is released by the pancreas, causing hepatic glucose production to decrease and glucose to be taken up by insulin-dependent tissues, mainly skeletal muscle [16]. In an insulin-resistant state the ability of insulin to inhibit hepatic glucose release and to promote glucose uptake is impaired. In a previous study [6] we showed in anesthetized rats that acute enzymatic glycocalyx degradation was associated with a decrease in insulin-mediated glucose disposal, suggesting a role for the glycocalyx in regulation of insulin sensitivity. In the current study, we similarly demonstrated this role in conscious rats and showed that the evoked insulin resistance did not affect glucose tolerance because of an increased pancreatic insulin release in response to an exogenous glucose load. These data suggest that loss of glycocalyx, which is regarded an early marker of vascular vulnerability in humans at risk for cardiovascular disease, is associated with an acute impairment of insulin sensitivity. This defect does, however, not directly manifest itself by glucose intolerance due to a compensatory insulin response.

\section{Role for glycocalyx in regulation of muscle insulin sensitivity}

Insulin-mediated glucose uptake in muscle has been coupled to the ability of insulin to rapidly increase capillary blood volume, and it has been suggested that this enables insulin to be efficiently delivered to the myocytes $[8,9]$. While traditionally the insulinmediated increase in capillary blood volume was explained by an increase in the number of perfused capillaries (capillary recruitment) [7], we recently showed in anesthetized rats that insulin can also increase blood volume within already perfused microvessels by increasing blood accessibility into the glycocalyx, and that this vascular action of insulin was impaired after enzymatic glycocalyx degradation. Further, it was suggested that this impaired insulin-mediated microvascular blood volume increase in muscle underlied the $\sim 30 \%$ reduction in glucose disposal rate during an intravenous insulin tolerance test after hyaluronidase treatment in the rats [6]. To check whether the reduction of glucose disposal from the blood was due to diminished insulin action in skeletal muscle, Akt phosphorylation (expressed as the ratio of phosphorylated Akt to total Akt) was measured in soleus muscle after the IVITT in a few of these anesthetized rats $(n=5$, unpaired measurements). The amount of Akt phosphorylated was $0.16 \pm 0.03$ in control rats versus $0.09 \pm 0.02$ in hyaluronidase treated rats (unpublished observations). These data suggest that the amount of insulin that was delivered towards the muscle and activating the myocytes was decreased. In contrast in the liver there seemed no difference in Akt phosphorylation between the control rats and the hyaluronidase treated rats $(0.46 \pm 0.11$ in control rats versus $0.54 \pm 0.11$ in hyaluronidase treated 
rats) (unpublished observations). These data indicated a novel role for the endothelial glycocalyx in the regulation of insulin sensitivity.

Insulin tolerance tests in our previous study were performed without the use of somatostatin and during isoflurane anesthesia [6], and it has been shown before that isoflurane anesthesia affects glucose utilization $[17,18]$. In the currentstudy we, therefore measured glucose and insulin tolerance in conscious rats one week after cannulation. The animals well recovered from the surgery after one week as illustrated by comparable body weights to pre-surgery body weights, and physiological blood pressures and heart rates, as well as blood glucose and plasma insulin levels at baseline. Furthermore, these parameters were comparable between the first and second test in the control group, indicating that this model is suitable to perform repeated measurements. In contrast to the IVITT performed during anesthesia in which glucose-mediated insulin release is already greatly inhibited by the isoflurane anesthesia [19], in the conscious animals somatostatin was used to block the endogenous insulin and glucagon production. The effectiveness of somatostatin was illustrated by the significant decrease of glucose and insulin levels after 30 minutes of insulin infusion in all groups (Table 4.1). Further in the anesthetized rats the bolus of insulin infused was supraphysiological $(1 \mathrm{U} / \mathrm{kg})$, while in the current study a more physiological bolus of insulin $(0.1 \mathrm{U} / \mathrm{kg})$ was infused. The reduction in insulin sensitivity after hyaluronidase treatment was confirmed in the present study in which we found a comparable (i.e, $\sim 25 \%$ ) reduction in glucose disposal rate in conscious rats after hyaluronidase treatment, indicating that the decrease in insulin-mediated glucose disposal after glycocalyx damage was not greatly influenced by the isoflurane anesthesia.

The reduction in insulin sensitivity was not accompanied by an impaired glucose tolerance (Fig. 4.1). However, it appeared that about 1.5 fold more insulin was needed to dispose the intravenously infused glucose load in the rats that had received hyaluronidase before the $2^{\text {nd }}$ test (Fig. 4.2). The increased insulin response seemed primarily explained by an increased release of insulin by the pancreas as shown by the elevated c-peptide levels after hyaluronidase treatment (Fig. 4.3). C-peptide is cosecreted when insulin is released by the pancreas in equimolar amounts; however $\mathrm{C}$-peptide is not cleared by the liver and the clearance of $\mathrm{C}$-peptide from the circulation is slower compared to that of insulin $[20,21]$. In addition to an increased insulin release by the $\beta$-cells, it cannot be ruled out that a diminished clearance of insulin from the blood as a result of a compromised insulin delivery to the target tissues may have contributed to the increased insulin response to glucose infusion after hyaluronidase treatment. The current data does not allow us to discriminate whether the increased insulin release after hyaluronidase was a result of a direct effect of hyaluronidase on the $B$-cell or the result of a rapid feedback of the decrease in peripheral insulin sensitivity. 
While there is currently a distinct lack of information regarding the contribution of hyaluronan or the glycocalyx on regulation of insulin release by the pancreas, it has been well recognized in rodent, dog, en human studies that a healthy pancreas is readily capable to compensate for a reduction in insulin sensitivity [16,22]. The precise mechanisms by which a normal organism detects insulin resistance and compensates with hyperinsulinemia remain unknown at the moment. The data of the current study indicate that the pancreas is able to compensate immediately for the reduced insulin sensitivity induced by acute glycocalyx degradation.

\section{Clinical relevance}

While in the current study glycocalyx degradation was induced by a bolus of the enzyme hyaluronidase, a treatment which was in previous animal studies shown to effectively reduce glycocalyx thickness and barrier properties $[10,11]$, additional studies have shown that short-term hyperglycemia and acute hyperlipidemic conditions rapidly initiate glycocalyx loss as well $[23,24,25]$. As a result, it has been suggested that glycocalyx loss may be an early event in the development of endothelial dysfunction during exposure to traditional risk factors [26]. Given the indicated relationship between endothelial dysfunction and insulin resistance, our finding that insulin sensitivity is decreased after acute degradation of the glycocalyx, may well indicate glycocalyx loss as common target linking endothelial dysfunction to insulin resistance, e.g. during the metabolic syndrome. Our results show that the decrease in insulin sensitivity induced by glycocalyx loss is not readily transferred into glucose intolerance due to a compensatory insulin response, thereby resembling an early stage of insulin resistance in the progression to type II diabetes. When unrecognized for a prolonged period, this stage may be followed by dysfunction and loss of $\beta$-cells and finally progress into overt type II diabetes. Early detection of glycocalyx loss, which can nowadays be performed using sublingual SDF imaging [27], may in the future facilitate identification of humans at risk for cardiovascular and associated metabolic disease. 


\section{References}

1. Paneni F, Beckman JA, Creager MA, Cosentino F (2013) Diabetes and vascular disease: pathophysiology, clinical consequences, and medical therapy: part I. Eur Heart J 34: 24362443.

2. Clark MG (2008) Impaired microvascular perfusion: a consequence of vascular dysfunction and a potential cause of insulin resistance in muscle. Am J Physiol Endocrinol Metab 295: E732-750.

3. Rattigan S, Richards SM, Keske MA (2013) Microvascular contributions to insulin resistance. Diabetes 62: 343-345.

4. Bergman RN (2007) [Orchestration of homeostasis of glucose metabolism]. Journ Annu Diabetol Hotel Dieu: 127-138.

5. Richards OC, Raines SM, Attie AD (2010) The role of blood vessels, endothelial cells, and vascular pericytes in insulin secretion and peripheral insulin action. Endocr Rev 31: 343363.

6. Eskens BJ, Mooij HL, Cleutjens JP, Roos JM, Cobelens JE, et al. (2013) Rapid insulin-mediated increase in microvascular glycocalyx accessibility in skeletal muscle may contribute to insulin-mediated glucose disposal in rats. PLoS One 8: e55399.

7. Rattigan S, Wheatley C, Richards SM, Barrett EJ, Clark MG (2005) Exercise and insulinmediated capillary recruitment in muscle. Exerc Sport Sci Rev 33: 43-48.

8. Vincent MA, Clerk LH, Lindner JR, Klibanov AL, Clark MG, et al. (2004) Microvascular recruitment is an early insulin effect that regulates skeletal muscle glucose uptake in vivo. Diabetes 53: 1418-1423.

9. Vincent MA, Clerk LH, Rattigan S, Clark MG, Barrett EJ (2005) Active role for the vasculature in the delivery of insulin to skeletal muscle. Clin Exp Pharmacol Physiol 32: 302-307.

10. Cabrales P, Vazquez BY, Tsai AG, Intaglietta M (2007) Microvascular and capillary perfusion following glycocalyx degradation. J Appl Physiol 102: 2251-2259.

11. Henry CB, Duling BR (1999) Permeation of the luminal capillary glycocalyx is determined by hyaluronan. Am J Physiol 277: H508-514.

12. van den Berg BM, Vink H, Spaan JA (2003) The endothelial glycocalyx protects against myocardial edema. Circ Res 92: 592-594.

13. VanTeeffelen JW, Brands J, Janssen BJ, Vink H (2013) Effect of acute hyaluronidase treatment of the glycocalyx on tracer-based whole body vascular volume estimates in mice. J Appl Physiol 114: 1132-1140.

14. Jazet IM, Pijl H, Frolich M, Schoemaker RC, Meinders AE (2005) Factors predicting the blood glucose lowering effect of a 30-day very low calorie diet in obese Type 2 diabetic patients. Diabet Med 22: 52-55.

15. Borghouts LB, Backx K, Mensink MF, Keizer HA (1999) Effect of training intensity on insulin sensitivity as evaluated by insulin tolerance test. Eur J Appl Physiol Occup Physiol 80: 461466. 
16. Defronzo RA (2009) Banting Lecture. From the triumvirate to the ominous octet: a new paradigm for the treatment of type 2 diabetes mellitus. Diabetes 58: 773-795.

17. Diltoer M, Camu F (1988) Glucose homeostasis and insulin secretion during isoflurane anesthesia in humans. Anesthesiology 68: 880-886.

18. Tanaka K, Kawano T, Tomino T, Kawano H, Okada T, et al. (2009) Mechanisms of impaired glucose tolerance and insulin secretion during isoflurane anesthesia. Anesthesiology 111: 1044-1051.

19. Zuurbier CJ, Keijzers PJ, Koeman A, Van Wezel HB, Hollmann MW (2008) Anesthesia's effects on plasma glucose and insulin and cardiac hexokinase at similar hemodynamics and without major surgical stress in fed rats. Anesth Analg 106: 135-142, table of contents.

20. Cobelli C, Toffolo GM, Dalla Man C, Campioni M, Denti P, et al. (2007) Assessment of beta-cell function in humans, simultaneously with insulin sensitivity and hepatic extraction, from intravenous and oral glucose tests. Am J Physiol Endocrinol Metab 293: E1-E15.

21. Frangioudakis G, Gyte AC, Loxham SJ, Poucher SM (2008) The intravenous glucose tolerance test in cannulated Wistar rats: a robust method for the in vivo assessment of glucosestimulated insulin secretion. J Pharmacol Toxicol Methods 57: 106-113.

22. Bergman RN, Ader M, Huecking K, Van Citters G (2002) Accurate assessment of beta-cell function: the hyperbolic correction. Diabetes 51 Suppl 1: S212-220.

23. van den Berg BM, Spaan JA, Vink H (2009) Impaired glycocalyx barrier properties contribute to enhanced intimal low-density lipoprotein accumulation at the carotid artery bifurcation in mice. Pflugers Arch 457: 1199-1206.

24. Vink H, Constantinescu AA, Spaan JA (2000) Oxidized lipoproteins degrade the endothelial surface layer : implications for platelet-endothelial cell adhesion. Circulation 101: 15001502.

25. Zuurbier CJ, Demirci C, Koeman A, Vink H, Ince C (2005) Short-term hyperglycemia increases endothelial glycocalyx permeability and acutely decreases lineal density of capillaries with flowing red blood cells. J Appl Physiol 99: 1471-1476.

26. Nieuwdorp M, Meuwese MC, Vink H, Hoekstra JB, Kastelein JJ, et al. (2005) The endothelial glycocalyx: a potential barrier between health and vascular disease. Curr Opin Lipidol 16: 507-511.

27. Broekhuizen LN, Mooij HL, Kastelein JJ, Stroes ES, Vink H, et al. (2009) Endothelial glycocalyx as potential diagnostic and therapeutic target in cardiovascular disease. Curr Opin Lipidol 20: 57-62. 


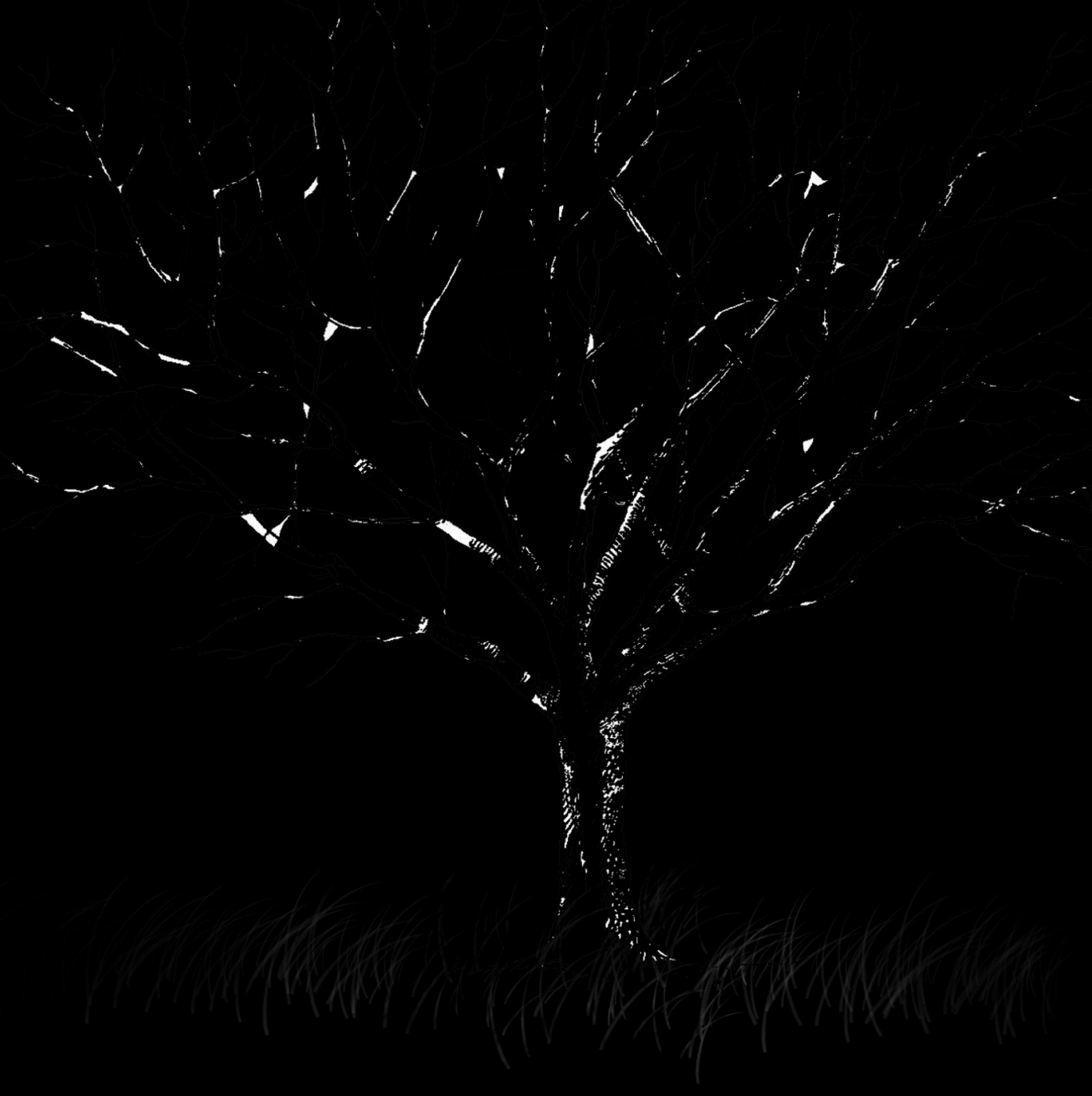


Chapter 5

\title{
Early impairment of skeletal muscle endothelial glycocalyx barrier properties in diet-induced obesity in mice
}

\author{
Bart J.M. Eskens \\ Thomas M. Leurgans \\ Hans Vink \\ Jurgen W.G.E. VanTeeffelen
}

In adapted form published in Physiological Reports. 2014: Jan 6 (Published online before print) 


\section{Abstract}

While previous studies have indicated an important role for the endothelial glycocalyx in regulation of microvascular function, it was recently shown that acute glycocalyx degradation in rats was associated with an impaired insulin-mediated glucose disposal. The aim of the current study was to determine whether glycocalyx damage in skeletal muscle occurs at an early stage of diet-induced obesity (DIO).

The microcirculation of the hindlimb muscle of anesthetized C57Bl/6 mice, fed chow (CON) or a high-fat diet (HFD) for 6 and 18 weeks (w), respectively, was visualized with a Sidestream Dark-field camera, and glycocalyx barrier properties were derived from the calculated perfused boundary region (PBR). Subsequently, an intraperitoneal glucose tolerance test was performed and the area under the curve (AUC) of blood glucose was calculated.

Impairment of glycocalyx barrier properties was already apparent after $6 \mathrm{w}$ of HFD and remained after 18w of HFD (PBR (in $\mu \mathrm{m}$ ): $0.81 \pm 0.03$ in CON_6w vs. $0.97 \pm 0.04$ in HFD_6w and $1.02 \pm 0.07$ in HFD_18w (both $\mathrm{P}<0.05$ )). Glucose intolerance appeared to develop more slowly (AUC (in mmol/L*120 min): $989 \pm 61$ in CON_6w vs. $1204 \pm 89$ in HFD_6w ( $\mathrm{P}=0.11)$ and $1468 \pm 84$ in HFD_18w $(\mathrm{P}<0.05))$.

The data indicate that damage to the endothelial glycocalyx is an early event in diet-induced obesity. It is suggested that glycocalyx damage may contribute to the development of insulin resistance in obesity. 


\section{Introduction}

Obesity is a growing global health problem, as it has been associated with an increased risk for developing cardiovascular complications and type II diabetes. Endothelial dysfunction has been indicated to play a central role in both aspects [1,2]. At the luminal side of the endothelium, the endothelial surface layer, consisting of proteoglycans and glycosaminoglycans in dynamic association with the plasma and its soluble components, resides $[3,4,5,6]$. The glycocalyx contributes to the regulation of multiple aspects of endothelial function [7], including the delivery and exchange of plasma solutes and hormones [8,9], shear-mediated release of nitric oxide, and homeostasis of the vascular wall $[10,11]$. Previous animal and human studies showed that severe acute $[12,13]$ as well as long-term hyperlipidemic [14] and hyperglycemic conditions $[15,16]$ resulted in significant reductions of whole-body glycocalyx volume and impaired microvascular glycocalyx barrier properties $[14,16,17,18]$. Consequently, the hypothesis has been put forward that glycocalyx loss may be an important step in the development of endothelial dysfunction during conditions of increased cardiovascular risk [7,19]. Recently, we provided evidence in rats that the endothelial glycocalyx also plays a role in the regulation of insulin sensitivity [20]. We showed in rats that insulin-mediated increases in microvascular blood volume in muscle included an increased accessibility of circulating blood into the glycocalyx; the importance of this effect in the metabolic action of insulin was illustrated by the observation that enzymatic degradation of the glycocalyx using hyaluronidase was associated with an acute impairment of insulinmediated glucose disposal from the blood [20]. These recent data suggest that loss of glycocalyx may, thus, not only be a consequence of a disturbance in glucose metabolism $[15,16]$, but may as well contribute to it, thereby providing a target which links endothelial dysfunction to insulin resistance. To appreciate this contribution better, it is important to know whether glycocalyx damage is a relatively early process in the development of insulin resistance during risk factor exposure. Herefore, we determined whether glycocalyx damage occurs at a relative early stage of diet-induced obesity (DIO). In particular, we wanted to know whether glycocalyx damage would be manifested in the microcirculation of skeletal muscle, since this tissue constitutes the major site for insulin-mediated glucose disposal in the body.

In the current study we used the high-fat diet (HFD)-fed C57BL/6 mouse model, which is a widely used animal model to study mechanisms of impaired glucose tolerance and (early) type 2 diabetes [21,22]. Previous studies showed that feeding these mice with a HFD for several weeks induced visceral fat deposition and was associated with a progressive loss of insulin sensitivity over time [22]. Furthermore, HFD has been indicated to induce endothelial dysfunction in large vessels $[23,24]$. We assessed the 
occurrence of glycocalyx damage in skeletal muscle microcirculation at a relative early ( 6 weeks) and at a later (18 weeks) stage of DIO, and related this to the development of glucose intolerance in this model. 


\section{Methods}

\section{Animals and diet}

The experimental protocols were approved by the Animal Ethics Care and Use committee of Maastricht University (AEC protocol numbers: 2010-101). After arrival from the external supplier (Harlan, Horst, The Netherlands) mice (C57Bl/6; n=31) were housed at the animal facility of Maastricht University and received standard chow (Ssniff GmbH, Soest, Germany, containing on caloric basis $9 \%$ fat, $58 \%$ carbohydrates and $33 \%$ protein) for 6 weeks (CON_6w; n=7) and 18 weeks (CON_18w; n=8), or a HFD (Research Diets, New Brunswick, NJ, containing on caloric basis $60 \%$ fat, $20 \%$ carbohydrate and $20 \%$ protein), also for 6 weeks (HFD_6w; n=8) and 18 weeks (HFD_18w; n=8), respectively. All animals had unrestricted access to water. Weekly measurements of body weight, blood pressure using a CODA non-invasive blood pressure monitoring system (Kent Scientific), and glucose levels and plasma insulin levels via blood sampling of the saphenous vein were performed in the conscious animal after a morning fast $(4 \mathrm{~h})$. Blood glucose $(\sim$ $5 \mu \mathrm{l}$ ) was measured with a glucose meter (Ascencia Contour), and about $40 \mu \mathrm{l}$ blood was collected from the tail using a $75 \mu \mathrm{l}$ glass capillary tube (Hirschmann, Germany) to measure plasma insulin levels with an ELISA (ALPCO Diagnostics, Salem, NH).

\section{Experimental protocol}

At the day of experiment, after an overnight fast (10-12 h) mice were anesthetized using an intraperitoneal injection of $0.39 \mathrm{mg} / \mathrm{kg}$ fentanyl, $7.81 \mathrm{mg} / \mathrm{kg}$ midazolam and $7.81 \mathrm{mg} / \mathrm{kg}$ acepromazine [25]. Anesthesia was maintained by an additional bolus after $60-90$ minutes of $0.10 \mathrm{mg} / \mathrm{kg}$ fentanyl, $1.56 \mathrm{mg} / \mathrm{kg}$ midazolam and $1.56 \mathrm{mg} / \mathrm{kg}$ acepromazine. The combination of fentanyl, midazolam and acepromazine has been recently introduced in mice studies of insulin sensitivity $[25,26]$, since other anesthetics have regularly been shown to have considerably affect glucose and/or insulin levels [27]. The animal was put in a prone position and body temperature was monitored with a rectal probe and maintained at $\sim 37^{\circ} \mathrm{C}$ with the use of a heating pad and lamp. During anesthesia a cannula was inserted intraperitoneally and the hindlimb muscle was exposed by a small incision in the skin. The muscle was suffused with a bicarbonatebuffered physiological salt solution (PSS) of the following composition (in mM): 131.9 $\mathrm{NaCl}, 4.7 \mathrm{KCl}, 2.0 \mathrm{CaCl} 2,1.2 \mathrm{MgSO} 4,20 \mathrm{NaHCO} 3$ and equilibrated with 5\% $\mathrm{CO}_{2}-95 \% \mathrm{~N}_{2}$ to obtain a $\mathrm{pH}$ of \pm 7.4 . Preparations were equilibrated for 20 minutes and hereafter glycocalyx barrier properties and glucose tolerance were measured. 


\section{Imaging of muscle microcirculation}

To measure the effect of the HFD on glycocalyx barrier properties, the microcirculation of the hindlimb muscle was visualized 5 times at baseline for 10 minutes with a Sidestream Dark-field (SDF) camera [20]. The SDF camera is equipped with a $5 \mathrm{X}$ magnifying objective lens system-containing probe, imaging the RBCs in the tissueembedded microcirculation using green pulsed LED ring illumination [28].

\section{Intraperitoneal glucose tolerance test}

To determine glucose tolerance, an intraperitoneal glucose tolerance test (IPGTT) was performed immediately after the SDF measurements. Mice were infused with a bolus of $1 \mathrm{~g} / \mathrm{kg}$ glucose $(0.1 \mathrm{~g} / \mathrm{ml})$ via the i.p. cannula. Blood glucose $(\sim 5 \mu \mathrm{l})$ was measured, via tail bleeding, at $\mathrm{t}=-10$ and 0 (pre) and $\mathrm{t}=5,10,20,30,40,50,60,70,80,90,100,110$ and 120 minutes after the glucose infusion. In addition, about $40 \mu \mathrm{l}$ blood was collected from the tail using a $75 \mu$ l glass capillary tube at $t=0$ (pre) and $t=10,30,60$ and 90 minutes after glucose infusion to determine systemic hematocrit and plasma insulin levels Thus in total of maximal of $275 \mu \mathrm{L}$ blood was collected in an animal during the IPGTT. It has been indicated that this amount does not cause local trauma [29].

\section{Muscle capillary density}

At the end of the IPGTT, when the animal was still under anesthesia, the hindlimb muscle was removed and immediately fixed in a $4 \%$ formaldehyde solution for subsequent histological analysis of capillary density.

\section{Data analysis}

\section{Measurements of glycocalyx barrier properties in muscle}

Glycocalyx barrier properties were calculated as described previously [20,30]. Briefly, microvessels with a continuous RBC flow were manually selected in the recorded movies (100 frames). In each frame, lines were placed approximately every $10 \mu \mathrm{m}$ perpendicular to the vessel direction along the length of the microvessel. Each line represented a vessel segment; for each vessel segment a total of 21 parallel (every $\pm 0.5 \mu \mathrm{m}$ ) intensity profiles was plotted (using ImageJ, National Institutes of Health, Bethesda, MD) and RBC column width (full width half maximum) was determined for all 100 consecutive frames in a movie, revealing a total of $2100 \mathrm{RBC}$ column width measurements for a vessel segment (21 profiles X 100 frames). The cumulative distribution of the RBC column widths for these 2100 measurements was constructed and used to determine median RBC column diameter $\left(\mathrm{D}_{\mathrm{P} 50}\right)$; in addition, RBC column widths percentiles between P25 and P75 were 
fitted with a linear fit to determine the perfused diameter $\left(\mathrm{D}_{\text {perf }}\right)$ for the vessel segment. The difference between the $\mathrm{D}_{\text {perf }}$ and the $\mathrm{D}_{\mathrm{P} 50}$ divided by two is defined as the perfused boundary region (PBR). The majority of the vessel segments had a median RBC column diameter between 4 and $6 \mu \mathrm{m}$ (Fig. 5.2A), and only PBRs of these size segments were considered in the analysis. Per individual recording in an animal, calculated PBRs for all vessel segments were pooled. Subsequently, PBRs were averaged for the 5 recordings that were made per experiment, resulting in a single PBR value per animal.

\section{Intraperitoneal glucose tolerance test}

As a reflection of the circulating levels of glucose during the IPGTT we calculated the total area under the curve (AUC) of the glucose concentration versus time by the linear trapezoidal rule for the period of 0-120 minutes after glucose infusion (Fig. 5.3A). As a reflection of the circulating insulin levels we calculated the AUC of the insulin concentration versus time by the linear trapezoidal rule for the period of 0-90 minutes after glucose infusion (Fig. 5.3B).

\section{Muscle capillary density}

Paraffin-embedded hindlimb muscles were sectioned and from each muscle 3-6 slides were stained with $200 \mu$ l FITC-labeled lectin from triticum vulgaris (WGA-FITC; 50 $\mu \mathrm{g} / \mathrm{ml}$, Sigma) for 30 minutes in the dark at room temperature $\left(20^{\circ} \mathrm{C}\right)$, washed three times with PBS and mounted with DAPI (Vectashield). Tissues were visualized and photographed using a Leica DFC320 digital camera (Leica, Rijswijk, The Netherlands) at 400x magnification (Leica DM3000 microscope, Leica, Rijswijk, The Netherlands). System control and imaging processing were performed using Leica QWin Image Processing and Analysis morphometry software (Leica Microsystems, Cambridge, United Kingdom). For each slide capillary density was determined by counting the number of capillaries per $\mathrm{mm}^{2}$ muscle surface area. For a muscle the values of all stained slides were averaged revealing 1 value of capillary density per animal.

\section{Statistical analysis}

All data are presented as means \pm SEM. A 2 way ANOVA followed by post hoc Bonferroni correction was used for analysis of the weekly measurements of body weight, blood pressure, blood glucose and plasma insulin levels measured in the conscious mice with diet and time as independent variables. Statistical differences between AUC of glucose levels, AUC of plasma insulin levels and the PBR in the anesthetized mice were tested with Student's unpaired t-tests. The group of mice that received chow for 6 weeks was used as reference group. Furthermore, the relationship between the PBR and the AUC 
Chapter 5

of glucose was tested using correlation analysis. A value of $\mathrm{P}<0.05$ was considered statistically significant. 


\section{Results}

\section{Systemic data}

Body weight, blood pressure, baseline glucose and insulin levels were measured after a morning (4h) fasting period. Body weight (Fig 5.1A) and insulin levels (Fig 5.1D) were significantly different between diets, as well as in time. Glucose levels were significantly different between both treatments as well, however not in time (Fig 5.1C). There were no significant differences in blood pressure (Fig 5.1B).

A)

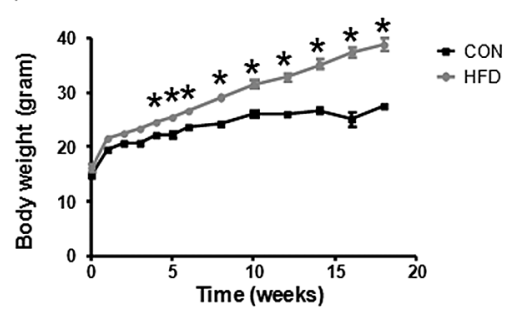

C)

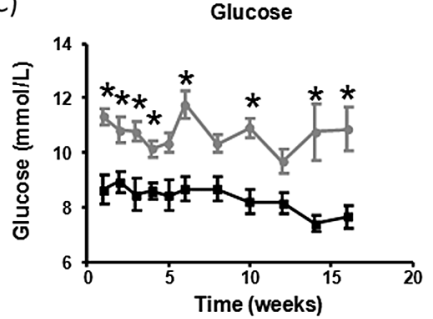

B)

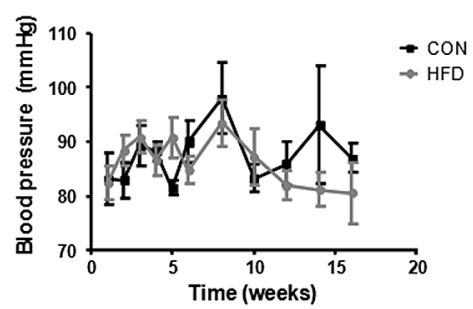

D)

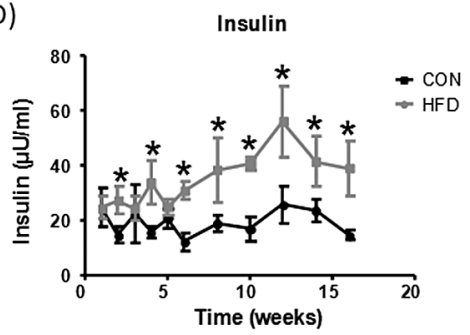

Figure 5.1 Animal characteristics.

Weekly measurements of body weight (A), blood pressure by the tail cuff method (B), blood glucose (C) and plasma insulin levels (D) via the saphenous vein were performed after a morning fast $(4 \mathrm{~h})$ in conscious mice that received chow (black line) or a HFD (grey line) for 6 and 18 weeks. Body weights and insulin levels were significantly different between diets, as well as in time. The glucose levels were significantly different between diets as well, however not in time. There were no significant differences in blood pressure. ${ }^{*}, \mathrm{P}<0.05$ compared to control diet (Bonferroni post hoc test)

\section{Glycocalyx barrier properties in muscle}

The PBR in the skeletal muscle microcirculation of the mice that received chow for 6 weeks was $0.81 \pm 0.03 \mu \mathrm{m}$, and this parameter was significantly increased in the mice that were fed a HFD during this period $(0.97 \pm 0.04 \mu \mathrm{m})$ as well as in mice that were fed a HFD for 18 weeks (1.02 $\pm 0.07 \mu \mathrm{m}$ ) (Fig. 5.2B). The PBR between the mice that received chow for 6 and 18 weeks (PBR in Con_18w was $0.87 \pm 0.08 \mu \mathrm{m}$ ), as well as between the mice that were fed a HFD for 6 and 18 weeks was not significantly different. 
Since our previous data [20] demonstrated that damage to the glycocalyx was associated with an impaired ability for insulin to dispose glucose, we related the PBR to the AUC of glucose during the IPGTT in all individual animals for the four groups (Fig. 5.2C). There was a significant correlation between the baseline PBR and AUC of glucose measured during the IPGTT, suggesting that a greater reduction in glycocalyx barrier properties in muscle was associated with a greater inability to dispose the administered glucose bolus.

A)

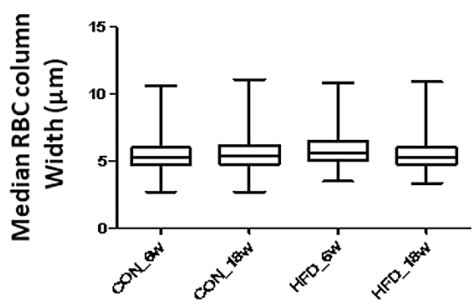

B)

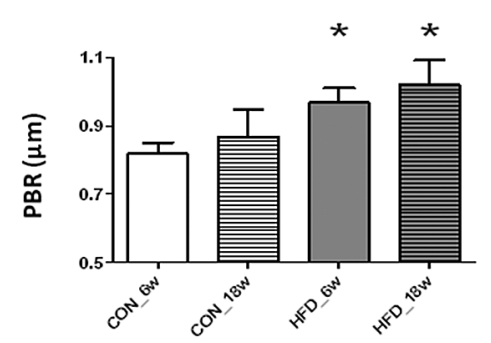

Figure 5.2 Hindlimb imaging.

From each movie (total length: 100 frames) recorded by the SDF camera the distribution of the width of the red blood cell (RBC) column in each visible microvessel was determined (see Methods). A. Distribution of median RBC column width of all measured vessels segments $(\mathrm{n}=$ 1575 in CON_6w, n=1378 in CON_18w, n=1493 in HFD_6w, and $n=1391$ in HFD_18w). B. Mean

$\mathrm{R}^{2}=0.22$

C)

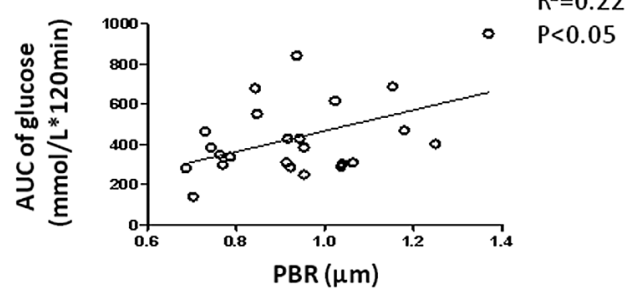
\pm SEM of PBR measured in the vessel segments with a median RBC column between 4 and $6 \mu \mathrm{m}$. *, $\mathrm{P}<0.05$ compared to CON_6w (unpaired t-test). C. Relation between the the PBR measured at baseline (X-axis) and the corresponding AUC of glucose measured during the IPGTT (Y-axis) for all individual experiments in the current study. Correlation analysis revealed a $\mathrm{R}^{2}$ of 0.22 $(\mathrm{P}<0.05)$.

\section{Intraperitoneal glucose tolerance test}

An IPGTT was performed after an overnight fast under anesthesia after 6 weeks and 18 weeks of chow or HFD. Baseline glucose levels, as well as insulin levels, were not different between the mice that received chow for 6 and 18 weeks before the IPGTT (respectively $6.1 \pm 0.2 \mathrm{mmol} / \mathrm{l}$ and $11.9 \pm 1.5 \mu \mathrm{U} / \mathrm{ml}$ after 6 weeks versus $6.0 \pm 0.4 \mathrm{mmol} / \mathrm{l}$ and $11.0 \pm 1.2 \mu \mathrm{U} / \mathrm{ml}$ after 18 weeks). Further, in contrast to the increased baseline blood glucose and plasma insulin levels in the HFD mice measured in the conscious state after a morning fast, glucose levels and insulin levels appeared not increased at baseline before the IPGTT at 6 weeks $(6.9 \pm 0.5 \mathrm{mmol} / \mathrm{l}$ and $13.3 \pm 2.4 \mu \mathrm{U} / \mathrm{ml})$ when 
mice were under anesthesia. In the 18 week HFD-fed mice baseline glucose levels were also not different $(7.2 \pm 0.5 \mathrm{mmol} / \mathrm{l})$, while insulin levels tended to be increased $(18.7 \pm$ $2.4 \mu \mathrm{U} / \mathrm{ml} ; \mathrm{p}=0.08$ ) in these mice.

After i.p. injection of glucose in the 6 weeks chow mice, blood glucose levels increased to a peak of $11.4 \pm 0.7 \mathrm{mmol} / \mathrm{l}$ after $20 \mathrm{~min}$, and then gradually returned to baseline after 120 min (Fig. 5.3A). Plasma insulin levels were increased at the first measurement (10 $\mathrm{min}$ ) and remained elevated for up to $90 \mathrm{~min}$ after the glucose injection (Fig. 5.3B). Glucose and insulin responses did not differ in the mice that were fed chow for 18 weeks. In the mice that received a HFD for 6 weeks, the peak in blood glucose was 13.1 $\pm 0.6 \mathrm{mmol} / \mathrm{l}$ and occurred after $30 \mathrm{~min}$, while similarly returning to baseline after 120 min (Fig. 5.3A). As a result, the corresponding AUC of glucose was not increased after a HFD for 6 weeks during the IPGTT $(\mathrm{P}=0.11)$. The initial insulin response after $10 \mathrm{~min}$

A)

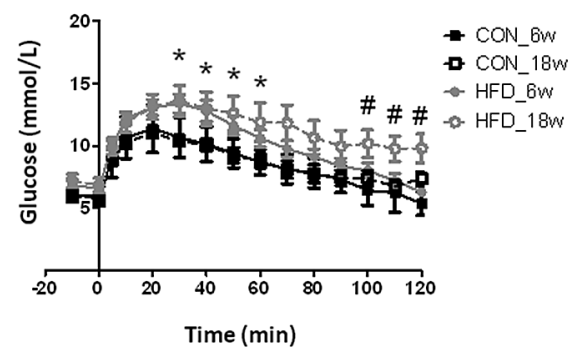

B)

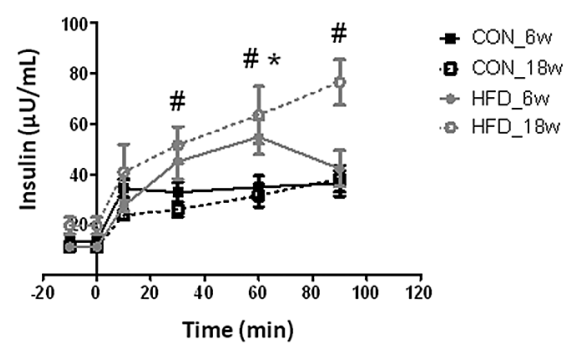

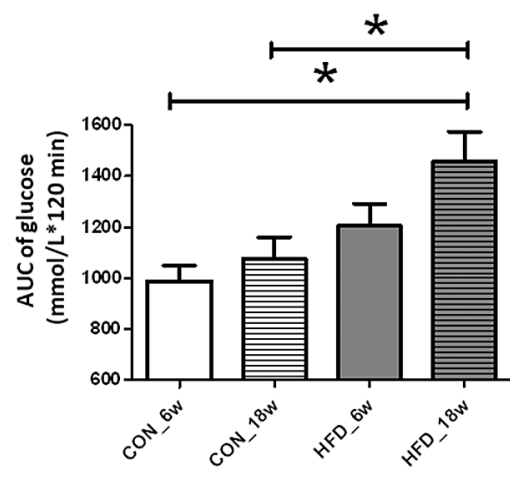
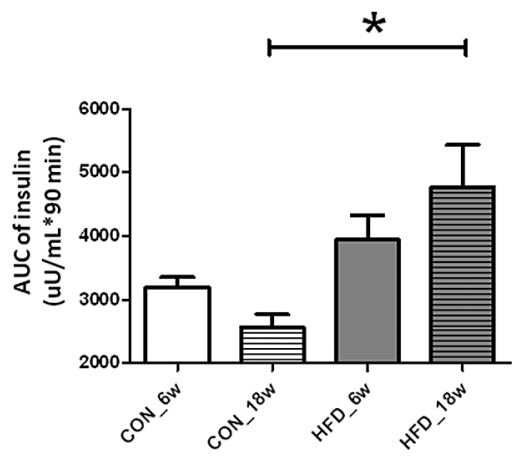

Figure 5.3 Glucose tolerance tests.

A. Mean \pm SEM of blood glucose in time after an i.p. bolus of glucose $(1 \mathrm{~g} / \mathrm{kg})$ (left panel).

As a reflection of the glucose levels during the IPGTT the total area under the curve (AUC) was calculated for the period of 0-120 minutes after glucose infusion by the linear trapezoidal rule (right panel). ${ }^{*} \mathrm{P}<0.05$, HFD_6w compared to CON_6w (unpaired t-test); \#, P<0.05, HFD_18w compared to CON_6w

B. Mean \pm SEM of plasma insulin levels in time after an i.p. bolus of glucose $(1 \mathrm{~g} / \mathrm{kg})$ (left panel). As a reflection of the insulin levels at the end of the IPGTT, the total AUC of insulin levels was calculated for the period of 0-90 minutes after glucose infusion by the linear trapezoidal rule (right panel). ${ }^{*} \mathrm{P}<0.05$, HFD_6w compared to CON_6w (unpaired t-test); \#, P<0.05, HFD_18w compared to CON_6w 
was comparable to that in chow animals; however, insulin levels further increased up to 60 minutes after glucose infusion (Fig. 5.3B), after which they decreased to a level comparable to that in chow mice after 90 minutes. After a HFD for 18 weeks, peak glucose showed a similar response as in the mice fed the HFD for 6 weeks, but the subsequent return to baseline was incomplete, resulting in increased glucose levels after $120 \mathrm{~min}$. Consequently, the AUC of glucose during the IPGTT was significantly increased in these animals $(\mathrm{P}<0.05$; Fig. 5.3A). Further, insulin levels increased gradually after the glucose administration, resulting in a significant increase in plasma insulin concentration at 30 , 60 and 90 min. $(\mathrm{P}<0.05$; Fig. 5.3B).

\section{Muscle capillary density}

No differences in muscle capillary density were observed in the mice that were fed a HFD for 6 weeks or 18 weeks, or chow for 18 weeks, compared to the mice that received chow for 6 weeks (Fig. 5.4)

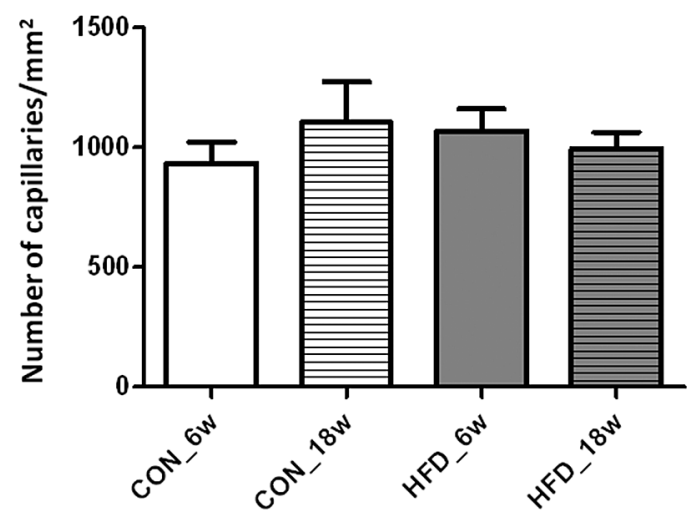

Figure 5.4 Structural capillary density. Structural capillary density was measured in paraffin-embedded hindlimb muscles of mice that were fed chow for 6 weeks $(n=4)$, chow for 18 weeks ( $n=5)$, HFD for 6 weeks $(n=4)$, or HFD for

18 weeks ( $\mathrm{n}=5$ ) using a WGA-FITC staining (see Methods.) 


\section{Discussion}

In the microcirculation, the RBC column is separated from the endothelium by a gap at both sides [17,31,32]. An important part of this cell free layer consists of the glycocalyx [33], a compartment that has been demonstrated to protect the endothelium against harmful stimuli $[4,34]$ and to control tissue delivery of insulin [20]. While it was previously shown that the dimensions of the glycocalyx were reduced in type II diabetes [17] and that severe hyperglycemic and hyperlipidemic conditions induce glycocalyx damage $[12,13,15,16]$, there is little known about the presentation of glycocalyx loss in relation to the disturbed glucose homeostasis during obesity. In the current study we assessed glycocalyx barrier properties in skeletal muscle using SDF imaging at an early and later stage of diet-induced obesity (DIO) in mice, by feeding them a HFD for 6 and 18 weeks, respectively. Glycocalyx barrier properties in hindlimb muscle microcirculation were found to be impaired after 6 weeks already. Our results suggest that in obesity glycocalyx damage represents an early aspect of microvascular dysfunction which may as well contribute to the development of glucose intolerance.

\section{Impaired glucose tolerance development in HFD-fed mice}

The HFD-fed mouse model has been used as a robust model to study the development of impaired glucose tolerance and early type II diabetes, and resembles human obesity more closely than other (genetic) mouse models. In a previous study from our group it was shown as a proof of principle that placement of C57Bl/6 and ApoE3-Leiden mice on a high fat diet for a period of 3 months was associated with loss of glycocalyx in capillaries as studied by intravital microscopy of the cremaster microcirculation [14]. By using a comparable dietary intervention we aimed in the current study to examine an early occurrence of glycocalyx damage in hindlimb muscle, and relate this to the time of development of glucose intolerance. In the HFD-fed mouse model, increases in fasting blood glucose levels and plasma insulin levels have been reported to appear already after 1 week of HFD, resulting in a stable hyperglycemia and a progressively increased hyperinsulinemia over time [22,35]. These data indicate that in this model hepatic insulin sensitivity is rapidly deteriorated and partly compensated by an increased insulin release [36,37]. In line herewith, we observed increases in blood glucose after a morning fast in the conscious animals already after 1 week of HFD feeding which were more or less constant in the following weeks, while insulin levels more slowly increased over time, becoming significantly elevated after 6 weeks of diet (Fig. 5.1). In contrast to these measurements in the conscious state, baseline glucose levels were not significantly different between the control animals and HFD-fed animals when put under anesthesia (Fig. 5.3A). This finding is in agreement with a previous study in mice, 
which used a similar type of anesthesia and HFD composition as we did in the current study; no differences in baseline glucose levels were found after feeding a HFD for 1 , 3 or 10 months in this study [35]. The authors of this study also reported increases in baseline insulin levels after feeding a HFD for 3 months. For comparison, in the current study, baseline insulin levels tended to be increased $(\mathrm{P}=0.08)$ after 18 weeks of HFD when the animals were under anesthesia.

As a measurement for muscle insulin sensitivity [37], we performed an IPGTT after 6 and 18 weeks of feeding a HFD (or chow) while the animal was under anesthesia. Although peak glucose levels were increased and delayed after 6 weeks of HFD, the recovery of blood glucose to baseline seemed not yet affected resulting in no significant increase for the AUC of blood glucose. In contrast, in the mice that received the HFD for 18 weeks the recovery of blood glucose was greatly impaired and glucose levels significantly elevated after 2 h (Fig. 5.3A), resulting in a significant increased AUC of glucose. Similarly, while insulin levels had returned to normal 90 minutes after the glucose infusion in the mice that received a HFD for 6 weeks, these were still significantly elevated in the 18 weeks of the HFD group (Fig. 5.3B). These data describe, in line with previous studies [22,35], the progressive decrease of muscle insulin sensitivity in mice upon feeding a HFD. The development of insulin resistance is accompanied by an increased insulin secretion, which initially seems to enable normal glucose tolerance to be maintained [38], yet is insufficient to compensate for the decrease in insulin sensitivity after 18 weeks of HFD, as indicated by the hyperinsulinemia yet significant glucose intolerance.

\section{Glycocalyx barrier properties in HFD-fed mice}

DIO has been associated with endothelial dysfunction, mainly measured in aortic rings and mesenteric arteries [23,24,39]. However, insulin-mediated glucose uptake occurs principally in skeletal muscle [40], where the microcirculation regulates the delivery of insulin towards the myocytes $[40,41]$. The notion is that insulin, by stimulating the endothelium, increases blood volume in the muscle capillaries and thereby facilitates its own transport towards the myocytes $[42,43]$. Consequently, an impaired microvascular insulin response due to endothelial dysfunction has been suggested to contribute to the development of insulin resistance $[44,45]$. Recently, we provided evidence that the glycocalyx plays a role in the insulin-stimulated capillary blood volume increase and associated glucose disposal [20,30]. We, therefore, tested in the current study if glycocalyx damage is relevant in the process of insulin resistance development during pro-diabetic conditions. Glycocalyx barrier properties were measured in the hindlimb muscle capillaries of obese mice by using SDF imaging and analysis of the outward variations in RBC column width $[30,46,47,48]$. In the current study, glycocalyx barrier 
properties were measured in capillaries with a median RBC column width between the 4 and $6 \mu \mathrm{m}$, which coincided with a PBR of $0.81 \pm 0.03 \mu \mathrm{m}$ in control mice. Feeding a HFD for 6 weeks caused the PBR to be significantly increased with $0.15 \pm 0.04 \mu \mathrm{m}$. In the following 12 weeks of the diet, the PBR remained elevated at this level while intolerance to glucose infusion clearly developed. These data suggest that glycocalyx damage was manifested already after 6 weeks of HFD and, based on our previous study, it is anticipated that it may have contributed to the worsening of glucose tolerance. Although a decrease in insulin sensitivity during obesity has been related to a decrease in the number of capillaries present $[40,44,45]$, we did not observe significant changes in capillary density in the hindlimb muscle of the mice that were fed a HFD for 6 or 18 weeks (Fig. 5.4). Rather than structural changes in the microcirculation of the muscle, it is suggested, therefore, that the decrease in insulin sensitivity in these mice may have resulted from an impaired insulin delivery to the myocytes due to an impaired ability to recruit capillary blood volume or to transport insulin to and across the endothelium because of the affected glycocalyx [20]. While 6 weeks was chosen as the earliest time point for assessment of glycocalyx loss during the development of DIO in the current study, earlier changes in glucose metabolism after start of the HFD, such as those reflected by the increase in fasting plasma glucose levels after one week already (Fig. 5.1C), could as well have initiated glycocalyx damage earlier in the development of DIO. Short-term hyperglycemia in itself, albeit at much higher levels than occurring in the current study, was previously shown to diminish glycocalyx barrier properties [16]. In line herewith, St Pierre et al. showed in a recent study that the ability of insulin to recruit microvascular blood volume in skeletal muscle in a rat model was already impaired after feeding a HFD for 4 weeks, and this impaired microvascular response was associated with an impaired insulin-mediated glucose uptake during an isoglycemic hyperinsulinaemic clamp [49]. In summary, the data of the present study indicate early damage to the glycocalyx, before the development of overt glucose intolerance, in a mouse model of diet-induced obesity. These findings indicate that glycocalyx damage may well underlie the reported association between endothelial dysfunction and impaired insulin action during obesity. Future studies will be needed, however, to resolve the true staging of glycocalyx damage development during DIO, and to substantiate the contribution of this damage to the development of insulin resistance and glucose intolerance. 


\section{References}

1. Kim JA, Montagnani M, Koh KK, Quon MJ (2006) Reciprocal relationships between insulin resistance and endothelial dysfunction: molecular and pathophysiological mechanisms. Circulation 113: 1888-1904.

2. Schalkwijk CG, Stehouwer CD (2005) Vascular complications in diabetes mellitus: the role of endothelial dysfunction. Clin Sci (Lond) 109: 143-159.

3. Pries AR, Secomb TW, Gaehtgens P (2000) The endothelial surface layer. Pflugers Arch 440: 653-666.

4. Reitsma S, Slaaf DW, Vink H, van Zandvoort MA, oude Egbrink MG (2007) The endothelial glycocalyx: composition, functions, and visualization. Pflugers Arch 454: 345-359.

5. Tarbell JM, Pahakis MY (2006) Mechanotransduction and the glycocalyx. J Intern Med 259: 339-350.

6. Van Teeffelen JW, Brands J, Stroes ES, Vink H (2007) Endothelial glycocalyx: sweet shield of blood vessels. Trends Cardiovasc Med 17: 101-105.

7. Nieuwdorp M, Meuwese MC, Mooij HL, Ince C, Broekhuizen LN, et al. (2008) Measuring endothelial glycocalyx dimensions in humans: a potential novel tool to monitor vascular vulnerability. J Appl Physiol 104: 845-852.

8. VanTeeffelen JW, Brands J, Jansen C, Spaan JA, Vink H (2007) Heparin impairs glycocalyx barrier properties and attenuates shear dependent vasodilation in mice. Hypertension 50 : 261-267.

9. Woodcock TE, Woodcock TM (2012) Revised Starling equation and the glycocalyx model of transvascular fluid exchange: an improved paradigm for prescribing intravenous fluid therapy. Br J Anaesth 108: 384-394.

10. Gouverneur M, Berg B, Nieuwdorp M, Stroes E, Vink H (2006) Vasculoprotective properties of the endothelial glycocalyx: effects of fluid shear stress. J Intern Med 259: 393-400.

11. Lopez-Quintero SV, Amaya R, Pahakis M, Tarbell JM (2009) The endothelial glycocalyx mediates shear-induced changes in hydraulic conductivity. Am J Physiol Heart Circ Physiol 296: H1451-1456.

12. van den Berg BM, Spaan JA, Vink H (2009) Impaired glycocalyx barrier properties contribute to enhanced intimal low-density lipoprotein accumulation at the carotid artery bifurcation in mice. Pflugers Arch 457: 1199-1206.

13. Vink H, Constantinescu AA, Spaan JA (2000) Oxidized lipoproteins degrade the endothelial surface layer : implications for platelet-endothelial cell adhesion. Circulation 101: 15001502.

14. Constantinescu A, Spaan JA, Arkenbout EK, Vink H, Vanteeffelen JW (2011) Degradation of the endothelial glycocalyx is associated with chylomicron leakage in mouse cremaster muscle microcirculation. Thromb Haemost 105: 790-801.

15. Nieuwdorp M, van Haeften TW, Gouverneur MC, Mooij HL, van Lieshout MH, et al. (2006) Loss of endothelial glycocalyx during acute hyperglycemia coincides with endothelial dysfunction and coagulation activation in vivo. Diabetes 55: 480-486. 
16. Zuurbier CJ, Demirci C, Koeman A, Vink H, Ince C (2005) Short-term hyperglycemia increases endothelial glycocalyx permeability and acutely decreases lineal density of capillaries with flowing red blood cells. J Appl Physiol 99: 1471-1476.

17. Broekhuizen LN, Lemkes BA, Mooij HL, Meuwese MC, Verberne H, et al. (2010) Effect of sulodexide on endothelial glycocalyx and vascular permeability in patients with type 2 diabetes mellitus. Diabetologia 53: 2646-2655.

18. Constantinescu AA, Vink H, Spaan JA (2003) Endothelial cell glycocalyx modulates immobilization of leukocytes at the endothelial surface. Arterioscler Thromb Vasc Biol 23: 1541-1547.

19. Noble MI, Drake-Holland AJ, Vink H (2008) Hypothesis: arterial glycocalyx dysfunction is the first step in the atherothrombotic process. QJM 101: 513-518.

20. Eskens BJM, Mooij HL, Cleutjens JPM, Roos JMA, Cobelens JE, et al. (2013) Rapid InsulinMediated Increase in Microvascular Glycocalyx Accessibility in Skeletal Muscle May Contribute to Insulin-Mediated Glucose Disposal in Rats. PLoS ONE 8: e55399.

21. Costa RR, Villela NR, Souza MG, Boa BC, Cyrino FZ, et al. (2011) High fat diet induces central obesity, insulin resistance and microvascular dysfunction in hamsters. Microvasc Res 82: 416-422.

22. Winzell MS, Ahren B (2004) The high-fat diet-fed mouse: a model for studying mechanisms and treatment of impaired glucose tolerance and type 2 diabetes. Diabetes 53 Suppl 3: S215-219.

23. Ketonen J, Pilvi T, Mervaala E (2010) Caloric restriction reverses high-fat diet-induced endothelial dysfunction and vascular superoxide production in $\mathrm{C} 57 \mathrm{Bl} / 6$ mice. Heart Vessels 25: 254-262.

24. Molnar J, Yu S, Mzhavia N, Pau C, Chereshnev I, et al. (2005) Diabetes induces endothelial dysfunction but does not increase neointimal formation in high-fat diet fed C57BL/6J mice. Circ Res 96: 1178-1184.

25. Coomans CP, Geerling JJ, Guigas B, van den Hoek AM, Parlevliet ET, et al. (2011) Circulating insulin stimulates fatty acid retention in white adipose tissue via KATP channel activation in the central nervous system only in insulin-sensitive mice. J Lipid Res 52: 1712-1722.

26. van den Berg SA, Guigas B, Bijland S, Ouwens M, Voshol PJ, et al. (2010) High levels of dietary stearate promote adiposity and deteriorate hepatic insulin sensitivity. Nutr Metab (Lond) 7: 24.

27. Zuurbier CJ, Keijzers PJ, Koeman A, Van Wezel HB, Hollmann MW (2008) Anesthesia's effects on plasma glucose and insulin and cardiac hexokinase at similar hemodynamics and without major surgical stress in fed rats. Anesth Analg 106: 135-142, table of contents.

28. Goedhart PT, Khalilzada M, Bezemer R, Merza J, Ince C (2007) Sidestream Dark Field (SDF) imaging: a novel stroboscopic LED ring-based imaging modality for clinical assessment of the microcirculation. Opt Express 15: 15101-15114.

29. Diehl KH, Hull R, Morton D, Pfister R, Rabemampianina Y, et al. (2001) A good practice guide to the administration of substances and removal of blood, including routes and volumes. J Appl Toxicol 21: 15-23. 
30. Vlahu CA, Lemkes BA, Struijk DG, Koopman MG, Krediet RT, et al. (2012) Damage of the endothelial glycocalyx in dialysis patients. J Am Soc Nephrol 23: 1900-1908.

31. Henry CB, Duling BR (1999) Permeation of the luminal capillary glycocalyx is determined by hyaluronan. Am J Physiol 277: H508-514.

32. Vink H, Duling BR (1996) Identification of distinct luminal domains for macromolecules, erythrocytes, and leukocytes within mammalian capillaries. Circ Res 79: 581-589.

33. Kim S, Ong PK, Yalcin O, Intaglietta M, Johnson PC (2009) The cell-free layer in microvascular blood flow. Biorheology 46: 181-189.

34. van den Berg BM, Vink H, Spaan JA (2003) The endothelial glycocalyx protects against myocardial edema. Circ Res 92: 592-594.

35. Ahren B, Pacini G (2002) Insufficient islet compensation to insulin resistance vs. reduced glucose effectiveness in glucose-intolerant mice. Am J Physiol Endocrinol Metab 283: E738744.

36. Del Prato S, Marchetti P, Bonadonna RC (2002) Phasic insulin release and metabolic regulation in type 2 diabetes. Diabetes 51 Suppl 1: S109-116.

37. Nathan DM, Davidson MB, DeFronzo RA, Heine RJ, Henry RR, et al. (2007) Impaired fasting glucose and impaired glucose tolerance: implications for care. Diabetes Care 30: 753-759.

38. Bergman RN, Ader M, Huecking K, Van Citters G (2002) Accurate assessment of beta-cell function: the hyperbolic correction. Diabetes 51 Suppl 1: S212-220.

39. Sachidanandam K, Hutchinson JR, Elgebaly MM, Mezzetti EM, Wang MH, et al. (2009) Differential effects of diet-induced dyslipidemia and hyperglycemia on mesenteric resistance artery structure and function in type 2 diabetes. J Pharmacol Exp Ther 328: 123130.

40. Baron AD (1994) Hemodynamic actions of insulin. Am J Physiol 267: E187-202.

41. Rattigan S, Richards SM, Keske MA (2013) Microvascular contributions to insulin resistance. Diabetes 62: 343-345.

42. Barrett EJ, Wang H, Upchurch CT, Liu Z (2011) Insulin regulates its own delivery to skeletal muscle by feed-forward actions on the vasculature. Am J Physiol Endocrinol Metab 301: E252-263.

43. Vincent MA, Clerk LH, Lindner JR, Klibanov AL, Clark MG, et al. (2004) Microvascular recruitment is an early insulin effect that regulates skeletal muscle glucose uptake in vivo. Diabetes 53: 1418-1423.

44. Clark MG (2008) Impaired microvascular perfusion: a consequence of vascular dysfunction and a potential cause of insulin resistance in muscle. Am J Physiol Endocrinol Metab 295: E732-750.

45. de Jongh RT, Serne EH, RG IJ, de Vries G, Stehouwer CD (2004) Impaired microvascular function in obesity: implications for obesity-associated microangiopathy, hypertension, and insulin resistance. Circulation 109: 2529-2535.

46. Donati A, Damiani E, Domizi R, Romano R, Adrario E, et al. (2013) Alteration of the sublingual microvascular glycocalyx in critically ill patients. Microvasc Res. 
47. Martens RJ, Vink H, van Oostenbrugge RJ, Staals J (2013) Sublingual microvascular glycocalyx dimensions in lacunar stroke patients. Cerebrovasc Dis 35: 451-454.

48. Mulders TA, Nieuwdorp M, Stroes ES, Vink H, Pinto-Sietsma SJ (2013) Non-invasive assessment of microvascular dysfunction in families with premature coronary artery disease. Int J Cardiol.

49. St-Pierre P, Genders AJ, Keske MA, Richards SM, Rattigan S (2010) Loss of insulin-mediated microvascular perfusion in skeletal muscle is associated with the development of insulin resistance. Diabetes Obes Metab 12: 798-805. 


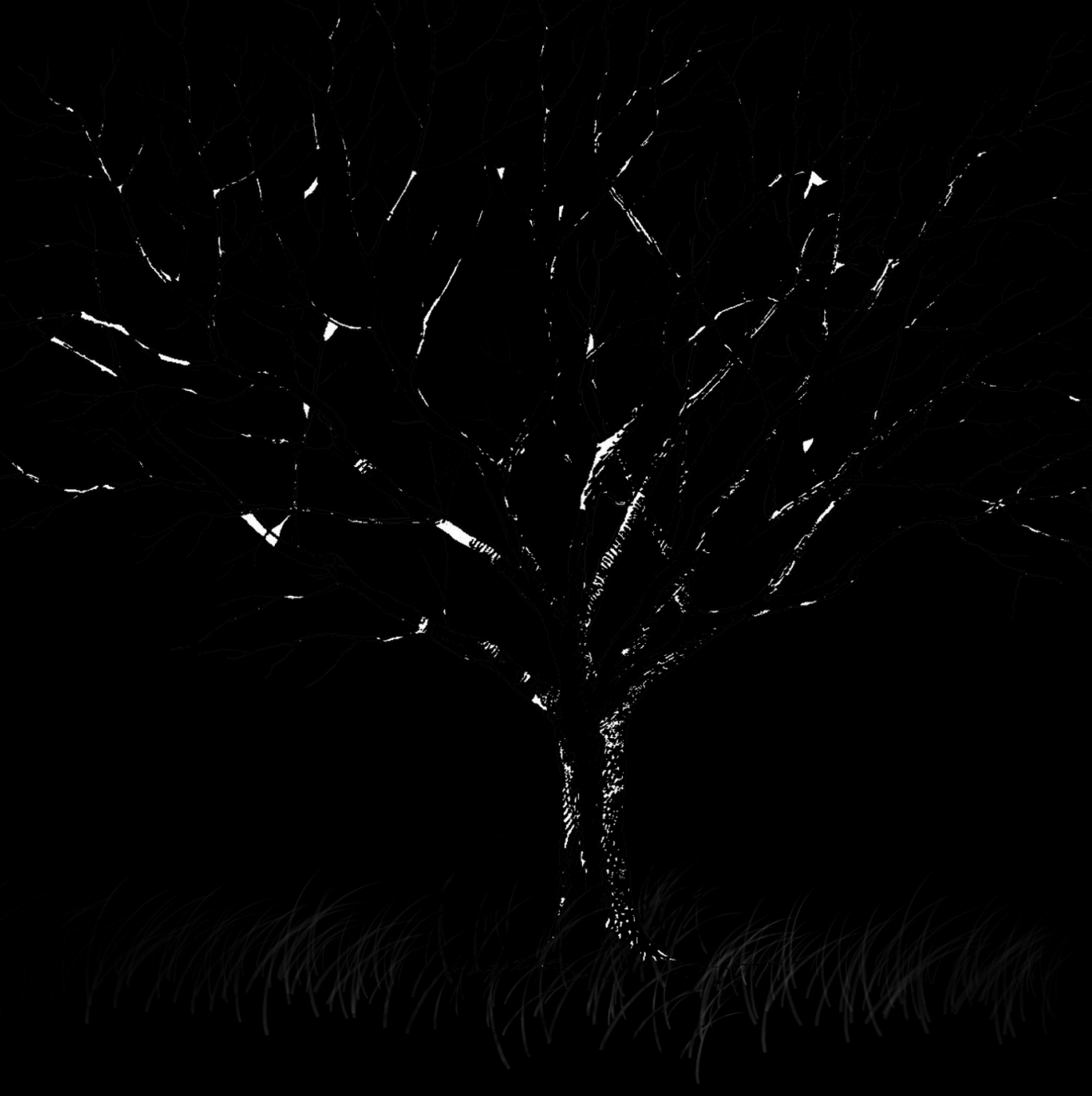


Chapter 6

\title{
Effects of two weeks of metformin treatment on whole-body glycocalyx barrier properties in $\mathbf{d b} / \mathbf{d b}$ mice
}

\author{
Bart J.M. Eskens \\ Coert J Zuurbier \\ Judith van Haare \\ Hans Vink \\ Jurgen W.G.E. VanTeeffelen
}

In adapted form published in Cardiovascular Diabetology. 2013 Dec 5;12:175 (Published online before print) 


\section{Abstract}

The anti-diabetic drug metformin has been demonstrated to exert a protective effect against vascular complications in diabetes independent of its glucose lowering action. Since the endothelial glycocalyx has been indicated to have important vasculoprotective properties and to be vulnerable to degradation by hyperglycemic conditions, we evaluated in the current study the effect of short-term metformin treatment on wholebody glycocalyx barrier properties in a mouse model of type II diabetes ( $\mathrm{db} / \mathrm{db}$ mouse). Glycocalyx barrier properties were measured in an acute experiment in three groups of mice: 1) db/db mice without treatment serving as controls, 2) db/db mice which received metformin for two weeks in the drinking water serving as experimental group, and 3) C57Bl/6 mice serving as reference group. Animals were put under anesthesia (ketamine, medetomidine, atropine) and carotid artery blood pressure was continuously monitored. To probe the glycocalyx a mixture of the tracers FITC-labeled $70 \mathrm{kDa}$ dextrans (Dex70) or fluorescein-labeled red blood cells (RBCs) versus Texas Red-labeled $40 \mathrm{kDa}$ dextrans (Dex40) was infused and blood samples subsequently collected for $30 \mathrm{~min}$ to determine the initial vascular distribution volume and clearance of these tracers. Urine was collected and dry-to-wet weight of heart and kidney were determined after the experiment. Group differences were tested using unpaired t-tests. Metformin treatment did not affect body weight, fasting blood glucose and arterial blood pressure. Compared to $\mathrm{C} 57 \mathrm{Bl} / 6$ mice, $\mathrm{db} / \mathrm{db}$ mice showed a diminished initial exclusion and increased vascular clearance of Dex70 versus Dex40 $(\mathrm{P}<0.05)$, and both were improved by the metformin treatment $(\mathrm{P}<0.05)$. While urine production was higher in the $\mathrm{db} / \mathrm{db}$ mice compared to $\mathrm{C} 57 \mathrm{Bl} / 6(\mathrm{P}<0.05)$, heart and kidney of the metformin treated animals showed comparable dry-to-wet weights compared to the C57Bl/6 mice. Two weeks of metformin in the drinking water is associated with an improvement in glycocalyx barrier properties in $\mathrm{db} / \mathrm{db}$ mice, as evidence by an enhanced exclusion and retention of $70 \mathrm{kDa}$ dextrans in the vasculature and improved hydration of heart and kidney. Previous reported cardiovascular benefits of metformin may well involve an improvement of the endothelial glycocalyx. 


\section{Introduction}

Metformin (dimethylbiguanide) is an orally administered insulin-sensitizing drug used to lower blood glucose concentrations in patients with non-insulin dependent diabetes mellitus (NIDDM) [1,2]. Compared with other biguanides, metformin expresses the best balance of potent activity and low toxicity. It is the most popular anti-diabetic drug in the United States and one of the most prescribed drugs in this country. The insulinsensitizing effect of metformin has been suggested to be the result of many actions, including an increased insulin-mediated glucose disposal, increased translocation of glucose transporters, suppressed hepatic glucose output, increased intestinal glucose use and decreased fatty-acid oxidation $[1,3,4]$. In addition to its glucose lowering effects, metformin has been found to exhibit beneficial cardiovascular effects in patients with NIDMM [5,6]. A major benefit seems to involve alleviation of endothelial dysfunction $[7,8]$ as metformin was for example demonstrated to increase NO bioavailability [9]. As a result, it is considered that metformin has vasculoprotective properties [10], but the mechanisms behind these actions are not completely understood at the moment.

The endothelial glycocalyx is the polysaccharide rich, gel-like layer located at the luminal side of all blood vessels, which has been demonstrated the last decades to be a gatekeeper of the vascular wall by regulating many aspects of endothelial function $[11,12,13]$. In various experimental models, enzymatic glycocalyx treatment was shown to reduce shear stress dependent NO production [14], to increase leukocyte and platelet adherence to the endothelium $[15,16]$, and to increase fluid and protein leakage across the vasculature $[17,18]$. Recent studies from our laboratory showed that hyperglycemic conditions in humans (i.e., 6 h of a hyperglycemic clamp in healthy controls [19], type 1 [20] and 2 diabetics [21]) were associated with reduced glycocalyx dimensions and/or an increased release of glycocalyx constituents in plasma. These indications that high glucose levels induce the loss of glycocalyx barrier properties in humans were preceded by an experimental study in mice, in which it was shown that the vascular retention of $70 \mathrm{kDa}$ dextrans, considered as a plasma tracer whose access into the glycocalyx is significantly limited, was impaired during acute hyperglycemia in healthy animals and during chronic hyperglycemia in the $\mathrm{db} / \mathrm{db}$ model of NIDDM [22]. The loss of glycocalyx barrier properties was accompanied by a disturbed fluid balance, as reflected by dehydration of heart and kidney, and significant increases in systematic hematocrit and urine production [22].

Given the vasculoprotective effects of metformin on the one hand, and the indicated role of the glycocalyx in orchestrating vascular wall homeostasis on the other hand, we hypothesize that metformin may improve glycocalyx properties in NIDDM. We tested this hypothesis in the current study in the $\mathrm{db} / \mathrm{db}$ mouse model of NIDDM by determining 
whole-body volume distribution of circulating plasma and $70 \mathrm{kDa}$ dextrans versus 40 $\mathrm{kDa}$ dextrans and the vascular retention of both dextrans [23] after administration of metformin in the drinking water for 2 weeks. In addition, the effect of metformin on the whole-body fluid balance was evaluated by measurements of hematocrit, urine production, and kidney and heart hydration [22]. The data of the current study indicate that short-term metformin treatment in a mouse model of NIDDM is associated with improved glycocalyx barrier properties and tissue hydration. 


\section{Methods}

\section{Animals \& treatments}

All procedures were in accordance with requirements of the Animal Ethics Care and Use committee of the Academic Medical Center in Amsterdam. Experiments were performed on male $\mathrm{db} / \mathrm{db}$ and $\mathrm{C} 57 \mathrm{Bl} / 6$ mice which were obtained from Harlan (Horst, the Netherlands) at an age of 5 weeks. After arrival from the supplier, $\mathrm{db} / \mathrm{db}$ mice $(n=20)$ received standard chow and water ad libitum for two weeks. Then, after an overnight fast $\mathrm{db} / \mathrm{db}$ mice were weighed and a blood sample collected via puncture of the saphenous vein for determination of blood glucose concentration with a glucose meter (Ascensia Contour). Db/db mice were subsequently divided into two groups: the experimental group $(n=10)$ received metformin in their drinking water $(0.33$ $\mathrm{mg} / \mathrm{ml}$ ) for two weeks until the acute experiment, while the control group $(\mathrm{n}=10)$ maintained receiving normal drinking water for this period. For $n=6$ animals in each group, daily intake of water was estimated by weighing of the water bottle every day; as a consequence, these animals were housed in groups of two mice per cage. Midway the treatment period, body weights and fasting blood glucose were measured for the second time in the $\mathrm{db} / \mathrm{db}$ mice. $\mathrm{C} 57 \mathrm{Bl} / 6$ mice $(\mathrm{n}=10)$ receiving normal drinking water served as reference group; no measurements were performed in these animals until the acute experiment.

\section{Acute experiment}

Mice were overnight fasted. Preparation of the animals on the day of experiment was as described previously [23]. Briefly, the mice were anesthetized with ketamine (125 mg/ $\mathrm{kg})$-medetomidine $(0.2 \mathrm{mg} / \mathrm{kg})$-atropine $(0.5 \mathrm{mg} / \mathrm{kg})$. A tracheotomy was performed and mechanical ventilation was started by connecting the trachea tube to a pressurecontrolled ventilator (SAR-830/P; CWE). Animals were ventilated with a gas mixture of $1: 1 \mathrm{O}_{2}: \mathrm{N}_{2}$. Respiration was set at 90 breaths/min with a peak inspiratory pressure of $18 \mathrm{cmH}_{2} \mathrm{O}$ and a positive end-expiratory pressure of $2 \mathrm{cmH}_{2} \mathrm{O}$. Depth of anesthesia was maintained according to stability of blood pressure and lack of toe pinch reflex by continuous i.p. infusion at a rate of $10 \mathrm{ml} / \mathrm{kg} / \mathrm{h}$ of ketamine $(3.5 \mathrm{mg} / \mathrm{ml})$, medetomidine $(20 \mu \mathrm{g} / \mathrm{ml})$ and atropine $(7.5 \mu \mathrm{g} / \mathrm{ml})$. The carotid artery and jugular vein were cannulated for monitoring blood pressure and heart rate, and for infusion purposes, respectively. Temperature was controlled at $37^{\circ} \mathrm{C}$ using rectal temperature monitoring, a temperature-controlled heating pad and an infrared lamp. After instrumentation, an equilibration period of $30 \mathrm{~min}$ was allowed. A blood sample was taken from the tail for measurement of blood glucose. 
To delineate the glycocalyx barrier properties, a bolus injection of two distinct tracers was administered, and their dilution in blood measured for 30 min [22,23,24,25]. In each mouse, the distribution volume of either FITC-labelled $70 \mathrm{kDa}$ dextrans (Dex70; Sigma-Aldrich) ( $n=5$ per group) or circulating plasma ( $n=5$ per group) as glycocalyxhindered tracer was compared to that of simultaneously infused Texas Red-labelled $40 \mathrm{kDa}$ dextrans (Dex40; Invitrogen-Molecular Probes), which are considered to have unlimited access to the entire intraluminal volume $[23,26] .0 .1 \mathrm{ml}$ of dextran mix $(2.5$ $\mathrm{mg} / \mathrm{ml}$ Dex70 + $10 \mathrm{mg} / \mathrm{ml}$ Dex40 in phosphate-buffered saline) was manually infused in the jugular vein in $1 \mathrm{~min}$, and blood was subsequently sampled (30 $\mu \mathrm{l}$ ) through tail bleeding at $\mathrm{t}=-5$ (pre), 2, 5, 10, 15, 20, and $30 \mathrm{~min}$ after start of the tracer infusion. Circulating plasma was derived from the dilution of fluorescein-labelled red blood cells (RBCs) and large vessel hematocrit $[20,23,25]$. Thereto, blood $(\sim 1 \mathrm{ml})$ was collected from a donor mouse ( $\mathrm{C} 57 \mathrm{Bl} / 6)$ by cardiac punction, centrifuged, and the RBCs labelled with sodium fluorescein $(250 \mathrm{mg} / \mathrm{ml}$ ) for $5 \mathrm{~min}$. After washing, the labelled cells were resuspended in saline to the initial volume; two min before infusion, $0.1 \mathrm{ml}$ of the labelled blood was mixed with an equal volume of Dex $40(15 \mathrm{mg} / \mathrm{ml})$ and $0.1 \mathrm{ml}$ of this tracer mix was infused in the animal in $1 \mathrm{~min}$. Blood samples ( $5 \mu \mathrm{l})$ were collected in heparinized capillaries through tail bleeding at $\mathrm{t}=-5$ (pre), and 2, 3, 4, and 5 min after start of the infusion for determination of the fraction of labelled RBCs, while in addition $30 \mu \mathrm{l}$ samples were collected in $\sim 30 \mathrm{~s}$ at $\mathrm{t}=-5$ (pre), 2, 5, 10, 15, 20, and $30 \mathrm{~min}$ for determination of Dex40 concentrations.

In each mouse, urine production was assessed by collecting visibly excreted urine during the duration of the experiment in a capillary tube together with the remaining urine content in the bladder right after the mouse had been euthanized (at $\mathrm{t}=35 \mathrm{~min}$ ) $[22,23]$. In addition, the heart and the kidneys were collected after the experiment, blotted, and their wet weight measured [22]. Tissues were stored at $70^{\circ} \mathrm{C}$ for three days, and then weighed again for obtaining dry weight.

\section{Tracer analysis}

Labeled RBCs were measured using a FACScan analyzer (FACSCalibur; Becton Dickinson, Mountain View, CA), with at least 100,000 cells being counted to measure the circulating fraction of labeled cells $[20,23,25]$. Data were analyzed using Cellquest (Becton Dickinson, San Jose, CA). The circulating plasma volume was calculated as [(1 - Ht) x Vrbc] / Ht, where $V r b c$ is the circulating red blood cell volume ([1/circulating fraction of labelled RBCs] x volume of labelled cells injected) and $H t$ is the large vessel hematocrit $[20,23,25]$. The fraction of labeled cells at $t=2,3,4,5 \mathrm{~min}$ was averaged and used as circulating fraction; unlabeled erythrocytes obtained before the injection $(t=-5$ 
min) served as negative controls. The sum of both circulating RBC and plasma volume revealed total blood volume.

For the blood samples containing dextrans, capillaries were centrifuged, hematocrit was determined, and plasma collected and stored at $-20^{\circ} \mathrm{C}$ until fluorescence analysis. In each sample, fluorescence was measured at 490/535 nm (excitation/ emission) for the Dex70 and at 595/615 nm for Dex40 with a spectrophotometer (VICTOR; PerkinElmer) and dextran concentrations calculated in reference to defined dilutions of the infused tracer mix in plasma from donor mice $[22,23,24,25]$. Concentrations were normalized to the amount injected. For Dex70, the time-concentration curve was fitted with a monoexponential function $[22,23,24,25]$, and the initial distribution volume determined from the extrapolated dilution at the start of tracer injection. For Dex40, linear extrapolation of the concentration between $\mathrm{t}=2$ and $\mathrm{t}=5 \mathrm{~min}$ to the start of injection was used, because this dextran has been indicated to rapidly egress from the circulation [23]. Vascular clearance was defined as the percentage decrease in dextran concentration the end of the experiment ( $\mathrm{t}=30 \mathrm{~min}$ ) compared to the extrapolated concentration at the start of tracer injection ( $\mathrm{t}=0 \mathrm{~min}$ ) $[23,24]$.

Urine samples were stored at $-20^{\circ} \mathrm{C}$ until analysis when dextran concentrations were calculated in reference to defined dilutions of the infused tracer mix in urine from donor mice. The percentage dextran recovery in the urine in an experiment was determined from the total volume of urine sampled and its dextran concentration, normalized to the amount injected [23].

\section{Statistics}

Summary data are reported as means \pm SEM. Because of the differences in body weight between $\mathrm{db} / \mathrm{db}$ and $\mathrm{C} 57 \mathrm{Bl} / 6$ mice, tracer distribution volumes were normalized for body weight. Differences between the metformin-treated mice and control db/db mice, as well as the reference $\mathrm{C} 57 \mathrm{Bl} / 6$ mice, were evaluated using unpaired t-tests. Results were considered statistically significant with $P \leq 0.05$. 


\section{Results}

At an age of 7 weeks, db/db mice were divided in a control group which continued with normal drinking water for two weeks and an experimental group which received metformin at a concentration of $0.33 \mathrm{mg} / \mathrm{ml}$ in the drinking water for the same period. Daily water intake was $32.4 \pm 2.5$ and $37.7 \pm 0.9 \mathrm{ml} / 100 \mathrm{~g}$ body weight in the control and metformin-treated $\mathrm{db} / \mathrm{db}$ mice, respectively $(\mathrm{P}=0.08)$. Body weight and fasting blood glucose were weekly measured, and were not affected by the metformin (Figure 6.1).
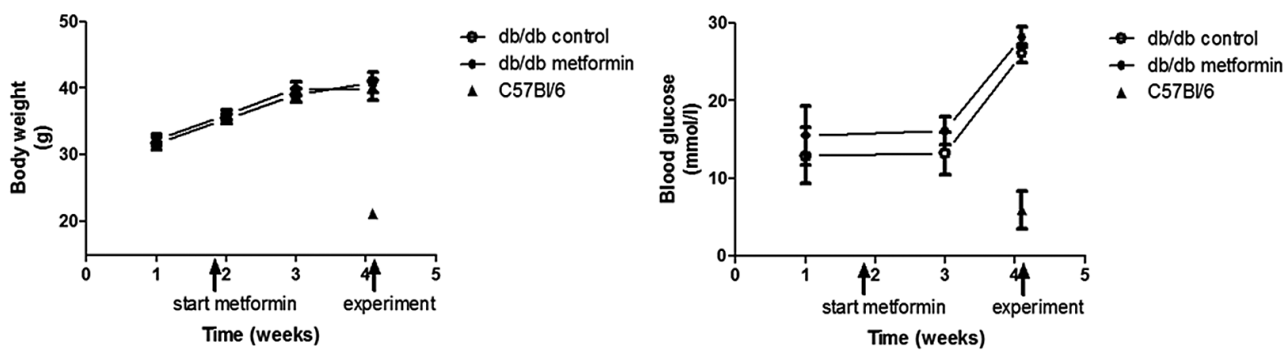

Figure 6.1 Body weights and blood glucose levels.

Top: body weight was measured every week in the $\mathrm{db} / \mathrm{db}$ mice $(\mathrm{n}=20)$. The first measurement (week 1$)$ was at an age of 6 weeks. One week later the control group $(n=10)$ continued with normal drinking water while the experimental group $(n=10)$ started with the metformin in the water for two weeks until the acute experiment (week 4). C57Bl/6 mice ( $\mathrm{n}=10)$ were used as reference group in the acute experiment.

Bottom: blood glucose in the $\mathrm{db} / \mathrm{db}$ mice was measured one week before and one week after start of the metformin, as well as during the acute experiment. The sharp rise in glucose during the acute experiment is likely explained by the anesthetic conditions

After two weeks, glycocalyx barrier properties were measured in an acute experiment. Blood glucose during the experiment was found to be similarly elevated in both groups of $\mathrm{db} / \mathrm{db}$ mice compared to the earlier measurements in the awake animals (Figure 6.1), likely as a result of the anesthesia. While blood pressures were higher in the $\mathrm{db} / \mathrm{db}$ mice compared to the $\mathrm{C} 57 \mathrm{Bl} / 6$ mice during the experiment, they did not differ between the metformin and control group (Figure 6.2). Heart rates were comparable between the three groups of mice (Figure 6.2).
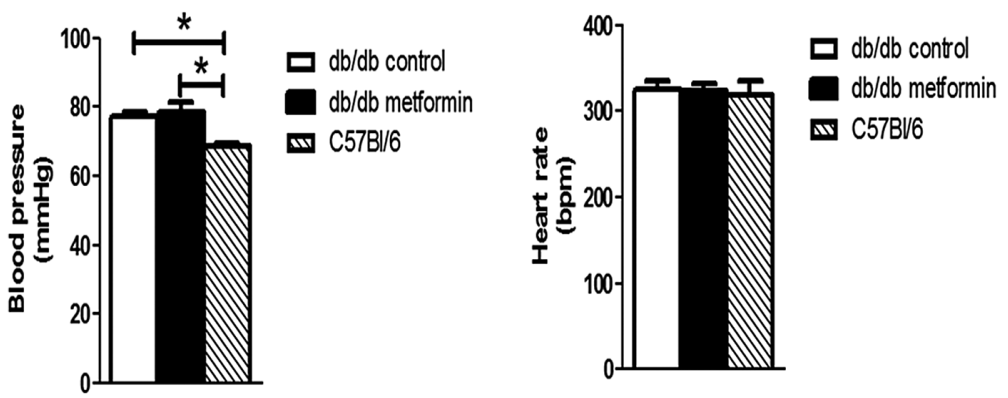

Figure 6.2 Hemodynamics.

Carotid artery blood pressure (left) and heart rate (right) were measured continuously in the anesthetized mice during the acute experiment. Values represent average pressure/rate for the entire duration of the experiment (from $\mathrm{t}=-10 \mathrm{~min}$ until $\mathrm{t}=30 \mathrm{~min}$ ). ${ }^{*}, \mathrm{P}<0.05$ versus $\mathrm{C} 57 \mathrm{Bl} / 6$ mice. 
Whole-body distribution volumes (normalized to body weight) of the different tracers are shown in Figure 6.3A. Hematocrits (in \%) were not different between the three groups (control db/db: $45.8 \pm 2.8$; metformin db/db: $45.0 \pm 3.1$; C57Bl/6: $44.0 \pm 3.8$ ). As shown in our previous studies $[23,25]$, distribution volumes were lower for circulating plasma, derived from the dilution of labeled RBCs and hematocrit, compared to the dextrans (Figure 6.3A). Distribution volumes for all considered tracers were lower in the $\mathrm{db} / \mathrm{db}$ compared to the $\mathrm{C} 57 \mathrm{Bl} / 6$, and did not differ between the metformin treated and control db/db groups (Figure 6.3A). Glycocalyx-excluded volume for plasma and Dex70, derived from the individual differences in Dex40 distribution volume versus those for circulating plasma and Dex70, respectively, are shown in Figure 6.3B. In line with our previous study [23], exclusion volume for plasma was larger than for Dex70 in all animal groups. While exclusion for plasma was not affected in the metformin treated animals, exclusion volume for Dex70 was significantly improved in this group, and not different from the $\mathrm{C} 57 \mathrm{Bl} / 6$ animals anymore.
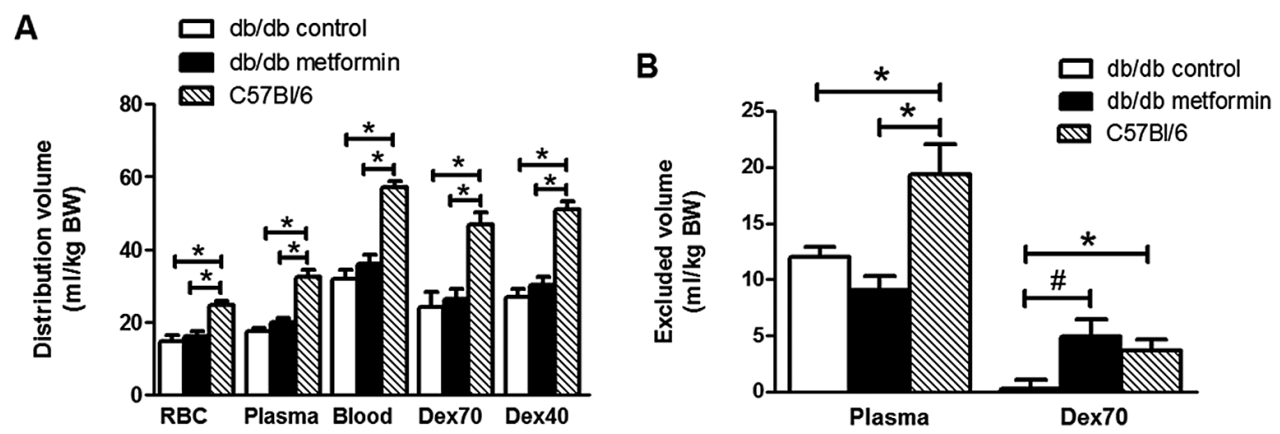

Figure 6.3 Systemic (glycocalyx excluded) distribution volumes.

A: systemic volumes of distribution (normalized to body weight) of circulating blood, i.e., the sum of red blood cell (RBC) and plasma volume (derived from RBC space and hematocrit), and 70 (Dex70) (both $n=5$ per group) and $40 \mathrm{kDa}$ dextrans (Dex40) ( $\mathrm{n}=10$ per group). ${ }^{*}, \mathrm{P}<0.05$ versus $\mathrm{C} 57 \mathrm{Bl} / 6$ mice

B: whole-body glycocalyx volumes for circulating plasma and Dex70 (both $n=5$ per group), calculated from the difference between their respective distribution volume versus that of Dex $40 .{ }^{*}, \mathrm{P}<0.05$ compared to $\mathrm{C} 57 \mathrm{Bl} / 6$ mice; \#, $\mathrm{P}<0.05$ metformin versus control $\mathrm{db} / \mathrm{db}$.

Dextran clearance data are shown in Figure 6.4. In line with previous studies [22,23,24], vascular clearance of Dex40 was larger than that of Dex70, yet was not different between the three animal groups. Vascular clearance of Dex70 was higher in the $\mathrm{db} /$ $\mathrm{db}$ mice compared to the $\mathrm{C} 57 \mathrm{Bl} / 6$ mice, and tended to decrease after treatment with metformin (38 $\pm 5 \%$ of injected Dex70 cleared in $30 \mathrm{~min}$ in control $\mathrm{db} / \mathrm{db}$ versus 28 $\pm 1 \%$ in metformin treated group $(\mathrm{p}=0.086)$ ) (Figure $6.4 \mathrm{~A}$, left). When accounting for individual differences in Dex40 clearance rate [24], Dex70 clearance was significantly 
decreased in the metformin treated $\mathrm{db} / \mathrm{db}$ compared to the control $\mathrm{db} / \mathrm{db}$ mice, but still much larger than in the $\mathrm{C} 57 \mathrm{Bl} / 6$ mice (Figure 6.4A, right).

The diminished vascular clearance of Dex70 compared to Dex40 in the metformin treated mice appeared not associated with a reduction in the amount of Dex70 excreted in the urine at the end of the experiment. Thus, about $15 \%$ of the injected amount of Dex70 was detected in the urine of both groups of $\mathrm{db} / \mathrm{db}$ mice, which was about double $(\mathrm{P}<0.05)$ of that found in the urine of the $\mathrm{C} 57 \mathrm{Bl} / 6$ mice (Figure $6.4 \mathrm{~B}$, left). Similar to the vascular clearance characteristics, the amount of Dex40 retrieved in urine was higher than that of Dex70, i.e., about 35-40\% of the injected amount, and comparable for all three animal groups (Figure 6.4B, left). When correcting for differences in Dex40 recovery between individual animals, no differences were found in the amount of Dex70 retrieved in urine at the end of the experiment.

\section{A}
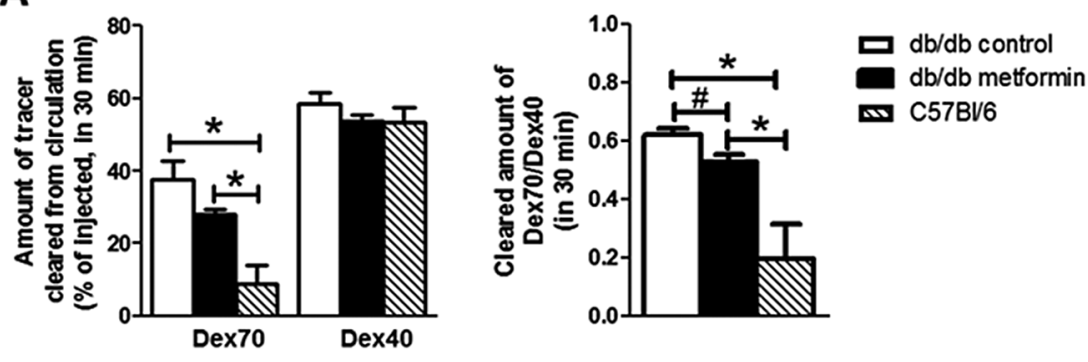

B
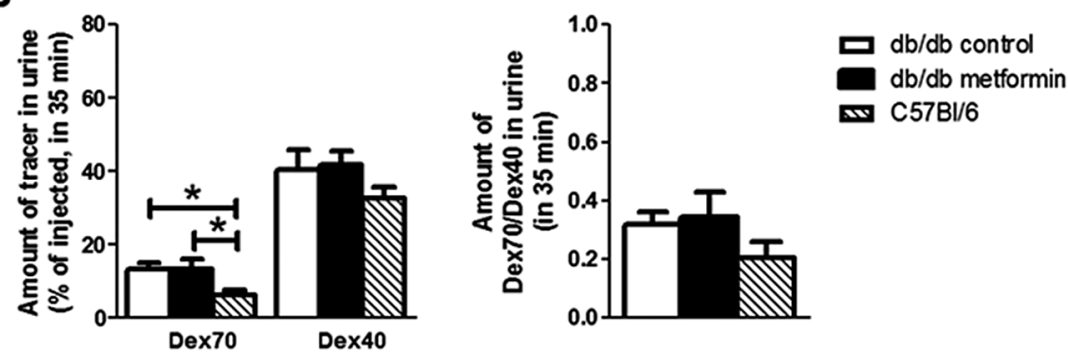

Figure 6.4 Vascular clearance and urine appearance of dextrans.

A. Left. Calculated amount of 70 (Dex70) and $40 \mathrm{kDa}$ dextran (Dex40) cleared from the circulation after injection ( $\mathrm{t}=0 \mathrm{~min}$ ) until the last time point of blood sampling ( $\mathrm{t}=30 \mathrm{~min}$ ). Right: cleared amount of Dex70 divided by Dex40. *, $\mathrm{P}<0.05$ compared to C57Bl/6 mice; \#, $\mathrm{P}<0.05$ metformin versus control db/db.

B. Left. Measured amount of dextran in urine collected during the experiment and in bladder after euthanization of the animal ( $\mathrm{t}=35 \mathrm{~min})$. Right: urine amount of Dex70 divided by Dex40. *, $\mathrm{P}<0.05$ compared to $\mathrm{C} 57 \mathrm{Bl} / 6$ mice.

The collected urine volumes were not different between the control and metformin treated $\mathrm{db} / \mathrm{db}$ mice, and both were larger than in the $\mathrm{C} 57 \mathrm{Bl} / 6$ mice (Figure 6.5A). 
To evaluate organ hydration, the dry-to-wet weight ratio for heart and kidneys were determined [22]. Higher dry-to-wet weight ratio's, reflecting a decreased water content, were found for both tissues of the control $\mathrm{db} / \mathrm{db}$ mice versus $\mathrm{C} 57 \mathrm{Bl} / 6$ mice. In contrast, the ratios of the metformin treated $\mathrm{db} / \mathrm{db}$ mice were not different from those of the $\mathrm{C} 57 \mathrm{Bl} / 6$ mice (Figure 6.5B); the beneficial effect of metformin appeared larger in the heart than in the kidney.

A

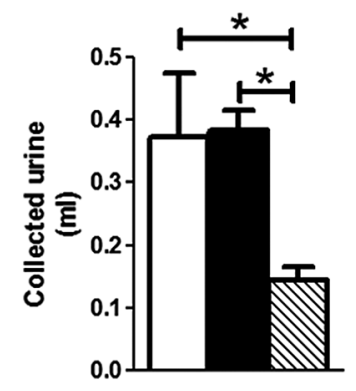

B

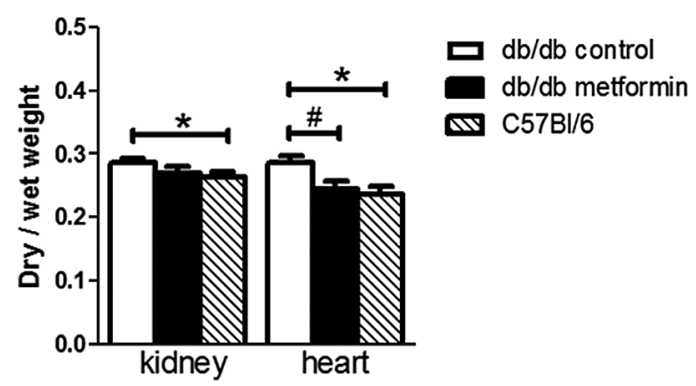

Figure 6.5 Urine production and tissue hydration.

A. Urine volumes collected during the experiment and in bladder after euthanization of the animal $(\mathrm{t}=35$ min). *, $\mathrm{P}<0.05$ compared to $\mathrm{C} 57 \mathrm{Bl} / 6$ mice.

B. Dry-to-wet weight ratios. Heart and kidneys were collected after the experiment and their wet weight measured, after which organs were stored at $70^{\circ} \mathrm{C}$ for three days, and then weighed again for obtaining dry weight. *, $\mathrm{P}<0.05$ compared to $\mathrm{C} 57 \mathrm{Bl} / 6$ mice; \#, $\mathrm{P}<0.05$ metformin versus control db/db. 


\section{Discussion}

In the present study we showed that metformin treatment for 2 weeks in $\mathrm{db} / \mathrm{db}$ mice resulted in an improvement of the endothelial glycocalyx barrier properties in the circulation as evidenced by the increased whole-body exclusion volume of Dex70 compared to Dex40 and enhanced vascular retention of Dex70 compared to Dex40. This improvement coincided with an improved hydration of heart and kidney in these mice. The two week treatment with metformin did not significantly affect blood glucose levels, indicating that the effects of metformin occurred independent from a change in fasting glucose. These data suggest that the previous reported cardiovascular benefits of metformin may involve an improvement of the endothelial glycocalyx.

\section{Short-term metformin does not affect blood glucose}

Metformin has been famed for its protective effect against vascular complications in NIDDM independent of its glycemic lowering action [5,6]. Improvement of endothelial function has been considered to contribute to metformin's vasculoprotective effect [9], as treatment was shown to improve endothelium-dependent vasodilation and microvascular reactivity in humans $[7,27]$. Because the endothelial glycocalyx has been indicated to play a major role in protection of the endothelium and regulation of its functions $[11,12]$, we were interested in the current study whether metformin would improve the recently reported glycocalyx perturbation in $\mathrm{db} / \mathrm{db}$ mice [22]. Because changes in blood glucose itself have been shown to affect glycocalyx properties [19,22], we aimed in the present study to limit the blood-glucose lowering effect of metformin by treating the mice for a short period of time only at a relatively mild dose of the drugs. Indeed, we did not observe a reduction in blood glucose levels in the metformin treated $\mathrm{db} / \mathrm{db}$ mice compared to the control $\mathrm{db} / \mathrm{db}$ mice. Water intake during metformin administration was $\sim 35 \mathrm{ml} / 100 \mathrm{~g} /$ day (see Results), which with the dose of $0.33 \mathrm{mg} /$ $\mathrm{ml}$ agrees with an average metformin intake of $\sim 100 \mathrm{mg} / \mathrm{kg}$ per day. In previous studies in mice, it was shown that higher doses of metformin (150-250 mg/kg/day) for a longer period of time (4 weeks) did lower blood glucose levels [28,29]. Also, contrasting to previous studies which showed that a 3 week treatment with metformin at a dose of $300-500 \mathrm{mg} / \mathrm{kg} /$ day prevented the hypertension induced by fructose feeding in rats $[9,30]$, the two week treatment period of the lower dose in the current study did not affect blood pressure in the $\mathrm{db} / \mathrm{db}$ mice.

\section{Short-term metformin improves glycocalyx barrier properties}

Whole body vascular volume and clearance measurements of different tracers to delineate the barrier properties of the endothelial glycocalyx have been applied 
in previous experimental animal and human studies [19,20,22,23,24,25]. These measurements are based on intravital microscopic observations showing that circulating blood and large dextrans (mol mass $\geq 70 \mathrm{kDa}$ ) are significantly excluded from the glycocalyx, in contrast to $40 \mathrm{kDa}$ dextrans, which seem to have unlimited access to this domain $[26,31,32]$. Recently, it was shown that these whole-body measurements were sensitive to enzymatic glycocalyx degradation using hyaluronidase [23], and hence corroborate the intravital measurements that these tracers can indeed be used for detection of generalized glycocalyx degradation. We found that both circulating plasma and Dex70 excluding glycocalyx volume were diminished in $\mathrm{db} / \mathrm{db}$ mice compared to the $\mathrm{C} 57 \mathrm{Bl} / 6$ mice, indicating impaired glycocalyx barrier properties in this mouse model. The perturbed glycocalyx barrier was associated with a significant clearance of Dex70 from the circulation at a rate that was comparable to that observed after enzymatic glycocalyx degradation $[23,24]$. Two weeks of metformin in the $\mathrm{db} / \mathrm{db}$ mice improved the glycocalyx barrier, as evidenced by the increased Dex70 excluding glycocalyx volume which appeared indistinguishable from that measured in the $\mathrm{C} 57 \mathrm{Bl} / 6$ mice. The improvement coincided with a modest reduction in the vascular clearance of Dex70, in line with previous reports of a reduced vascular permeability after metformin treatment [10]. Although metformin has been previously shown to alleviate microalbuminuria in type II diabetes patients [33], the improved Dex70 retention in the metformin treated mice in the current study seemed not explained by a reduced renal clearance. More likely, the reduced clearance from the circulation might represent a slow equilibration of this tracer with the glycocalyx domain and subsequent extravasation [23]. Nevertheless, the ratio of the Dex70 versus Dex40 clearance was still considerably higher in the metformin treated $\mathrm{db} / \mathrm{db}$ mice compared to the $\mathrm{C} 57 \mathrm{Bl} / 6$ mice, indicating that other mechanisms involved in regulation of vascular permeability were still compromised in these mice. Furthermore, the two week metformin treatment appeared not to improve the glycocalyx exclusion of circulation plasma, indicating that, despite the improved exclusion of Dex70, the glycocalyx barrier properties were not functionally similar to those in non-diabetic mice. In agreement with our previous study [23], glycocalyx exclusion of circulating plasma was found to be substantially larger than the exclusion of Dex70 dextrans in all animal groups, indicating that these two measurements may reflect different characteristics of glycocalyx barrier function.

\section{Short-term metformin improves hydration of heart and kidney}

The improved glycocalyx barrier properties after metformin were associated with an improved hydration of heart and kidney, resulting in comparable dry-to-wet weight ratios in these tissues versus the $\mathrm{C} 57 \mathrm{Bl} / 6$ mice. Although the glycocalyx has been 
indicated to play an important role in regulation of capillary fluid filtration and organ fluid balance [34,35], the available data in the current study could not altogether substantiate whether the increased water content in heart and kidney after metformin was the single result of the improved glycocalyx barrier properties. Thus, hematocrit was not decreased in the metformin treated animals, indicating that intravascular fluid retention was not augmented. On the other hand, there was a trend for a higher daily water intake in the metformin group $(\mathrm{P}<0.08)$, while urine volumes collected in the acute experiments were very comparable for both diabetic groups. Also, whole-body volumes of distribution for the different tracers did appear to be somewhat larger in the metformin treated mice compared to the controls (Figure 6.3), suggesting that metformin increased the tracer available microvascular volume either in a structural or functional manner. In line herewith, metformin has previously been shown to improve obesity- and diabetes-induced reductions in microvascular and capillary density [10].

\section{Conclusions}

The results of the current study show significant recovery of Dex70 excluding glycocalyx volume and systemic clearance rates in $\mathrm{db} / \mathrm{db}$ mice after short-term treatment with metformin, independent of blood glucose changes. The improved Dex70 excluding glycocalyx volume was associated with a significant restoration of the fluid balance in heart and kidneys in these mice. Our results suggest, therefore, that an improvement of endothelial glycocalyx function may contribute to the reported cardiovascular benefits of metformin. While it has been indicated that metformin can lower the free radical load in the vasculature [10], and free radicals have been implicated in the evoked glycocalyx loss during exposure to cardiovascular risk conditions [36], including hyperglycemia $[19,22]$, further studies are needed to determine the precise mechanisms involved in the glycocalyx restoring effect of metformin. 


\section{References}

1. Bailey CJ, Turner RC (1996) Metformin. N Engl J Med 334: 574-579.

2. Kirpichnikov D, McFarlane SI, Sowers JR (2002) Metformin: an update. Ann Intern Med 137: 25-33.

3. Matthaei S, Reibold JP, Hamann A, Benecke H, Haring HU, et al. (1993) In vivo metformin treatment ameliorates insulin resistance: evidence for potentiation of insulin-induced translocation and increased functional activity of glucose transporters in obese (fa/fa) Zucker rat adipocytes. Endocrinology 133: 304-311.

4. Zou MH, Kirkpatrick SS, Davis BJ, Nelson JS, Wiles WGt, et al. (2004) Activation of the AMPactivated protein kinase by the anti-diabetic drug metformin in vivo. Role of mitochondrial reactive nitrogen species. J Biol Chem 279: 43940-43951.

5. Bailey CJ (2008) Metformin: effects on micro and macrovascular complications in type 2 diabetes. Cardiovasc Drugs Ther 22: 215-224.

6. Wiernsperger $N$ (2007) 50 years later: is metformin a vascular drug with antidiabetic properties? The British Journal of Diabetes \& Vascular Disease 2007 7: 204-210.

7. Vitale C, Mercuro G, Cornoldi A, Fini M, Volterrani M, et al. (2005) Metformin improves endothelial function in patients with metabolic syndrome. J Intern Med 258: 250-256.

8. Mather KJ, Verma S, Anderson TJ (2001) Improved endothelial function with metformin in type 2 diabetes mellitus. Journal of the American College of Cardiology 37: 1344-1350.

9. Katakam PV, Ujhelyi MR, Hoenig M, Miller AW (2000) Metformin improves vascular function in insulin-resistant rats. Hypertension 35: 108-112.

10. Wiernsperger NF (2000) Metformin: intrinsic vasculoprotective properties. Diabetes Technol Ther 2: 259-272.

11. Nieuwdorp M, Meuwese MC, Vink H, Hoekstra JB, Kastelein JJ, et al. (2005) The endothelial glycocalyx: a potential barrier between health and vascular disease. Curr Opin Lipidol 16: 507-511.

12. Van Teeffelen JW, Brands J, Stroes ES, Vink H (2007) Endothelial glycocalyx: sweet shield of blood vessels. Trends Cardiovasc Med 17: 101-105.

13. Lipowsky HH (2012) The endothelial glycocalyx as a barrier to leukocyte adhesion and its mediation by extracellular proteases. Annals of biomedical engineering 40: 840-848.

14. Mochizuki S, Vink H, Hiramatsu O, Kajita T, Shigeto F, et al. (2003) Role of hyaluronic acid glycosaminoglycans in shear-induced endothelium-derived nitric oxide release. Am J Physiol Heart Circ Physiol 285: H722-726.

15. Constantinescu AA, Vink H, Spaan JA (2003) Endothelial cell glycocalyx modulates immobilization of leukocytes at the endothelial surface. Arterioscler Thromb Vasc Biol 23: 1541-1547.

16. Mulivor AW, Lipowsky HH (2002) Role of glycocalyx in leukocyte-endothelial cell adhesion. American journal of physiology Heart and circulatory physiology 283: H1282-1291. 
17. van den Berg BM, Vink H, Spaan JA (2003) The endothelial glycocalyx protects against myocardial edema. Circ Res 92: 592-594.

18. Becker BF, Chappell D, Jacob M (2010) Endothelial glycocalyx and coronary vascular permeability: the fringe benefit. Basic research in cardiology 105: 687-701.

19. Nieuwdorp M, van Haeften TW, Gouverneur MC, Mooij HL, van Lieshout MH, et al. (2006) Loss of endothelial glycocalyx during acute hyperglycemia coincides with endothelial dysfunction and coagulation activation in vivo. Diabetes 55: 480-486.

20. Nieuwdorp M, Mooij HL, Kroon J, Atasever B, Spaan JA, et al. (2006) Endothelial glycocalyx damage coincides with microalbuminuria in type 1 diabetes. Diabetes 55: 1127-1132.

21. Broekhuizen LN, Lemkes BA, Mooij HL, Meuwese MC, Verberne H, et al. (2010) Effect of sulodexide on endothelial glycocalyx and vascular permeability in patients with type 2 diabetes mellitus. Diabetologia 53: 2646-2655.

22. Zuurbier CJ, Demirci C, Koeman A, Vink H, Ince C (2005) Short-term hyperglycemia increases endothelial glycocalyx permeability and acutely decreases lineal density of capillaries with flowing red blood cells. J Appl Physiol 99: 1471-1476.

23. Vanteeffelen JW, Brands J, Janssen BJ, Vink H (2013) Effect of acute hyaluronidase treatment of the glycocalyx on tracer-based whole body vascular volume estimates in mice. Journal of applied physiology 114: 1132-1140.

24. VanTeeffelen JW, Brands J, Jansen C, Spaan JA, Vink H (2007) Heparin impairs glycocalyx barrier properties and attenuates shear dependent vasodilation in mice. Hypertension 50: 261-267.

25. Meuwese MC, Broekhuizen LN, Kuikhoven M, Heeneman S, Lutgens E, et al. (2010) Endothelial surface layer degradation by chronic hyaluronidase infusion induces proteinuria in apolipoprotein E-deficient mice. PloS one 5: e14262.

26. Vink H, Duling BR (1996) Identification of distinct luminal domains for macromolecules, erythrocytes, and leukocytes within mammalian capillaries. Circ Res 79: 581-589.

27. Kraemer de Aguiar LG, Laflor CM, Bahia L, Villela NR, Wiernsperger N, et al. (2007) Metformin improves skin capillary reactivity in normoglycaemic subjects with the metabolic syndrome. Diabet Med 24: 272-279.

28. Fujita H, Fujishima H, Koshimura J, Hosoba M, Yoshioka N, et al. (2005) Effects of antidiabetic treatment with metformin and insulin on serum and adipose tissue adiponectin levels in $\mathrm{db} / \mathrm{db}$ mice. Endocr J 52: 427-433.

29. Tang T, Reed MJ (2001) Exercise adds to metformin and acarbose efficacy in $\mathrm{db} / \mathrm{db}$ mice. Metabolism 50: 1049-1053.

30. Verma S, Bhanot S, McNeill JH (1994) Antihypertensive effects of metformin in fructosefed hyperinsulinemic, hypertensive rats. The Journal of pharmacology and experimental therapeutics 271: 1334-1337.

31. Vink H, Duling BR (2000) Capillary endothelial surface layer selectively reduces plasma solute distribution volume. Am J Physiol Heart Circ Physiol 278: H285-289. 
32. VanTeeffelen JW, Constantinescu AA, Brands J, Spaan JA, Vink H (2008) Bradykinin- and sodium nitroprusside-induced increases in capillary tube hematocrit in mouse cremaster muscle are associated with impaired glycocalyx barrier properties. J Physiol 586: 32073218.

33. Erdmann E (2006) Microalbuminuria as a marker of cardiovascular risk in patients with type 2 diabetes. Int J Cardiol 107: 147-153.

34. Levick JR, Michel CC (2010) Microvascular fluid exchange and the revised Starling principle. Cardiovasc Res 87: 198-210.

35. Jacob M, Bruegger D, Rehm M, Stoeckelhuber M, Welsch U, et al. (2007) The endothelial glycocalyx affords compatibility of Starling's principle and high cardiac interstitial albumin levels. Cardiovasc Res 73: 575-586.

36. Becker BF, Chappell D, Bruegger D, Annecke T, Jacob M (2010) Therapeutic strategies targeting the endothelial glycocalyx: acute deficits, but great potential. Cardiovascular research 87: 300-310. 


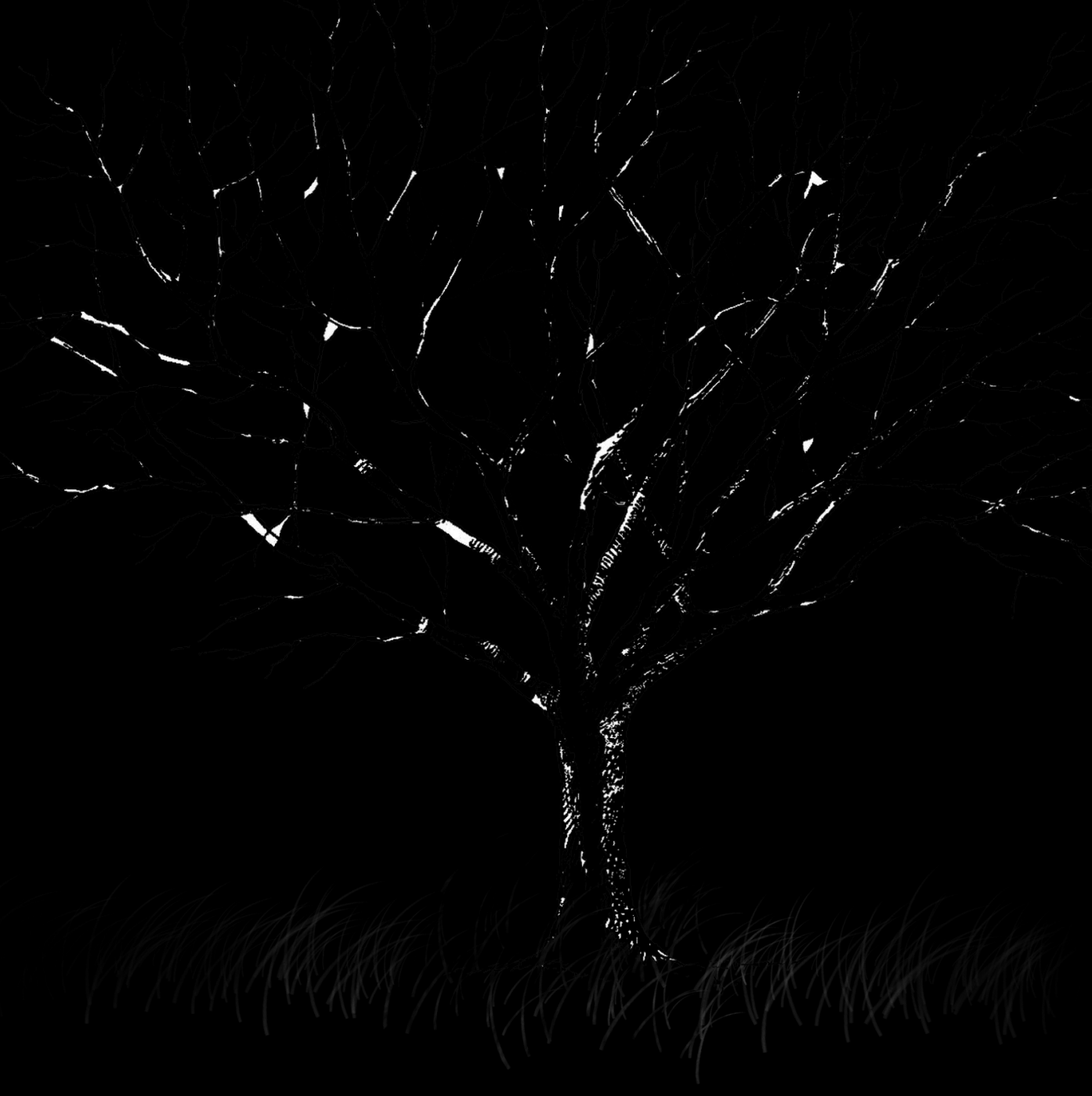


Chapter 7

\title{
Improvement of insulin resistance in diet-induced obese mice by sulodexide, an endothelial glycocalyx mimetic.
}

\author{
Bart J.M. Eskens \\ Hans Vink \\ Jurgen W.G.E. VanTeeffelen
}

Submitted 


\section{Abstract}

Recently, we showed that the induction of peripheral insulin resistance in diet-induced obese mice was accompanied by impaired barrier properties of the endothelial glycocalyx in the microcirculation of hindlimb muscle. We hypothesized in the current study that sulodexide, an endothelial glycocalyx mimetic, would improve insulinmediated glucose disposal in high-fat diet (HFD) fed mice.

Mice received a HFD for 6 or 18 weeks with or without therapy. Therapy consisted of sulodexide $(0.15 \mathrm{mg} / \mathrm{mL})$ or, as a reference, metformin $(0.3 \mathrm{mg} / \mathrm{mL})$ in the drinking water in the last two weeks of the HFD feeding period. To evaluate insulin action, mice were anesthetized; subsequently, they received a bolus of $1 \mathrm{~g} / \mathrm{kg}$ glucose via an i.p. cannula (IPGTT) while glucose and insulin levels were monitored for 120 and 90 minutes, respectively.

Two weeks of sulodexide treatment in the 6 weeks HFD fed mice was associated with significantly lower glucose levels measured during the IPGTT without a significant change in insulin levels. After a HFD for 18 weeks, sulodexide treatment did not significantly reduce glucose levels during the IPGTT yet insulin resistance appeared to be improved, as reflected by a significant decrease of the product of the area under the curve for both the glucose and insulin levels. Two weeks of metformin treatment did not affect glucose tolerance in the 6 weeks HFD fed mice. Metformin did also not affect glucose and insulin levels after 18 weeks of HFD.

Oral sulodexide treatment for 2 weeks is able to improve insulin-mediated glucose disposal in diet-induced obese mice. Our data indicate that timely treatment with the glycocalyx-mimetic sulodexide can be a potential therapy to alleviate insulin resistance and prevent the development of glucose intolerance and type II diabetes in obesity. 


\section{Introduction}

Obesity is a fast growing health-related problem, and is associated with a major risk for developing insulin resistance. Insulin resistance refers to a decreased capacity of insulin to regulate nutrient metabolism, and can initially be compensated by an increased secretion of insulin [1,2]. However, chronic secretion of large amounts of insulin to overcome tissue insensitivity can lead, in predisposed individuals, to pancreatic $ß$-cell failure and to the development of type II diabetes [3,4]. Understanding the origin of insulin resistance is of uttermost importance for the development of novel diagnostic and therapeutic tools to battle the expected burden of type II diabetes. Our recent data suggest that the endothelial glycocalyx may play a pivotal role in regulation of vascular insulin sensitivity and that damage to the endothelial glycocalyx may play a role in the pathogenesis of insulin resistance in obesity. First, we found that acute enzymatic degradation of the glycocalyx in rats resulted in an inability of insulin to recruit microvascular blood volume in muscle and this was accompanied by a decrease in insulin-mediated glucose disposal [5]. Next, we found evidence for glycocalyx degradation in muscle microcirculation in mice after already 6 weeks of a high fat diet (HFD). Of relevance, at this time point glucose intolerance seemed not fully manifested [6], indicating that glycocalyx damage may be an early event in diet-induced obesity (DIO) which may contribute to the development of glucose intolerance in this model. As a result, therapeutic interventions aiming at a recovery of the glycocalyx should be considered for improving insulin-mediated glucoregulation in DIO. In the current study we tested if the recently proposed glycocalyx-mimetic sulodexide would be able to alleviate insulin sensitivity in the HFD mouse model. Sulodexide is a glycosaminoglycan of natural origin extracted from mammalian intestinal mucosa, containing a mixture of $80 \%$ low-molecular-mass heparan sulphate and $20 \%$ dermatan sulphate [7]. Glycosaminoglycan chains contain numerous specific binding sites for plasma-derived proteins, and restoration of these chains may therefore improve functions of the glycocalyx [7]. As a reference treatment we used metformin, which is the most prescribed anti-hyperglycemic drug worldwide, and an anti-diabetic drug that has been shown to prevent cardiovascular complications [8]. It has been suggested that metformin improves glycocalyx dimensions as well, and this could be a possible explanation for the beneficial effects of metformin on endothelial function $[9,10]$. In the current study mice were fed a HFD for 6 or 18 weeks after which we performed an intraperitoneal glucose tolerance test (IPGTT) [6]. To evaluate the effect of the therapy, sulodexide and metformin were administrated via the drinking water for 2 weeks at the end of the feeding period. 


\section{Methods}

\section{Animals and diet}

All procedures were approved by the requirements of the Animal Ethics Care and Use committee of Maastricht University. After arrival from the external supplier (Harlan, Horst, The Netherlands) the animals $(n=37)$ were housed at the animal facility of Maastricht University and received a HFD (Research Diets, New Brunswick, NJ, containing on caloric basis $60 \%$ fat, $20 \%$ carbohydrate and $20 \%$ protein) for 6 or 18 weeks and water ad libitum. The HFD treated animals were divided into a group without therapy ( 6 weeks $n=5,18$ weeks $n=6)$, a group that received sulodexide $(0.15$ $\mathrm{mg} / \mathrm{mL} ; 6$ weeks $\mathrm{n}=5,18$ weeks $\mathrm{n}=8)$, and a group that received metformin $(0.3 \mathrm{mg} / \mathrm{mL}$; 6 weeks $n=5,18$ weeks $n=8$ ) in their drinking water in the last two weeks of the feeding period. Weekly ( 6 weeks HFD) or two weekly (18 weeks HFD) measurements of body weight, blood pressure using a CODA non-invasive blood pressure monitoring system (Kent Scientific), and blood glucose levels and plasma insulin levels via blood sampling of the saphenous vein were performed in the conscious animal after a morning fast (4 h). Blood glucose ( $\sim 5$ l blood) was measured with a glucose meter (Ascencia Contour). Further, about $40 \mu$ blood was collected using a $75 \mu$ l glass capillary tube (Hirschmann, Germany) and centrifuged to collect plasma for the measurement of insulin levels with an ELISA (ALPCO Diagnostics, Salem, NH).

\section{Experimental protocol}

At the day of experiment, after an overnight fast (10-12 h), mice were anesthetized using an intraperitoneal injection (i.p.) of $0.39 \mathrm{mg} / \mathrm{kg}$ fentanyl, $7.81 \mathrm{mg} / \mathrm{kg}$ midazolam and 7.81 $\mathrm{mg} / \mathrm{kg}$ acepromazine, and anesthesia was maintained by an additional bolus after 60-90 minutes of $0.10 \mathrm{mg} / \mathrm{kg}$ fentanyl, $1.56 \mathrm{mg} / \mathrm{kg}$ midazolam and $1.56 \mathrm{mg} / \mathrm{kg}$ acepromazine. The animal was put in a prone position and body temperature was maintained between $36^{\circ} \mathrm{C}$ and $37^{\circ} \mathrm{C}$ with the use of a heating pad and lamp and monitored with a rectal probe. During anesthesia a cannula was inserted intraperitoneally for glucose infusion [6]

\section{Intraperitoneal glucose tolerance test}

To determine glucose tolerance an IPGTT was performed. Mice were infused with a bolus of $1 \mathrm{~g} / \mathrm{kg}$ glucose $(0.1 \mathrm{gram} / \mathrm{mL})$ via the i.p. cannula. Blood glucose was measured, via tail bleeding, with a glucose meter at $t=-10$ and 0 (pre) and $t=5,10,20,30,40,50$, $60,70,80,90,100,110$ and 120 minutes after the glucose infusion. About $40 \mu \mathrm{l}$ blood was collected from the tail using a $75 \mu$ glass capillary tube to determine systemic 
hematocrit and plasma insulin levels with an ELISA at $\mathrm{t}=0$ (pre) and $\mathrm{t}=10$, 30, 60 and 90 minutes after glucose infusion.

\section{Data analysis}

Effects of therapy on blood glucose and plasma insulin levels were evaluated during baseline and during the various time points of the tolerance test. Also, as a reflection of the circulating levels of glucose during the IPGTT we calculated the total area under the curve (AUC) of the glucose concentration versus time by the linear trapezoidal rule for the period of 0-120 minutes after glucose infusion (Fig. 7.2A). Similarly, as a reflection of the circulating insulin levels we calculated the AUC of the insulin concentration versus time by the linear trapezoidal rule for the period of 0-90 minutes after glucose infusion (Fig. 7.2B). As an index of baseline insulin resistance, the HOMA-IR ((Baseline glucose $\mathrm{X}$ baseline insulin)/22.5) was calculated [11], while as an index of peripheral insulin resistance during the IPGTT the IR-index, which is the product of the AUC of glucose and AUC of insulin was calculated [12].

All data are presented as means \pm SEM. Statistical differences were tested with Student's unpaired t-tests. A value of $\mathrm{P}<0.05$ was considered statistically significant. 


\section{Results}

\section{Baseline characteristics}

Baseline characteristics of the HFD mice measured before the animals received the therapy, i.e., up to 16 weeks after start of the HFD, are shown in Figure 7.1. For reference, the characteristics in a group of mice on chow (presented in [6]) are shown as well (grey dashed line). As shown in our previous study [6], HFD was associated with increases in body weight, and baseline glucose and insulin levels, without a change in blood pressure. These parameters were not different between the three (no, sulodexide, or metformin treatment) groups. Neither metformin, nor sulodexide did have an effect on body weight in the mice that received a HFD for 6 weeks. However, compared to the body weight measured after feeding a HFD for 18 weeks without therapy $(37.9 \pm$ 1.6 grams), the body weight was lower after metformin treatment (33.2 \pm 1.2 grams; $\mathrm{P}<0.05)$, while it tended to be decreased after sulodexide treatment (33.8 \pm 1.4 grams; $\mathrm{P}=0.08)$.

A)

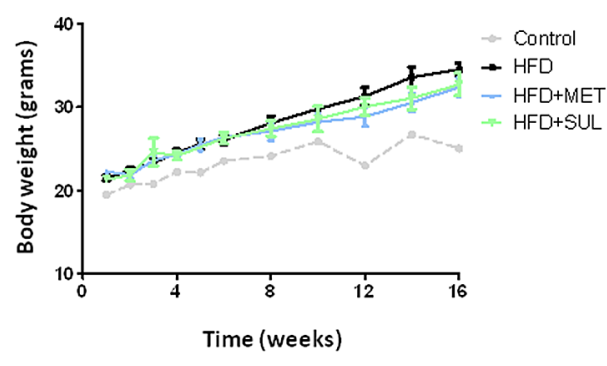

C)

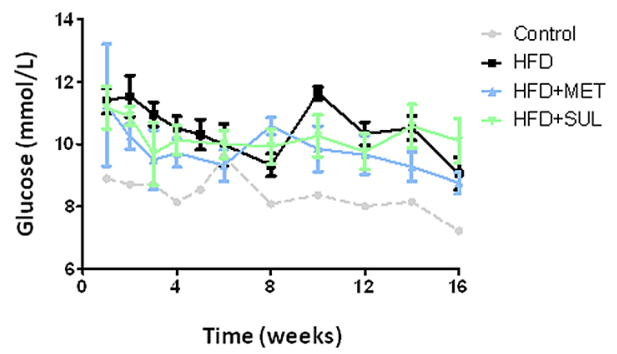

B)

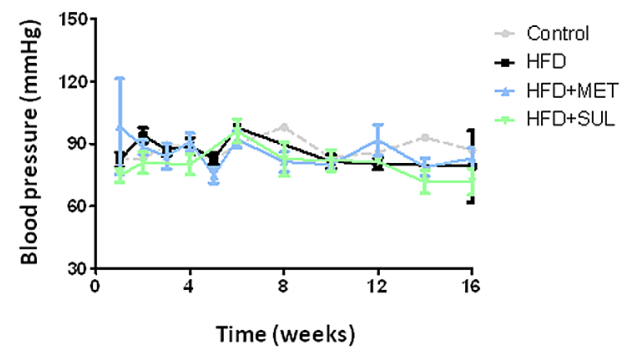

D)

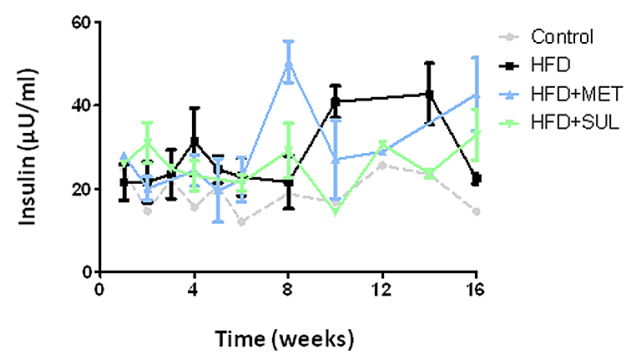

Fig 7.1 Mean \pm SEM of body weight (A), blood pressure (B), and baseline glucose levels (C) and insulin levels in the 16 weeks that the mice received a HFD. The dashed grey line represents the values of the control group from our previous study [6]. After 16 weeks the mice received either sulodexide or metformin therapy in the final two weeks of the experiment, while the remaining groups did not receive any treatment. 


\section{IPGTT}

\section{Baseline}

Baseline glucose and insulin levels measured before the start of the IPGTT are shown in table $7 / 1$. In the mice that were fed a HFD for 6 weeks baseline glucose and insulin levels were not affected by the two week sulodexide treatment. Baseline glucose levels were also not changed by metformin treatment, however baseline insulin levels were significantly increased $(\mathrm{P}<0.05)$ after metformin. In the mice that were fed a HFD for 18 weeks, baseline glucose and baseline insulin levels were not different in the mice that were treated by any of both therapies. The HOMA-IR was not affected by sulodexide or metformin after both a HFD for 6 weeks as well as for 18 weeks.

Table 7.1. Baseline circulating glucose and insulin values (measured before the start of the IPGTT)

\begin{tabular}{|c|c|c|c|c|c|c|}
\hline \multirow[b]{2}{*}{ Therapy } & \multicolumn{3}{|c|}{ HFD for 6 weeks } & \multicolumn{3}{|c|}{ HFD for 18 weeks } \\
\hline & Without & Sulodexide & Metformin & Without & Sulodexide & Metformin \\
\hline Blood glucose (mmol/L) & $6.8 \pm 0.6$ & $6.2 \pm 0.5$ & $7.0 \pm 1.1$ & $6.4 \pm 0.7$ & $5.5 \pm 0.3$ & $6.5 \pm 0.9$ \\
\hline $\begin{array}{l}\text { Plasma Insulin } \\
(\mu \mathrm{U} / \mathrm{ml})\end{array}$ & $9.7 \pm 0.4$ & $11.0 \pm 1.6$ & $16.7 \pm 2.5^{*}$ & $18.3 \pm 4.2$ & $11.9 \pm 2.3$ & $17.0 \pm 3.8$ \\
\hline HOMA-IR & $2.81 \pm 0.32$ & $3.11 \pm 0.58$ & $5.54 \pm 1.63$ & $5.24 \pm 1.25$ & $2.85 \pm 0.53$ & $5.29 \pm 1.43$ \\
\hline
\end{tabular}

Baseline glucose and insulin levels measured during anesthesia before the start of the IPGTT in mice that were fed a HFD for 6 or 18 weeks, respectively. As a measurement for baseline insulin resistance the HOMAIR ((Baseline glucose X baseline insulin)/22.5) was calculated. * $\mathrm{P}<0.05$ compared to HFD mice without treatment.

\section{Glucose tolerance test}

In the 6 weeks HFD fed mice, sulodexide treatment was associated with a significant decrease in blood glucose at $\mathrm{t}=10,20$ and 30 minutes after glucose infusion (Fig. 7.2, panel A). This decrease was, however, not sufficient to decrease the total AUC of the glucose levels significantly, yet this value was very close to the values obtained in our previous study in the chow group (Fig 7.2., panel B). Also, although insulin levels were not significantly decreased by sulodexide, the AUC of insulin was very close to that measured in the chow fed animals in our previous study. Metformin treatment did not improve glucose and insulin levels measured during the IPGTT in the 6 weeks HFD-fed mice. 
A)
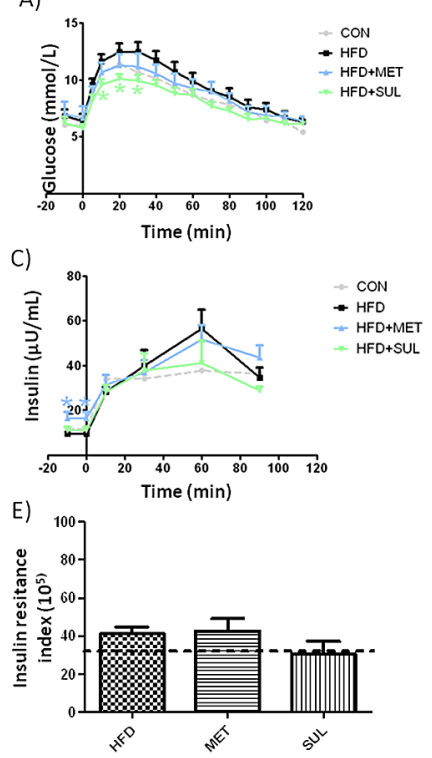

B)

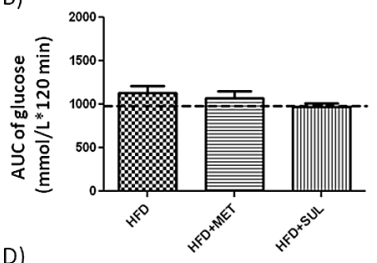

D)

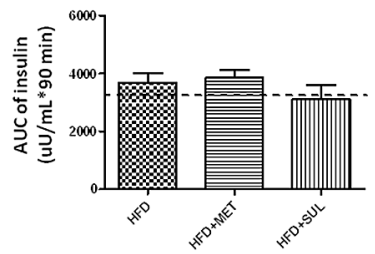

Fig 7.2 In panel A the glucose levels during the IPGTT in the mice that received a HFD for 6 weeks without therapy, with sulodexide (SUL) or metformin (MET) therapy are shown while in panel B the corresponding AUC of glucose levels during the IPGTT are shown. The insulin levels during the IPGTT are shown in panel C and the AUC of insulin depicted in panel D. In panel E the IR-index (product of AUC glucose and AUC insulin) is shown. The dashed grey (panel A and C) or black line (panel B, D and E) represents the values of the control group (chow) from our previous study [6] *. P<0.05 compared to HFD.

In contrast to the effect of sulodexide on improvement of blood glucose levels during the IPGTT after 6 weeks of HFD, glucose levels were not significantly affected by this treatment in the mice that were fed the HFD for 18 weeks (Fig 7.3, panel A). Although there was also no significant difference in plasma insulin levels between the three groups during the IPGTT (Fig 7.3, panel C), the AUC of insulin was again close to the value observed in animals that received chow for 18 weeks in our previous study. The IR-index was significantly lower in the sulodexide treated mice compared to the nontreated mice. 

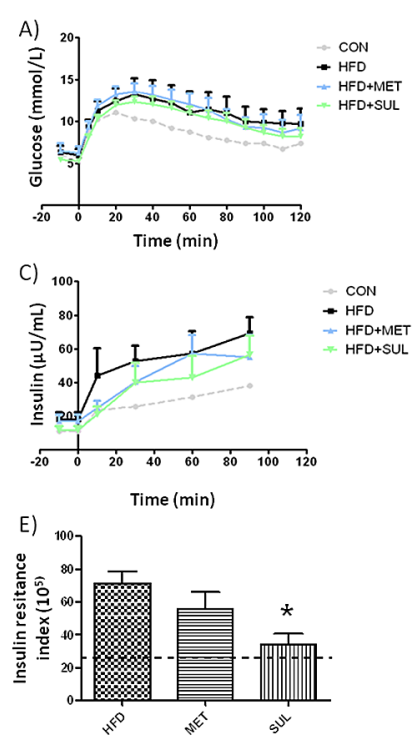

B)

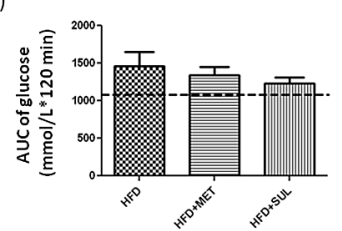

D)

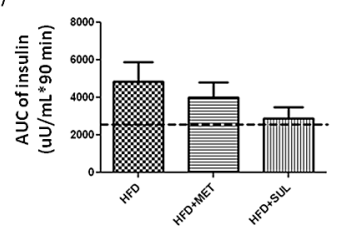

Fig 7.3 In panel A the glucose levels during the IPGTT in the mice that received a HFD for 18 weeks without therapy or with sulodexide or metformin therapy are shown while in panel B the corresponding AUC of glucose levels during the IPGTT are shown.. The insulin levels during the IPGTT are shown in panel C and the AUC of insulin are shown depicted in panel D. In panel E the IR-index (product AUC glucose and AUC insulin) is shown The dashed grey (panel A and C) or black line (panel B,D and E) represents the values of the control group (chow) from our previous study [6] *. P $<0.05$ compared to HFD). 


\section{Discussion}

Sulodexide is a glycosaminoglycan, containing a mixture of $80 \%$ low-molecular-mass heparan sulphate and 20\% dermatan sulphate [7]. Given the abundance of these molecules in the endothelial glycocalyx, it may be considered to be a glycocalyx mimetic. Indeed, sulodexide treatment was recently shown to partially restore glycocalyx barrier properties in type II diabetic subjects [7], and this effect was associated with a reduction of the albumin clearance from the circulation in these subjects. It was not tested whether the improvement of the glycocalyx barrier properties by sulodexide was associated with an improvement in insulin sensitivity and glucose tolerance in the diabetics. In the current study we tested if short-term sulodexide would improve insulin-mediated glucose disposal at a relatively early and a later stage of diet-induced insulin resistance. Herefore, mice were fed a HFD for 6 weeks or 18 weeks with or without sulodexide in their drinking water in the last 2 weeks of the feeding period. It was found that sulodexide improved blood glucose levels during an IPGTT in the face of similar insulin levels in the mice that were fed a HFD for 6 weeks. Furthermore, in the mice that were fed a HFD for 18 weeks, sulodexide improved the insulin resistance index. These data indicate that sulodexide improves insulin-mediated glucoregulation in DIO and suggest that recovery of the endothelial glycocalyx may be useful target in diabetes-prone conditions.

\section{Rationale of the study}

The glycocalyx occupies a large volume of the microcirculation, and plays an important role in protection of the endothelium [13]. In addition to earlier studies in humans and experimental animals, in which it was shown that acute conditions of severe hyperglycemia $[14,15]$ were associated with immediate glycocalyx damage, we recently provided evidence that glycocalyx damage also developed in the early stages of dietinduced obesity, before the presence of overt glucose intolerance. Together with the finding that acute enzymatic degradation of the glycocalyx resulted in an impaired insulin-mediated glucose disposal [5], these data suggest that glycocalyx damage may not only be a consequence of a defective insulin action and resultant hyperglycemia but may actually contribute to them. As a result, the glycocalyx may be a worthwhile target for therapy directed at improvement of insulin sensitivity in DIO. Since previous studies in rodents had shown that infusion of glycocalyx components, such as hyaluronan [16] and heparan sulfates [17], could restore a degraded glycocalyx and its protective function, we hypothesized in the current study that sulodexide would improve insulin sensitivity in diet-induced obese mice. 


\section{Methodological considerations}

\section{HFD}

The HFD-fed mouse model has been used to study mechanisms of impaired glucose tolerance and type II diabetes [18,19] and to evaluate new treatments $[20,21]$. In our previous study we showed that feeding a HFD for 6 weeks in mice did not affect baseline glucose and insulin levels and was associated with rather mild increases in glucose and compensatory insulin secretion during the IPGTT, which did not yet result in a significant increase in the total AUC of glucose or insulin levels during the test [6]. In the current study, we also calculated the IR-index as the product of the AUC of both parameters $[22,23]$. It has been argued by Matsuda and DeFronzo that this index provides a better reflection of muscle insulin resistance during a glucose tolerance test than for example the ratio of both parameters, since normal or higher glucose levels with higher insulin levels reflects the presence of insulin resistance [12]. The IR-index (Fig 7.2E) was not significantly increased in the mice that were fed a HFD for 6 weeks, indicating that insulin resistance was not fully present at this stage (Fig 7.4, left panel). After 18 weeks of HFD baseline insulin and glucose levels were also not significantly changed but glucose disposal appeared impaired for the entire $2 \mathrm{~h}$ after the glucose infusion, resulting in a significantly elevated AUC of glucose. In addition, insulin levels tended to be increased as well. These data indicate that after feeding a HFD for 18 weeks, insulin resistance was more aggravated and indeed the IR-index was clearly increased at this stage (Fig 7.3E).

A)

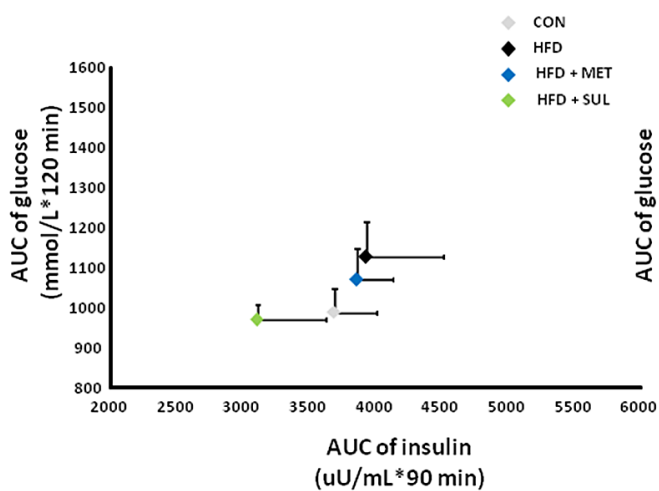

B)

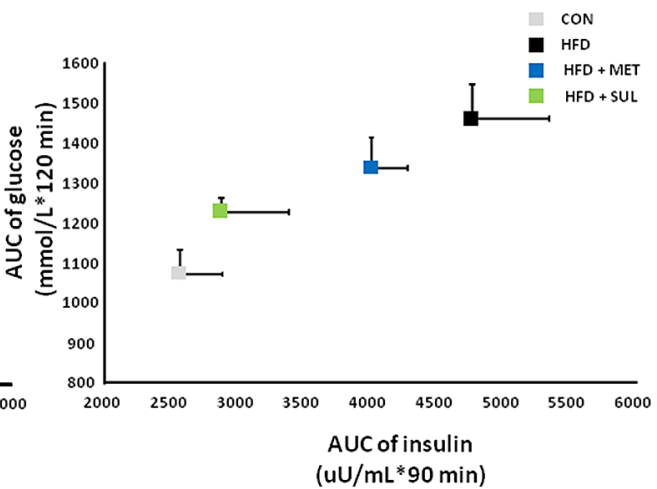

18 weeks

(uU/mL*90 min)

Fig 7.4 In panel A the relation between the AUC of glucose and AUC of insulin are shown for the mice that received a HFD for 6 weeks. In panel B the relation between the AUC of glucose and AUC of insulin are shown for the mice that received a HFD for 18 weeks. The data from the control group are the data obtained in [6]. 


\section{Treatments}

Sulodexide was used in previous clinical studies to test the effect in diabetic nephropathy, and it has been shown that sulodexide treatment for several weeks was associated with an improvement in albuminuria in type I and II diabetic patients [24,25]. However, other studies showed that sulodexide did not have a renoprotective benefit and was ineffective in decreasing urine albumin excretion in type 2 diabetic patients. As a result, the effect of sulodexide in diabetic nephropathy is still unclear [26,27]. In a diabetic rat model it was shown that sulodexide treatment for 5 and 10 weeks improved acetylcholineinduced relaxation preferentially in the smaller arteries, indication that sulodexide has a beneficial effect on endothelial function [28]. Since the glycocalyx has been shown to play an important role in regulation of endothelial function, including regulation of the bioavailability of NO, these data may well reflect an improvement of the endothelial glycocalyx by the sulodexide treatment. A limitation of the current study is that properties of the glycocalyx were not measured. However, Broekhuizen et al. recently showed the efficacy of sulodexide in improving glycocalyx barrier properties in type II diabetics. In this study 8 week sulodexide treatment restored sublingual glycocalyx dimensions and this was accompanied by an improvement in systemic vascular permeability [7]. Compared to the study of Broekhuizen et al. in which sulodexide was orally administrated in human subjects at a concentration of $200 \mathrm{mg} /$ day (approximately $2.9 \mathrm{mg} / \mathrm{kg} /$ day) for 2 months, we gave in the present study sulodexide via the drinking water to mice only for a period of two weeks. The concentration sulodexide that was administrated to the mice $(0.15 \mathrm{mg} / \mathrm{mL})$ was, however, much higher per kg body weight; assuming a water intake of $3 \mathrm{ml}$ per day, the mice got administered a sulodexide dose of approximately $11.25 \mathrm{mg} / \mathrm{kg} /$ day. In line with previous studies [7,28], no significant changes in baseline glucose levels were observed. However, in addition to the previous reported beneficial effects of sulodexide on endothelial function [28] and glycocalyx barrier properties [7], we found that sulodexide decreased the elevated glucose levels during an IPGTT at an early state of DIO. The blood glucose and plasma insulin levels measured during the IPGTT in the mice that were fed a HFD for 6 weeks in combination with sulodexide were very comparable to these levels measured during an IPGTT in control mice (Fig 7.2A). Remarkably, it appeared even that the relation between the AUC of glucose and the AUC of insulin was improved compared to control mice (Fig 7.4, left panel), but additional studies in control mice are needed to verify this. At a later stage of DIO, after feeding a HFD for 18 weeks, sulodexide also appeared to improve insulinmediated glucoregulation, as evidenced from Fig. 7.4. Although glucose levels during the test were not significantly reduced, the insulin resistance index was significantly 
decreased in the sulodexide treated mice, indicating that less insulin was needed for an improved glucose disposal due to the improved insulin sensitivity.

As a reference we used metformin in the current study. The main target of metformin has been suggested to be the liver, namely inhibition of hepatic gluconeogenesis. In addition, metformin has been shown to improve insulin action in muscle, adipose tissue and endothelium as well [29]. Surprisingly, two weeks of metformin was associated with significantly increased baseline insulin levels. However, the HOMA-IR was not increased, indicating that baseline insulin sensitivity was not significantly affected by the treatment. Furthermore, while metformin has been shown to improve insulin-mediated glucose disposal in muscle in previous studies [8,30,31], we did not find evidence for this in our metformin treated animals. Since in the reported studies metformin was generally administrated for a longer period of time or at higher concentrations, it might be argued that the two weeks of metformin treatment might have been too short to improve insulin-mediated glucoregulation in the current study. Nevertheless, It has been shown that metformin inhibits visceral obesity and lipid accumulation and thereby reduces body weight [32,33]; in line with this, we found in the current study that two weeks of metformin treatment improved body weight in the mice that were fed a HFD for 18 weeks. Furthermore, short-term metformin treatment has been indicated to improve endothelial function [8,34] and glycocalyx barrier properties $[6,10]$ in insulin-resistant rats and mice. The concentration of metformin used in the drinking water in the current study was comparable with our previous study (100mg/kg/d) [9], in which two weeks of metformin did also not affect fasting glucose levels. It could well be that the beneficial effects of metformin on the barrier properties of the glycocalyx were insufficient to improve glucoregulation after two weeks already. While long-term metformin treatment has proven beneficial for insulin-mediated glucose homeostasis, additional studies need to be performed to investigate the contribution of a potentially restored glycocalyx to this.

\section{Conclusion}

The results of the current study show that short-term treatment with sulodexide, a presumed glycocalyx mimetic, improves insulin sensitivity in diet-induced obese mice. In addition to the previous reported beneficial effects of sulodexide on glycocalyx barrier properties, this suggests that sulodexide may hinder the development of glucose intolerance and ultimately type II diabetes. Sulodexide could, therefore, be a potential new therapeutic for obese people predisposed for developing insulin resistance. 


\section{References}

1. DeFronzo RA (2004) Pathogenesis of type 2 diabetes mellitus. Med Clin North Am 88: 787835, ix.

2. DeFronzo RA, Tripathy D (2009) Skeletal muscle insulin resistance is the primary defect in type 2 diabetes. Diabetes Care 32 Suppl 2: S157-163.

3. Porte D, Jr., Kahn SE (2001) beta-cell dysfunction and failure in type 2 diabetes: potential mechanisms. Diabetes 50 Suppl 1: S160-163.

4. Weir GC, Bonner-Weir S (2004) Five stages of evolving beta-cell dysfunction during progression to diabetes. Diabetes 53 Suppl 3: S16-21.

5. Eskens BJ, Mooij HL, Cleutjens JP, Roos JM, Cobelens JE, et al. (2013) Rapid insulin-mediated increase in microvascular glycocalyx accessibility in skeletal muscle may contribute to insulin-mediated glucose disposal in rats. PLoS One 8: e55399.

6. Eskens BJ, Leurgans TM, Vink H, VanTeeffelen JW (2014) Early impairment of skeletal muscle endothelial glycocalyx barrier properties in diet-induced obesity in mice. Physiological Reports 2: e00194.

7. Broekhuizen LN, Lemkes BA, Mooij HL, Meuwese MC, Verberne H, et al. (2010) Effect of sulodexide on endothelial glycocalyx and vascular permeability in patients with type 2 diabetes mellitus. Diabetologia 53: 2646-2655.

8. Bailey CJ (2008) Metformin: effects on micro and macrovascular complications in type 2 diabetes. Cardiovasc Drugs Ther 22: 215-224.

9. Eskens BJ, Zuurbier CJ, van Haare J, Vink H, van Teeffelen JW (2013) Effects of two weeks of metformin treatment on whole-body glycocalyx barrier properties in $\mathrm{db} / \mathrm{db}$ mice. Cardiovasc Diabetol 12: 175.

10. Wiernsperger NF (2007) Review: 50 years later: is metformin a vascular drug with antidiabetic properties? The British Journal of Diabetes \& Vascular Disease 7: 204-210.

11. Matthews DR, Hosker JP, Rudenski AS, Naylor BA, Treacher DF, et al. (1985) Homeostasis model assessment: insulin resistance and beta-cell function from fasting plasma glucose and insulin concentrations in man. Diabetologia 28: 412-419.

12. Matsuda M, DeFronzo RA (1999) Insulin sensitivity indices obtained from oral glucose tolerance testing: comparison with the euglycemic insulin clamp. Diabetes Care 22: 14621470.

13. Van Teeffelen JW, Brands J, Stroes ES, Vink H (2007) Endothelial glycocalyx: sweet shield of blood vessels. Trends Cardiovasc Med 17: 101-105.

14. Zuurbier CJ, Demirci C, Koeman A, Vink H, Ince C (2005) Short-term hyperglycemia increases endothelial glycocalyx permeability and acutely decreases lineal density of capillaries with flowing red blood cells. J Appl Physiol 99: 1471-1476.

15. Nieuwdorp M, van Haeften TW, Gouverneur MC, Mooij HL, van Lieshout MH, et al. (2006) Loss of endothelial glycocalyx during acute hyperglycemia coincides with endothelial dysfunction and coagulation activation in vivo. Diabetes 55: 480-486. 
16. Rubio-Gayosso I, Platts SH, Duling BR (2006) Reactive oxygen species mediate modification of glycocalyx during ischemia-reperfusion injury. Am J Physiol Heart Circ Physiol 290: H2247-2256.

17. Constantinescu AA, Vink H, Spaan JA (2003) Endothelial cell glycocalyx modulates immobilization of leukocytes at the endothelial surface. Arterioscler Thromb Vasc Biol 23: 1541-1547.

18. Ahren B, Pacini G (2002) Insufficient islet compensation to insulin resistance vs. reduced glucose effectiveness in glucose-intolerant mice. Am J Physiol Endocrinol Metab 283: E738744.

19. Winzell MS, Ahren B (2004) The high-fat diet-fed mouse: a model for studying mechanisms and treatment of impaired glucose tolerance and type 2 diabetes. Diabetes 53 Suppl 3: S215-219.

20. Ahren B, Holst JJ, Yu S (2000) 1,5-Anhydro-D-fructose increases glucose tolerance by increasing glucagon-like peptide-1 and insulin in mice. Eur J Pharmacol 397: 219-225.

21. Reimer MK, Holst JJ, Ahren B (2002) Long-term inhibition of dipeptidyl peptidase IV improves glucose tolerance and preserves islet function in mice. Eur J Endocrinol 146: 717 727.

22. Levine R, Haft DE (1970) Carbohydrate homeostasis. N Engl J Med 283: 237-246.

23. Myllynen P, Koivisto VA, Nikkila EA (1987) Glucose intolerance and insulin resistance accompany immobilization. Acta Med Scand 222: 75-81.

24. Gambaro G, Kinalska I, Oksa A, Pont'uch P, Hertlova M, et al. (2002) Oral sulodexide reduces albuminuria in microalbuminuric and macroalbuminuric type 1 and type 2 diabetic patients: the Di.N.A.S. randomized trial. J Am Soc Nephrol 13: 1615-1625.

25. Poplawska A, Szelachowska M, Topolska J, Wysocka-Solowie B, Kinalska I (1997) Effect of glycosaminoglycans on urinary albumin excretion in insulin-dependent diabetic patients with micro- or macroalbuminuria. Diabetes Res Clin Pract 38: 109-114.

26. Lewis EJ, Lewis JB, Greene T, Hunsicker LG, Berl T, et al. (2011) Sulodexide for kidney protection in type 2 diabetes patients with microalbuminuria: a randomized controlled trial. Am J Kidney Dis 58: 729-736.

27. Packham DK, Wolfe R, Reutens AT, Berl T, Heerspink HL, et al. (2011) Sulodexide fails to demonstrate renoprotection in overt type 2 diabetic nephropathy. J Am Soc Nephrol 23: 123-130.

28. Kristova V, Liskova S, Sotnikova R, Vojtko R, Kurtansky A (2008) Sulodexide improves endothelial dysfunction in streptozotocin-induced diabetes in rats. Physiol Res 57: 491494.

29. Diamanti-Kandarakis E, Christakou CD, Kandaraki E, Economou FN (2010) Metformin: an old medication of new fashion: evolving new molecular mechanisms and clinical implications in polycystic ovary syndrome. Eur J Endocrinol 162: 193-212.

30. DeFronzo RA, Barzilai N, Simonson DC (1991) Mechanism of metformin action in obese and lean noninsulin-dependent diabetic subjects. J Clin Endocrinol Metab 73: 1294-1301. 
31. Musi N, Hirshman MF, Nygren J, Svanfeldt M, Bavenholm P, et al. (2002) Metformin increases AMP-activated protein kinase activity in skeletal muscle of subjects with type 2 diabetes. Diabetes 51: 2074-2081.

32. Alexandre KB, Smit AM, Gray IP, Crowther NJ (2008) Metformin inhibits intracellular lipid accumulation in the murine pre-adipocyte cell line, 3T3-L1. Diabetes Obes Metab 10: 688690.

33. Tajima K, Nakamura A, Shirakawa J, Togashi Y, Orime K, et al. (2013) Metformin prevents liver tumorigenesis induced by high-fat diet in C57Bl/6 mice. Am J Physiol Endocrinol Metab 305: E987-998.

34. Wiernsperger NF (2000) Metformin: intrinsic vasculoprotective properties. Diabetes Technol Ther 2: 259-272. 


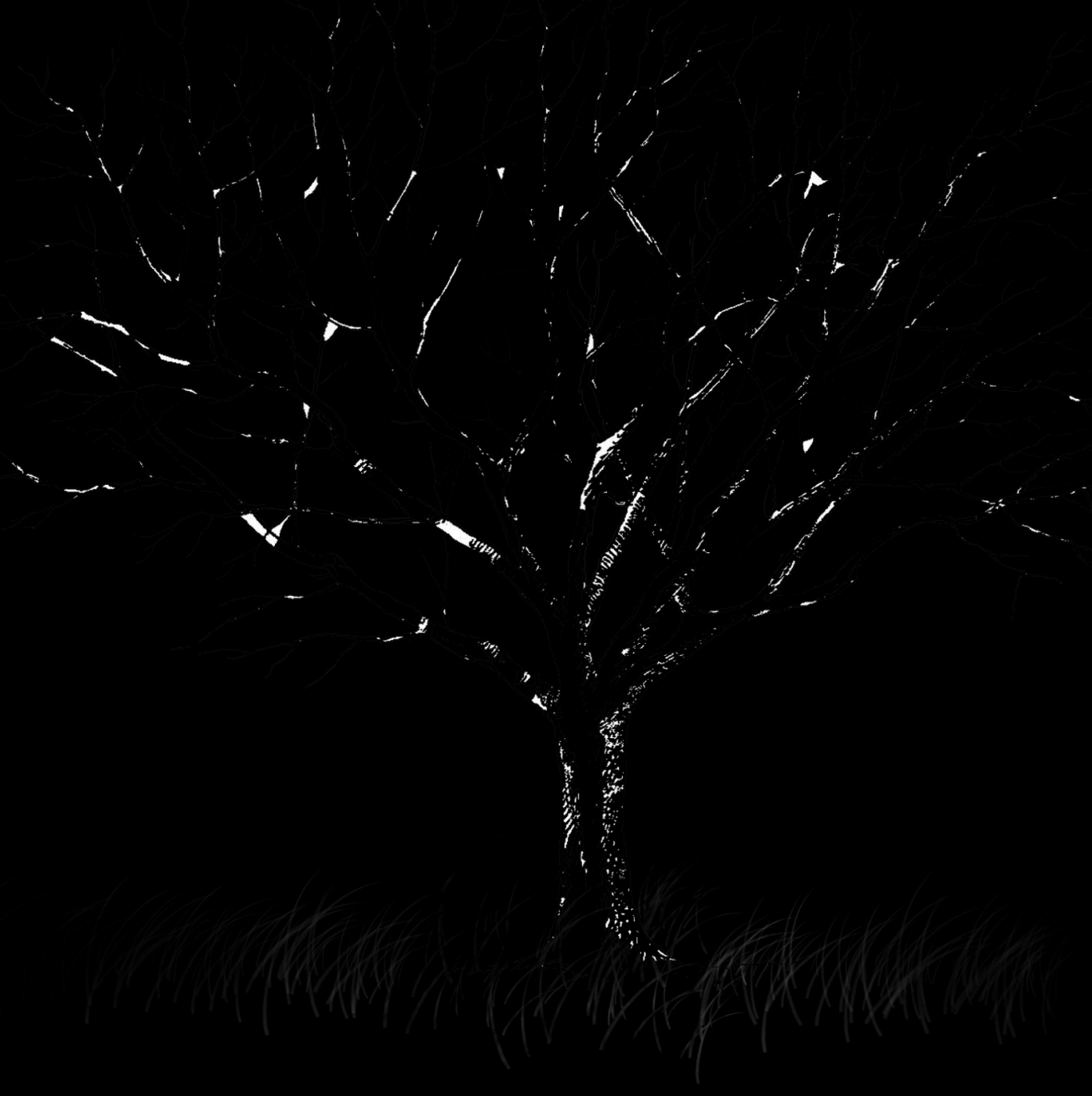


Chapter 8

\title{
General discussion
}

\author{
Bart J.M. Eskens \\ Hans Vink \\ Jurgen W.G.E. VanTeeffelen
}




\section{Introduction}

Diabetes type II is commonly grouped with other pathologies including dyslipidemia, hypertension, cardiovascular disease and obesity; insulin resistance has been indicated to underlie the development of these conditions [1]. Insulin resistance associated with diabetes is usually considered a cellular inability of insulin to increase glucose disposal or suppress glucose production, leading to hyperglycemia. However, insulin resistance manifests itself in many tissues and cell types including the endothelium [1]. Endothelial dysfunction often coincides with the development of insulin resistance, and has been associated with an impaired insulin and nutrient access to muscle and other tissues $[1,2,3]$. This is explained by the fact that, in order to promote the transport of insulin and nutrients, insulin can expand microvascular blood volume even under conditions where total blood flow is unchanged $[2,4]$. Further, the endothelium has significant barrier properties, and appears to actively regulate insulin delivery from the blood towards the interstitium. Altogether, the concept has been put forward that a compromised vascular endothelium may play a pivotal role in the development of insulin resistance $[1,2,3,5]$. The luminal side of the endothelium is decorated with the glycocalyx (Fig 8.1), which is the first compartment which blood-borne nutrients and pro-inflammatory factors encounter when they pass through the circulation $[6,7,8]$.

Two photon laser scanning microscopy of mouse cremaster muscle microvasculature

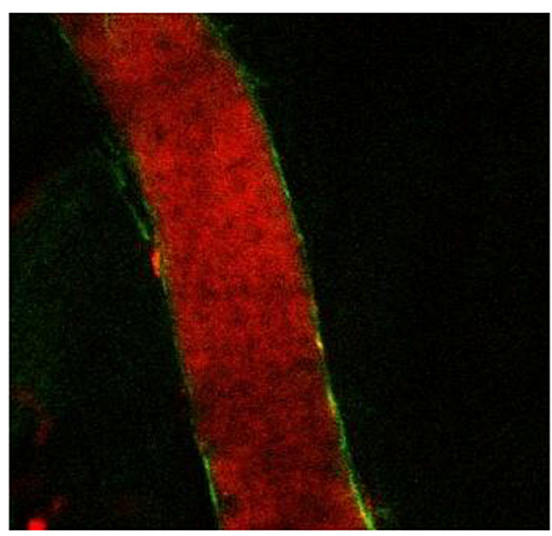

Fig 8.1. Two photon laser scanning microscopy of mouse cremaster muscle microvasculature. Microvessel (diameter $\sim 15 \mu \mathrm{m})$ is visualized using Texas Red labeled $70 \mathrm{kDa}$ dextrans (red) for luminal staining and FITC-labeled WGA-lectin (green) for glycocalyx staining.

Since the glycocalyx shields the vascular wall from direct exposure to the flowing blood it constitutes the first barrier in protecting the endothelium against atherogenic insults [7], and it has been shown that damage to the glycocalyx is linked and contributes to endothelial dysfunction $[9,10,11]$. We hypothesized in the current thesis that insulin would increase microvascular blood volume in muscle by modulation of glycocalyx 
barrier properties. Based on previous experimental data suggesting that insulinmediated blood volume recruitment in the microcirculation is a rate-limiting step for insulin-mediated glucose disposal, particularly in insulin-resistant conditions [12], insulin-mediated glycocalyx modulation would, therefore, be an important step in regulation of insulin delivery and transport from the blood towards the skeletal muscle tissue. Although insulin is a small-sized molecule $(6 \mathrm{kDa})$, it has been suggested that insulin is not easily exchanged across the capillary endothelium $[13,14]$, while there is also still controversy whether insulin crosses the end othelium by an active $[15,16,17,18]$ or a passive pathway $[19,20]$. Beyond the potential role of insulin to promote its own movement into endothelial cells [12], it has been suggested that insulin could promote its own delivery, and that of glucose, by increasing the blood flow to the muscle. However, the increase in total muscle blood flow has been shown to be slow and to occur only after 30 minutes in the presence of physiological insulin concentrations. In contrast, insulin has been demonstrated at these concentrations to increase microvascular blood volume in skeletal muscle within 10 minutes already [21,22]. While the exact mechanism by which insulin increases microvascular blood volume has been unknown for a long time, we suggest from our data obtained in the current thesis that the glycocalyx plays an important role in this.

\section{Insulin-mediated recruitment of microvascular blood volume includes modulation of the glycocalyx}

Whereas several previous studies have pointed out the potential of insulin to increase capillary blood volume in muscle $[13,21,22,23]$, the origin for this microvascular insulin effect has remained unknown due to the lack of in vivo observations of individual capillary responses to insulin. As a proof of principle, in chapter 2 , we tested if insulin was able to increase blood volume within already perfused capillaries. Herefore, insulin, at a concentration of $20 \mu \mathrm{U} / \mathrm{ml}$ and $200 \mu \mathrm{U} / \mathrm{ml}$, was topically administrated onto the cremaster muscle of control mice as well as of diabetic $(\mathrm{db} / \mathrm{db})$ mice. The results of this study showed that insulin robustly increased capillary tube hematocrit in already perfused individual capillaries in control mice, while in contrast, in the $\mathrm{db} / \mathrm{db}$ mice, in which evidence of glycocalyx degradation was shown in a previous study [24], this action of insulin was compromised. Since insulin and glucose are distributed in the circulating plasma, it would have been worthwhile to evaluate whether the plasma volume in the capillaries was actually also increased during insulin administration. These experiments require the use of a labeled plasma tracer which can be ambiguous due to the fact that commonly used tracers such as albumin may not only distribute into the circulating plasma but may access the glycocalyx domain as well $[25,26]$. Nevertheless, in previous 
studies agonist-induced increases in capillary tube hematocrit were consistently found to coincide with increases in distribution volume of large dextrans in the capillary due to an increased permeation of the dextrans into the glycocalyx [27,28], indicating that the observed increase in capillary tube hematocrit in the presence of insulin was paralleled by an increase in capillary plasma volume. Furthermore, our results indicate that insulin-mediated augmentation of blood volume may take place at the level of the individual capillary, challenging the commonly held belief that the increase in capillary blood volume by insulin is the result of the recruitment of previously unperfused capillaries. Intravital microscopy of muscle microcirculation using transillumination can only be performed in an invasive manner on specialized muscle preparations, and is therefore not applicable in human subjects. Hence, a new approach was developed in our laboratory to measure glycocalyx properties using epi-illumination of easily accessible tissues in the human, such as under the tongue. Herefore, an already available handheld Sidestream Darkfield (SDF) camera was used in combination with newly developed software, which analyzed the temporal and spatial variation in width of the RBC column in the microvasculature to delineate the barrier properties of the glycocalyx [29,30,31]. While in the intravital microscopy studies transillumination of cremaster tissue at a high magnification enables the endothelial lining of individual capillaries to be depicted and blood-excluded glycocalyx properties to be determined from the time-averaged gap between the circulating RBCs and the endothelium [32,33], SDF imaging is performed at a relative low magnification using epi-illumination, and as a result visualization of the anatomic boundaries of the microvessels is troublesome [34]. Therefore, the novel analysis uses the dynamic range of the RBC column width to determine the position of the outer edge of the RBC perfused core as a reflection of the glycocalyx properties. To validate these measurements, a direct test to determine whether loss of glycocalyx dimension is reflected by outward radial displacement of circulating RBCs has been performed using intravital microscopy. For this experiment, mice (FVB/N background) which express a Green Fluorescent Protein (GFP) under the direction of the endothelialspecific receptor tyrosine (Tie2) were used (GFP-EC mice). In these mice, endothelial cells can be imaged and localized by their specific expression of GFP. These GFPEC mice were prepared for intravital microscopic observation of the cremasteric microcirculation as described in chapter 2 . Microvessels were alternately observed at high magnification using bright-field microscopy with a $435 \mathrm{~nm}$ band pass interference filter (blue light) in the light path for depiction of the RBC column and epi-illumination for examination of the GFP signal using the appropriate filters for fluorescein. Two images (Fig 8.2), were used to measure the anatomic vessel width by determining the position of the endothelium by the GFP intensity peaks while the perfused diameter was measured by determining the width of the RBC profile at half height intensity. From 
these measurements, the RBC-EC gap, i.e., the space between endothelial cells and RBC column, was determined by calculating the difference between the vessel diameter and the perfused diameter divided by two (as the gap is present on both sides of the RBC column). For in total 16 vessels in 7 mice, paired measurements were performed before and 30 minutes after hyaluronidase treatment (35 U, jugular vein infusion) to be able to determine the effect of glycocalyx degradation on the outward displacement of the RBC column. We showed that enzymatic degradation using hyaluronidase resulted in an outward movement of the outer edge of the RBC column towards the endothelium by $0.8 \pm 0.3$, without a significant in vessel diameter, indicating that measuring the dynamic range of the RBC column width can be used as a reflection of the glycocalyx barrier properties [35].
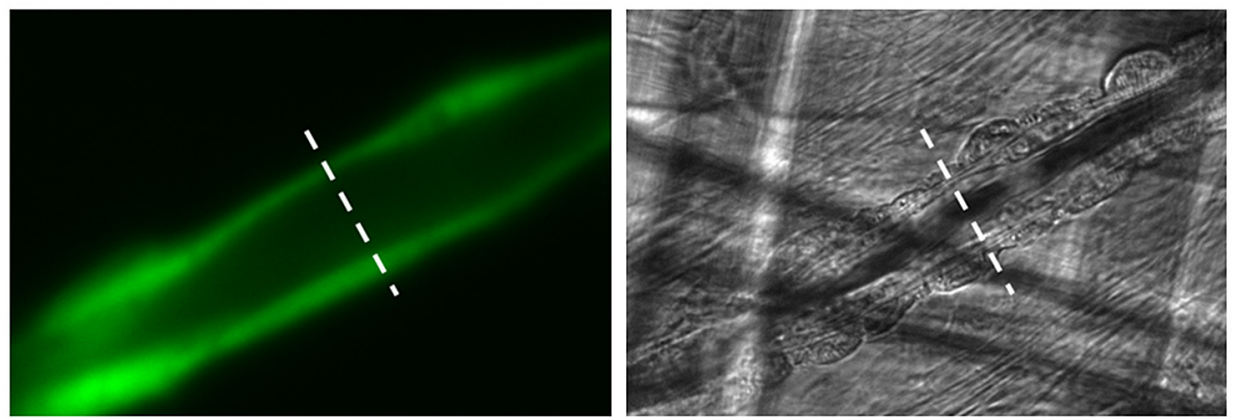

Fig 8.2 Example of the epifluorescence- (GFP, green) and trans-illumination (RBC, black) images made for measurement of both the microvessel width using the endothelial cell GFP signal and the perfused diameter using the RBC column width.

In anesthetized rodents, SDF imaging can also be performed on hindlimb muscle. In contrast to the cremaster muscle, the hindlimb muscle truly represents a skeletal muscle, which is a major target for insulin-mediated glucose uptake and storage. In chapter 3, we used this technique to measure glycocalyx barrier properties on the hindlimb muscle of rats before and during a constant infusion of insulin $(6 \mathrm{mU} / \mathrm{min} / \mathrm{kg})$. The results showed that insulin infusion resulted in a rapid outward movement of RBCs into the glycocalyx domain in the microvasculature. This insulin-mediated impairment of the glycocalyx barrier properties coincided with a rapid increase in capillary tube hematocrit, in line with the results obtained in mice in chapter 2 . In contrast, after enzymatic glycocalyx degradation using hyaluronidase the ability of insulin to modulate glycocalyx properties and to increase capillary blood volume in individual capillaries was impaired. These data support our hypothesis that modulation of the glycocalyx is involved in the rapid insulin-mediated increase in microvascular blood volume in muscle. 


\section{Role of the glycocalyx in the transcapillary transport of insulin}

It has been suggested that the rapid insulin-mediated increase in capillary blood volume would facilitate the delivery of insulin towards the skeletal muscle tissue [12]. We showed in chapter 3 that insulin increased microvascular blood volume by glycocalyx modulation within 5-10 minutes, but the relevance of this rapid volume increase for the transcapillary exchange of insulin was not determined. In a pilot study we, therefore, determined the rate by which insulin is exchanged from the capillaries towards the interstitium in the cremaster muscle, using Two-Photon laser scanning microscopy and fluorescently labeled insulin. In $\mathrm{C} 57 \mathrm{Bl} / 6$ mice, the cremaster muscle was exposed as described in chapter 2 , and $0.05 \mathrm{ml}$ of Texas-red 70kDa dextrans (Dex70) (10mg/ $\mathrm{mL}$ ) was infused to demarcate the capillary network. 10 minutes later, $0.05 \mathrm{~mL}$ of FITC labeled insulin $(0.6125 \mathrm{mg} / \mathrm{mL})$ was intravenously infused in the mouse. The intravascular, as well as the extravascular fluorescence intensities of Dex70 and insulin were followed in time, and the percentage of the extravascular concentration compared to the intravascular concentration was calculated as a measure of the extravasation of the tracer (Fig 8.3 A). During control conditions Dex70, which is partially excluded by the glycocalyx $[28,36,37]$, was shown to be primarily confined to the intravascular space. In contrast, insulin was shown to rapidly leak out of the capillaries and to enter the cremaster tissue. This is in line with the study of Barrett and coworkers [18,38], who showed that FITC labeled insulin rapidly (within 10 minutes) disappeared from the blood and was taken up by the endothelial cells after intravenous administration in rats. They observed, in vivo [18] and ex vivo [18,38], that FITC-insulin was localized with insulin receptors in endothelial cells, and that blockade of these receptors diminished the transport of insulin across the endothelium, suggesting that the insulin binding to its receptor may play a role in insulin's movement into or across the endothelium.

To test the contribution of the glycocalyx to the insulin extravasation in the mouse cremaster, light-dye treatment was performed for 1-5 min [33] to degrade the glycocalyx. As a result of the treatment Dex70 started to extravasate rapidly, while the extravasation of insulin decreased. These pilot observations suggest that glycocalyx damage is associated with an impaired transcapillary exchange of insulin (Fig 8.3B and Fig 8.3D). 
A)

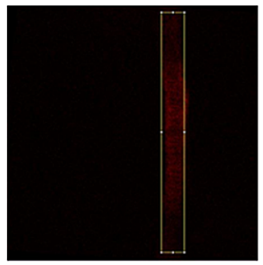

Intravascular

concentration

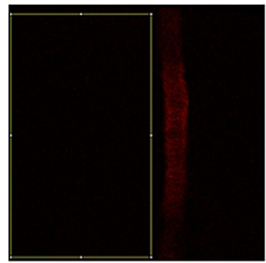

Extravascular concentration
B)

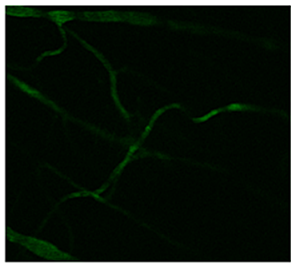

$\mathrm{t}=2 \mathrm{~min}$

after insulin infusion

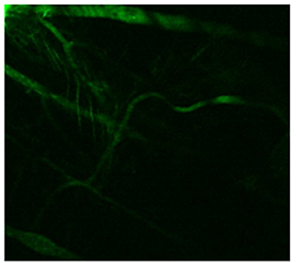

$\mathrm{t}=10 \mathrm{~min}$ after insulin infusion

C) extravascular Dex70 (\% of Intravascular Intensity)

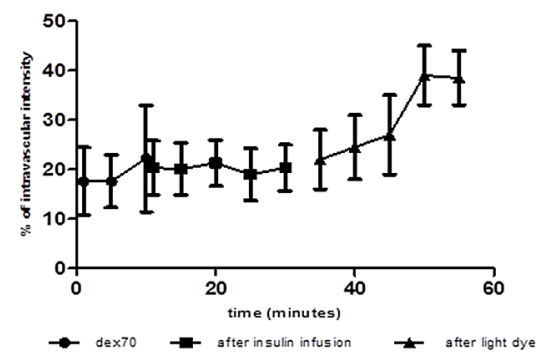

D) extravascular Insulln (\% of Intravascular Intensity)

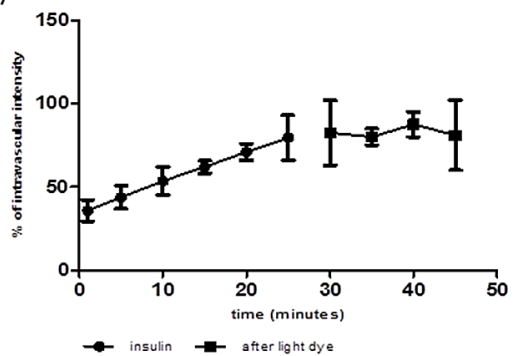

Fig 8.3 A) Example of a Dex 70 image of a cremaster microvessel (diameter $\sim 5 \mu \mathrm{m}$ ) visualized by two-photon microscopy. Intravascular (left) and extravascular (right) intensity of the tracer was measured in time and their ratio used to reflect the amount of extravasation. B. Visualization of time-dependent distribution of fluorescent insulin at relatively low magnification (field of view $158 \times 158 \mu \mathrm{m}$ ) in mouse cremaster muscle. It can be appreciated that the transcapillary leakage of FITC-insulin occurs rapidly C. Extravascular concentration of Dex70 relative to intravascular concentration in time $(n=5)$ D. Extravascular concentration of FITC-insulin relative to the intravascular concentration in time $(n=5)$.

In addition to the studies of Barrett and coworkers, we envision that the glycocalyx facilitates the transport of insulin from the blood towards the receptors on the endothelium. Experimental support for this interaction between the glycocalyx and the insulin receptors is sparse, except for one study which demonstrated a remarkable correlation between the localization of the insulin receptor and the presence of glycocalyx coating in isolated adipocytes [39]. It would be interesting to verify whether this association also holds for the endothelium. The impaired insulin extravasation after light-dye treatment might thus reflect a compromised transport of insulin through the glycocalyx mesh towards its receptors on the endothelium. Of note however, almost $80 \%$ of the insulin was already outside the vessel when light-dye treatment was performed and therefore the reduction in extravasation might be caused by the fact that the amount of insulin outside the vessel was already saturated. Further experiments are needed to support these pilot data. In order to appreciate the rate of insulin extravasation, the transport of insulin needs to be compared to the rate of extravasation of inulin, an inert molecule of a similar same size as insulin. Furthermore, it would be worthwhile 
to follow the transport of insulin in more detail, and investigate if, like mentioned by Barrett and coworkers, insulin is first taken up and processed by the endothelial cells before it is transported towards the interstitium, and whether this process is impaired after glycocalyx degradation. Given the intrinsic structural and functional association between the glycocalyx and the endothelial cells, it can be anticipated that pathophysiological conditions associated with degradation of the glycocalyx may also affect the number of functional insulin receptors on the endothelium. A strong link between matrix-metalloprotease (MMP) activation and shedding of glycocalyx components has been found in response to inflammatory and ischemic stimuli, for example [40], and proteolytic cleavage of the insulin receptor by MMP activation has been suggested a mechanism contributing to insulin resistance [41].

\section{The glycocalyx is involved in regulation of insulin sensitivity}

Based on previous studies which showed a strong association between the ability of insulin to increase microvascular blood volume and to dispose glucose in muscle, we hypothesized that insulin-mediated glycocalyx modulation is important for insulinmediated glucose disposal, and hence insulin sensitivity. In chapter $\mathbf{3}$ we showed that acute enzymatic glycocalyx degradation in the rats was associated with a 35\% reduction in insulin-mediated glucose disposal from the circulation during an IVITT. While these observations were performed in anesthetized rats requiring a supraphysiological dose of insulin $(1 \mathrm{U} / \mathrm{kg})$, we confirmed these results in conscious rats using a more physiological concentration of insulin $(0.1 \mathrm{U} / \mathrm{kg})$ in chapter 4 . Further, in line with the reduction in insulin sensitivity found with the IVITTs, it appeared that about 1.5 fold more insulin was needed to dispose an intravenously infused glucose load during an IVGTT in rats that had received a bolus of hyaluronidase compared to control rats. These data indicate that damage to the endothelial glycocalyx may contribute to the development of insulin resistance, but that acute compensation of the $\beta$-cells cause normal glucose tolerance to be maintained. It was not possible to identify from our data whether the increased insulin release was due to a direct effect of the hyaluronidase bolus on the pancreas, or whether it reflected the accurate feed-back of the decrease in peripheral insulin sensitivity. Nevertheless, the compensation appeared to be immediate, exemplifying the proficiency of glucoregulation of the body. This compensation is expected to fail at the long term when there is a loss of $\beta$-cell mass, causing hyperglycemia to develop, and finally leading to diabetes $[42,43,44]$. Future studies aiming at a chronic degradation of the endothelial glycocalyx are needed to evaluate the staging of these processes.

To verify that the reduction in glucose disposal rate during the IVITT reflected an impaired insulin action at the skeletal muscle and not the liver, we looked at the cellular 
activation of insulin pathways in both tissues in a few rats in chapter 4 . Herefore, the soleus muscle and liver at the end of the IVITT were collected, and we looked at insulin signaling in these tissues. Tissues were isolated at $\mathrm{t}=30 \mathrm{~min}$ after the insulin injection, and immediately frozen at $-80^{\circ} \mathrm{C}$. After crushing, western blotting was performed to measure the amount of phosphorylated Akt (pAkt) and total Akt. Total Akt served as a loading control, and the ratio of pAkt to total Akt was calculated as a measure of soleus and liver activation by insulin in the animals. We found that the amount of Akt phosphorylated after the IVITT tended to be decreased in the hyaluronidase treated rats, indicating that the amount of insulin that was delivered towards the muscle and activating signaling pathways in the myocytes was indeed decreased. In contrast in the liver there was no difference in Akt phosphorylation between the control rats and the hyaluronidase treated rats (Fig. 8.4). These pilot data support the role of the glycocalyx in regulation of insulin-mediated glucose uptake in skeletal muscle. While in the presence of a healthy glycocalyx, insulin is rapidly and effectively delivered to the skeletal muscle cells to stimulate glucose uptake, insulin delivery and subsequent glucose uptake seems impaired when the glycocalyx is damaged.

Skeletal muscle (soleus)

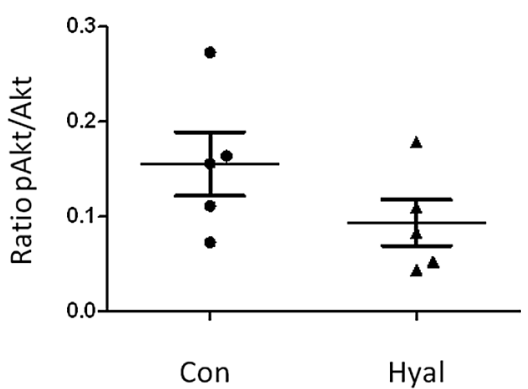

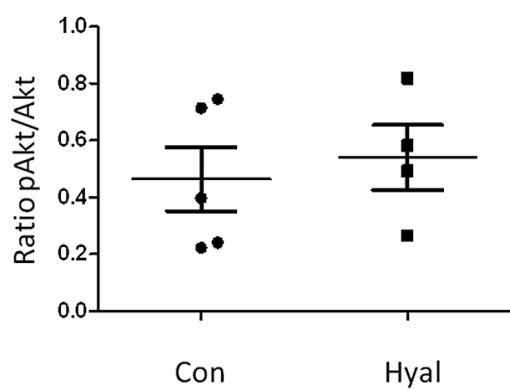

Con

Liver

Fig 8.4 The ratio of pAkt to total Akt measured in the soleus muscle (left panel) and liver (right panel) of control animals and hyaluronidase treated animal after an IVITT (data from a subset of animals as described in Chapter 3).

\section{Glycocalyx damage develops during diet-induced obesity}

Since our results showed that acute enzymatic degradation of the glycocalyx resulted in a decreased insulin sensitivity in skeletal muscle, the next step was to test if glycocalyx damage in muscle was evident during pathophysiological conditions associated with the development of insulin resistance. The global epidemic of obesity is driving the increased incidence and prevalence of insulin resistance and its cardiovascular complications $[45,46,47]$. Therefore, we tested if damage to the glycocalyx in muscle is an early event 
in diet-induced obesity (DIO). We measured the barrier properties of the glycocalyx and glucose tolerance in the high-fat diet (HFD) mouse model, which is frequently used to study mechanisms of impaired glucose tolerance and (early) type 2 diabetes. In chapter $\mathbf{5}$ we showed that the glycocalyx barrier properties in hindlimb muscle microcirculation of HFD-fed mice were impaired after 6 weeks already, before the manifestation of overt glucose intolerance, as evidenced from the absence of a significant increase in integrated blood glucose levels in response to a glucose tolerance test. In the following 12 weeks of the diet, glucose intolerance developed while glycocalyx barrier properties remained impaired to the same extent. These data, therefore, indicate that glycocalyx damage is an early event in diet-induced obesity. Based on the studies described in chapter 3 and 4 , we suggest that the early glycocalyx damage may actually also contribute to the development of insulin resistance in these conditions. Whereas 6 weeks of DIO was the earliest time point in which the glycocalyx barrier properties were evaluated in our study, other studies have shown evidence of even earlier vascular alterations in this model $[48,49]$. Kim and co-workers determined the time course of the development of inflammation and insulin resistance in various tissues and found biochemical evidence of inflammation, endothelial dysfunction, and insulin resistance in the thoracic aorta already after one week, which was much earlier than the appearance of these impairments in liver, skeletal muscle, and adipose tissue. These observations indicate that the vasculature is more susceptible than other tissues to the deleterious effects of nutrient overload. With the glycocalyx fulfilling the important role as gate-keeper protecting the vascular wall and the endothelium, prevention of glycocalyx damage or restoration of glycocalyx barrier properties in insulin resistant prone conditions should be taken into consideration when attempting to hinder the pathogenesis of diabetes.

\section{Restoration of glycocalyx barrier properties: therapeutic opportunities}

Since the endothelium has been indicated to play an important role in the delivery of insulin and glucose towards its target tissues, this compartment is a promising target for both diabetes and cardiovascular complications [50]. Several therapies have already been developed, however not yet applied in humans, which were indicated to improve endothelial function and thereby insulin-mediated glucose disposal, e.g. therapies to improve NO bioactivity [51,52], to recruit muscle microvasculature [53], to decrease ET-1 activity $[54,55]$ and to improve vascular insulin signaling $[56,57,58]$. Since we showed that damage to the glycocalyx develops during conditions of obesity at a time point which may well precede the development of endothelial dysfunction and overt glucose intolerance, we hypothesized that restoration or prevention of obesity-induced glycocalyx damage would delay or prohibit the development of insulin resistance and 
ultimately type II diabetes in this model. In the current thesis we, therefore, evaluated the effects of the well-known anti-diabetic drug metformin and of the glycocalyx-mimetic sulodexide in chapter 6 and 7. Metformin is the most prescribed anti-hyperglycemic drug worldwide. We were interested to evaluate this drug because it has been shown in previous studies that metformin may prevent cardiovascular complications, but the underlying mechanisms for this effect have not been resolved [59]. Therefore, we tested the effect of metformin on glycocalyx barrier properties in the same mouse model of type 2 diabetes which we used in chapter 2 , i.e., the $\mathrm{db} / \mathrm{db}$ mouse. Herefore, the distribution of large dextrans (70kDa dextrans), which are significantly excluded from the glycocalyx, and small dextrans (40kDa dextrans), having unlimited access to this domain, were measured. This technique has been used frequently to measure wholebody glycocalyx volumes in humans and experimental animals $[24,26,36,60,61,62]$. We found that the Dex70 excluding glycocalyx volume was significantly improved in the $\mathrm{db} /$ $\mathrm{db}$ mice by a two week treatment with metformin, and this improvement in glycocalyx barrier properties coincided with a reduced vascular clearance rate of this dextran compared to Dex40. From this it can be concluded that metformin improved glycocalyx dimensions; this improvement of glycocalyx function is suggested to contribute to the reported cardiovascular benefits of metformin. In chapter 7 , we also tested the effect of short-term metformin on insulin-mediated glucose homeostasis in mice that received the same HFD as used in chapter 5 to induce insulin resistance. We did not observe an effect of metformin on insulin-mediated glucose homeostasis in diet-induced obese (DIO) mice, suggesting that the beneficial effects of metformin on the barrier properties of the glycocalyx were insufficient to improve glucoregulation after two weeks already. While long-term metformin treatment has proven beneficial for insulin-mediated glucose homeostasis $[63,64]$, additional studies need to be performed to investigate the contribution of a potentially restored glycocalyx to this. In contrast to metformin, two weeks of sulodexide administration was found to improve glucose levels during an intraperitoneal glucose tolerance test in mice that were in an early stage of DIO. Sulodexide can be considered a more specific glycocalyx mimetic than metformin, and this component was previously shown to partially restore glycocalyx barrier properties in type II diabetic subjects [60]. Remarkably, the glucose and insulin levels measured in the HFD-fed mice which were treated with sulodexide were comparable to these levels measured in control mice, indicating that short-term sulodexide treatment at an early stage of DIO may completely restore insulin sensitivity induced by nutrient overload and prevent the development of diabetes in obesity. In the mice that were at a later stage of DIO sulodexide also improved insulin resistance, however not to the values measured in control mice. These data suggest that, the earlier the glycocalyx can be recovered in the development of peripheral insulin resistance, the better the 
improvement may be. Since we did not measure glycocalyx properties in this study, we cannot directly link the improvement of glucose tolerance to an improvement in glycocalyx barrier properties. However, Broekhuizen et al. [60] showed that sulodexide improved glycocalyx dimensions, using sublingual SDF imaging and dye-exclusion in the retina, in control human subjects, as well as in human subjects with type II diabetes. In their study sulodexide was administrated for 2 months instead of 2 weeks, however the concentration they used was 3-4 times lower than in our study. Altogether, noninvasive glycocalyx measurements in combination with a therapy that can recover the glycocalyx, like sulodexide, can be promising for subjects with impaired glucose tolerance as a result of insulin resistance. In addition to conventional drugs, recent interest has appeared for the use as functional foods as source for therapy and preventive strategy against metabolic diseases and their cardiovascular complications. Food containing polyphenols were, for example, shown to be associated with an improvement in endothelial function and insulin resistance [65]. It would be of great interest to evaluate the effect of these food components on the structural and functional properties of the endothelial glycocalyx. In the future more studies need to be performed to study the exact mechanisms by which these components, and other more conventional drugs, may improve the glycocalyx. This may ultimately lead to the development of novel and specific drugs which target protection of the endothelium and its associated glycocalyx, thereby sustaining microvascular perfusion and exchange, processes which are both essential for an optimal insulin-mediated glucoregulation.

\section{Conclusion}

The main results of the studies described in the current thesis are depicted in Figure 8.5. Damage to the glycocalyx may well be the "common soil" which links both endothelial dysfunction and (vascular) insulin resistance. While, it was described in previous studies that the glycocalyx is vulnerable to degradation by a variety of commonly known risk factors, and that the glycocalyx damage is accompanied by impairments in endothelial function $[6,7,31]$, the results of the current thesis indicate that glycocalyx damage is also accompanied by an impaired insulin-induced glucose uptake in muscle due to an inability of insulin to recruit microvascular blood volume and to promote transcapillary transport of insulin. We focused in the thesis on the detrimental effects of obesity, and it was shown that this risk factor induces glycocalyx damage already at an early time point. Since the number of obese subjects is increasing rapidly - the world health organization mentions that since 1980 obesity has nearly doubled and in 2008 more than $10 \%$ of the world's adult population was obese- and obesity is a major contributor to the prevalence of cardiovascular diseases $[66,67,68]$, the findings gathered in the 
studies described in this thesis seem very useful for therapeutic interventions in this group of people. Two potential therapeutics were already tested in the thesis and the results suggest that targeting the glycocalyx may indeed hinder the pathogenesis of (vascular) insulin resistance and finally type II diabetes.

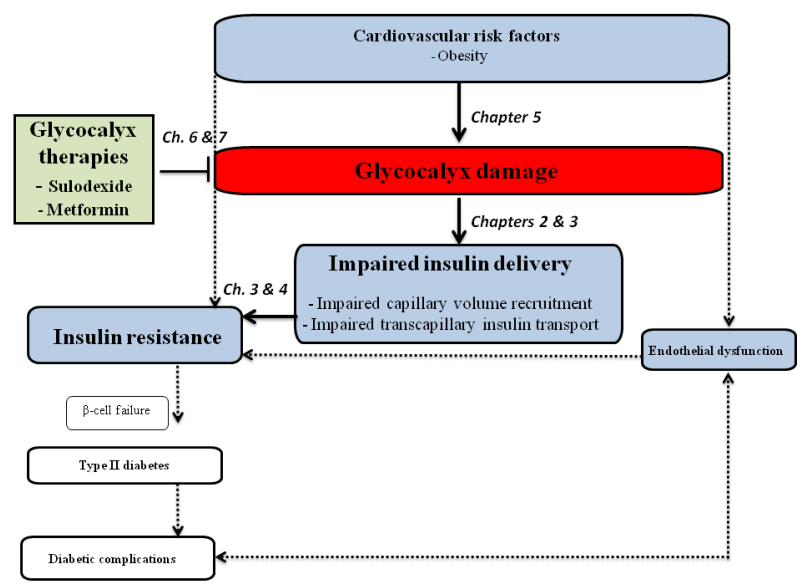

Fig 8.5 Overview of the main results of this thesis.

The glycocalyx constitutes the initial barrier between the circulating blood and the vascular wall with its endothelium. Glycocalyx damage as a result of exposure to cardiovascular risk factors, such as obesity, is accompanied by an inability of insulin to recruit microvascular blood volume in skeletal muscle, which will contribute to the development of insulin resistance and, when unrecognized and untreated for a long period, finally diabetes. Restoration of the glycocalyx at an early stage of insulin resistance may, however, delay or prevent the development of type II diabetes. Since glycocalyx degradation has been shown in earlier studies to induce endothelial dysfunction, glycocalyx damage may well underlie the well-described relation between endothelial dysfunction and insulin resistance. 


\section{References}

1. Kolka CM, Bergman RN (2013) The endothelium in diabetes: its role in insulin access and diabetic complications. Rev Endocr Metab Disord 14: 13-19.

2. Barrett EJ, Liu Z (2013) The endothelial cell: an "early responder" in the development of insulin resistance. Rev Endocr Metab Disord 14: 21-27.

3. Liu Z (2013) The vascular endothelium in diabetes and its potential as a therapeutic target. Rev Endocr Metab Disord 14: 1-3.

4. Sjoberg KA, Rattigan S, Hiscock N, Richter EA, Kiens B (2011) A new method to study changes in microvascular blood volume in muscle and adipose tissue: real-time imaging in humans and rat. Am J Physiol Heart Circ Physiol 301: H450-458.

5. Muniyappa R, Sowers JR (2013) Role of insulin resistance in endothelial dysfunction. Rev Endocr Metab Disord 14: 5-12.

6. Reitsma S, Slaaf DW, Vink H, van Zandvoort MA, oude Egbrink MG (2007) The endothelial glycocalyx: composition, functions, and visualization. Pflugers Arch 454: 345-359.

7. van den Berg BM, Nieuwdorp M, Stroes ES, Vink H (2006) Glycocalyx and endothelial (dys) function: from mice to men. Pharmacol Rep 58 Suppl: 75-80.

8. VanTeeffelen JW (2008) How to prevent leaky vessels during reperfusion? Just keep that glycocalyx sealant in place! Crit Care 12: 167.

9. Beresewicz A, Czarnowska E, Maczewski M (1998) Ischemic preconditioning and superoxide dismutase protect against endothelial dysfunction and endothelium glycocalyx disruption in the postischemic guinea-pig hearts. Mol Cell Biochem 186: 87-97.

10. Nieuwdorp M, van Haeften TW, Gouverneur MC, Mooij HL, van Lieshout MH, et al. (2006) Loss of endothelial glycocalyx during acute hyperglycemia coincides with endothelial dysfunction and coagulation activation in vivo. Diabetes 55: 480-486.

11. Salmon AH, Satchell SC (2012) Endothelial glycocalyx dysfunction in disease: albuminuria and increased microvascular permeability. J Pathol 226: 562-574.

12. Barrett EJ, Eggleston EM, Inyard AC, Wang H, Li G, et al. (2009) The vascular actions of insulin control its delivery to muscle and regulate the rate-limiting step in skeletal muscle insulin action. Diabetologia 52: 752-764.

13. Barrett EJ, Wang H, Upchurch CT, Liu Z (2011) Insulin regulates its own delivery to skeletal muscle by feed-forward actions on the vasculature. Am J Physiol Endocrinol Metab 301: E252-263.

14. Wascher TC, Wolkart G, Russell JC, Brunner F (2000) Delayed insulin transport across endothelium in insulin-resistant JCR:LA-cp rats. Diabetes 49: 803-809.

15. Bar RS, Boes M, Sandra A (1988) Vascular transport of insulin to rat cardiac muscle. Central role of the capillary endothelium. J Clin Invest 81: 1225-1233.

16. King GL, Johnson SM (1985) Receptor-mediated transport of insulin across endothelial cells. Science 227: 1583-1586. 
17. Schnitzer JE, Oh P, Pinney E, Allard J (1994) Filipin-sensitive caveolae-mediated transport in endothelium: reduced transcytosis, scavenger endocytosis, and capillary permeability of select macromolecules. J Cell Biol 127: 1217-1232.

18. Wang H, Liu Z, Li G, Barrett EJ (2006) The vascular endothelial cell mediates insulin transport into skeletal muscle. Am J Physiol Endocrinol Metab 291: E323-332.

19. Hamilton-Wessler M, Ader M, Dea MK, Moore D, Loftager M, et al. (2002) Mode of transcapillary transport of insulin and insulin analog NN304 in dog hindlimb: evidence for passive diffusion. Diabetes 51: 574-582.

20. Steil GM, Ader M, Moore DM, Rebrin K, Bergman RN (1996) Transendothelial insulin transport is not saturable in vivo. No evidence for a receptor-mediated process. J Clin Invest 97: 1497-1503.

21. Eggleston EM, Jahn LA, Barrett EJ (2007) Hyperinsulinemia rapidly increases human muscle microvascular perfusion but fails to increase muscle insulin clearance: evidence that a saturable process mediates muscle insulin uptake. Diabetes 56: 2958-2963.

22. Vincent MA, Clerk LH, Lindner JR, Klibanov AL, Clark MG, et al. (2004) Microvascular recruitment is an early insulin effect that regulates skeletal muscle glucose uptake in vivo. Diabetes 53: 1418-1423.

23. Zhang L, Vincent MA, Richards SM, Clerk LH, Rattigan S, et al. (2004) Insulin sensitivity of muscle capillary recruitment in vivo. Diabetes 53: 447-453.

24. Zuurbier CJ, Demirci C, Koeman A, Vink H, Ince C (2005) Short-term hyperglycemia increases endothelial glycocalyx permeability and acutely decreases lineal density of capillaries with flowing red blood cells. J Appl Physiol 99: 1471-1476.

25. Jacob M, Conzen P, Finsterer U, Krafft A, Becker BF, et al. (2007) Technical and physiological background of plasma volume measurement with indocyanine green: a clarification of misunderstandings. J Appl Physiol (1985) 102: 1235-1242.

26. VanTeeffelen JW, Brands J, Janssen BJ, Vink H (2013) Effect of acute hyaluronidase treatment of the glycocalyx on tracer-based whole body vascular volume estimates in mice. J Appl Physiol 114: 1132-1140.

27. Platts SH, Duling BR (2004) Adenosine A3 receptor activation modulates the capillary endothelial glycocalyx. Circ Res 94: 77-82.

28. VanTeeffelen JW, Constantinescu AA, Brands J, Spaan JA, Vink H (2008) Bradykinin- and sodium nitroprusside-induced increases in capillary tube haematocrit in mouse cremaster muscle are associated with impaired glycocalyx barrier properties. J Physiol 586: 32073218.

29. Martens RJ, Vink H, van Oostenbrugge RJ, Staals J (2013) Sublingual microvascular glycocalyx dimensions in lacunar stroke patients. Cerebrovasc Dis 35: 451-454.

30. Mulders TA, Nieuwdorp M, Stroes ES, Vink H, Pinto-Sietsma SJ (2013) Non-invasive assessment of microvascular dysfunction in families with premature coronary artery disease. Int J Cardiol.

31. Vlahu CA, Lemkes BA, Struijk DG, Koopman MG, Krediet RT, et al. (2012) Damage of the endothelial glycocalyx in dialysis patients. J Am Soc Nephrol 23: 1900-1908. 
32. Constantinescu AA, Vink H, Spaan JA (2001) Elevated capillary tube hematocrit reflects degradation of endothelial cell glycocalyx by oxidized LDL. Am J Physiol Heart Circ Physiol 280: H1051-1057.

33. Vink H, Duling BR (1996) Identification of distinct luminal domains for macromolecules, erythrocytes, and leukocytes within mammalian capillaries. Circ Res 79: 581-589.

34. Goedhart PT, Khalilzada M, Bezemer R, Merza J, Ince C (2007) Sidestream Dark Field (SDF) imaging: a novel stroboscopic LED ring-based imaging modality for clinical assessment of the microcirculation. Opt Express 15: 15101-15114.

35. Dane MJ, Khairoun M, Lee DH, van den Berg BM, Eskens BJ, et al. (2014) Association of Kidney Function with Changes in the Endothelial Surface Layer. Clin J Am Soc Nephrol.

36. Henry CB, Duling BR (1999) Permeation of the luminal capillary glycocalyx is determined by hyaluronan. Am J Physiol 277: H508-514.

37. Vink H, Duling BR (2000) Capillary endothelial surface layer selectively reduces plasma solute distribution volume. Am J Physiol Heart Circ Physiol 278: H285-289.

38. Genders AJ, Frison V, Abramson SR, Barrett EJ (2013) Endothelial cells actively concentrate insulin during its transendothelial transport. Microcirculation 20: 434-439.

39. Jarett L, Smith RM (1975) Ultrastructural localization of insulin receptors on adipocytes. Proc Natl Acad Sci U S A 72: 3526-3530.

40. Lipowsky HH (2011) The endothelial glycocalyx as a barrier to leukocyte adhesion and its mediation by extracellular proteases. Ann Biomed Eng 40: 840-848.

41. DeLano FA, Schmid-Schonbein GW (2008) Proteinase activity and receptor cleavage: mechanism for insulin resistance in the spontaneously hypertensive rat. Hypertension 52 : 415-423.

42. Bergman RN, Finegood DT, Kahn SE (2002) The evolution of beta-cell dysfunction and insulin resistance in type 2 diabetes. Eur J Clin Invest 32 Suppl 3: 35-45.

43. Prentki M, Nolan CJ (2006) Islet beta cell failure in type 2 diabetes. J Clin Invest 116: 18021812.

44. Weir GC, Bonner-Weir S (2004) Five stages of evolving beta-cell dysfunction during progression to diabetes. Diabetes 53 Suppl 3: S16-21.

45. Kahn BB, Flier JS (2000) Obesity and insulin resistance. J Clin Invest 106: 473-481.

46. Kahn SE, Hull RL, Utzschneider KM (2006) Mechanisms linking obesity to insulin resistance and type 2 diabetes. Nature 444: 840-846.

47. Reaven GM (1988) Banting lecture 1988. Role of insulin resistance in human disease. Diabetes 37: 1595-1607.

48. Kim F, Pham M, Maloney E, Rizzo NO, Morton GJ, et al. (2008) Vascular inflammation, insulin resistance, and reduced nitric oxide production precede the onset of peripheral insulin resistance. Arterioscler Thromb Vasc Biol 28: 1982-1988. 
49. St-Pierre P, Genders AJ, Keske MA, Richards SM, Rattigan S (2010) Loss of insulin-mediated microvascular perfusion in skeletal muscle is associated with the development of insulin resistance. Diabetes Obes Metab 12: 798-805.

50. Eringa EC, Serne EH, Meijer RI, Schalkwijk CG, Houben AJ, et al. (2013) Endothelial dysfunction in (pre)diabetes: characteristics, causative mechanisms and pathogenic role in type 2 diabetes. Rev Endocr Metab Disord 14: 39-48.

51. Ayala JE, Bracy DP, Julien BM, Rottman JN, Fueger PT, et al. (2007) Chronic treatment with sildenafil improves energy balance and insulin action in high fat-fed conscious mice. Diabetes 56: 1025-1033.

52. Carlstrom M, Larsen FJ, Nystrom T, Hezel M, Borniquel S, et al. (2010) Dietary inorganic nitrate reverses features of metabolic syndrome in endothelial nitric oxide synthasedeficient mice. Proc Natl Acad Sci U S A 107: 17716-17720.

53. Fu Z, Zhao L, Chai W, Dong Z, Cao W, et al. (2013) Ranolazine recruits muscle microvasculature and enhances insulin action in rats. J Physiol 591: 5235-5249.

54. Lteif A, Vaishnava P, Baron AD, Mather KJ (2007) Endothelin limits insulin action in obese/ insulin-resistant humans. Diabetes 56: 728-734.

55. Shemyakin A, Salehzadeh F, Esteves Duque-Guimaraes D, Bohm F, Rullman E, et al. (2011) Endothelin-1 reduces glucose uptake in human skeletal muscle in vivo and in vitro. Diabetes 60: 2061-2067.

56. Booth G, Stalker TJ, Lefer AM, Scalia R (2002) Mechanisms of amelioration of glucoseinduced endothelial dysfunction following inhibition of protein kinase $\mathrm{C}$ in vivo. Diabetes 51: 1556-1564.

57. Murakami T, Frey T, Lin C, Antonetti DA (2012) Protein kinase cbeta phosphorylates occludin regulating tight junction trafficking in vascular endothelial growth factor-induced permeability in vivo. Diabetes 61: 1573-1583.

58. Tabit CE, Shenouda SM, Holbrook M, Fetterman JL, Kiani S, et al. (2012) Protein kinase C-beta contributes to impaired endothelial insulin signaling in humans with diabetes mellitus. Circulation 127: 86-95.

59. Bailey CJ (2008) Metformin: effects on micro and macrovascular complications in type 2 diabetes. Cardiovasc Drugs Ther 22: 215-224.

60. Broekhuizen LN, Lemkes BA, Mooij HL, Meuwese MC, Verberne H, et al. (2010) Effect of sulodexide on endothelial glycocalyx and vascular permeability in patients with type 2 diabetes mellitus. Diabetologia 53: 2646-2655.

61. Cabrales P, Vazquez BY, Tsai AG, Intaglietta M (2007) Microvascular and capillary perfusion following glycocalyx degradation. J Appl Physiol 102: 2251-2259.

62. Nieuwdorp M, Mooij HL, Kroon J, Atasever B, Spaan JA, et al. (2006) Endothelial glycocalyx damage coincides with microalbuminuria in type 1 diabetes. Diabetes 55: 1127-1132.

63. DeFronzo RA, Barzilai N, Simonson DC (1991) Mechanism of metformin action in obese and lean noninsulin-dependent diabetic subjects. J Clin Endocrinol Metab 73: 1294-1301. 
64. Musi N, Hirshman MF, Nygren J, Svanfeldt M, Bavenholm P, et al. (2002) Metformin increases AMP-activated protein kinase activity in skeletal muscle of subjects with type 2 diabetes. Diabetes 51: 2074-2081.

65. Munir KM, Chandrasekaran S, Gao F, Quon MJ (2013) Mechanisms for food polyphenols to ameliorate insulin resistance and endothelial dysfunction: therapeutic implications for diabetes and its cardiovascular complications. Am J Physiol Endocrinol Metab 305: E679686.

66. Eckel RH (1997) Obesity and heart disease: a statement for healthcare professionals from the Nutrition Committee, American Heart Association. Circulation 96: 3248-3250.

67. Lavie CJ, Milani RV, Ventura HO (2009) Obesity and cardiovascular disease: risk factor, paradox, and impact of weight loss. J Am Coll Cardiol 53: 1925-1932.

68. Whitlock G, Lewington S, Sherliker P, Clarke R, Emberson J, et al. (2009) Body-mass index and cause-specific mortality in 900000 adults: collaborative analyses of 57 prospective studies. Lancet 373: 1083-1096. 


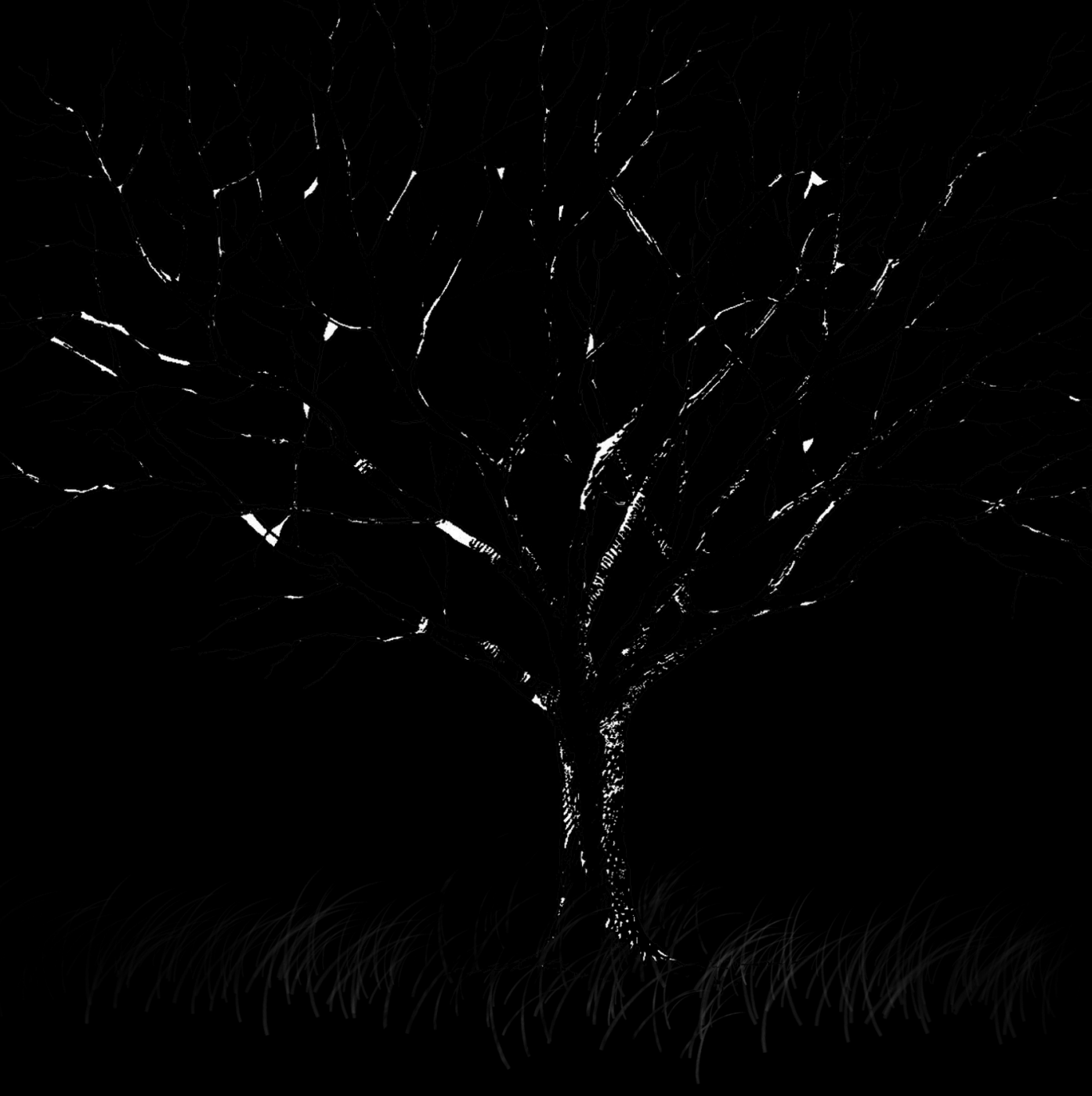


Chapter 9

Appendix 


\section{Summary}

In this thesis the role of the endothelial glycocalyx in the regulation of insulin sensitivity in the muscle was investigated. The glycocalyx is the protective layer between the endothelium and the circulating blood, and was previously shown to be involved in multiple aspects of endothelial function. While endothelial dysfunction has been associated with the development of insulin resistance and ultimately type II diabetes, the actual relation between both has been unclear in the past. We hypothesized that a damaged glycocalyx may be the missing link.

The glycocalyx is the first compartment which nutrients (e.g. glucose) and hormones (e.g. insulin) encounter when they pass through the circulation towards the insulindependent tissues, such as the skeletal muscle. In chapter $\mathbf{1}$ a general introduction is provided, in which the possible interaction between the endothelial glycocalyx and the delivery of insulin towards its target tissues is described.

In chapter 2, the effect of insulin on capillary blood volume was tested. It was demonstrated that administration of insulin onto the cremaster muscle in $\mathrm{C} 57 \mathrm{Bl} / 6$ mice was associated with an increase in tube hematocrit in individual capillaries. In contrast, topical insulin administration onto the cremaster muscle of diabetic mice (db/ $\mathrm{db}$ mice), which were previously associated with glycocalyx loss, was associated with a reduction in the number of blood-perfused capillaries and a lack of effect on blood volume in the remaining capillaries.

In chapter 3, the effect of insulin on the glycocalyx and its relation to insulinmediated recruitment of microvascular blood volume was studied. Using SDF imaging, in combination with our newly developed software to measure glycocalyx barrier properties in the microcirculation, we showed that during healthy conditions insulin was able to rapidly modulate the glycocalyx in such a way that microvascular blood volume within already perfused microvessels could increase. In rats, in which the endothelial glycocalyx was enzymatically degraded by a single bolus of hyaluronidase the ability of insulin to recruit microvascular blood volume was, however, impaired, and this was associated with an impaired insulin-mediated glucose disposal during an intravenous insulin tolerance test.

While these studies were performed in anesthetized rats, in chapter 4 we confirmed that glycocalyx degradation is associated with an impaired insulin-mediated glucose disposal measured in conscious rats under more physiological conditions. Furthermore, 
in this study we showed that, in line with the reduction in insulin sensitivity, about 1.5 fold more insulin was needed to dispose intravenously infused glucose in the rats in which glycocalyx damage was induced. These data indicate that acute glycocalyx damage triggers the development of insulin resistance, but that in an early stage the induced insulin resistance can be compensated by an increased insulin release by the pancreas.

Since obesity has been associated with insulin resistance and endothelial dysfunction, in chapter $\mathbf{5}$ it was tested if glycocalyx damage was an early event in the development of diet-induced obesity (DIO). We showed that glycocalyx barrier properties were impaired already after 6 weeks of high fat diet (HFD) in mice, before glucose intolerance was fully manifested. In the following 12 weeks of feeding a HFD to mice, glucose intolerance developed, without a further impairment of glycocalyx barrier properties. These data indicate that glycocalyx damage is an early event in DIO.

From the previous data, we were interested in therapeutic opportunities for glycocalyx restoration and their effect on insulin sensitivity. In chapter 6 , the effect of short-term metformin administration on glycocalyx barrier properties was measured in $\mathrm{db} / \mathrm{db}$ mice. Metformin is the most prescribed anti-hyperglycemic drug worldwide, and while it has been shown by others that metformin improves endothelial dysfunction, the exact mechanism for this effect is still unknown. Evaluation of the whole-body distribution of large $(70 \mathrm{kDa})$ versus small dextrans $(40 \mathrm{kDa})$, revealed that two weeks of metformin in the drinking water improved the glycocalyx barrier properties in the $\mathrm{db} / \mathrm{db}$ mice. It is anticipated that the metformin-mediated improvement of the glycocalyx may contribute to the reported cardiovascular benefits of metformin.

In chapter 7 the effect of two week treatment of metformin as well as of the suggested glycocalyx mimetic sulodexide on improving insulin resistance in the HFD mouse was studied. We did not observe an effect of metformin on insulin-mediated glucose homeostasis in diet-induced obese (DIO) mice, suggesting that the beneficial effects of metformin on the barrier properties of the glycocalyx were insufficient to improve glucoregulation after two weeks already. Sulodexide, in constrast, did improve glucose levels measured during an intraperitoneal glucose tolerance test in mice which had received the HFD for 6 weeks. Also, at a later stage of DIO (18 weeks), short-term sulodexide treatment was shown to improve insulin resistance. Sulodexide was previously shown to partially restore glycocalyx barrier properties in type II diabetic subjects and appears to be a promising glycocalyx therapy. 
The findings of the current thesis are discussed in chapter 8. We conclude that glycocalyx damage seems to be a "common soil" for endothelial dysfunction and (vascular) insulin resistance. The glycocalyx may, therefore, be a very useful target for diagnosis and therapeutic interventions in obese people, because of their increased risk for developing insulin resistance and type II diabetes, and ultimately cardiovascular disease. 


\section{Nederlandse samenvatting}

In dit proefschrift is de rol van de endotheliale glycocalyx in de regulatie van insuline gevoeligheid in de spier onderzocht. De glycocalyx is de beschermende laag tussen het endotheel en het circulerende bloed, en recentelijk is aangetoond dat de glycocalyx betrokken is bij verschillende aspecten van endotheliale dysfunctie. Endotheliale dysfunctie is in eerdere studies geassocieerd met de ontwikkeling van insuline resistentie, maar de precieze relatie tussen beide is onduidelijk gebleven in het verleden. Onze hypothese is dat een beschadigde glycocalyx de missende link is.

De glycocalyx is het eerste compartiment dat nutriënten (bijv. glucose) en hormonen (bijv. insuline) tegenkomen wanneer ze door het circulerende bloed naar de insulinegevoelige weefsels, zoals de spieren, gaan. Hoofdstuk $\mathbf{1}$ is een algemene introductie, waarin de mogelijke interactie tussen de endotheliale glycocalyx en het transport van insuline naar de insuline-gevoelige weefsels is beschreven.

In hoofdstuk 2 is het effect van insuline op het bloedvolume in de haarvaten onderzocht. Er is aangetoond dat toediening van insuline op de cremaster spier van muizen samengaat met een toename in hematocriet in haarvaten. In tegenstelling, toediening van insuline op de cremaster spier van diabetische muizen, waarin eerder glycocalyx beschadiging aangetoond is, gaat samen met een afname in het aantal met bloed gevulde haarvaten. Verder was in deze muizen een effect van insuline op een toename in bloedvolume afwezig.

In hoofdstuk 3 is het effect van insuline op de glycocalyx en de relatie tot de insulingemedieerde toename van het bloedvolume in de haarvaten bestudeerd. Met SDF opgenomen beelden, in combinatie met door ons nieuw ontwikkelde software om de glycocalyx barrière eigenschappen in de microcirculatie te meten, hebben we aangetoond dat tijdens gezonde condities insuline in staat is om de glycocalyx snel te moduleren op een manier dat het bloedvolume in de haarvaten toeneemt. In ratten, waarin de endotheliale glycocalyx enzymatisch beschadigd was met behulp van een eenmalige bolus van hyaluronidase, is de mogelijkheid van insuline om het bloed volume in de haarvaten te laten toenemen afgenomen. Deze afname ging samen met een verminderde insuline-gemedieerde glucose opname tijdens een intraveneuze insuline tolerantie test.

Deze vorige studies zijn uitgevoerd in ratten die onder anesthesie waren, maar in

hoofdstuk 4 is bevestigd dat afbraak van de glycocalyx ook in wakkere ratten, tijdens 
meer fysiologische condities, samengaat met een afgenomen insuline-gemedieerde glucose opname. Verder is in deze studie aangetoond dat, in lijn met de afname in insuline gevoeligheid, ongeveer 1.5 keer meer insuline nodig is om een intraveneuze glucose toediening in ratten waarin glycocalyx schade geïnduceerd was, te klaren. Deze data tonen aan dat acute glycocalyx beschadiging de ontwikkeling van insuline resistentie triggert, maar dat in een vroeg stadium de geïnduceerde insuline resistentie gecompenseerd kan worden door een verhoogde afgifte van insuline door de alvleesklier.

Omdat obesitas geassocieerd is met insuline resistentie en endotheel dysfunctie, is in hoofdstuk 5 getest of glycocalyx beschadiging vroeg voorkomt in de ontwikkeling van dieet-geïnduceerde obesitas. We hebben aangetoond dat de glycocalyx barrière eigenschappen reeds afgenomen zijn na toediening van een dieet met een hoog vet gehalte gedurende 6 weken in muizen, dit voordat glucose intolerantie volledig was ontwikkeld. In de daarop volgende 12 weken tijdens het voeden van het dieet met een hoog vet gehalte aan de muizen ontwikkelde glucose intolerantie zich, zonder een verdere afname van de glycocalyx barrière eigenschappen. Deze data tonen aan dat glycocalyx schade een vroegtijdig effect is in de onwikkeling van dieet-geïnduceerde obesitas.

Vanuit bovengenoemde data waren we geïnteresseerd in de therapeutische mogelijkheden voor glycocalyx herstel and het effect daarvan op insuline gevoeligheid. In hoofdstuk 6 is het effect van korte metformine toediening op glycocalyx barrière eigenschappen gemeten in obese muizen. Metformine is het meest voorgeschreven medicijn bij diabeten wereldwijd, en hoewel anderen hebben aangetoond dat metformine endotheliale dysfunctie verbetert is het precieze mechanisme voor dit effect vooralsnog onbekend. Evaluatie van de lichaamsdistributie van grote $(70 \mathrm{kDa})$ versus kleine dextranen $(40 \mathrm{kDa})$ toonde aan dat metformine gedurende twee weken in het drinkwater de glycocalyx barrière eigenschappen verbetert in obese muizen. Het is te verwachten dat de metformine-gemedieerde verbetering van de glycocalyx zal bijdragen aan de gerapporteerde voordelen op hart en bloedvaten van metformine.

In Hoofdstuk 7 is het effect van de behandeling van 2 weken metformine en van 2 weken sulodexide, een gesuggereerd glycocalyx mimeticum, op de verbetering van insuline resistentie in muizen die met een dieet met hoog vet gehalte gevoed werden getest. We vonden geen effect van metformine op de insuline-gemedieerde glucose homeostase in de muizen waarbij obesitas geïnduceerd was. Dit suggereert dat de voordelige effecten van 2 weken metformine op de barrière eigenschappen onvoldoende waren om de glucose regulatie al te verbeteren. Sulodexide daarentegen 
verbeterde de glucose spiegels gemeten tijdens een intraperitoneale glucose tolerantie test in muizen die met een dieet met een hoog vet gehalte voor 6 weken waren gevoed. Ook tijdens een later tijdstip na toediening van dit dieet (18 weken) is aangetoond dat sulodexide behandeling insuline resistentie verbetert. Het was al eerder aangetoond dat sulodexide gedeeltelijk de glycocalyx barrière eigenschappen in personen met type II diabetes verbetert. Sulodexide lijkt dus een veelbelovende therapie.

De bevindingen van dit proefschriift worden bediscussieerd in hoofdstuk 8. We concluderen dat glycocalyx schade de gemeenschappelijk basis lijkt te zijn voor endotheel dysfunctie en (vasculaire) insuline resistentie. De glycocalyx kan, daarom, een belangrijk doelwit zijn voor de diagnose en therapeutische behandeling van mensen met obesitas vanwege hun toenemende risico voor de ontwikkeling van insuline resistentie en type II diabetes, en uiteindelijk hart- en vaatziekten. 


\section{List of publications}

Eskens BJ, Vink H, VanTeeffelen JW Improvement of insulin resistance in diet-induced obese mice by sulodexide, an endothelial glycocalyx mimetic. 2014 Submitted

Dane MJ, Khairoun M, Lee DH, van den Berg BM, Eskens BJ, Boels MG, van Teeffelen JW, Rops AL, van der Vlag J, van Zonneveld AJ, Reinders ME, Vink H, Rabelink TJ. Association of Kidney Function with Changes in the Endothelial Surface Layer. Clin J Am Soc Nephrol. 2014: Jan 23. (published online before print).

Eskens BJ, Leurgens TM, Vink H, VanTeeffelen JW. Early impairment of skeletal muscle endothelial glycocalyx barrier properties in diet-induced obesity in mice. Physiol Rep. 2014: Jan 6 (published online before print).

Eskens BJ, Cobelens HE, Vink H, VanTeeffelen JW. Acute enzymatic glycocalyx degradation results in reduced insulin sensitivity but normal glucose tolerance in conscious rats. Cardiovascular Endocrinology 2013: Dec 18. (published online before print).

Eskens BJ, Zuurbier CJ, van Haare J, Vink H, van Teeffelen JW. Effects of two weeks of metformin treatment on whole-body glycocalyx barrier properties in $\mathrm{db} / \mathrm{db}$ mice. Cardiovasc Diabetol. 2013 Dec 5;12:175. (published online before print).

Eskens BJ, Mooij HL, Cleutjens JP, Roos JM, Cobelens JE, Vink H, Vanteeffelen JW. Rapid insulin-mediated increase in microvascular glycocalyx accessibility in skeletal muscle may contribute to insulin-mediated glucose disposal in rats. PLoS One. 2013;8(1):e55399.

Ketelslegers HB, Godschalk RW, Eskens BJ, Dallinga JW, Gottschalk RW, van Schooten FJ, van Delft JH, Kleinjans JC. Mol Carcinog. 2009 Aug;48(8):685-91. doi: 10.1002/ mc.20530. 


\section{Dankwoord}

De start van het schrijven van dit dankwoord betekent tegelijk ook het einde van het schrijven van dit proefschrift. In 2007 heb ik de kans gekregen om te beginnen aan dit traject op de afdeling Fysiologie aan de Universiteit van Maastricht. Tijdens deze periode waren er vele hoogtepunten, maar waren er ook momenten dat dit proefschrift een "never ending story" leek. Tijdens deze momenten zijn er gelukkig altijd mensen geweest om dit leed te delen of te helpen. Voor diegenen die mij geholpen hebben op wat voor manier dan ook is dit dankwoord.

First of all, I would like to thank my promotor Prof. Dr. Thomas Unger; I am really thankful that you agreed on being my promoter.

Dan een grote dank aan mijn co-promotoren Dr. Hans Vink en Dr. Jurgen van Teeffelen. Beste Hans, "mister glycocalyx", jouw enthousiasme voor de wetenschap werkt zeer aanstekelijk. Onze besprekingen/discussies werkten altijd zeer motiverend en ik ging hier altijd vandaan met nieuwe ideeën en zin om deze ideeën tot resultaten om te zetten. Ook wanneer ik het vertrouwen even verloor, na bijvoorbeeld een afwijzing van een manuscript, gaf jij dat vertrouwen meteen terug, wat uiteindelijk bijgedragen heeft tot meerdere publicaties en dit proefschrift.

Beste Jurgen, de samenwerking met jou heb ik altijd als zeer prettig ervaren. Je stond altijd klaar om te helpen en de juiste adviezen te geven. Je hebt me enorm geholpen met het opzetten van de experimenten en het interpreteren van de data. Verder heb je een enorme bijdrage geleverd aan het schrijven en reviseren van de manuscripten en dus aan het eindresultaat van dit proefschrift. Daarnaast was het in de mensa tijdens de maandagavondmaaltijden, op de squashbaan en in de bar tijdens congressen ook erg gezellig waarbij het niet alleen maar over wetenschap ging maar ook vaak over wielrennen en voetbal. Verder wil ik nog steeds graag revanche voor de verloren squashwedstrijd.

Dan wil ikgraag de rest van de glycocalyx groep bedanken voor de prettige samenwerking. Hanneke, hier is het dankwoord waar je zo vaak om gevraagd hebt. Uiteraard vergeet ik jou niet, jij hebt mij heel erg geholpen met mijn experimenten. Het verfijnde werk, wat in het begin niet altijd aan mij besteed was, beheers jij heel goed. Door jouw secure operaties heb ik de experimenten goed kunnen uitvoeren. Ook heb ik veel van je geleerd op het gebied van microchirurgie. Sjef en Sjak, kamergenoten, van jullie computer/matlab kennis heb ik vaak gebruik gemaakt, dit heeft heel erg geholpen met het analyseren van de data en veel computerergenissen voorkomen. Judith B, bedankt 
voor de hulp vooral ook bij congressen in mijn beginperiode. Martijn, jouw resultaten verkregen tijdens jouw afstudeerstage komen nog terug in de discussie van dit boekje. Succes met het afronden van jouw boekje. Judith $\mathrm{H}$, als laatste bij de glycocalyx groep gekomen, maar toch veel samengewerkt. Ook jij succes met het afronden van jouw boekje. Hans $\mathrm{M}$, ons onderzoek had veel raakvlakken en jouw kennis daarover heeft mij enorm geholpen, verder zal ik het congres in Vancouver niet snel vergeten. Bernard bedankt voor alle hulp in het begin vanuit Maastricht, maar later ook vanuit Leiden. Ook wil ik mijn studenten bedanken: Thomas, Marcel, Paul, Sascha, Baukje en Thijs. Ik heb jullie met veel plezier begeleid en hopelijk enthousiast(er) gemaakt voor het wetenschappelijk onderzoek. Jullie hebben in elk geval een nuttige bijdrage geleverd aan het onderzoek.

Dan wil ik uiteraard ook de mede- (oud) AIO's bedanken voor de steun en gezelligheid binnen en buiten het werk. Mark, Vries, bedankt voor de inbreng van jouw nuttige, maar vooral ook veel nutteloze kennis tijdens werk maar ook tijdens het drinken van speciaal bieren (voor jou vaak ook een 7-up). Felix, Flix, het congres in Los Angeles met de hottub op het dak zal ik niet snel vergeten. Bart $\mathrm{H}$, de karmelietjes om iets te vieren, de vele gezamenlijke congressen in binnen- en buitenland hebben tot leuke momenten geleid. Anneleen, met jou, zoals je het zelf noemt 'snelle-vele-babbel-persoonlijkheid' was het altijd gezellig. Vincenza, Paesana, the lunches and breaks in the afternoon with a kinderbueno were always very nice and helpful and I'll never forget the trip to Scario for your wedding. Kelly, Kelie, wat hebben we veel lol gehad, maar ook serieuze dingen besproken tijdens onze dagelijkse koffie's. Irma, $I L A$, bij jou kon ik altijd binnen lopen om over het werk te praten en voor de gezelligheid.

Dan wil ik verder ook Chantal, Sanne, Geertje en Allard bedanken voor alle hulp op de verschillende labs. Jullie stonden altijd klaar om mij te helpen en heb grote waardering daarvoor. Ook een dank aan Vivian en Bianca, bij jullie kon ik altijd aankloppen als ik iets nodig had. Verder wil ik uiteraard ook de overige collega's van de afdeling Fysiologie graag bedanken voor de prettige samenwerking.

Van de afdeling pathologie wil ik dan nog Dr. Jack Cleutjens bedanken, Jack bedankt voor al jouw hulp bij de histologie analyses.

Verder wil ik graag Prof. Dr. Oude Egbrink, Prof. Dr. Schalkwijk, Prof. Dr. van Loon, Prof. Dr. Struijker-Boudier en Dr. Serné hartelijk danken voor het beoordelen van dit proefschrift. 
Daarnaast is de tijd buiten het werk minstens zo belangrijk geweest. Ik wil daarom allereerst mijn vrienden bedanken: Anne, Mathieu, Roel, Mischa, Toon, Matthijs, Allan, Vincent, Geert, Ruud, Martijn, Jesse en Rein. Jullie rol is heel belangrijk geweest, jullie waren er altijd wanneer nodig voor serieuze gesprekken maar ook om gewoon slap te ouwehoeren. Mathieu, hiernaast ook nog bedankt voor de hulp bij het bedenken en designen van mijn cover. Anne, ook ik vind het erg bijzonder dat we al samen verslagen maakten tijdens de middelbare school en uiteindelijk samen in cafe de Unie zaten om onze proefschriften af te ronden. Jij hebt dit allemaal al achter de rug en een heel mooi resultaat afgeleverd.

Jesse en Rein, paranimfen, mijn keuze voor jullie als paranimf was snel gemaakt. Jullie hebben de gehele periode van dichtbij meegemaakt. Koersen, een film, eten, en/of een biertje waren een vaste prik op de dinsdagavond. Mede dankzij jullie heb ik een hele leuke tijd gehad in Maastricht. Ik vind het dan ook heel bijzonder dat jullie mijn paranimfen zijn. Bedankt voor dit alles!

Als laatst nog mijn familie. Mijn broertjes Tom en Roel, en mijn zusje Kim, wil ik bedanken voor het aanhoren van het misschien voor jullie soms onbegrijpelijke onderzoek. Het doet me goed te weten dat ik altijd bij jullie terecht kan.

Papa en mama, ik ben echt heel erg dankbaar voor de kansen die jullie mij gegeven hebben. Jullie hebben altijd achter mijn keuze gestaan en de aanwezige steun en het positivisme hebben mij enorm gestimuleerd. Zonder jullie was dit proefschrift er waarschijnlijk nooit gekomen. Een hele grote dank! 


\section{Curriculum vitae}

Bart Johannes Maria Eskens was born on February 3, 1983 in Tilburg, the Netherlands. He attended and graduated from d'Oultremontcollege in Drunen. After his graduation in 2001, he studied Biological Health Sciences in Maastricht. In 2005 he completed his Master Degree with a thesis entitled: 'Genotyping of single nucleotide polymorphisms (SNPs) as a biomarker for genetic susceptibility' at the department of Health Risk Analysis and Toxicology, Maastricht University.

His interest in research attracted Bart to join the Cardiovascular Research Institute in Maastricht (CARIM) in the Netherlands. In June 2007 he got the opportunity to join the Department of Physiology for a PhD-position at the lab of Hans Vink and Jurgen van Teeffelen. He started working on (pre)-diabetes and the role of the glycocalyx in the regulation of insulin sensitivity in skeletal muscle. This PhD project was funded by the Dutch Diabetes Research Foundation (grant number 2006.00.027) for the period of 4 years. In 2011 he worked also on another project: Biomarkers for the prediction and early diagnosis of diabetes and diabetes related cardiovascular complications (PREDICCt) which was funded by the Center for Translational Molecular Medicine. The obtained data from his research resulted in several publications in peer-reviewed international scientific journals. Furthermore, he attended several (inter)national conferences to present his work.

From July 2012 till August 2013 he started as a Research Associate and later as a Product Manager at Glycocheck B.V. Maastricht, The Netherlands. Currently, he has been working as a Compliance Associate at Amgen B.V., Breda, The Netherlands. 